\title{
Competitividad Organizacional: Estudio de factores
}

Amado Olivares Leal, Elda Patricia Castro Cota, Pabla Peralta Miranda, Francisco Espinoza Morales

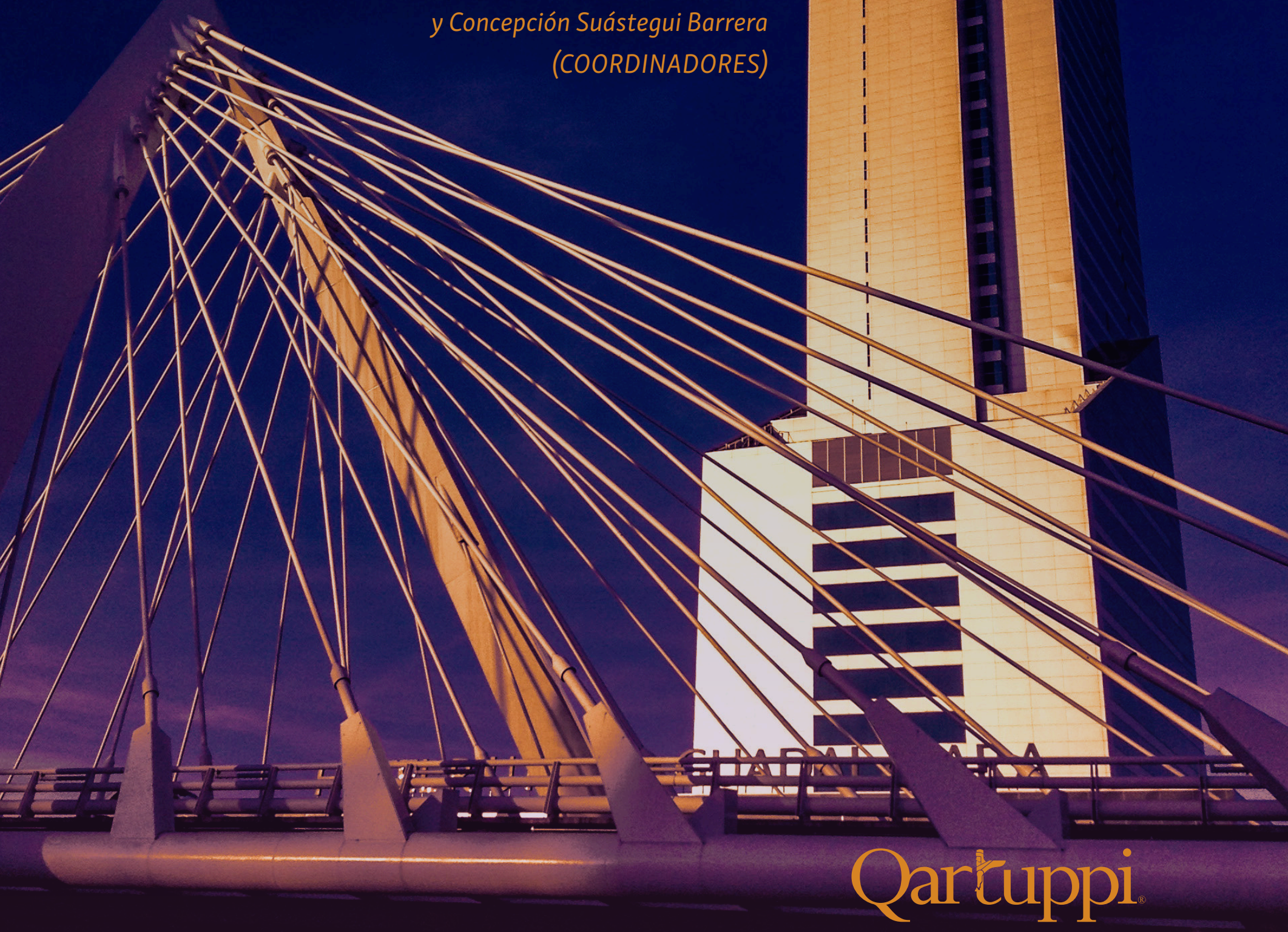




\section{Competitividad Organizacional: Estudio de factores}

Amado Olivares Leal, Elda Patricia Castro Cota, Pabla Peralta Miranda, Francisco Espinoza Morales

y Concepción Suástegui Barrera

(COORDINADORES) 


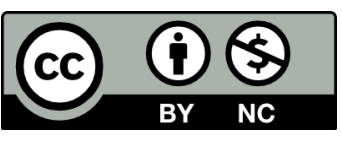

Esta obra está bajo una Licencia Creative Commons

Atribución-NoComercial 4.0 Internacional.

https://creativecommons.org/licenses/by-nc/4.0/deed.es

\section{COMPETITIVIDAD ORGANIZACIONAL: ESTUDIO DE FACTORES}

lera. edición, enero 2019

ISBN 978-607-98270-5-2

DOI 10.29410/QTP.19.01

D.R. @ 2019. Qartuppi, S. de R.L. de C.V.

Villa Turca 17, Col. Villas del Mediterráneo

Hermosillo, Sonora 83220 México

http://www.qartuppi.com

Edición y Diseño: Qartuppi, S. de R.L. de C.V.

Diseño de portada: León Felipe Irigoyen Morales 


\section{Contenido}

7

Presentación

Amado Olivares Leal

8

PARTE I

LA COMPETITIVIDAD EN LAS ORGANIZACIONES PÚBLICAS Y PRIVADAS

$9 \quad$ Capítulo 1

Análisis estratégico de la competitividad del sector porcino en Yucatán Antonio Emmanuel Pérez Brito, María Marlene Martín Méndez y Gabriel Jesús Pérez Brito

$25 \quad$ Capítulo 2

Agrotecnología y competitividad, una aplicación en sistemas de ambiente protegido (invernaderos) en el Estado de Hidalgo Guillermo Velázquez Valadez, Jenny Lizbeth Villalobos García y José Antonio Morales Castro

$47 \quad$ Capítulo 3

Factor Infraestructura: subfactores y variables que inciden en la competitividad de las PyMes de servicios navieros en Manzanillo Pablo Adrián Magaña Sánchez, Mario de Jesús Naranjo González y Luis Octavio Ríos Silva 
56 PARTE II

\section{LAS ESTRATEGIAS ORGANIZACIONALES}

$57 \quad$ Capítulo 4

Influencia de la cultura organizacional y el liderazgo en la producción

de capital intelectual como ventaja competitiva

Martha Lucía Moya Pardo y Héctor Manuel Gómez Gómez

$76 \quad$ Capítulo 5

Estructura de sueldos: un ejemplo práctico para una microempresa

Angélica María Rascón Larios, Francisco Espinoza Morales y Pabla Peralta Miranda

92 Capítulo 6

El recurso humano en las Pymes del sector comercial en México

Rosa María Rincón Ornelas, Lidia Amalia Zallas Esquer

y María Guadalupe Alvarado Ibarra

104 Capítulo 7

Estrategias promocionales para la reactivación del turismo

en El Triunfo, Baja California Sur, México

Elda Patricia Castro Cota, Melany Araduvi Gómez Vizcarra y Amado Olivares Leal

118 PARTE III

INNOVACIÓN, COMPETITIVIDAD Y ESTRATEGIAS EDUCATIVAS

119 Capítulo 8

Autoevaluación: una experiencia para comparar y contrastar dos modelos

de evaluación de calidad de programas educativos de posgrado

Blanca Isela Ramírez, Mirna Sulema Oleta Luna y Concepción Suástegui Barrera 
137 Capítulo 9

Experiencias de aprendizaje por proyectos, para la adquisición de competencias profesionales en estudiantes universitarios Elsa Armida Ortega Verdugo, Nubia J. Félix Orduño y Yessica Lara Soto

154 Capítulo 10

Diagnóstico de los factores que impactan el índice de reprobación en alumnos de educación secundaria.

Caso: Escuela Secundaria Federal en Tijuana, Baja California, México Arabela Arcos y Luis Alfonso Valencia Ponce

163 PARTE IV

POLIITICA SOCIAL Y AMBIENTAL DE LA EMPRESA

164 Capítulo 11

Paradigmas sobre la problemática de los Residuos Ambientales

Eléctricos y Electrónicos (RAEE)

Berenice Citlalli Cárdenas Aragón y Rosalinda Gámez Gastélum

184 Capítulo 12

La universidad y su responsabilidad con la sustentabilidad:

el caso de la Universidad de Sonora

Ramona Flores-Varela, Juana Alvarado-Ibarra y Angélica Ochoa-Flores 


\section{Presentación}

La Red de Líderes Investigadores en Innovación, Competitividad y Estudios Organizacionales (Red LIICEO) se congratula en presentar el libro Competitividad Organizacional: Estudio de factores, resultado del esfuerzo institucional de las diversas Universidades para que nuestros profesores logren nuevos derroteros en la investigación.

Llevar a cabo el estudio de la competitividad organizacional y de sus factores es uno de los objetivos más ambiciosos que pueda plantearse todo administrador de negocios, profesores, investigadores y estudiantes, debido al cúmulo de retos que implica para la organización productora o comercializadora, en sus diversas áreas (financiera, administrativa, legal, entre otras), la generación de conocimientos que les permita implementar ventajas competitivas, que aseguren y mantengan su liderazgo en el sector productivo y social en el que participan.

Un estudio detallado de los factores de la competitividad es una herramienta que permite al gerente $y / o$ ejecutivo realizar un proceso de implementación, para seleccionar el camino adecuado hacia el logro de sus metas y objetivos, que les proporcionará ventajas comparativas.

Competitividad Organizacional: Estudio de factores está integrado por doce capítulos, estructurados en cuatro núcleos temáticos y tiene como objetivo guiar al directivo en el proceso de adecuación de los conocimientos presentados y de irse adaptando a sus características propias, así como detallar con exactitud la información de mayor utilidad que les permita tomar una mejor decisión y optimizar relativamente los esfuerzos de su organización.

Esperamos que con este libro logre usted su entrada exitosa al razonamiento de los factores de competitividad y sobre esta base pueda edificar sus conocimientos futuros.

Amado Leal Olivares

Presidente red LIICEO 


\section{PARTE I \\ LA COMPETITIVIDAD \\ EN LAS ORGANIZACIONES PÚBLICAS Y PRIVADAS}




\section{Capítulo 1}

Análisis estratégico de la competitividad del sector porcino en Yucatán

Antonio Emmanuel Pérez Britoํㅜㄴ María Marlene Martín Méndez²

y Gabriel Jesús Pérez Brito

\footnotetext{
${ }^{1}$ Universidad Autónoma de Yucatán, México. antonio.perez@correo.uady.mx

2 Universidad Autónoma de Yucatán, México. marlene.martin@correo.uady.mx

3 Universidad Autónoma de Yucatán, México. gabriel.perez@correo.uady.mx
} 


\section{Introducción}

Desde la domesticación de ciertos animales para el consumo humano alrededor del 4900 a.C., el cerdo ha mantenido una posición importante en la producción de alimentos cárnicos para tal fin. Esto se demuestra con el consumo mundial de carne de cerdo que excede a todos los demás consumos de este tipo de productos (Moeller y Crespo, 2009).

Para satisfacer la creciente demanda de los consumidores, la producción mundial de carne de porcino ha ido en aumento y alcanzó un incremento de casi el 75\% entre 1980 y 2001, esta producción se dio especialmente en China -mayor productor mundial- y en los países que integran la Organización para la Cooperación y el Desarrollo Económicos (OCDE), donde el crecimiento fue significativo particularmente en Corea, Polonia y Estados Unidos, y en menor medida en la Unión Europea; en contraste, la producción decreció en Japón en ese mismo período (OCDE, 2003).

Por otro lado, la OCDE (2003) señala que, debido a la rápida expansión de la demanda mundial de carne y la necesidad proyectada de un aumento del $20 \%$ en la producción mundial de alimentos para 2020, el sector porcino seguirá representando un satisfactor importante para esta demanda. La tendencia ascendente de producción porcina sucede en regiones del mundo donde se consume aproximadamente el $60 \%$ de todo el consumo mundial de esta carne, estas regiones mantienen una ventaja en términos de costos de producción y precios en el comercio exterior, y están caracterizadas por un alto crecimiento económico y un aumento del ingreso disponible de la población (Stępień y Sapa, 2016).

Por su parte, la Organización de las Naciones Unidas para la Alimentación y la Agricultura $(F A O, 2016)$ manifiesta que la comercialización de la carne de cerdo se ha convertido en un sector de importancia para la economía mundial, su producción está distribuida internacionalmente (excepto en aquellas regiones que mantienen ciertas reservas culturales) y su industria ha alcanzado un alto nivel de demanda de insumos, así como un elevado rendimiento gracias a la incorporación de tecnologías que incrementan la eficiencia de los procesos productivos.

Para Stępień y Sapa (2016), los factores directos que han moldeado el mercado porcino en los últimos años han sido: el aumento de la demanda de carne a escala mundial (aunque limitada como resultado de la crisis económica entre 2008 y 2009), el desarrollo del comercio 
internacional y la modificación de la estructura geográfica de exportaciones e importaciones, la disminución de los costos de producción (principalmente del forraje) y el aumento de los requisitos de protección del medio ambiente y calidad de la carne.

La FAO proyecta que la producción mundial de cerdo crecerá en promedio un $0.8 \%$ anual hasta 2030 y el poder del mercado se concentrará cada vez más en los grandes países productores como China, Estados Unidos, Brasil, Alemania, España, Rusia y Vietnam, en contraste con los países musulmanes que, por razones religiosas, su producción de cerdo es mínima, o nula (Fair Bank Guide, 2018).

De acuerdo con el Departamento de Agricultura de los Estados Unidos (USDA, por sus siglas en inglés), la sólida demanda durante 2017 está impulsando una gran expansión en la producción de carne de cerdo en todos los países, respaldada por el fuerte crecimiento económico mundial que aumenta los ingresos de los consumidores y apoya la demanda de carne roja; por su parte, el precio del forraje se encuentra en niveles relativamente bajos y las enfermedades como la peste porcina o el virus de la diarrea epidémica porcina, aunque continúan en algunas regiones, no se consideran una limitante para la producción (USDA, 2018).

En México, en específico en el estado de Yucatán, el desarrollo de la porcicultura ha estado relacionado con aspectos económicos y sociales que fueron generados por la industria henequenera, cuya decadencia en su momento abrió paso para que algunas iniciativas del gobierno en turno, consideraran el empleo de la mano de obra en diversas actividades productivas alternas, entre las cuales se encontraba la porcicultura (Leyva, Cobos y Mendoza, 2009).

De acuerdo con el Instituto Nacional de Estadística y Geografía (INEGI), Yucatán tenía 2,097,075 habitantes, lo que representaba el 1.8\% de la población total del País. En dicho estado, durante el 2014, 64 de cada 100 personas de 15 o más años de edad (39 hombres y 25 mujeres) eran económicamente activas. El $62 \%$ de las personas ocupadas trabajaban en el sector comercio y servicios, el $27 \%$ lo hacían en la industria y el $11 \%$ en el sector agrícola, cría y explotación de animales, pesca y caza (INEGI, 2015).

El sector que más aportó al Producto Interno Bruto (PIB) del estado en cuestión, fue el comercio; por cada 100 pesos de PIB, 21.78 le correspondieron a dicho sector, le siguieron la industria manufacturera con 16.80 , los servicios inmobiliarios y de alquiler de bienes muebles 
e intangibles con 12.78, la industria de la construcción con 11.32 y, por último, 4.98 pesos los aportaron los servicios educativos (INEGI, 2015).

En Yucatán, la carne de cerdo se comercializa en fresco, directo para consumo y como materia prima industrial, cabe señalar que la demanda de carnes de calidad y presentaciones procesadas, como los embutidos y los jamones, excede a la oferta de productores y procesadores estatales (Leyva et al., 2009).

Históricamente, la península de Yucatán ha sido un mercado deficitario en la producción de carne de cerdo en relación con la demanda regional. Sin embargo, a partir de la década de los noventa, la producción de carne de cerdo experimentó un crecimiento acelerado; mientras que, de 1984 a 1992, la media anual de producción de carne en canal fue de 17,662.62 toneladas, en 1993 y 1994 ascendió a 38,278.26 toneladas, tal cantidad permitió cubrir el 95\% de la demanda regional. Esta alza en la producción de carne porcina en Yucatán, se debió en gran medida a que la estructura del subsector cambió notablemente en términos técnicos, financieros y económicos, debido a la participación de grandes empresas productivas, así como al establecimiento de nuevos esquemas asociativos, especialmente entre particulares y ejidatarios (Drucker, Escalante, Gómez y Magaña, 2017).

Este capítulo presenta los resultados de una investigación realizada con productores porcícolas del estado de Yucatán cuyo objetivo general fue identificar el nivel de competitividad que tiene dicho sector a través de la aplicación de las herramientas de Porter, denominadas El Diamante de la Ventaja Nacional y El Modelo de las Cinco Fuerzas.

\section{Competitividad}

A lo largo de la historia, la competitividad ha sido descrita por varios autores como un concepto teórico, multidimensional y relativo, asociado con los mecanismos de mercado (Siudek y Zawojska, 2014).

Una de las primeras aproximaciones al concepto de competitividad proviene de Smith (1977), quien consideró que los esfuerzos sostenidos para el aumento de la exportación darían como resultado un aumento de las entradas de metales preciosos, lo que repercutiría de manera positiva en el bienestar nacional. 
Cada parte implicada en el libre comercio puede obtener beneficios al especializarse en la producción de bienes en los que se tiene una ventaja absoluta; en este sentido, es válido que cada país exporte los bienes que produce al menor costo e importe los bienes que produce a los costos más altos (Smith, 1977).

Sin embargo, la ventaja absoluta en la producción de un producto básico no es necesaria ni suficiente para el comercio mutuamente beneficioso; un país puede experimentar una desventaja absoluta en la producción de todos sus productos en comparación con otro país y, aun así, obtener beneficios mediante el comercio internacional con otros diferentes países, esto ocurre debido a la ventaja relativa comparativa en la producción mundial de algunos productos básicos. La ventaja absoluta respecto de un país en la producción de un producto básico no es suficiente (Gupta, 2015).

Ricardo (1817) estableció, en su momento, que el término de ventaja comparativa hacía referencia a la capacidad de producir bienes y servicios a un menor costo de oportunidad, esto no necesariamente implicaba producir a un volumen mayor. Un país puede beneficiarse del comercio exterior incluso si carece de una ventaja absoluta sobre sus socios comerciales en la producción de bienes, ya que solo necesita tener una ventaja relativa en cualquier bien para poder venderlo en el exterior.

De acuerdo con Ince, Kozanoğlu y Demir (2011), uno de los marcos conceptuales más influyentes para el trabajo teórico y empírico sobre la competitividad es el modelo de HeckscherOhlin propuesto en 1933, este considera que la ventaja comparativa cambia con el tiempo, dependiendo de las diferencias entre los países de acuerdo con las dotaciones de los factores y los cambios en la tecnología. El modelo Heckscher-Ohlin indica que el comercio aumenta la demanda de los bienes producidos por el abundante recurso del país. Dado que el recurso abundante en la mayoría de los países en desarrollo es la mano de obra, la predicción es un aumento en la demanda de bienes de mano de obra intensiva (Ince et al., 2011). Por otro lado, la comercialización le brinda a un país en desarrollo la oportunidad de aprender de las tecnologías más avanzadas del mundo desarrollado (Ince et al., 2011).

Schumpeter (1943) afirmaba que, para la realidad capitalista, lo que cuenta en la competencia es la nueva mercancía, las nuevas tecnologías, la nueva fuente de suministro, el nuevo 
tipo de organización y la competencia que otorga un costo decisivo o una ventaja de calidad, ésta no golpea los márgenes de los beneficios y los resultados de las empresas existentes, pero afecta sus cimientos y su existencia.

La década de 1970 puede considerarse como el punto de inflexión en la visión de la globalización, debido a que se produjo un aumento en las inversiones extranjeras directas de los países, lo que causó un cambio en el segmento comercial de las empresas; por otro lado, la década de 1980 detonó el liberalismo de muchas políticas económicas en los países en desarrollo (Arslan y Tatlıdil, 2012).

\section{Herramientas para el Análisis Estratégico de la Competitividad}

\section{El modelo de las cinco fuerzas}

Según Porter (2008, citado por Pérez, Bojórquez, Nuño y Santillana, 2014), la parte medular de la formulación de la estrategia es el hacer frente a la competencia. En la lucha por un segmento de mercado, la competencia no se manifiesta únicamente en los otros jugadores; la competencia de una industria está enraizada en los fundamentos económicos y existen fuerzas competitivas que van mucho más allá de los combatientes establecidos en el mercado. Clientes, proveedores, competidores potenciales y productos sustitutos, son todos los actores que podrían tener una mayor o menor prominencia dependiendo del mercado. El estado de la competencia de una industria depende de cinco fuerzas básicas:

1. Amenazas de entrada. Nuevos competidores en una industria traen consigo nuevas capacidades, el deseo de ganar una cuota de mercado y, frecuentemente, recursos substanciales. La seriedad de la amenaza de entrada depende de las barreras que presente la industria y de la reacción de los competidores existentes. Si las barreras de entrada son altas, los nuevos competidores pueden esperar una fuerte represalia de los competidores existentes. Las seis principales barreras de entrada son: las economías de escala, la diferenciación de productos, los requerimientos de capital, las desventajas de costos, el acceso a los canales de distribución y las políticas gubernamentales. 
2. El poder de los proveedores. Estos actores pueden ejercer poder sobre los participantes en una industria al elevar precios o reducir la calidad de los bienes y servicios que ofrecen. Este grupo puede generar poder si:

a. El mercado está dominado por un grupo reducido de proveedores.

b. El producto que ofrecen es único.

c. No están obligados a contender con otros productores para vender en la industria.

d. Poseen una amenaza creíble de integración vertical hacia adelante en la industria respectiva.

e. La industria no es un cliente importante para el grupo de proveedores.

3. El poder de los compradores. La mayor parte de la fuente de poder de los compradores se atribuye a los consumidores como grupo, así como a los compradores industriales y comerciales. Los consumidores tienden a ser más sensibles frente a productos no diferenciados y a productos que sean caros en relación con sus ingresos. Los compradores son poderosos si:

a. Se concentran o compran en grandes volúmenes.

b. Los productos comprados son estándares o no diferenciados.

c. El producto no le ahorra dinero al comprador.

d. Desarrollan una integración vertical hacia atrás para elaborar el producto.

4. Productos sustitutos. Los productos sustitutos limitan las ganancias en tiempos normales. Dichos productos generan reducción de precios y mejoras en el desempeño.

5. Competidores existentes. Estos actores usan tácticas para defenderse, las cuales pueden basarse en estrategias de precios, introducción de productos y peleas publicitarias. Una intensa rivalidad está relacionada con la presencia de numerosos factores tales como:

a. La cantidad de competidores es numerosa o bien, son iguales en tamaño y poder.

b. El crecimiento de la industria es lento.

c. Al producto o servicio le hace falta diferenciación.

d. Las barreras de salida son altas. 
e. Los costos fijos son elevados.

f. Los rivales son diferentes en estrategias, origen y personalidad.

\section{El Diamante de la Ventaja Nacional}

Porter (2008, citado por Pérez et al., 2014), señala que en la búsqueda de respuestas a las siguientes preguntas: ¿por qué ciertas compañías ubicadas en ciertas naciones son capaces de conseguir innovación?, ¿por qué son capaces de superar las barreras del cambio y de la innovación las cuales acompañan al éxito?, desarrolla este modelo, que se basa en cuatro atributos de una nación, atributos que individualmente y como sistema constituyen el diamante de la ventaja nacional, es decir, el campo de juego que cada nación establece y opera para sus industrias. Esos atributos crean el entorno nacional en el cual las compañías nacen y aprenden a competir.

Además, Porter señala que cuando un entorno nacional permite y soporta una mayor acumulación de activos especializados y de habilidades, las compañías ganan una ventaja competitiva; esto también sucede cuando dicho entorno proporciona mejor información y puntos de vista en relación con las necesidades de productos y de procesos. Finalmente, el autor también menciona que, cuando el entorno nacional presiona a las compañías a innovar e invertir, éstas obtienen una ventaja competitiva que pueden mantener a lo largo del tiempo.

Los atributos del diamante de Porter son los siguientes:

1. Las condiciones de los factores. Se refiere a la posición de una nación en relación a los factores de producción, tales como su infraestructura o las habilidades de su mano de obra, ésta es indispensable para competir en una industria determinada.

Los factores indispensables de la producción son aquellos que involucran una inversión sostenida y abundante; para sostener una ventaja competitiva, un factor puede estar altamente especializado para satisfacer necesidades particulares de la industria a la que pertenece. Las naciones tienen éxito en industrias en donde son particularmente buenas para la creación de factores; la ventaja competitiva proviene de la presencia de instituciones de clase mundial que primero crean factores especializados y luego trabajan continuamente para su actualización. 
2. Las condiciones de la demanda. Se considera la naturaleza de la demanda del mercado en relación a los productos o servicios de la localidad. Las naciones obtienen ventajas competitivas en industrias donde la demanda local proporciona a las compañías información clara sobre las nuevas necesidades de los compradores. También, se ganan ventajas en industrias donde los compradores presionan a las compañías nacionales a innovar de manera más rápida, lo que permite alcanzar ventajas competitivas sofisticadas mayores en relación con los rivales extranjeros.

3. Industrias relacionadas y de apoyo. Se refiere a la presencia o ausencia, en una nación, de proveedores para las diferentes industrias, así como de otras industrias relacionadas que en el ámbito internacional son competitivas. Las empresas de una nación se benefician cuando los proveedores son competidores globales, esto no significa que para generar una ventaja competitiva todos tengan que serlo.

4. La estrategia de la empresa, la estructura y su rivalidad. Describe las condiciones que rigen una nación en relación a cómo las compañías son creadas, organizadas y administradas, así como la naturaleza de la competencia doméstica. La competitividad en una industria específica resulta de la convergencia de prácticas de gestión y modelos organizacionales en un país, así como de las fuentes de ventaja competitiva en la industria. Los países difieren notablemente en las metas que sus compañías e individuos pretenden alcanzar. Las compañías reflejan las características de los mercados nacionales de capital, así como las prácticas compensatorias para los gerentes; la motivación individual a trabajar y aplicar las habilidades, es también importante para desarrollar ventajas competitivas. Las naciones tienden a competir en actividades que la gente admira o de las cuales depende, es decir, aquellas en las que surgen héroes nacionales. 


\section{Sector Porcino}

Según datos del Servicio de Información Agroalimentaria y Pesquera (SIAP, 2017), la producción de carne de cerdo en México en 2016 ascendió a 1,376 toneladas provenientes de aproximadamente 16,794 animales sacrificados y con un valor de $\$ 56,892,934$.30. Cabe mencionar que, entre 2006 y 2016, el consumo anual de carne de cerdo por persona, creció a una tasa promedio anual de 3.1\%, al término de dicho período, el consumo per cápita se ubicó en $18.6 \mathrm{~kg}$ al año.

El sector comercial de la carne de cerdo en México creció muy rápido en los últimos años, lo que expandió y consolidó su producción, por ello, los productores comerciales más grandes del país han aplicado mejoras en sus operaciones, tales como: agregar instalaciones para el procesamiento de alimentos, procesamiento de carne y para el almacenamiento en frío. También han incursionado en la utilización de técnicas de reproducción sofisticadas y de alimentación que mejoran las características específicas de la carne. También han enfocado su interés a la sostenibilidad de esta actividad con la inversión en energía renovables (USDA, 2017).

En México, los principales estados productores de carne de cerdo por peso de carcasa son Jalisco, Sonora, Puebla y Yucatán, que representan más de la mitad de la producción nacional, cabe mencionar que los demás estados de la república, producen carne de cerdo en pequeñas cantidades (USDA, 2017).

Yucatán, además de ser el cuarto productor de carne porcina en México, es una zona importante para su producción ya que cuenta con un adecuado cerco sanitario gracias a su situación natural como península y las estrictas medidas de bioseguridad, esto ha mantenido al estado libre de diarrea epidémica porcina y ha favorecido su rápido crecimiento en la industria en los últimos años (USDA, 2017).

La carne de cerdo producida en Yucatán es principalmente exportada a Japón con una gran aceptación, también se envía a Corea del Sur, Estados Unidos, Canadá, Hong Kong y Taiwán, y ha logrado la apertura del mercado en China al dársele reconocimiento a los estándares de calidad e inocuidad de la carne de cerdo yucateca (SAGARPA, 2016). 


\section{Metodología}

En la presente investigación se aplicó un tipo de investigación cualitativa. Este estudio, según la dimensión temporal, es de corte transversal, no experimental, y trató de determinar los procesos adecuados que permitiesen identificar el nivel de competitividad de los productores de carne de ganado porcino del estado de Yucatán; el año en el que se realizó el trabajo de campo fue el 2017 y fue un trabajo exploratorio que pretendió identificar la situación actual de la industria de producción de carne porcina en el estado de Yucatán.

Para el análisis de las herramientas de Porter, se obtuvo información con base en la revisión y análisis de todos los documentos que fue posible acopiar relacionados con el tema. Así como los bancos de datos estadísticos oficiales, nacionales e internacionales y en particular del Estado de Yucatán. También, se obtuvo información a través de entrevistas con los directivos de las principales asociaciones ganaderas porcinas del Estado, funcionarios públicos, investigadores, académicos y prestadores de servicios. Igualmente, se obtuvo información de distribuidores y comercializadores de los principales insumos para la producción porcina y, finalmente, de algunos productores, desarrolladores y acopiadores de cerdos.

\section{Resultados}

En la presente sección, se presentan los resultados obtenidos con base en el cuestionario aplicado a las personas relacionadas al sector estudiado, así como a la revisión documental y bancos estadísticos mencionados en la sección anterior.

\section{Análisis e interpretación de datos}

En la figura 1, se presenta el Modelo de las cinco fuerzas para el análisis de la demanda del sector porcícola. Se observa que dicho sector es bastante competido, posee barreras de entrada y de salida altas, así como un alto poder de negociación de proveedores y clientes. 


\section{BARRERAS DE ENTRADA}

Alta: Se requiere de una inversión de capital muy fuerte, debido a la utilización de alta tecnología para este sector con el fin de cumplir con las certificaciones.
BARRERAS DE SALIDA

Alta: Empresas líderes en el mercado doméstico. Regulaciones laborales que representan altos costos para la empresa.

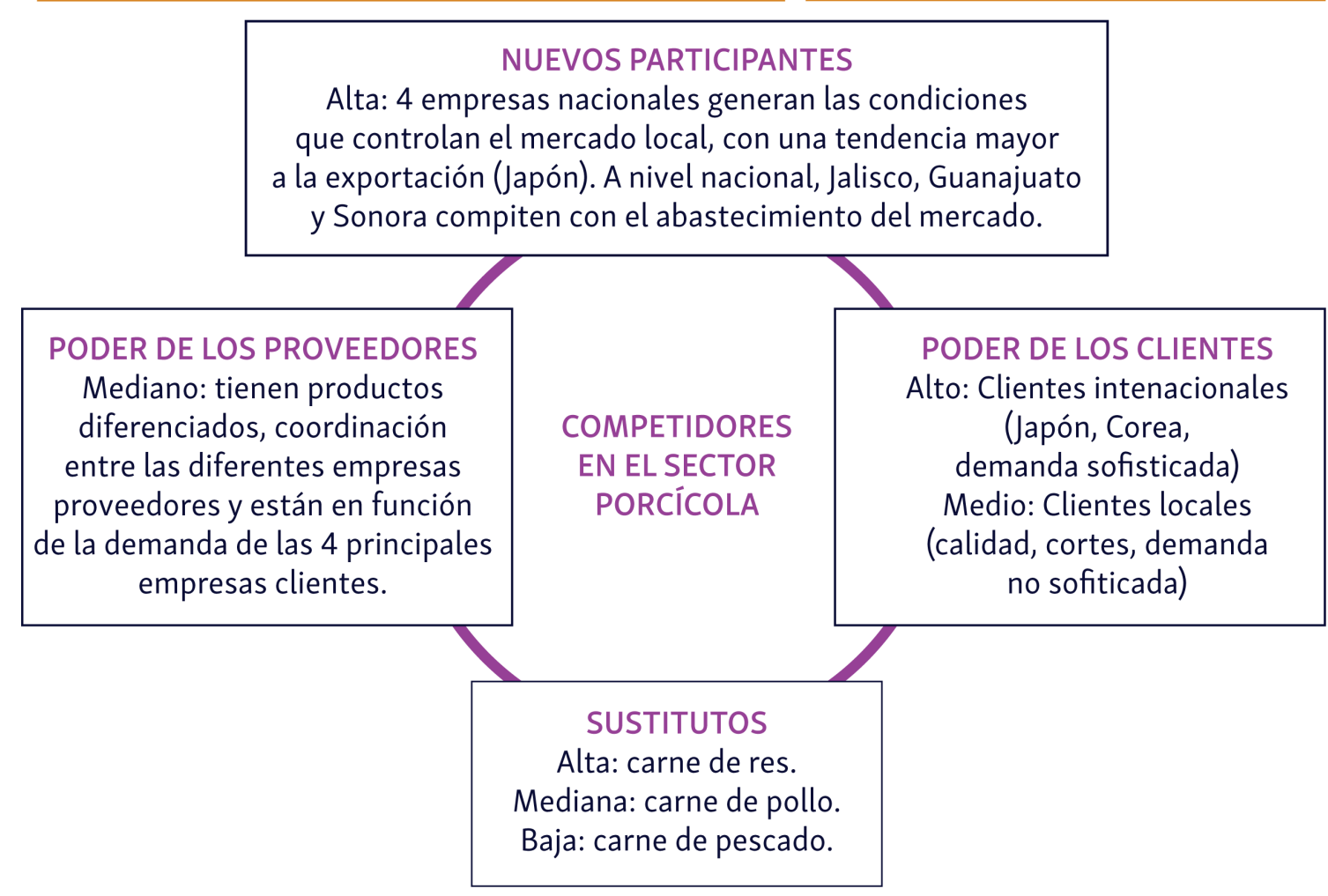

Figura 1. Modelo de las cinco duerzas aplicado al sector porcícola.

Fuente: Elaboración propia con datos de la investigación.

En la figura 2 se presenta el Diamante de la Ventaja Nacional. Se observa que la estructura del país y las bondades del estado de Yucatán ofrecen oportunidades para los productores de carne de ganado porcino existentes; así, son generadores de ventaja competitiva para esta actividad económica. 
Altos estándares de sanidad e inocuidad

Alzas en los precios

de los insumos

Inestabilidad económica

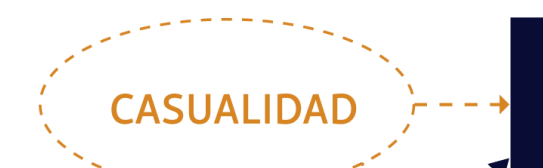

(PROCAMPO)

\section{ESTRATEGIA,} ESTRUCTURA Y RIVALIDAD

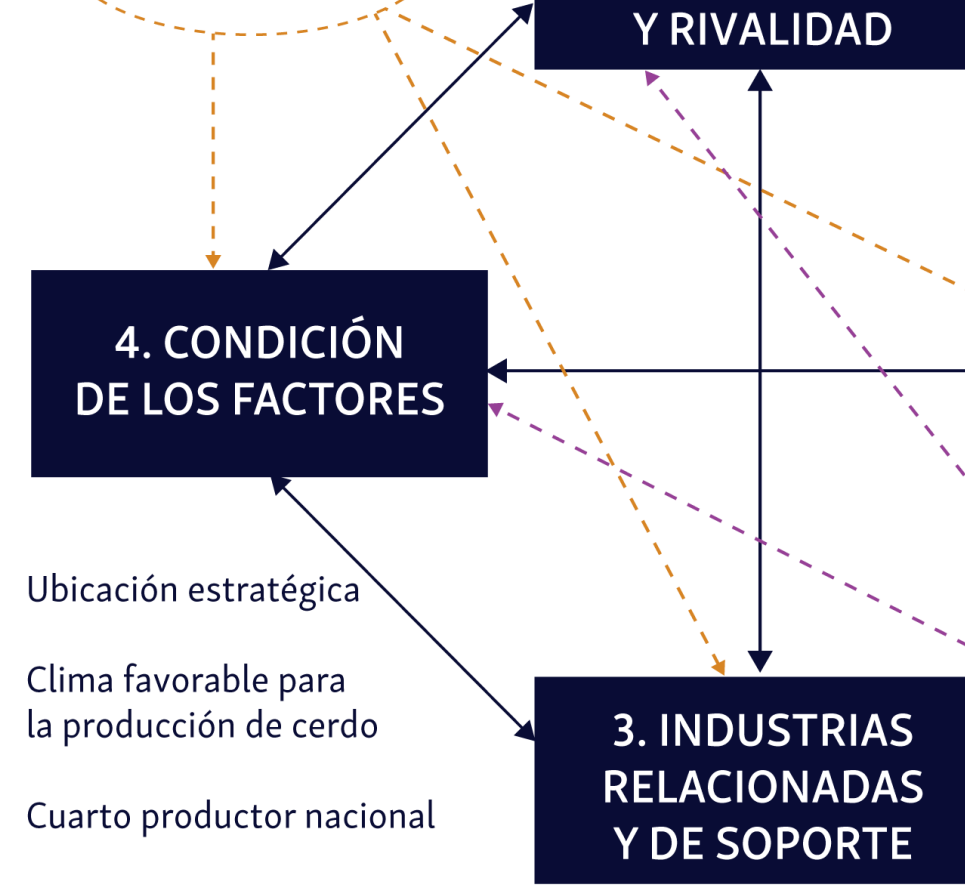

Alta tecnificación

Infraestructura adecuada

Escasa información

de los mercados
INDUSTRIAS RELACIONADAS:

Restaurantera

Supermercados

Carnicerías

Procesamiento (embutidos)

INDUSTRIAS DE SOPORTE:

Comercializadoras

de productos balanceados

Empacadoras
Mercado interno poco sofisticado

Consumo medio a nivel nacional

Mercado externo sofisticado

\section{CONDICIONES} DE DEMANDA

Figura 2. Diamante de la ventaja nacional.

Fuente: Elaboración propia con datos de la investigación. 


\section{Conclusiones y recomendaciones}

El estado de Yucatán cuenta con una serie de características favorables para la producción y comercialización de la carne de cerdo como lo son: adecuada ubicación geográfica, alta calidad de materia prima, área libre de fiebre porcina clásica, facilidades a la inversión extranjera, disposición y oportunidades para asociarse con empresas mexicanas exportadoras, sobre oferta de trabajadores calificados y buena respuesta de los productores locales hacia la apertura comercial.

Sin embargo, existen factores que afectan indiscutiblemente el desarrollo de esta industria, como lo son: las variaciones en los precios internacionales, los cambios bruscos en la demanda, la inflación, la inestabilidad en las políticas financieras que afectan los costos, el aumento en obstáculos y burocratismo, una creciente competencia debido a la apertura de mercados y una escasa información de los mismos, apertura constante de los contenedores en los puntos de inspección instalados en las carreteras del estado, alto costo financiero para apoyar el crecimiento de las empresas, vinculación reducida entre centros de investigación, universidades y empresas y, algo muy importante, la falta de un modelo estratégico de comercialización.

Por otro lado, se señala la importancia de fortalecer la estrategia de integración vertical, reuniendo un mayor número de granjas porcícolas para poder ampliar las plantas de sacrificio y proceso, con lo cual se garantizará contar siempre con carne para materia prima y, sobre todo, se conseguirá disminuir los costos de producción y contrarrestar las fluctuaciones en los precios de mercado.

Finalmente, es necesario que al gobierno le quede claro que la rentabilidad de una industria no es el único criterio para decidirse a impulsarla, dado que la creación de empleos, el crecimiento de la producción y el impacto en las actividades conexas son detonadores de la economía regional. 


\section{Referencias}

Arslan, N., \& Tatlıdil, H. (2012). Defining and Measuring Competitiveness: A Comparative Analysis of Turkey With 11 Potential Rivals. International Journal of Basic \& Applied Sciences, 12(2), 31-43.

Drucker, A., Escalante, R., Gómez, V. y Magaña, S. (2017). La Industria Porcina en Yucatán. Revista Latinoamericano en Economía, 135(34), 105-124.

Fair Bank Guide. (2018). Risking Animal Welfare. Case Study on Investments in Chicken and Pig Meat Production. Recuperado de https://eerlijkegeldwijzer.nl/media/374008/2018-02praktijkonderzoek-dierenwelzijn.pdf

Gupta, S. (2015). Comparative Advantage and Competitive Advantage: An Economics Perspective and a Synthesis. Athens Journal of Business and Economics, 1(1), 9-22.

Ince, M., Kozanoğlu, O., \& Demir, M. (2011). The Heckscher-Ohlin Trade Theory and Technological Advantages: Evidence from Turkey and USA. Asian Transactions on Basic \& Applied Sciences, 1(4), 17-21.

Instituto Nacional de Estadística y Geografía (INEGI). (2015). Conociendo Yucatán. Recuperado de http://internet.contenidos.inegi.org.mx/contenidos/productos//prod_serv/contenidos/ espanol/bvinegi/productos/estudios/conociendo/702825213237.pdf

Leyva, C., Cobos, R. y Mendoza, A. (2009). El Mercado de la Carne de Cerdo de Yucatán, 19952005. Revista de economía, 26(72), 69-100.

Moeller, S., \& León, F. (2009). Overview of World Swine and Pork Production. Agricultural Sciences, 1, 195-208.

Organización de las Naciones Unidas para la Alimentación y la Agricultura (FAO). (2016). Pigs and... Recuperado de http://www.fao.org/ag/againfo/themes/en/pigs/home.html

Organización para la Cooperación y el Desarrollo Económicos (OCDE). (2003). Agriculture, Trade and the Environment: The Pig Sector. Paris: OCDE.

Pérez, A., Bojórquez, M., Nuño, J. y Santillana, J. (2014). El Modelo de Clúster y la Filosofía Lean en la Ganadería Bovina de Yucatán. México: UPAEP.

Ricardo, D. (1817). On the Principles of Political Economy and Taxation. Inglaterra: John Murray. 
Schumpeter, J. (1943). Capitalism, Socialism, and Democracy. Inglaterra: G. Allen y Unwin ltd. Secretaría de Agricultura, Ganadería, Desarrollo Rural, Pesca y Alimentación (SAGARPA). (2016). Arrancan Exportaciones de Carne de Cerdo de Yucatán hacia China. Recuperado de http://www.sagarpa.gob.mx/Delegaciones/distritofederal/boletines/2016/agosto/ Documents/JAC0361-31.PDF

Servicio de Información Agroalimentaria y Pesquera (SIAP). (2017). Sistema de Información Agroalimentaria de Consulta (SIACON-NG) [Software].

Siudek, T., \& Zawojska, A. (2014) Competitiveness in the Economic Concepts, Theories and Empirical Research. Oeconomia, 13(1), 91-108.

Smith, A. (1977). An Inquiry into the Nature and Causes of the Wealth of Nations. EE.UU.: University of Chicago Press.

Stępień, S., \& Sapa, A. (2016). Chinese Pork Sector in the Process of World Economy Globalization. Research Papers of the Wroclaw University of Economics, (447), 156-157. http://dx.doi. org/10.15611/pn.2016.447.13

United States Department of Agriculture (USDA). (2017). Mexico. Livestock and Products Semiannual. Mexico's Livestock Sector Remains Healthy. Recuperado de https://gain.fas. usda.gov/Recent\%20GAIN\%20Publications/Livestock\%20and\%20Products\%20Semiannual_Mexico\%20City_Mexico_3-12-2017.pdf 


\section{Capítulo 2}

Agrotecnología y competitividad, una aplicación en sistemas de ambiente protegido (invernaderos) en el Estado de Hidalgo

Guillermo Velázquez Valadez ${ }^{1}$, Jenny Lizbeth Villalobos García y José Antonio Morales Castro

\footnotetext{
${ }^{1}$ Instituto Politécnico Nacional, México. gvelazquezva@ipn.mx

2 Instituto Politécnico Nacional, México. jenvillalobos85@gmail.com

${ }^{3}$ Instituto Politécnico Nacional, México. antoniomorales64@hotmail.com
} 


\section{Introducción}

En el Estado de Hidalgo, la agricultura bajo ambiente controlado se ha desarrollado paulatinamente, a través del Programa Normal Estatal de Alianza para el Campo, desarrollando actividades de construcción, equipamiento, asesoría técnica y capacitación, principalmente. Con esta óptica, se han construido en el Estado más de 120 invernaderos con una superficie superior a los 380 mil metros cuadrados dedicados a la producción de jitomate, pimiento morrón, calabacita, pepino, plantas de ornato y flores. Sin embargo, la producción de cultivos se realiza en su mayoría a cielo abierto, estos cultivos están supeditados a las condiciones ambientales que en la mayoría de los casos le son adversas, lo cual representa pérdidas constantes de las cosechas.

Sobre esa base, la presente investigación busca realizar un análisis económicoadministrativo que compare la productividad, rendimientos y ventas de los productores de tomate rojo (jitomate), bajo cielo abierto y bajo ambiente controlado (invernadero) en el Estado de Hidalgo y se tenga elementos para una toma de decisiones que beneficie a los productores.

Las cadenas globales de valor es un concepto relevante dentro lo que se conoce como los mercados agrícolas globalizados, a partir de este fenómeno, las empresas agrícolas desarrollan estrategias que les permite aumentar su competitividad y productividad, esto a su vez implica, tener acceso a nuevos mercados internacionales. Uno de los agentes que representa un papel importante en su funcionamiento es la tecnología; dentro de sus características tiene la facultad de delimitar qué productos se deben producir, en qué cantidad, para qué plaza y cuáles son las normas de calidad que deben ser cumplidas.

En este contexto, se plantea la siguiente hipótesis: los productores de tomate rojo (jitomate) en el Estado de Hidalgo requieren actualizar sus métodos de producción y aplicar procesos tecnológicos a través de cosechar en la modalidad de invernadero, sobre esta situación, se debe reemplazar el método de cosechar a cielo abierto, debido a que el control que se obtiene en el sistema de invernadero permite rendimientos más altos, mayor producción e incremento en sus ventas, proporcionando así, mayores beneficios a los productores y sus familias.

Las preguntas de investigación formuladas son:

- ¿Cuáles son los beneficios que aporta el sistema de cosecha en invernadero a los productores de jitomate del Estado de Hidalgo? 
- ¿Qué niveles de producción, eficiencia y control en el cultivo de jitomate, obtiene el productor y cuáles son la diferencia con la modalidad de cultivo a cielo abierto?

\section{Economía agrícola: relación microeconomía-tecnología}

Dentro del ámbito agroeconómico existen variables microeconómicas que inciden en las decisiones de los agricultores y consumidores; por ello, es necesario analizar el concepto de producción y su relación con la economía agrícola:

- La producción y el segundo teorema del bienestar. Señala que:

En una economía de intercambio puro, todas las asignaciones eficientes en el sentido de Pareto constituyen un equilibrio competitivo posible, siempre y cuando los consumidores muestren preferencias convexas. En la que haya producción, ocurre lo mismo, pero en ese caso deben ser convexas no sólo las preferencias de los consumidores, sino también los conjuntos de producción de las empresas. (Varian, 2010, p. 311)

- Producción agrícola. Se define como: "el resultado de la acción progresiva o simultanea de diversos factores: la semilla sobre el suelo, las labores de cultivos, los abonos y el trabajo de la recolección" (Gómez, 1964, p. 22).

- Sistemas de producción agropecuarios. "Es el conjunto de insumos, técnicas, mano de obra, tenencia de la tierra y organización de la población para producir uno o más productos agrícolas" (Jouve, 1988, p. 34).

\section{Teoría microeconómica de la agricultura}

La microeconomía enfocada en el estudio de la producción agrícola permite analizar las formas en que son destinados los recursos para la producción en dicho sector. Es posible identificar el impacto del bienestar a productores y consumidores; así como, la mejor asignación de los recursos en la agricultura, pues estos, al ser escasos, deben destinarse de manera eficiente. De acuerdo a Rosales, Apaza y Bonilla (2004), a nivel microeconómico, las decisiones de los productores 
y los consumidores se enfocan en maximizar su bienestar económico. Desde la perspectiva de los productores se busca maximizar sus beneficios por diferentes medios, sujetándose a restricciones tecnológicas, de capital y de mano de obra, aceptando cierto riesgo debido a externalidades, acoplándose a las estructuras de mercado.

\section{Función tecnológica}

En primera instancia, se considera la tecnología como el conjunto factible de posibilidades de planes de producción, es decir, el proceso de transformación de insumos a producto. De acuerdo a Rosales et al. (2004), la tecnología puede expresarse de la siguiente forma:

$$
Y=\{(y,-x)\}=\{(Y 1, Y 2, \ldots, Y m-X 1,-X 2, \ldots,-X n)\}
$$

Donde:

$\mathrm{Y}=$ vector producto - insumo

$\mathrm{Y}=(\mathrm{Y} 1, \mathrm{Y} 2, \ldots, \mathrm{Ym})$ vector de producto

$-X=-X 1,-X 2, \ldots,-X n$ vector de insumos

La empresa debe tener en cuenta sus múltiples posibilidades de planes de producción, para ello, estima las combinaciones de producción viables entre insumos y producto para poder elegir su mejor alternativa.

\section{Competitividad empresarial}

Es generada a través de distintos elementos; todos ellos, encaminados a mejorar el desempeño de la firma como: el capital humano, la localización, canales de distribución internos y externos, insumos de calidad, entre otros. La competitividad genera una estrategia en la empresa, la cual moldea a la cadena global de valor; en este contexto, existe la posibilidad de que la empresa elija generar la mayor parte de sus insumos de manera interna o generar una cadena global de valor que le brinde beneficios y una mejor posición en comparación a los competidores del mercado.

Existen cuatro panoramas que afectan a la cadena global de valor, basado en la estrategia competitiva: 
- Panorama de segmento. La variedad de los productos y la porción del mercado que se pueda cubrir juegan papeles importantes en la competitividad. Al diversificar la gama de productos que se ofrecen se puede llegar a más clientes.

- Grado de integración. Se refiere a cuántas empresas van a producir un bien o servicio para satisfacer la demanda del mercado. Para realizar esta fase, las empresas realizan un análisis de las ventajas y desventajas que se obtendrían si se decidiera realizar una integración.

- Panorama geográfico. De acuerdo a la cobertura que tiene la empresa y a los planes de distribución que tiene la misma, es importante delimitar una zona geográfica para operar.

- Panorama industrial. Se refiere al número de interrelaciones que existen al interior de las unidades de negocios las cuales pueden bajar el costo o elevar la especialización. (Porter, 2010).

\section{Agrotecnología}

La aplicación de la tecnología en el sector agrícola ha servido históricamente como herramienta mediadora entre el hombre y la naturaleza, entendiéndose como un proceso que no compete solo a un agente o un grupo social, sino a la cohesión entre diferentes agentes que interactúan para lograr un proceso de cambio tecnológico e innovación, mismos que, impactan directamente a la producción agropecuaria. Sobre este entendido, se habrá de diferenciar a estos agentes que influyen en el proceso citado: productores primarios, agroindustrias, organizaciones sociales y privadas, estado, agentes financieros, centros de capacitación e instituciones de educación superior (Aguilar, 2005).

Para la industria agrícola es de suma importancia estar actualizada respecto a la innovación aplicable a la productividad del campo, lo anterior, con el propósito de adecuarse a las condiciones que impone el mercado internacional y a las políticas de autogestión, aquí radica la relevancia de reconocer las principales tendencias en materia tecnológica del campo, pues es una variable de consolidación y desarrollo de los productores agrícolas.

Hernández (2009), define agrotecnología como "la aplicación del conocimiento humano para desarrollar la agricultura" (párr. 1), y señala que en la actualidad se identifican dos principales corrientes de la misma: 
- Convencional. Basada en el desarrollo de tecnología avanzada para cubrir las necesidades primarias de la agricultura como riego y control de plagas, y que son el origen de lo que se identificó como "revolución verde" en el siglo pasado, en la actualidad la hidroponía, los transgénicos y los cultivos protegidos son ejemplos de esta corriente.

- Agroecología. O ciencia de la agricultura orgánica; que, a través de un estudio y revaloración científica de las técnicas agrícolas tradicionales, busca formas en que la interacción con el ecosistema sea más amigable y las nuevas técnicas de agricultura sean más respetuosas con el medio ambiente.

\section{La tecnología como factor de competitividad}

La competitividad de la empresa es determinada principalmente por la tecnología que, si bien es una parte esencial de la competitividad, también es un agente de cambio que tiene efectos en la optimización de tiempos e incrementos en la eficiencia. Para entender el concepto de tecnología es conveniente revisar el concepto de Schumpeter (1942), quien introduce el término de destrucción creativa el cual parte de la innovación y menciona que "en el proceso de innovación que tiene lugar en una economía de mercado, los productos nuevos destruyen viejas empresas y modelos de negocios, las innovaciones son la fuerza que hay detrás de crecimiento económico" (p. 2). En la empresa se puede decir que cuando existe la innovación tecnológica, se detona la competitividad a través de incrementos en la productividad.

\section{Estudio económico de la producción bajo ambientes protegidos en el Estado de Hidalgo} De acuerdo al Instituto Nacional de Estadística y Geografía (INEGI, 2017a), en su Anuario Estadístico y Geográfico de Hidalgo 2017, la población total en el Estado es de 2,858,359 habitantes, de los cuales 1,161,088 son económicamente activos, de este universo 190,030 (16.36\%) habitantes se dedican al ámbito agropecuario.

Según el último Censo Agrícola, Ganadero y Forestal realizado por el INEGI (2007b), la superficie en unidades de producción agropecuaria corresponden a poco más de la mitad de la superficie del país, con un total de 112,349,000 hectáreas, de las cuales 1,147,601 hectáreas corresponden a Hidalgo (1.1\%); sin embargo, en estas hectáreas se ubican 298,309 unidades de 
producción que representan el 5.3\% de las unidades registradas en todo el país, lo que ubica al Estado en el séptimo lugar nacional, respecto al número de unidades de producción.

Tabla 1. Unidades de producción y superficie, en municipios, Estado de Hidalgo

\begin{tabular}{lcccccc}
\multirow{2}{*}{ Municipios } & Unidades & Total & \multicolumn{2}{c}{ Unidades productivas con actividad } \\
\cline { 6 - 7 } & productivas & Hectáreas & Absolutas & Relativas & Absolutas & Relativas \\
\hline Estado de Hidalgo & 298309 & 1147601 & 205774 & 69.0 & 738965 & 64.4 \\
\hline Huejutla de Reyes & 16735 & 32195 & 14920 & 89.2 & 29638 & 92.1 \\
\hline Ixmiquilpan & 13183 & 29317 & 7566 & 57.4 & 13229 & 45.1 \\
\hline Tlanchinol & 7461 & 26168 & 6170 & 82.7 & 21026 & 80.4 \\
\hline San Felipe Orizatlan & 7403 & 30263 & 6141 & 83.0 & 26500 & 87.6 \\
\hline San Salvador & 6950 & 12452 & 4367 & 62.8 & 7961 & 63.9 \\
\hline Alfajayucan & 6943 & 22186 & 3785 & 54.5 & 11189 & 50.4 \\
\hline Zimapán & 6788 & 17856 & 3735 & 55.0 & 8555 & 47.9 \\
\hline Cardonal & 6661 & 20005 & 3551 & 53.3 & 9531 & 47.6 \\
\hline Huichapan & 6477 & 29054 & 4672 & 72.1 & 18766 & 64.6 \\
\hline Resto de municipios & 219708 & 928105 & 150867 & 68.7 & 592571 & 63.8 \\
\hline
\end{tabular}

Fuente: INEGI, $2017 \mathrm{~b}$.

De la superficie total registrada por dicho censo en Hidalgo, 64 de cada 100 hectáreas están destinadas para actividades agropecuarias, un porcentaje muy similar al del resto del país de 61 de cada 100. Los municipios con mayor superficie son: Huejutla de Reyes, con 32,195 hectáreas; San Felipe Orizatlán, con 30,263; Ixmiquilpan, con 29,317; y Huichapan, con 29,054 (tabla 1). En Hidalgo, el $52.1 \%$ de la superficie total, es superficie de labor, lo que quiere decir que está destinada para cultivos, a diferencia del resto del país que solo destina el 27.8\% para el mismo fin, de igual modo el $\mathbf{4 3 . 9} \%$ son superficies con pastos no cultivados, mientras que a nivel nacional el porcentaje es de $66.8 \%$, y solo el $0.7 \%$ de la superficie en Hidalgo son superficies sin vegetación. 
El Estado actualmente cuenta con más de 60 tipos de cultivos desarrollándose bajo invernadero, el tomate rojo es por mucho el más sembrado (tabla 2), esto debido a que los rendimientos por hectárea de este tipo de cultivo superan en 2.9 veces a sus similares en agricultura tradicional, de igual manera el ingreso por unidad de superficie es 4.2 veces mayor (Secretaría de Agricultura, Ganadería, Desarrollo Rural, Pesca y Alimentación [SAGARPA], 2010).

\section{Tabla 2. Superficie cosechada en invernadero por tipo de cultivo en el Estado de Hidalgo}

\begin{tabular}{lcc}
\multicolumn{1}{c}{$\begin{array}{c}\text { Cultivo desarrollado en instalaciones } \\
\text { de agricultura protegida }\end{array}$} & $\begin{array}{c}\text { Suma de Superficie } \\
\text { cosechada (Ha) }\end{array}$ & $\begin{array}{c}\text { Suma de número } \\
\text { de instalaciones }\end{array}$ \\
\hline acelga & 0.017 & 3 \\
\hline aguacate & 0.012 & 2 \\
\hline alcatraz & 0.701 & 5 \\
\hline apio & 0.020 & 2 \\
\hline boi choi & 0.123 & 5 \\
\hline brocoli & 0.120 & 4 \\
\hline cactus & 0.051 & 6 \\
\hline calabacita & 0.556 & 10 \\
\hline calabaza & 0.290 & 3 \\
\hline cebada forrajera & 0.027 & 2 \\
\hline cebolla & 0.226 & 13 \\
\hline chile morrón & 29.619 & 40 \\
\hline chile seco & 0.026 & 3 \\
\hline chile verde & 0.415 & 9 \\
\hline cilantro & 0.008 & 2 \\
\hline col (repollo) & 0.225 & 11 \\
\hline coliflor & 0.291 & 15 \\
\hline dalia & 0.563 & 4 \\
\hline & & 2 \\
\hline
\end{tabular}




\begin{tabular}{|c|c|c|}
\hline ejote & 0.20 & 2 \\
\hline espinaca & 0.035 & 2 \\
\hline flores & 1.185 & 23 \\
\hline fresa & 0.225 & 5 \\
\hline frijol & 0.045 & 3 \\
\hline frijol semilla & 0.220 & 2 \\
\hline frutales varios & 0.090 & 2 \\
\hline gladiola & 0.090 & 2 \\
\hline haba verde & 0.171 & 2 \\
\hline hongo seta (zeta) & 0.452 & 7 \\
\hline lechuga & 0.763 & 27 \\
\hline limonium & 0.500 & 2 \\
\hline maguey pulquero & 0.300 & 2 \\
\hline margarita & 0.176 & 2 \\
\hline noche buena & 0.549 & 4 \\
\hline nopal verdura & 15.622 & 82 \\
\hline pepino & 0.150 & 5 \\
\hline pino & 0.280 & 2 \\
\hline plantas de ornato & 0.075 & 2 \\
\hline rosa & 9.427 & 74 \\
\hline tomate rojo (semilla) & 0.010 & 1 \\
\hline tomate rojo (jitomate) & 97.913 & 756 \\
\hline tomate verde & 0.785 & 21 \\
\hline
\end{tabular}

Fuente: Elaboración propia con datos de SAGARPA, 2018. 
Alrededor del $86 \%$ de las unidades de producción son inferiores a 0.5 hectáreas, el $11.5 \%$ de 0.51 a 5 hectáreas y solo el $2.5 \%$ tienen más de 5 hectáreas. Esto indica que la mayor parte de los productores tienen unidades muy pequeñas de producción, lo que limita su acceso a la tecnología, la capacitación y la asistencia técnica [...] (Ponce, 2015)

Según la Asociación Mexicana de Constructores de Invernaderos (AMCI) y la SAGARPA, los costos para invernaderos varían dependiendo del tipo de tecnología que se ocupe, en el caso de Hidalgo, considerando los tipos de climas tan diversos que se encuentran en su territorio y de forma específica los que se emplean para el cultivo del tomate rojo (jitomate), los costos oscilan entre un invernadero simple con un mínimo de $\$ 220$ pesos por metro cuadrado hasta un invernadero para cualquier tipo de clima con un costo máximo de 510 pesos por metro cuadrado (tabla 3). Esto, debido a que estos tipos de invernaderos, son aptos para sembrar tanto tomates como pepinos, pimientos, berenjenas, melones, chiles, lechugas, flores, follajes, así como viverismo.

Es importante señalar que, una de las variables importantes que se debe considerar al construir un invernadero es la velocidad de los vientos, motivo por el cual la Norma Mexicana NMX-E-225-CNCP-2008 "Diseño y construcción de invernaderos", hace referencia a una tabla proporcionada por la Comisión Federal de Electricidad (CFE), en donde separa al país en regiones eólicas y sitúa al Estado de Hidalgo en una zona 5 donde la velocidad máxima promedio de sus vientos es de $80 \mathrm{~km} / \mathrm{h}$.

Es importante mencionar que, en Hidalgo, la agricultura protegida aún se encuentra en vías de crecimiento; sin embargo, en el 2008, se construyeron $150,000 \mathrm{~m}^{2}$ de invernaderos, mediante el Programa de Agricultura Protegida, lo que representó construir $12,500 \mathrm{~m}^{2}$ de invernaderos por mes para producir hasta 450 ton/año de hortalizas. Durante el 2010, a través del Proyecto Estratégico para la Agricultura Protegida (PROAP), que opera el Fideicomiso de Riesgo Compartido (FIRCO), el gobierno federal invirtió en el Estado de Hidalgo 18 millones de pesos, y para 2016 mediante el mismo Proyecto, se invirtieron poco más de 15 millones de pesos en 20 unidades de producción diferentes. 
Tabla 3. Tipo de tecnología en invernaderos y rango en precios por metro cuadrado construido

Tipo de

invernadero
Tecnología
Rango por $\mathrm{m}^{2}$ (pesos)

\section{Mínimo Máximo}

- Estructura ligera de Acero Galvanizado (en ocasiones, acero negro en las bases) con cubierta plástica

- No tiene paredes frontales ni laterales

Macro túnel - Estructura Móvil (muy fácil de instalar y quitar),

25 no lleva cimentación

- Incluye trazo, instalación, riego y acolchado

- Para zonas templadas y vientos máximos de 25 a $55 \mathrm{~km} / \mathrm{h}$

- Estructura metálica ligera

- Mallas antiáfidos en cubiertas y en perímetro

- Incluye sistema de tutoreo (20 a $\left.30 \mathrm{~kg} / \mathrm{m}^{2}\right)$

Malla sombra - Incluyen mano de obra de instalación, trazo y cimentación

- Sistema de riego localizado con inyección de fertilizante manual

- Dependiendo de la región resiste de 80 a 120 km

- Estructura de invernadero con ventilación cenital fija

- Ventilación perimetral con mallas

- Cubiertas en techumbres con polietileno y ventanas con malla antiáfidos

Invernadero - Incluye mano de obra de instalación, trazo, cimentación

tropicalizado - Sistema de riego localizado con inyección de fertilizante manual

- Proyectos llave en mano

- Dependiendo de la región del país resiste de 80 a 120 $\mathrm{km} / \mathrm{h}$

- Estructura de invernadero con ventila cenital fija

- Ventana cenital manual

Invernadero

- Ventana perimetral manual

para clima

- Sistema de riego localizado con inyección de fertilizante manual

templado

- Para climas templados y fríos

- Dependiendo de la región del país resiste de 80 a 120 $\mathrm{km} / \mathrm{h}$ 
Tipo de

invernadero
Rango por $\mathrm{m}^{2}$ (pesos)

Mínimo Máximo

- Estructura de invernadero con ventana cenital fija

- Ventana cenital motorizada

- Ventanas perimetrales motorizadas

Invernadero para cualquier clima

- Incluye automatización

- Incluye mano de obra de instalación, trazo y cimentación

- Sistema de riego localizado con inyección de fertilizante automático

- Proyectos llave en mano

- Dependiendo de la región del país resiste de 100 a 120 $\mathrm{km} / \mathrm{h}$

Fuente: Elaboración propia con datos de la AMCI/SAGARPA, 2010.

Como se señaló con anterioridad, dentro de las hortalizas que representan mayor utilidad sembradas en ambientes protegidos, así como las de mayor exportación, se encuentra el tomate rojo -en el Estado de Hidalgo, principalmente, se produce esta hortaliza-. De acuerdo con los datos proporcionados en el Panorama Agroalimentario del tomate rojo 2016 (Fideicomisos Instituidos en Relación con la Agricultura [FIRA], 2016), la producción de este producto en México creció a una tasa promedio anual de 3.3\% de 2005 a 2015, en este mismo periodo, la superficie total destinada a este cultivo en específico disminuyo en una tasa promedio de $3.8 \%$ anual, ya que mientras en 1980 se sembraron 85,500 hectáreas, para el 2000 se sembraron 75,900 hectáreas y solo 50,596 hectáreas se sembraron en 2015, esto debido principalmente al decremento de superficie cultivada a cielo abierto y al aumento de cultivos en condiciones de agricultura protegida (malla sombra e invernaderos). 


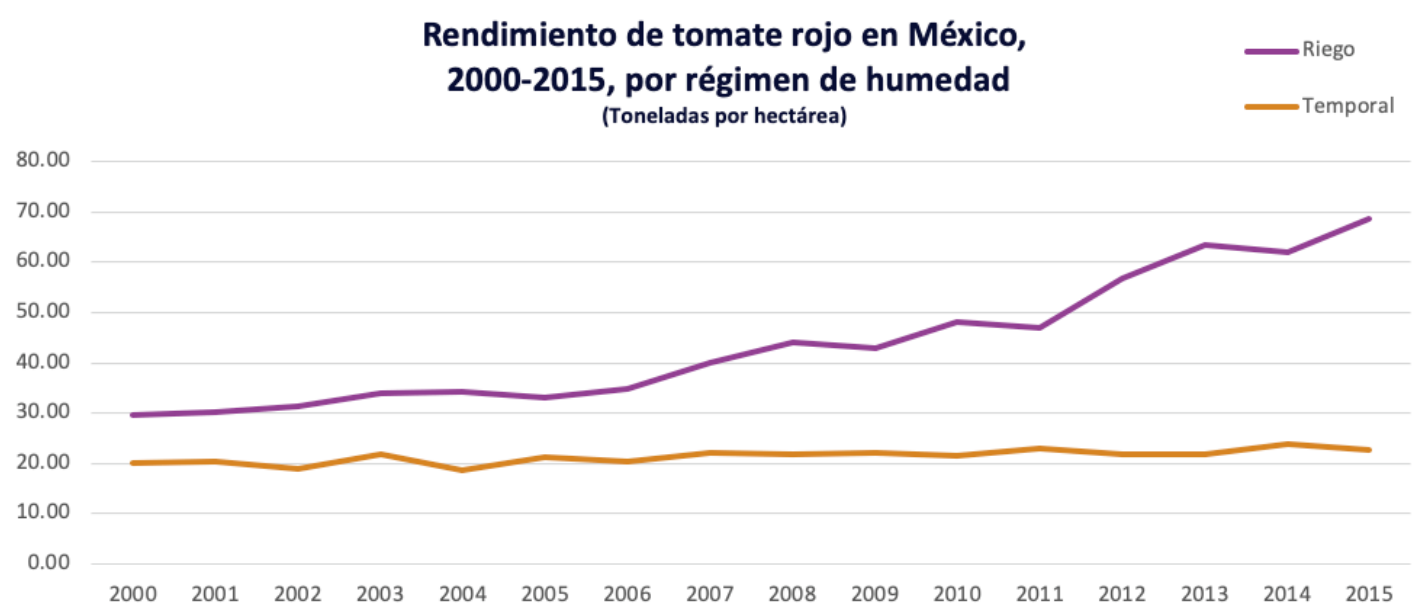

Figura 1. Rendimientos de tomate rojo por régimen de humedad.

Fuente: Elaboración propia con datos del Servicio de Información Agroalimentaria y Pesquera (SIAP).

Los precios reportados en el 2015 tienen diferencias notorias entre los producidos a cielo abierto y los producidos en invernadero. Mientras que el tomate Saladette y Bola a cielo abierto registraron un precio promedio nacional de 5,245 y 3,685 pesos por tonelada respectivamente, los precios de las mismas variedades de tomate producidos en invernadero tuvieron promedios de 6,763 y 5,305 pesos por tonelada respectivamente; lo que significa que los precios obtenidos de agricultura protegida fueron 29 y 44 por ciento mayores a los obtenidos a cielo abierto (FIRA, 2016, p. 22).

\section{Cálculo de la utilidad económica: caso Tomate Saladette}

Con el propósito de realizar una evaluación económica, que tome como eje principal la utilidad que se obtiene en la producción de tomate bajo condiciones de invernadero, se ejecutó un estudio de campo en cinco proyectos ubicados en las localidades de San Martín y San Pedro, ubicadas en el municipio de Eloxochitlán en el Estado de Hidalgo. En una primera fase, se calcularon los costos totales en que incurren los productores, posteriormente, se determinó el precio de venta por kilogramo promedio, bajo el siguiente procedimiento: 
Tabla 4. Precios del tomate Saladette en el mercado nacional

\begin{tabular}{lcccccc} 
& \multicolumn{2}{c}{2009} & \multicolumn{2}{c}{2011} \\
\cline { 2 - 7 } Mes & $\begin{array}{l}\text { Precio al } \\
\text { mayoreo }\end{array}$ & $\begin{array}{c}\text { Precio al } \\
\text { consumidor }\end{array}$ & $\begin{array}{c}\text { Precio al } \\
\text { mayoreo }\end{array}$ & $\begin{array}{c}\text { Precio al } \\
\text { consumidor }\end{array}$ & $\begin{array}{c}\text { Precio al } \\
\text { mayoreo }\end{array}$ & $\begin{array}{c}\text { Precio al } \\
\text { consumidor }\end{array}$ \\
\hline Enero & 6,832 & 11,674 & 6,851 & 11,886 & 8,680 & 13,248 \\
\hline Marzo & 4,939 & 7,023 & 6,851 & 10,041 & 10,336 & 15,644 \\
\hline Abril & 6,233 & 8,460 & 9,681 & 15,775 & 9,761 & 14,846 \\
\hline Mayo & 9,153 & 13,466 & 7,223 & 13,750 & 15,339 & 24,425 \\
\hline Junio & 8,993 & 13,309 & 6,083 & 11,224 & 9,094 & 15,836 \\
\hline Julio & 8,997 & 13,054 & 5,007 & 8,944 & 6,509 & 9,625 \\
\hline Agosto & 9,091 & 13,613 & 6,194 & 9,951 & 7,254 & 10,721 \\
\hline Septiembre & 10,696 & 14,710 & 6,569 & 10,396 & 6,698 & 10,110 \\
\hline Octubre & 9,790 & 15,567 & 11,118 & 16,084 & 6,187 & 10,358 \\
\hline Noviembre & 8,406 & 13,757 & 11,559 & 16,903 & 5,600 & 9,481 \\
\hline Diciembre & 7,612 & 13,322 & 10,347 & 15,451 & 7,299 & 11,401 \\
\hline
\end{tabular}

\begin{tabular}{lcccccc} 
& \multicolumn{2}{c}{2012} & \multicolumn{2}{c}{2013} & \multicolumn{2}{c}{2014} \\
\cline { 2 - 7 } Mes & $\begin{array}{l}\text { Precio al } \\
\text { mayoreo }\end{array}$ & $\begin{array}{c}\text { Precio al } \\
\text { consumidor }\end{array}$ & $\begin{array}{c}\text { Precio al } \\
\text { mayoreo }\end{array}$ & $\begin{array}{c}\text { Precio al } \\
\text { consumidor }\end{array}$ & $\begin{array}{c}\text { Precio al } \\
\text { mayoreo }\end{array}$ & $\begin{array}{c}\text { Precio al } \\
\text { consumidor }\end{array}$ \\
\hline Enero & 7,749 & 12,212 & 8,310 & 12,456 & 11,520 & 15,082 \\
\hline Febrero & 5,395 & 8,652 & 7,582 & 11,166 & 7,425 & 9,862 \\
\hline Marzo & 6,339 & 9,667 & 8,596 & 12,775 & 6,574 & 8,479 \\
\hline Abril & 6,009 & 9,279 & 8,334 & 12,168 & 7,652 & 10,834 \\
\hline Mayo & 6,974 & 9,404 & 9,697 & 13,225 & 7,285 & 9,181 \\
\hline Junio & 9,738 & 13,867 & 8,774 & 12,512 & 7,198 & 9,810 \\
\hline
\end{tabular}




\begin{tabular}{lcccccc} 
& \multicolumn{2}{c}{2012} & \multicolumn{2}{c}{2013} & \multicolumn{2}{c}{2014} \\
\cline { 2 - 7 } Mes & $\begin{array}{l}\text { Precio al } \\
\text { mayoreo }\end{array}$ & $\begin{array}{c}\text { Precio al } \\
\text { consumidor }\end{array}$ & $\begin{array}{c}\text { Precio al } \\
\text { mayoreo }\end{array}$ & $\begin{array}{c}\text { Precio al } \\
\text { consumidor }\end{array}$ & $\begin{array}{c}\text { Precio al } \\
\text { mayoreo }\end{array}$ & $\begin{array}{c}\text { Precio al } \\
\text { consumidor }\end{array}$ \\
Julio & 9,834 & 14,474 & 7,730 & 11,030 & 7,916 & 11,058 \\
\hline Agosto & 8,937 & 12,846 & 9,076 & 13,039 & 8,295 & 11,550 \\
\hline Septiembre & 10,984 & 15,515 & 10,674 & 14,353 & 9,932 & 14,047 \\
\hline Octubre & 10,509 & 16,025 & 10,694 & 14,610 & 9,981 & 14,540 \\
\hline Noviembre & 8,637 & 12,649 & 13,136 & 17,857 & 11,580 & 16,861 \\
\hline Diciembre & 9,457 & 13,686 & 17,155 & 22,720 & 11,842 & 23,785 \\
\hline
\end{tabular}

\begin{tabular}{|c|c|c|c|c|}
\hline \multirow[b]{2}{*}{ Mes } & \multicolumn{2}{|c|}{2015} & \multicolumn{2}{|c|}{2016} \\
\hline & $\begin{array}{l}\text { Precio al } \\
\text { mayoreo }\end{array}$ & $\begin{array}{l}\text { Precio al } \\
\text { consumidor }\end{array}$ & $\begin{array}{l}\text { Precio al } \\
\text { mayoreo }\end{array}$ & $\begin{array}{l}\text { Precio al } \\
\text { consumidor }\end{array}$ \\
\hline Enero & 10,522 & 14,706 & 16,433 & 22,969 \\
\hline Febrero & 8,084 & 10,573 & 13,345 & 18,107 \\
\hline Marzo & 12,334 & 15,940 & 13,090 & 17,384 \\
\hline Abril & 12,081 & 16,306 & 10,736 & 14,526 \\
\hline Mayo & 10,441 & 14,172 & 9,575 & 12,000 \\
\hline Junio & 10,385 & 14,106 & 9,867 & 12,400 \\
\hline Julio & 11,395 & 15,464 & & \\
\hline Agosto & 11,498 & 15,378 & & \\
\hline Septiembre & 11,226 & 16,221 & & \\
\hline Octubre & 10,929 & 15,757 & & \\
\hline Noviembre & 10,596 & 15,155 & & \\
\hline Diciembre & 16,280 & 21,536 & & \\
\hline
\end{tabular}

Fuente: Elaboración propia con datos del Sistema Nacional de Información e Integración de Mercados (SNIIM) e INEGI. 
Costos Producción + Costo Distribución + \% de Ganancia = Precio de Venta

Con los datos anteriores se calculó la utilidad con la siguiente formula:

Utilidad Total $=$ Ingreso Total - Costo total $(\mathrm{Ut}=\mathrm{It}-\mathrm{Ct})$

Los costos de producción en promedio son los siguientes:

Tabla 5. Costos de producción

\begin{tabular}{|c|c|c|c|}
\hline Concepto & Cantidad & Costo unitario (pesos) & Costo total (pesos) \\
\hline Pago al capital & & & $\$ 117,600.00$ \\
\hline Renta del Terreno & & $\$ 3,600.00$ & $\$ 3,600.00$ \\
\hline Total Inversión inicial & & & $\$ 121,200.00$ \\
\hline Tezontle & 16 viajes & $\$ 1,800.00$ & $\$ 28,800.00$ \\
\hline Semilla & & $\$ 19,200.00$ & $\$ 19,200.00$ \\
\hline Jornales (siembra y trasplante) & 10 & $\$ 200.00$ & $\$ 2,000.00$ \\
\hline Total Siembra & & & $\$ 50,000.00$ \\
\hline Nitrato de calcio & $1628 \mathrm{~kg}$ & $\$ 15.00$ & $\$ 24,420.00$ \\
\hline Nitrato de potasio & $528 \mathrm{~kg}$ & $\$ 15.00$ & $\$ 7,920.00$ \\
\hline Sulfato de potasio & $528 \mathrm{~kg}$ & $\$ 15.00$ & $\$ 7,920.00$ \\
\hline Magnesio & $1760 \mathrm{~kg}$ & $\$ 10.00$ & $\$ 17,600.00$ \\
\hline Mono potásico & $280 \mathrm{~kg}$ & $\$ 43.00$ & $\$ 12,040.00$ \\
\hline Total Fertilización & & & $\$ 69,900.00$ \\
\hline Aplicación de Curzate & $11.2 \mathrm{~kg}$ & $\$ 480.00$ & $\$ 5,376.00$ \\
\hline Aplicación de Equation PRO & $1-2 \mathrm{~g} / \mathrm{l}$ & $\$ 456.00$ & $\$ 2,553.60$ \\
\hline Total Pesticidas/Fungicidas & & & $\$ 7,929.60$ \\
\hline Riego & 8 meses & $\$ 150.00$ & $\$ 1,200.00$ \\
\hline Total Riego & & & $\$ 1,200.00$ \\
\hline
\end{tabular}




\begin{tabular}{lcrr} 
& Contidad & Costo unitario (pesos) & Costo total (pesos) \\
\hline Jornales & 63 & $\$ 200.00$ & $\$ 12,600.00$ \\
\hline Total Cosecha & & $\$ 12,600.00$ \\
\hline Bunega (desinfectar terreno) & 40 litros & $\$ 96.00$ & $\$ 3,840.00$ \\
\hline Reparación de naves & & $\$ 4,800.00$ \\
\hline Total Post cosecha & & $\$ 180.00$ & $\$ 8,640.00$ \\
\hline Energía eléctrica & & & $\$ 1,440.00$ \\
\hline Total Energía eléctrica & 31 viajes & $\$ 1,440.00$ \\
\hline Transporte & & $\$ 18,600.00$ \\
\hline Total Comercialización & 208 días & $\$ 18,600.00$ \\
\hline Sueldos & & $\$ 200.00$ & $\$ 41,600.00$ \\
\hline Total Sueldos & & $\$ 41,600.00$ \\
\hline Gran Total & & $\$ 333,109.60$ \\
\hline
\end{tabular}

Fuente: Elaboración propia con base en información proporcionada por cinco productores.

La producción obtenida fue de 92 toneladas, las cuales, se comercializaron principalmente a la central de abastos de Tulancingo, comerciantes provenientes de la Ciudad de México, tianguis de Eloxochitlán y tiendas de autoservicio; a un precio promedio de $\$ 9.00$ por kilogramo.

Tabla 6. Utilidad en pesos por kilogramo

\begin{tabular}{lcr}
\multicolumn{1}{c}{ Concepto } & Proyecto & MXN \$ / kg \\
\hline Ingreso total & $\$ 828,000.00$ & $\$ 9.00$ \\
\hline Costo total & $\$ 333,109.60$ & $\$ 3.62$ \\
\hline Ganancia neta total & $\$ 494,890.40$ & $\$ 5.38$ \\
\hline Ganancia neta por socio (4) & $\$ 123,722.60$ & $\$ 1.34$ \\
\hline
\end{tabular}

Nota: MXN \$ = Peso Mexicano.

Fuente: Elaboración propia con base en información proporcionada por productores. 
La tabla 6 muestra que la utilidad que se obtiene por cada kilogramo de tomate vendido es de MXN $\$ 1.34 / \mathrm{kg}$ por socio, cantidad que debe ser comparada con el margen de utilidad de otros Estados productores de tomate con la finalidad de determinar si se encuentran en el rango de mercado o habrá que implementar medidas: procesos productivos, tecnología y técnica de cultivo.

\section{Modelo correlacional}

Los productores de tomate rojo del estado de Hidalgo al contar con invernaderos y mayor superficie incrementan su volumen de producción; es por esto que, los productores hacen un esfuerzo para adquirir invernaderos, pues les permite mejorar su producción, minimizar sus costos, maximizar sus beneficios y lograrun desempeño óptimo en sus actividades empresariales; con esta actividad buscan mejorar el nivel y estilo de vida de todas las personas involucradas en el proceso productivo del jitomate. El modelo que se utiliza para este estudio es el siguiente:

Donde:

$$
V=P_{j}+S_{p}+T_{c}
$$

$V=$ Ventas $\quad P_{j}=$ Producción $\quad S_{p}=$ Superficie $\quad T_{c}=$ Tecnología

Para el análisis correlacional se siguió el siguiente proceso:

1. Recopilación de información bibliográfica.

2. Clasificación de la información y cifras.

3. Desarrollo de la estadística descriptiva.

4. Definición del software a utilizar para obtener la correlación.

5. Obtención de datos y gráficas.

6. Interpretación de los resultados.

El modelo propuesto sólo se aplica para los datos obtenidos del Estado de Hidalgo de manera anual en invernadero y a cielo abierto. Para obtener los datos correlacionales, se utilizó el Software Eviews 9.0; una vez realizadas las respectivas corridas, se obtuvieron las cifras de la tabla 7 y 8. 
Tabla 7. Correlación entre variables bajo invernadero

\begin{tabular}{cccc} 
Correlación Ventas & Producción & Superficie & Rendimiento \\
\hline $\mathrm{R}^{2}$ & 99.5 & 98.8 & 90.8 \\
\hline
\end{tabular}

Fuente: Elaboración propia.

Los coeficientes obtenidos entre variables bajo invernadero (tabla 7) muestran diferentes grados de interrelación que guardan las variables: producción $99.5 \%$, superficie $98.8 \%$ y rendimientos $90.8 \%$ con respecto a las ventas. Las tres variables muestran intervalos de alta significancia, a partir de esta base, se puede decir que los incrementos en la producción, superficie y rendimientos, influyen de manera positiva en las ventas; se observa una relación directa en estas cuatro variables.

Tabla 8. Correlación entre variables bajo cielo abierto

\begin{tabular}{cccc} 
Correlación Ventas & Producción & Superficie & Rendimiento \\
\hline $\mathrm{R}^{2}$ & 85.2 & 17.1 & 53.5 \\
\hline
\end{tabular}

Fuente: Elaboración propia.

Los coeficientes obtenidos entre variables bajo cielo abierto (tabla 8) son: producción $85.2 \%$, superficie $17.1 \%$ y rendimiento $53.5 \%$ con respecto a las ventas. Salvo la producción, el resto de las variables son de baja significancia. Con esta base, se afirma que el incremento en superficie o rendimiento, no necesariamente influye de manera positiva en las ventas puesto que estas variables no tienen una relación directa.

\section{Conclusiones}

- Se observó que la producción del tomate rojo (jitomate) bajo invernadero en el Estado de Hidalgo es viable y se encuentra en incremento, a pesar de los costos que implica la adquisición del mismo. 
- Los programas de apoyo al campo, tanto federal como estatal, deben de diseñar políticas, planes y programas, ajustados a la realidad de cada región e integrar el componente tecnológico que permita obtener un mayor índice de productividad.

- El análisis cuantitativo señala que las correlaciones entre las variables estudiadas se comportan de forma diferente, muestran una correlación alta en el caso del invernadero $y$, lo contrario, en el caso de cielo abierto.

- Estos datos nos aportan la suficiente confianza para concluir que los factores de producción, superficie y rendimiento son elementos claves para el incremento en ventas del producto obtenido en invernadero, mientras que las mismas variables no son claves en el caso del producto obtenido bajo cielo abierto.

- Los productores de tomate rojo (jitomate) en el Estado de Hidalgo requieren actualizar sus métodos de producción y aplicar procesos tecnológicos a través de la modalidad de invernadero; sobre esta situación, se debe reemplazar el método de cosechar a cielo abierto.

- El sistema de invernadero permite mayores beneficios a los productores y sus familias; lo anterior, se deduce al haber obtenido coeficientes de correlación en invernadero entre las ventas y la producción de $99.5 \%$, entre las ventas y la superficie de $98.8 \%$ y entre las ventas y el rendimiento de $90.8 \%$.

- En la modalidad de cielo abierto, los coeficientes de correlación son: ventas y producción $85.9 \%$; ventas y superficie $17.1 \%$ y ventas y rendimiento $53.5 \%$, que permite observar que las variables en invernadero interactúan y se corresponden. 


\section{Referencias}

Aguilar, A.J. (2005) Transferencia e Innovación Tecnológica en la Agricultura: Lecciones y Propuestas. Tesis. Universidad Autónoma Chapingo, México.

Asociación Mexicana de Constructores de Invernaderos/Secretaría de Agricultura, Ganadería, Desarrollo Rural, Pesca y Alimentación (AMCI/SAGARPA). (2010). Rangos de precios sugeridos para 5 tipos de invernaderos en México. México: AMCI/SAGARPA.

Fideicomisos Instituidos en Relación con la Agricultura (FIRA). (2016). Panorama Agroalimentario del tomate rojo 2016. México: FIRA. Recuperado de https://www.gob.mx/cms/uploads/ attachment/file/200635/Panorama_Agroalimentario_Tomate_Rojo_2016.pdf

Gómez, E. (1964). Funciones de producción en la agricultura. Revista de estudios agro-socialesMadrid, 13.

Hernández, A. (2009). Agrotecnología. ¿Qué es? Recuperado de https://agrotecnologia2.blogspot. com/search?q=aplicaci\%C3\%B3n+del+conocimiento

Instituto Nacional de Estadística y Geografía (INEGI). (2007). VII Censo Agrícola, Ganadero y Forestal. México: INEGI.

Instituto Nacional de Estadística y Geografía (INEGI). (2017a). Anuario estadístico y geográfico de Hidalgo 2017. México: INEGI.

Instituto Nacional de Estadística y Geografía (INEGI). (2017b). Censo Agropecuario 2017. Panorama General. México: INEGI.

Instituto Nacional de Estadística y Geografía (INEGI). (2017c). SNIIM Sistema Nacional de Información e Integración de Mercados. Recuperado de http://www.economia-sniim.gob. $\mathrm{mx} /$ INEGIfechas.asp

Jouve, P. (1988). Quelques reflexions sur la specificité et l'identification des systěmes agraries. Les cahiers de la Recherche Déveleppement. DSA-CIRAD, (20), 5-16.

Ponce, P. (2013). Producción de tomates en invernadero en México. Hortalizas. https://www. hortalizas.com/horticultura-protegida/produccion-de-tomates-en-invernadero-enmexico/

Porter, M. (2010). Ventaja Competitiva. España: Editorial Pirámide. 
Rosales, R.A., Apaza, E. y Bonilla, J.A. (2004). Economía de la producción de bienes agrícolas, teoría y aplicaciones. Documento. Facultad de Economía, Universidad de los Andes, Colombia. Recuperado de https://www.researchgate.net/publication/4938898_ECONOMIA_DE_ LA_PRODUCCION_DE_BIENES_AGRICOLAS

Secretaría de Agricultura, Ganadería, Desarrollo Rural, Pesca y Alimentación (SAGARPA). (2010). Monografía de cultivos. México: Subsecretaría de Fomento a los Agronegocios.

Secretaría de Agricultura, Ganadería, Desarrollo Rural, Pesca y Alimentación (SAGARPA). (2018). Atlas Agroalimentario. México: SAGARPA.

Servicio de Información Agroalimentariay Pesquera (SIAP).(s.f.). Estadística de ProducciónAgrícola, Datos Abiertos. Recuperado de http://infosiap.siap.gob.mx/gobmx/datosAbiertos.php Schumpeter, J.A. (1942). Business Cycles, a Theoretical, Historical and Statistical Analysis of the Capitalist Process. Nueva York: McGraw-Hill Book.

Varian, H. (2010). Microeconomía intermedia. Un enfoque moderno. España: Antoni Bosch. 


\section{Capítulo 3}

Factor Infraestructura: subfactores y variables que inciden en la competitividad de las PyMes de servicios navieros en Manzanillo

Pablo Adrián Magaña Sánchez $z^{1}$ Mario de Jesús Naranjo González ${ }^{2}$ y Luis Octavio Ríos Silva

\footnotetext{
${ }^{1}$ Universidad de Colima, México. pablo_magana@ucol.mx

2 Universidad de Colima, México. naranjo@ucol.mx

3 Universidad de Colima, México. Irios0@ucol.mx
} 


\section{Introducción}

En la actualidad, las empresas se enfrentan a clientes más exigentes e informados; las tecnologías de la información y el uso de Internet proporciona al usuario o consumidor un sinnúmero de opciones para adquirir sus productos o servicios, por tal motivo, el consumidor acude a diferentes proveedores para satisfacer sus necesidades y solo tendrá lealtad a la marca cuando un proveedor cumpla cabalmente con sus expectativas.

Lo anterior, ha obligado a las empresas a ser más competitivas, esforzarse por ofrecer mejores productos $y / 0$ servicios, e innovar en estrategias que les permitan tener mayores ventajas competitivas.

Según Porter (1990), esta ventaja competitiva nace de muchas actividades discretas que ejecuta la empresa al diseñar, fabricar, comercializar, entregar y apoyar su producto, cada una de ellas contribuye a su posición relativa en costos y sienta las bases de la diferenciación.

Así, la competitividad es la capacidad de una empresa para producir y mercadear productos en mejores condiciones de precio, calidad y oportunidades que sus rivales (Porter, 1987)

De acuerdo al modelo propuesto por el Instituto para el Desarrollo Gerencial (IMD, por sus siglas en inglés), existen cuatro factores determinantes de la competitividad: Desempeño económico, Eficiencia gubernamental, Eficiencia en los Negocios, e Infraestructura (Magaña, Naranjo y Deniz, 2017). Considerando este modelo, el presente trabajo tiene como objetivo conocer, del factor Infraestructura, los subfactores y variables que inciden en la competitividad de las pequeñas y medianas empresas de servicios navieros de Manzanillo, Colima, México. Este conocimiento permitirá a los dueños, gerentes o encargados del negocio tomar decisiones e implementar mejores estrategias competitivas.

\section{Marco teórico}

\section{Concepto de infraestructura}

Para efectos de esta investigación, es necesario hacer referencia al concepto de infraestructura. Para Marx (citado por Baena, 2014), la infraestructura es: 
el factor fundamental del proceso histórico y determina el desarrollo y cambio social, dicho de otro modo, cuando cambia la infraestructura cambia también el conjunto de la sociedad (las relaciones sociales, el poder, las instituciones y el resto de los elementos de la superestructura). (p. 8)

La infraestructura está compuesta por los medios de producción (recursos naturales, medios técnicos y fuerza de trabajo) y las relaciones de producción, establecidas por las personas, a partir del modo en que éstas se vinculan con las fuerzas productivas. De ella, depende la superestructura, es decir, las formas jurídicas y políticas, la filosofía, la religión, el arte y la ciencia (p. 8). La infraestructura es, entonces, la base material en la que se basa la sociedad, que incluye a la economía. Desde allí, se sostiene la estructura social, y más arriba, la superestructura.

También, existen otras definiciones para el término. Así, la infraestructura puede referirse a todos aquellos servicios o facilidades que se requieren en una empresa o sociedad para su buen funcionamiento como: puentes, abastecimientos de agua, electricidad, carreteras, entre otros. Una infraestructura bien desarrollada apoya la actividad económica e incluye desarrollos tecnológicos; si se invierte en investigación y desarrollo es casi seguro que una empresa mejore o aumente sus niveles de competitividad.

\section{Concepto de competitividad}

La competitividad se puede definir desde varias perspectivas. De acuerdo a Garelli (2000), la competitividad es la capacidad del entorno de una nación para mantener la creación de valor añadido y, por consiguiente, la competitividad de sus empresas.

Según Scott y Lodge (1985), la competitividad es la habilidad que tiene una nación de crear, producir, distribuir productos o servicios, en el comercio internacional, mientras obtiene utilidades crecientes sobre sus recursos.

Para Feenstra (1989 citado por Rojas, Chavarría y Sepúlveda, 2002), la "Competitividad es la capacidad de un país, un sector o una firma particular de participar en mercados extranjeros" (p. 49). 
Por otro lado, la "Competitividad es la capacidad de obtener ganancias a través de las exportaciones" (Helleiner, 1989 citado por Rojas et al., 2002, p. 49).

"Competitividad es la habilidad sostenida de obtener ganancias y mantener una participación de mercado... Esta definición presenta tres dimensiones importantes y medibles: ganancias, participación de mercado y, por medio de la palabra 'sostenible', adopta el aspecto temporal” (Dure, Martin y Westgren, 1992, citado por Rojas et al., 2002, p. 49).

La competitividad incluye tanto la eficiencia (alcanzar los objetivos al costo más bajo posible), como la efectividad (tener los objetivos adecuados) (Buckley, 1988).

Y, por último, la competitividad es la capacidad técnico-económica y de calidad que tienen las empresas en la forma de elaborar sus productos, siendo eficientes en sus gestiones ante el gobierno, como en sus actividades cotidianas y estando actualizados en todo tipo de infraestructura tanto física como tecnológica (Magaña, 2013).

\section{Anuario 2018 de Competitividad (IMD)}

En el Anuario de Competitividad Mundial 2018, elaborado por el IMD (con sede en Suiza), México retrocedió tres posiciones, de la 48 a la 51. Es la posición más baja que el país ha tenido desde 1997, cuando fue incluido en esta clasificación.

El retroceso de México es el "resultado del empeoramiento de las percepciones sobre la calidad de las instituciones y la legislación empresarial, como la facilidad para hacer negocios y algunos aspectos del gobierno corporativo" (Morales, 2018).

[...]La clasificación general estuvo liderada por Estados Unidos, Hong Kong, Singapur, Países Bajos, Suiza, Dinamarca, Emiratos Árabes Unidos, Noruega, Suecia y Canadá.

Chile es el único país de América Latina que está mejor posicionado que México, en el lugar 35, donde se mantuvo igual que en la edición anterior. El resto de los países de Latinoamérica presentó los siguientes resultados: Colombia pasó de la 54 a la 58; Perú subió de la 55 a la 54; Brasil avanzó de la 61 a la 60; Argentina escaló de la 58 la 56, y Venezuela se mantuvo en la 63. (Morales, 2018) 


\section{Metodología}

El instrumento que se utilizó, para efectos de esta investigación, fue un cuestionario de 19 preguntas con una escala del 1 al 6 . Este cuestionario tiene validez y confiabilidad a través del alfa de Cronbach del 0.72 y se ha utilizado en otras investigaciones, de donde se tomó como base el factor de infraestructura que es uno de los cuatro factores del IMD. El número de preguntas por cada subfactor se asignó de la siguiente manera: Infraestructura Básica (3), Infraestructura Tecnológica (4), Infraestructura Científica (1), Salud y Medio Ambiente (4), y Educación (7).

La investigación se aplicó en campo, donde se le solicitó al gerente de la empresa su colaboración en el llenado del cuestionario. Posteriormente, a través de un análisis estadístico se logró identificar cuáles son los subfactores y variables de infraestructura que inciden en la competitividad de las empresas de esta investigación. Cabe señalar que para poder identificar cuántas agencias navieras existen en Manzanillo se recurrió a la Asociación Mexicana de Agentes Navieros, A.C. (AMANAC) para determinar cuál sería la población objeto de estudio. Se encontró que existen registradas en esta asociación 20 agencias navieras en Manzanillo, Colima, de las cuales solo participaron 13, argumentando diversas situaciones las siete agencias restantes que decidieron no participar en esta investigación. El tratamiento estadístico o las herramientas que se utilizaron fueron las siguientes: 1) Estandarización de las variables y 2) La media aritmética (Lind, Marchal y Wathen, 2012), la cual es una medida de ubicación muy utilizada. Esta técnica se utilizó para integrar las 19 variables en un solo índice. Para esta investigación se consideraron medias diferentes para cada una de las agencias navieras y, utilizando el programa SPSS versión 22, estas medias se convirtieron o se estandarizaron. El valor medio es el 50\%, es decir, la mediana representa el $50 \%$ y la interpretación de los resultados donde se muestran valores del $50 \%$ hacia arriba o del $50 \%$ hacia abajo significa que están por arriba o por abajo de la media en términos de competitividad. Las dos herramientas estadísticas anteriores nos permitieron identificar los subfactores y variables de infraestructura que inciden en la competitividad de las empresas objeto de estudio. 


\section{Resultados}

A continuación, se presentan los resultados de esta investigación. En la tabla 1, se observan los subfactores y variables de las Pymes de servicios navieros de Manzanillo, Colima, México, que están por arriba de la media en materia de competitividad de acuerdo a la estandarización de variables. En total, 16 variables se encontraron por arriba de la media. Es decir, el 84.21\% del total de las variables impactan en la competitividad de estas empresas.

Tabla 1. Factor Infraestructura: subfactores y variables por arriba de la media en materia de competitividad

\begin{tabular}{|c|c|c|}
\hline Subfactor & Variables & I.C. \\
\hline \multirow{3}{*}{$\begin{array}{l}\text { Infraestructura } \\
\text { Básica }\end{array}$} & La infraestructura portuaria favorece el desarrollo empresarial & 0.5105 \\
\hline & $\begin{array}{l}\text { La infraestructura para la transportación de mercancías satisface } \\
\text { las necesidades portuarias }\end{array}$ & 0.5092 \\
\hline & $\begin{array}{l}\text { El mantenimiento y desarrollo de la infraestructura portuaria está } \\
\text { planificado y financiado adecuadamente }\end{array}$ & 0.5146 \\
\hline \multirow{4}{*}{$\begin{array}{l}\text { Infraestructura } \\
\text { Tecnológica }\end{array}$} & $\begin{array}{l}\text { Las Tecnologías de la Información y Comunicación (TICs) del puerto } \\
\text { favorece el desarrollo empresarial }\end{array}$ & 0.5259 \\
\hline & $\begin{array}{l}\text { En las empresas portuarias, los profesionales especializados en } \\
\text { TICs están disponibles en el mercado regional }\end{array}$ & 0.5153 \\
\hline & $\begin{array}{l}\text { La cooperación tecnológica entre las empresas portuarias está } \\
\text { desarrollada }\end{array}$ & 0.5234 \\
\hline & $\begin{array}{l}\text { La seguridad cibernética en las empresas portuarias tiene una } \\
\text { protección adecuada }\end{array}$ & 0.5269 \\
\hline $\begin{array}{l}\text { Infraestructura } \\
\text { Científica }\end{array}$ & $\begin{array}{l}\text { Las empresas portuarias respecto a las actividades de Investigación } \\
\text { y Desarrollo invierten recursos suficientes }\end{array}$ & 0.5059 \\
\hline \multirow{2}{*}{$\begin{array}{l}\text { Salud y } \\
\text { Medio Ambiente }\end{array}$} & Los problemas de contaminación no afectan la economía portuaria & 0.5030 \\
\hline & $\begin{array}{l}\text { En las empresas portuarias, el cumplimiento de las leyes } \\
\text { ambientales no obstaculiza su desarrollo económico }\end{array}$ & 0.5208 \\
\hline
\end{tabular}


La educación en gestión portuaria responde a las necesidades de la comunidad empresarial

El dominio de idiomas favorece el desarrollo económico de las empresas portuarias

Educación

La cultura económica del personal de empresas portuarias es alta

0.5059

La educación en las finanzas responde a las necesidades de las empresas portuarias

0.5159

El personal calificado está disponible en el mercado laboral

0.5021

La transferencia de conocimientos entre las empresas portuarias y universidades está muy desarrollada

0.5065

Nota: I.C. = Îndice de competitividad.

En la tabla 2, se observan los subfactores y variables de las Pymes de servicios navieros de Manzanillo, Colima, México, que están por abajo de la media en materia de competitividad de acuerdo a la estandarización de variables. Son en total tres variables, dos del subfactor Salud y Medio Ambiente, y uno del subfactor Educación.

Tabla 2. Factor Infraestructura: subfactores y variables por abajo de la media en materia de competitividad

\section{Subfactor}

\section{Variables}

En las empresas portuarias, los problemas de salud (enfermedades,

SIDA, alcohol y drogas) tienen un impacto significativo en el desarrollo económico

Salud y Medio Ambiente

En las empresas portuarias el desarrollo sostenible no es una prioridad

El sistema educativo afecta el desarrollo económico de las empresas portuarias

Nota: I.C. = Îndice de competitividad. 


\section{Conclusiones}

Esta investigación permitió tener un acercamiento palpable con los empresarios y conocer la problemática de las pequeñas y medianas empresas de servicios navieros de Manzanillo, Colima, México.

Dentro de los principales hallazgos encontrados podemos mencionar que la infraestructura básica existente y las tecnologías de la información y comunicación favorecen el desarrollo empresarial; se invierte suficiente en investigación y desarrollo; se cuenta con personal calificado; la contaminación no afecta la economía portuaria; el dominio de idiomas favorece el desarrollo económico de las empresas portuarias y la transferencia de conocimientos entre las empresas portuarias y universidades está desarrollada.

Hasta el momento, no existe otro estudio similar y consideramos que los hallazgos permitirán entre otras cosas, lo siguiente:

- Ser un pilar básico para la toma de decisiones de los pequeños y medianos empresarios (Pymes) de servicios navieros en Manzanillo, Colima, México.

- Generar nuevas líneas de investigación de empresas portuarias en otros puertos del país o incluso fuera del país.

- Servir como fuente de información para la toma de decisiones del gobierno federal, estatal y municipal. 


\section{Referencias}

Baena, G.M.E. (2014). Estructura socioeconómica de México. México: Grupo editorial Patria.

Buckley, P. (1988). Measures of International Competitiveness. A critical Survey. Journal of Marketing Management, 4(2), 175-200.

Garelli, S. (2004). Competitiveness of Nations: The fundamental. En World Competitiveness Yearbook: 1. Suiza: IMD.

Lind, D.A., Marchal, W.G. y Wathen, S.A. (2012). Estadística Aplicada a los negocios y la economía. México: McGraw Hill.

Magaña, P.A., Naranjo, M.J. y Deniz, A. (2017). Competitividad de las agencias navieras de Manzanillo, Colima, México en el año 2016. En A. Olivares, P. Peralta, J. Ochhoa y F. Espinoza (Coords.), Estrategias básicas de competitividad (pp. 85-96). Hermosillo: Qartuppi. http://dx.doi.org/10.29410/QTP.17.04

Morales, R. (2018). México cae a puesto 51 en competitividad. El Economista. Recuperado de https://www.eleconomista.com.mx/empresas/Mexico-cae-a-puesto-51-encompetitividad-20180524-0013.html

Porter, M. (1987). Ventaja Competitiva. Creación de un desempeño superior. México: Grupo Editorial Patria.

Porter, M. (1990). The Competitive Advantage of Nations. New York: The Free Press.

Rojas, P., Chavarría, H. y Sepúlveda (2002). Competitividad y cadenas agroalimentarias: una definición conceptual. En H. Chavarría, P. Rojas, P.y S. Sepúlveda (Comp.), Competitividad: Cadenas agroalimentarias y territorios rurales. Elementos conceptuales. México: IICA.

Scott B. y Lodge, G. (1985). U.S. Competitiveness in the World Economy. Boston: Harvard Business School Press. 


\section{PARTE II \\ LAS ESTRATEGIAS ORGANIZACIONALES}




\section{Capítulo 4}

Influencia de la Cultura Organizacional y el Liderazgo en la producción de capital intelectual como ventaja competitiva

Martha Lucía Moya Pardoy y Héctor Manuel Gómez Gómez²

${ }^{1}$ Universidad de la Salle, Colombia. marthalumoya@hotmail.com

2 Universidad de la Salle, Colombia. hmgomez@unisalle.edu.co 


\section{Introducción}

Para ser competente en el mercado actual es indispensable generar rasgos distintivos o marca personal, a partir de factores como el liderazgo, la cultura organizacional, el capital humano, y el capital intelectual, los cuales desempeñan un papel estratégico y decisivo en una organización. La cultura proporciona pautas de conductas, normas y valores con los cuales los integrantes se identifican para alcanzar objetivos compartidos, el liderazgo de sus dirigentes, el desarrollo de capacidades organizacionales, el capital humano, el conocimiento y el capital intelectual que produzca.

Las organizaciones modernas deben centrar su atención en factores que permitan el desarrollo de capacidades organizacionales indispensables para la creación del capital intelectual con el fin de generar ventaja competitiva. La estrategia para lograr esto es la gestión del talento humano que, según Jiménez (2011), se condiciona en tres factores: desde el punto de vista interno, comprender la estrategia de negocio (nivel de madurez en el que se encuentra la empresa, grado de globalización de sus operaciones y mercados, estructura de fondos propios, sectores en los que se opera, etc.). El segundo factor, el refuerzo de la cultura organizacional, y finalmente, el factor externo condicionado al mercado laboral tanto de la disponibilidad de oferta, como la demanda.

Calderón, Naranjo y Álvarez, (2010, citados por Moya, 2017a), en el estudio realizado en empresas colombianas de diferentes sectores y tamaños, concluyeron que las áreas de gestión humana generan valor para las empresas en cinco dimensiones: proyección organizacional (orientación estratégica), gestión del cambio, infraestructura organizacional (eficiencia y eficacia), liderazgo de las personas y responsabilidad social. En otras palabras, la gestión humana está estrechamente relacionada con la estrategia, la cultura organizacional, la gestión del conocimiento, la calidad, la productividad y la innovación.

Asimismo, se concluyó que una organización, verdaderamente basada en el saber, requiere un recurso humano calificado que sepa obtener valor de los activos intelectuales, políticas y estrategias que permitan el desarrollo de capacidades organizacionales, indispensables para la creación del capital intelectual, una forma distinta de ver las cosas, que reconozca en las ideas el valor potencial de transformarlas en licencias tecnológicas y una dependencia que 
tenga como función potenciar en la empresa el valor estratégico del conocimiento. Para lograr este objetivo la base fundamental es la cultura organizacional (que podría configurarse como capital cultural) a partir de la cual se puede inferir la estrategia de negocio (misión, visión, políticas, valores), estilos de actuación, nivel de madurez, tipos de liderazgo, etc.), por tal razón, planteamos una nueva investigación que permitiera entender ¿cuál es el impacto que genera la gestión de la cultura organizacional y el liderazgo en la generación de capital intelectual? -este documento es el resultado de la primera fase-.

\section{Metodología}

Para construir el marco referencial objeto de este estudio se realizó una búsqueda sistemática de información sobre capital intelectual, liderazgo y cultura organizacional, en bibliotecas, bases de datos y páginas de internet, bajo criterios de pertinencia, relevancia y rigurosidad, que permitió consolidar un acervo documental de cerca de 140 títulos. Tras revisar estos documentos se decidió hacer un análisis más detallado de 37 de ellos que, por sus aportes al estudio planteado, en su mayoría fueron incorporados al marco referencial que a continuación se presenta y cuyas referencias se pueden apreciar al final de este documento.

\section{Revisión teórica}

\section{Gestión del conocimiento}

La gestión del conocimiento según Durana, Çetindereb y Şahanc (2014, citado por Marulanda, López y Castellanos, 2016) es un proceso para facilitar las actividades relacionadas con el conocimiento, tales como su creación, transformación y uso; su objetivo es crear una organización de aprendizaje que evalúa, almacena, utiliza y comercializa experiencia y conocimiento auténtico de los empleados de la organización, con el fin de establecer una organización más potente y valiosa, más allá del total de cada componente que la constituye y más eficiente que sus competidores, propiciando ambientes de articulación organizacional interna y externa.

De igual forma, la gestión del conocimiento es útil en las organizaciones para: aumentar el rendimiento, la productividad y la competitividad de la organización, obtener, compartir y 
utilizar el conocimiento dentro de la organización de manera efectiva, mejorar las decisiones de la organización, mejorar los procesos de negocio y obtener buenas prácticas y reducir los costes de investigación y retrasos (Marulanda et al., 2016).

\section{Capital intelectual}

El capital intelectual en una organización actual se constituye en el activo intangible que genera valor. Stewart (1991) lo entiende como los conocimientos que tienen los individuos de la organización y que si son gestionados de forma adecuada (ideas que han sido formalizadas, capturadas y procesadas) generan ventaja competitiva. Para lograr visualizar y medir los intangibles que permitan generar ventaja competitiva y sostenibilidad a la organización se debe identificar el capital humano, crear mecanismos para medirlos, establecer procesos para desarrollarlos y potencializarlos $y$, por último, explicitar, sistematizar e internalizar los productos de tal manera que sean reflejados en los estados financieros (Moya, 2017a).

Edvinsson y Malone (1999) dividen el capital intelectual en: humano, structural y relacional. Esta clasificación conjuga las actitudes, aptitudes y capacidades de los seres humanos con las rutinas, procesos y sistemas organizativos, y las redes o ámbitos de relación.

El capital humano se refiere al conocimiento, valores, actitudes, habilidades y competencias que poseen las personas que trabajan en la empresa con el fin de crear, innovar, modificar, ajustar y regenerarlo). Hace referencia al conocimiento (explícito o tácito) útil para la empresa que poseen las personas y equipos de la misma, así como su capacidad para regenerarlo; es decir, su capacidad de aprender. Es la base de la generación de los otros dos tipos de capital intelectual (Naranjo, Parra y Zuluaga, 2016).

El mundo actual exige a las organizaciones contar con un colaborador diferente, con competencias, actitudes y agilidad intelectual que le permitan un pensamiento crítico y sistémico dentro del actual entorno tecnológico (Blázquez y Ramos, 2008 citado por Ramírez, 2010). De ahí la importancia de invertir en este capital para hacer frente a los desafíos competitivos. En este sentido, Bontis (1998) destaca la importancia del capital humano dentro del capital intelectual, señalando que es una fuente de innovación y de renovación estratégica. Por su parte, Sierra (2002, citado por Sánchez, Melián y Hormiga, 2007) expresa que los recursos humanos 
de la empresa son esenciales, tanto para facilitar la relación de la misma con el exterior como para el desarrollo de una actividad innovadora o creativa en el seno de la misma.

El capital estructural puede ser entendido como el conocimiento que la organización consigue explicitar, sistematizar e internalizar y que en un principio puede estar latente en las personas y equipos de la empresa. Quedan incluidos todos aquellos conocimientos estructurados de los que depende la eficacia y eficiencia interna de la empresa: los sistemas de información y comunicación, la tecnología disponible, los procesos de trabajo, las patentes, los sistemas de gestión, etc. (Díaz, 2007, p. 46). Este capital lo conforman la cultura organizacional (direccionamiento estratégico, clima organizativo), la estructura de la empresa, los procesos y la investigación, el desarrollo y la innovación en la que suele ubicarse la propiedad intelectual (marcas, patentes, licencias, entre otros) (Naranjo et al., 2016).

Cuestas (2010) define capital estructural como "la infraestructura que incorpora, forma y sostiene el capital humano" (p. 103) e incluye tres tipos: capital organizacional (inversión de la empresa en sistemas, herramientas y filosofía operativa), capital innovación (capacidad de renovación y los resultados de innovación en forma de derechos comerciales protegidos, propiedad intelectual y otros activos intangibles y talentos usados para crear y llevar rápidamente al mercado nuevos productos y servicios) y capital proceso (lo constituyen los procesos de trabajo, técnicas (ISO 9000) y programas para empleados que aumentan y fortalecen la eficiencia de producción o la prestación de servicios, es el conocimiento práctico que se utiliza en la creación continua de valor.

En este sentido, Bontis, Keow y Richardson (2000 citados por Naranjo et al., 2016), sostienen que el capital estructural representa todo el conocimiento institucionalizado en la empresa, esto es, todas las formas en las que pueda estar incorporado el conocimiento dentro de la organización diferente del que reside en los empleados, considerando desde la cultura, las rutinas, manuales de procedimiento, las estrategias organizativas o los procesos internos hasta los sistemas de información o bases de datos.

Sveiby (1997; 2001 citado por Ramírez, 2010) denomina esta dimensión como estructura interna, la cual está formada por todos aquellos conocimientos estructurados de los que depende la eficacia y eficiencia interna de la empresa, es decir, incluye las patentes, las ideas, las estructu- 
ras de funcionamiento, los sistemas de información y comunicación, la tecnología disponible, los procesos de trabajo, los sistemas de gestión, la cultura organizacional, el ambiente organizativo, etc., elementos que son propiedad de la empresa y que, por tanto, permanecen en ésta cuando el empleado se marcha. El capital estructural es, según Edvinsson y Malone (1999), la infraestructura que incorpora, forma y sostiene el capital humano. Miles y Quintillán, (2005, citados por Mena, Vásconez y Carguaytongo, 2017) afirman que es el conocimiento clave sistematizado, empaquetado, difundido y accesible, conformado por los procesos, la tecnología, la cultura, las rutinas, la capacidad de aprender, etc., y que permite formar y mantener el capital humano.

El capital relacional está conformado por las relaciones con los agentes del entorno, como los clientes, los proveedores, el gobierno y la competencia, y también las alianzas estratégicas o los modelos de integración junto con la responsabilidad social empresarial (Navas y Ortiz de Urbina, 2002 citado por Naranjo et al., 2016). El Modelo Intellectus (CIC-IADE, 2003) divide el Capital relacional en Capital negocio y el Capital social. El Modelo de Capital Intelectual, aplicado al sector bancario, denominado Modelo de los Cinco Capitales, está compuesto por el Capital humano, Capital organizativo, Capital tecnológico, Capital relacional de negocio y Capital social (Rodríguez, 2005).

A partir de la clasificación anterior, el Modelo de Capital Intelectual aplicado al sector Hotelero, se conforma por cinco capitales: humano (actitudes, formación, competencias), organizativo (cultura organizativa, estructura organizativa, aprendizaje organizativo y procesos organizativos), tecnológico (dotación tecnológica orientada a la operativa interna y dotación tecnológica orientada a funciones comerciales relacional de negocio) por último, el capital contextual (se refiere a la reputación e imagen corporativa, responsabilidad social corporativa, conservación del medio ambiente y ubicación (Rodríguez, 2005).

Si bien, es cierto que la cultura organizativa se incluye en el capital estructural, también lo es que, investigaciones actuales propenden por profundizar la influencia que ejerce sobre el capital intelectual en toda su extensión (León, Ponjuán y Torres, 2009). Por tanto, el capital cultural, se entiende como aquellas normas formales e informales, reglas y valores de determinada organización, sociedad o individuo, que de una forma u otra marcan la diferencia entre el resto de los agentes del entorno (Mena et al., 2017). 
En cuanto al modelo de Análisis de Madurez de la Gestión del Capital Intelectual propuesto por Romero y Pascual (2011), partieron del planteamiento de las tres dimensiones del capital: a. humano (capacidades, habilidades, destrezas, satisfacción del empleado, educación y entrenamiento), b. estructural (cultura, procesos y tecnología), y c. relacional (clientes, proveedores, socios y comunidad), desde una perspectiva socio-técnica, como resultado de la vinculación entre las tecnologías y sistemas de información, la cultura y el capital humano con la gestión del conocimiento organizacional para determinan un nivel de madurez de las capacidades.

Es decir, las pymes que adopten las nuevas tecnologías de la información para la gestión del conocimiento, el trabajo en equipo y un talento humano innovador como base de su cultura organizacional podrán alcanzar niveles de madurez adecuados para la producción de capital intelectual (Romero y Pascual, 2011).

De acuerdo con Bratianu (2018), las concepciones sobre el conocimiento dependen del punto de vista desde el que este se analice, por lo cual desde la administración se suele ver como recurso (generador de ventaja competitiva), mientras que desde la economía se percibe como capital (generador de rentabilidad). De manera que la expresión "capital intelectual" se enmarca en la perspectiva económico-financiera del conocimiento, que hace que los gerentes busquen capitalizarlo, es decir, incrementarlo con el paso del tiempo.

Sin embargo, este mismo autor hace una crítica a la forma tradicional como se ha concebido el capital intelectual, señalando siete mitos que dificultan su entendimiento:

- El capital intelectual es lineal. No es la "suma" de cada cosa que da ventaja competitiva, más bien la integración de las mismas.

- El capital intelectual es estático. No se debe manejar como inventarios y flujos de conocimiento (perspectiva estática), sino que el conocimiento emerge de las interacciones entre los miembros de una organización (perspectiva dinámica).

- El capital intelectual es racional. El conocimiento explícito se asocia con lo racional, sin embargo, el conocimiento tácito se asocia con las emociones, percepciones, intuiciones y valores.

- Los componentes del capital intelectual son el capital humano, el capital estructural y el capital relacional. Se deja de lado las interacciones con el capital racional, emocional y espiritual. 
- El componente crítico del capital intelectual es el capital humano. En la práctica suele ser más relevante el capital estructural que regula las relaciones entre las personas en el trabajo.

- El desempeño de la firma depende de su potencial de capital intelectual. El conocimiento es una construcción social, hecho y difundido a través de interacciones interpersonales que lo reinterpretan y modifican y lo relacionan con aprendizaje y cambio.

- El capital intelectual puede ser reportado en el marco contable. Debemos ser capaces de ir más allá de la contabilidad y registrar el capital intelectual, para comprender sus profundas raíces en el conocimiento racional, emocional y espiritual. (Bratianu, 2018)

\section{Cultura organizacional y capital intelectual}

La cultura organizacional puede ser definida como: "el conjunto de creencias y valores compartidos que ayudan a los individuos a comprender el funcionamiento de la organización, proporcionándoles las normas de comportamiento dentro de la misma" (Deshpandé y Webster, 1989 citado por Sánchez, et. al, 2006). A partir de este concepto identifican cuatro arquetipos culturales en función de los procesos y el enfoque de la organización en cultura tipo clan, adhocrática, jerárquica y mercado.

Tabla 1. Tipos de cultura según Cameron y Quinn (1999)

Tipo de

Cultura
Variables
Orientación

hacia el

control formal
Enfoque de

atención

El estilo de dirección se caracteriza por promover el trabajo en equipo, el consenso y la participación. Los valores compartidos por el personal son la lealtad, el compromiso

Clan con la empresa y la confianza mutua. El trabajo en equipo es muy importante. Estratégicamente es importante el Flexible Interno desarrollo humano de sus miembros. El éxito se basa en el desarrollo humano, el trabajo en equipo, el compromiso e interés por los trabajadores. 
La empresa es dinámica y emprendedora. El estilo de dirección se caracteriza por promover la iniciativa del individuo, la asunción de riesgos, la innovación, la libertad y la singularidad. Los valores compartidos por el personal Adhocracia son el compromiso con la innovación y el cambio contiFlexible Externo nuo. Estratégicamente es importante el dinamismo y la predisposición a aceptar nuevos retos. El éxito se basa en el desarrollo de productos únicos y novedosos. Ser líder en productos e innovación.

La empresa es jerarquizada, formalizada y estructurada. El estilo de dirección se caracteriza por promover la seguridad en el empleo, la permanencia en el puesto y la existencia de poca incertidumbre. Los valores compartidos Jerarquía por el personal son el respeto por las normas y políticas Estabilidad Interno formales y el cumplimiento con la jerarquía. Estratégicamente es importante la permanencia y la estabilidad de sus miembros. Eficiencia, control y funcionamiento fluido son aspectos clave. El éxito se basa en la eficiencia.

La empresa es una entidad orientada a resultados. La gente es muy competitiva y enfocada fundamentalmente a conseguir los objetivos. El estilo de dirección se caracteriza por promover la competitividad agresiva y la consecución de objetivos ambiciosos. Los valores compartidos Mercado por el personal son la agresividad, el espíritu ganador y la Estabilidad Externo consecución de los objetivos previstos. Estratégicamente es importante las acciones competitivas y el logro de objetivos agresivos. Se hace énfasis en la idea de vencer a la competencia. El éxito se basa en la penetración en el mercado y la cuota de mercado.

Fuente: Elaboración propia con base en Salazar (2008). 
Sánchez et al. (2006) plantean un modelo en donde consideran la cultura organizacional como un nuevo capital (núcleo central) en la medición del capital intelectual. Parten del análisis del tratamiento de la cultura que dan los modelos de medición de capital intelectual y se centra en el Modelo Intellectus (tabla 2).

\section{Tabla 2. Tratamiento de la cultura en los modelos de medición de capital intelectual}

\section{Modelos de Medición} de Capital Intelectual

Cuadro de Mando Integral o Balanced Scorecard (Kaplan y Norton)

Skandia Navigator (Leif Edvinsson) (Anne Brooking)

\section{Tratamiento de la Cultura}

La cultura se entiende desde el punto de vista del aprendizaje. Kaplan y Norton definen entre los indicadores de este activo, el alineamiento de los objetivos de las personas y equipos con la visión de la empresa, lo que refuerza la reciprocidad entre cultura y visión.

La composición del capital intelectual se encuentra determinada por una estructura de capas, de forma que el centro de la misma queda compuesto por la cultura y los valores de la empresa. Considera la cultura y valores organizativos como consecuencia del capital humano de la empresa.

Incluye la cultura dentro de los activos de infraestructura, entendiéndola como cultura corporativa. La define como "la forma en que se hacen las cosas". Comprende valores, ritos, rituales y héroes que son conocidos y compartidos por la fuerza de trabajo de la empresa.

La cultura organizacional cobra un papel importante en este modelo, se ubica dentro del capital estructural. La divide en cuatro categorías:

- Sistemas: forma en que la organización realiza sus procesos (toma de decisiones, comunicación...)

Modelo del Canadian Imperial Bank (Herbert Saint Onge) - Estructura: distribución de responsabilidades y definición de la posición de cada miembro de la organización.

- Estrategia: objetivos de la empresa y camino en que ésta trata de alcanzarlos.

- Cultura: suma de las opiniones individuales, creencias compartidas, valores y normas dentro de la organización. 
El conocimiento tácito que incluye intuiciones, perspectivas, creencias y valores de los individuos como resultado de sus experiencias, a pesar de tener un importante impacto en cada uno de estos elementos, proviene de la cultura, a diferencia del conocimiento explícito que es el conocimiento articulado. Existe una fuerte conexión entre la estrategia y la cultura de forma que, si éstas no son congruentes, el éxito y las ventajas competitivas serán difícilmente alcanzables.

Monitor de Activos Intangibles (Karl Eric Sveiby)

La cultura se entiende desde el punto de vista interno, pero se define como actitudes de empleados hacia su puesto de trabajo, los clientes y los superiores, lo que indica una relación con el bloque humano y el bloque externo de la organización.

La cultura organizacional aparece como elemento esencial en el desarrollo del capital estructural. Una organización con un fuerte capital estructural Modelo de la Universidad tendrá necesariamente una cultura que permita a los individuos probar Western Ontario cosas nuevas, fallar, aprender e intentarlo de nuevo.

(Nick Bontis)

De este modo, la cultura se entiende como una filosofía de negocio que permita a los individuos desarrollar sus ideas de forma que el capital estructural se vea fortalecido.

La cultura aparece como grupo componente del capital organizativo. De igual forma, también quedan incluidos en este bloque, los valores culturales, actitudes y comportamientos que estimulan la creatividad y la innovación, es decir, una cultura innovadora, explicitada en la confianza, apertura al diálogo, asunción de riesgos, experimentación, delegación y autorresponsabilización, reflexión y aceptación de los errores.

La cultura se encuentra ubicada en el capital estructural, concretamente en el capital organizativo. La define en "valores, normas y formas de actuación compartidos y asumidos por la mayor parte de las personas de Modelo Intellectus la organización que condicionan su comportamiento y los resultados corporativos". Como variables integradoras se mencionan: la homogeneidad cultural, la evolución de los valores culturales, el clima social y la filosofía de negocio (este último como elemento diferenciador).

Fuente: Elaboración propia con base en Sánchez et al. (2006). 
En el modelo propuesto considera la cultura como elemento esencial (tabla 3). La consideración del capital cultural lo definieron en dos niveles: cultura estructural (se fundamenta en variables estratégicas que presentan un alto grado de estabilidad en la empresa como valores que prevalecen a lo largo del tiempo, historia e idiosincrasia de los fundadores) y cultura operativa (justifica la conexión con cada uno de los cinco capitales integrantes del capital intelectual).

\section{Tabla 3. Tratamiento de la cultura en los modelos de medición de capital intelectual}

\section{Capital Descripción}

Proceso de adecuación que debe darse en toda organización entre los valores de los

Humano trabajadores de la misma y los de los directivos. La adecuación referida determinará lo que hemos denominado "valores culturales", que permitirán afirmar que la empresa es culturalmente fuerte.

La cultura se torna esencial al emerger del proceso interactivo continuo que se debe

Organizativo establecer entre los individuos y la estructura empresarial, configurando la "cultura organizacional”.

Cobra su sentido a través de la cultura, observando el proceso de adaptación de las personas a los avances tecnológicos y determinando cuál es la flexibilidad de

Tecnológico las mismas para favorecer los cambios y asumir los riesgos que la competitividad del mercado requiere en cada momento. De esta manera aludimos a la que hemos denominado "cultura innovadora o emprendedora".

de Negocio La devoción al cliente, orientación a la acción, autonomía y espíritu empresarial y y Social productividad del personal es lo que se denomina "cultura relacional".

Fuente: Elaboración propia con base en Sánchez et al. (2006).

Schein, en 1988 introdujo el concepto de presunciones y creencias, para explicar de forma más amplia el significado que para la organización tienen el concepto de cultura, la define entones como "... respuestas que ha aprendido el grupo ante sus problemas de subsistencia en su medio externo y ante sus problemas de integración interna”. (Pedraza, Obispo, Vásquez y Gómez, 2015, p. 18) 
Jaimes y Osorio (2009, citados por Rojas y Vera, 2016) exponen que la cultura organizacional desde la gestión del conocimiento, genera valor y le da ventaja competitiva. De igual manera, Minsal y Pérez (2007) afirma que la cultura está compuesta por valores, actitudes, comportamientos, visión, estrategias y acciones, que funcionan como sistema dinámico.

Gestionar conocimiento requiere que la persona interactúe consigo misma, con otras personas $y / 0$ con herramientas tecnológicas, para que sea efectiva requiere de una cultura organizacional moderna, impulsada desde la alta dirección, "que favorezca un ambiente estimulante para la colaboración, y a su vez brinde los métodos y herramientas para que sus miembros puedan compartir de manera eficiente su conocimiento explícito" (Pardo, Coronel, Bertone y Thomas, 2013, p. 1170).

\section{Análisis y presentación del liderazgo y cultura organizacional}

\section{Liderazgo y capital intelectual}

Debido a que el liderazgo transformacional y la cultura organizacional influyen y determinan una serie de importantes resultados de una organización, es importante explorar la relación entre el liderazgo y la cultura de la organización, con el propósito de aumentar la comprensión de cómo los líderes afectan el contexto social y también para lograr los resultados positivos en la organización. Schein (2004, citado por Chung, 2017) afirma que "se puede argumentar que lo único realmente importante que los líderes hacen es crear y gestionar la cultura; que el talento único de los líderes es su capacidad para entender y trabajar con la cultura" (p. 34).

Liberona y Ruiz (2013) concluyen que "El liderazgo y la dirección son necesarios para, en primer lugar, definir un plan de implementación, con objetivos claros y concretos; en segundo lugar, para incentivar y comprometer a la organización con el plan y sus objetivos" (p. 158). Consideran que para gestionar el conocimiento del capital humano los resultados positivos de la creación de capital intelectual dependerán de la cultura organizacional que profese cada organización.

Para lograr resultados positivos en un proceso de gestión del conocimiento es necesario alinear los conocimientos individuales y colectivos de las personas que componen la organización, 
con los objetivos, metas y visión de la organización, es necesario que el líder logre que todos los involucrados participen activamente y colaboren en el desarrollo de soluciones y prácticas de gestión del conocimiento; Naranjo (2011) citado por Rojas y Vera (2016) expresa que los líderes han de crear las condiciones necesarias para que el ciclo del conocimiento sea una realidad en la organización, brindando los recursos requeridos, siendo conscientes del tiempo que tardan en madurar este tipo de proyectos y la complejidad de los mismos, con especial cuidado de fomentar una cultura orientada al cambio y la innovación, donde la flexibilidad y la diversidad tienen cabida y se tenga alineado el conocimiento con la estrategia, tanto la competitiva, como la de negocio (p. 53).

\section{Liderazgo y gestión del conocimiento}

El candor (transparencia), entendido como franqueza, sinceridad, u honestidad es necesario en las empresas, dado que su ausencia sofoca las buenas ideas, ralentiza la toma de decisiones, incrementa los costos y afecta en general el desempeño de las organizaciones (Galpin y Whittington, 2009). Enfrentar con candor los hechos, genera una sólida atmósfera de diálogo que facilita el desarrollo eficaz de la estrategia y sienta las bases de confianza que demanda el liderazgo. Se suele asociar la candidez con la tendencia a suavizar malas noticias y ser amable con temas incómodos, pero en realidad esta exige dejar de lado la hipocresía para discutir abierta y constructivamente los problemas.

Bass, Avolio y Pointon (1990, citados por Quintanilla y Barrera, 2018) establecen una clara diferencia entre el liderazgo transaccional, que se limita a fijar metas, conducir procesos y controlar resultados; y el liderazgo transformacional, en el que se ejerce una influencia directa en los miembros del equipo para empoderarlos mediante una atmósfera de confianza que les permite incluso exceder las expectativas planteadas. De acuerdo con Besen, Tecchio, y Pereira (2017), el liderazgo, entendido como la influencia que ejercen los líderes en los seguidores, es un factor determinante para la generación y uso del conocimiento. En este contexto, el liderazgo determina el ambiente de trabajo, la cooperación entre individuos, el intercambio de conocimiento y el aprendizaje organizacional, buscando dar la bienvenida a nuevos paradigmas y orientar los procesos de cambio organizacional. 
El liderazgo auténtico se enfoca en principios y valores como la autenticidad, la confianza y la autoestima. La autenticidad es promovida por los propios líderes a través de su propia conciencia, aceptación, conocimiento, acciones y relaciones, fundadas en principios de transparencia, confianza, integridad y altos estándares morales. La autenticidad se basa en las experiencias personales de los individuos, sus valores, emociones, pensamientos y creencias, que determinan una manera de actuar propia que refleja su yo interior. En las empresas de hoy, el líder debe convertirse en un "arquitecto del conocimiento" (Besen et al., 2017, p. 9) capaz de proyectar el futuro, gestionar los recursos necesarios para construirlo, empoderar al equipo y retroalimentar sus resultados.

Avolio y Bass (2004, citados por Mendoza y Ortiz, 2006) identificaron ocho tipos de liderazgos, que incorporan de forma evolutiva elementos tanto del liderazgo transaccional como del transformacional:

- Administración pasiva por excepción (evita cualquier cambio en el statu quo y solo interviene cuando las circunstancias son excepcionales), el líder tiende hacia el laissez-faire o dejar hacer (evita tomar decisiones, es desordenado y permite a los demás hacer lo que les parece).

- Administración activa por excepción (pone atención a algunos problemas y tiene sistemas de monitoreo y control que le suministran alertas).

- Reconocimiento contingente (el líder establece objetivos claros y recompensas variadas).

- Consideración individual (el líder típico es un escucha activo y comunicador fuerte).

- Estímulo intelectual (lleva al líder a empoderar a otros para que piensen acerca de los problemas y desarrollen sus propias habilidades).

- Motivación e inspiración (tiene la habilidad de motivar a la gente para alcanzar un desempeño superior, ya que es bueno para convencer a los seguidores de sus habilidades).

- Influencia idealizada o carisma (son líderes percibidos por los seguidores como poseedores de un grado alto de moralidad, confianza e integridad).

Los líderes impactan las organizaciones a partir de estrategias que les permite mantener la cultura del grupo y de la organización, la motivación a las personas, para dar cumplimiento a 
los objetivos y de la gestión del conocimiento. Chung (2017) expresa que el liderazgo es clave para construir una cultura basada en la confianza, demostrando preocupaciones, manteniendo las promesas, la moralidad, la imparcialidad, la franqueza, la honestidad, la discreción, la coherencia, la integridad, la accesibilidad y la obtención de los resultados esperados. Si bien es cierto que existe una relación fuerte entre el liderazgo y la cultura organizacional, también lo es que no se ha estudiado a profundidad el impacto que genera esta relación en la gestión del conocimiento y la respectiva creación de capital intelectual.

\section{Conclusiones}

La gestión del conocimiento busca crear valor a partir de los activos intangibles que integran el capital intelectual de una organización, por lo tanto, el talento humano es indispensable para lograr una ventaja competitiva, estos son gestionados a través de una cultura organizacional que permita la creación y difusión de conocimiento.

La cultura organizacional y la gestión del conocimiento están fuertemente relacionadas, ya que sin unas buenas bases culturales dispuestas al cambio es imposible genera un verdadero proceso de gestión del conocimiento, pues el factor principal en este proceso es el recurso humano y si este no está dispuesto a cambiar y compartir su conocimiento es difícil generar nuevos conocimientos.

Las organizaciones necesitan transformar la información en conocimiento con el fin de difundirlo y utilizarlo para incrementar su capacidad innovadora y competitiva. Para convertirse en una organización que aprende, requiere de una cultura organizacional que integre a toda la organización, unas políticas y estrategias que permitan el desarrollo de capacidades organizacionales, indispensables para la creación del capital intelectual, a partir de los estilos de liderazgo.

La cultura organizacional, el liderazgo, el capital humano y la productividad son factores fundamentales para la generación de capital intelectual. En otras palabras, el capital humano es el pilar para lograr ventaja competitiva, el liderazgo la fuente de motivación y la cultura organizacional, la médula de la organización, que permite la creación y difusión de conocimiento. 


\section{Referencias}

Besen, F., Tecchio, E., \& Pereira, F. (2017). Authentic leadership and knowledge management. Lideranca autentica e a gestao do conhecimento. Gestao \& Producao, 24(1). http://dx.doi. org/10.1590/0104-530x898-13

Bratianu, C. (2018). Intellectual capital research and practice: 7 myths and one golden rule. Management and Marketing. Challenges for the Knowledge Society, 13(2), 859-879. http:// dx.doi.org/10.2478/mmcks-2018-0010

Bontis, N. (1998). Intellectual capital: An exploratory study that develops measures and models. Manage Decisions, 36(2), 63-76.

Cuesta, A. (2010). Gestión del Talento Humano y del Conocimiento. Bogotá: Editorial ECOE.

Chung, V. (2017). Impacto de la cultura organizacional en la relación entre el liderazgo y la gestión del conocimiento, en las escuelas profesionales de la Universidad Nacional Pedro Ruiz. (Tesis Doctoral). Universidad Peruana Unión. Unidad de Posgrado de Ciencias Humanas y Educación. Lima, Perú.

Díaz, L. (2007). Gestión del conocimiento y del capital intelectual: una forma de migrar hacia empresas innovadoras, productivas y competitivas. Revista EAN (61), 39-68. Recuperado de http://www.redalyc.org/pdf/206/20611495005.pdf

Edvinsson, L. y Malone, M.S. (1999). El capital Intelectual: Cómo identificar y calcular el valor de los recursos intangibles de su empresa. España: Gestión 2000.

Galpin, T., \& Whittington, J. (2009). Creating a culture of candor in the ledership classroom. Journal of leadership education, 8(2), 10-19. http://dx.doi.org/10.12806/V8/I2/AB2

Jiménez, A. (2011). Condicionantes de la estrategia de capital humano. En A. Jiménez, S. Marcos, E. Arce y C. Hillier-Fry, Gestión del talento y competitividad (pp. 11- 118). España: Almuzara.

León, M., Ponjuán, G. y Torres, D. (2009). Panorámica sobre la medición del conocimiento organizacional. Acimed, 19(6).

Liberona, D. y Ruiz, M. (2013). Análisis de la implementación de programas de gestión del conocimiento en las empresas chilenas. Estudios Gerenciales, 29(127), 151-160.

Macías, C. y Aguilera, A. (2012). Contribución de la gestión de recursos humanos a la gestión del conocimiento. Estudios gerenciales, 28(123), 133-148. Recuperado de www.icesi.edu.co/ revistas/index.php/estudios_gerenciales/article/view/1212/pdf 
Marulanda, C., López, M. y Castellanos, J. (2016). La cultura organizacional y su influencia en las buenas prácticas para la gestión del conocimiento en las Pymes de Colombia. Revista AD-minister, (29), 163-176.

Mena, C., Vásconez, H. y Carguaytongo, J. (2017). El capital intelectual desde una revisión teórica de la literatura publicada. Revista Científica Dominio de la Ciencia, 3, 29-50.

Mendoza, M.R. y Ortiz, C. (2006). El liderazgo transformacional, dimensiones e impacto en la cultura organizacional y eficacia de las empresas. Revista Facultad de Ciencias Económicas: Investigación y Reflexión, XIV(1), 118-134.

Minsal, D. y Pérez, Y. (2007). Hacia una nueva cultura organizacional: la cultura del conocimiento. Acimed 16(3). Recuperado de http://bvs.sld.cu/revistas/aci/vol16_3_07/aci08907.htm

Moya, M. (2017a). Propuesta de un modelo de madurez de la gestión del talento humano para el desarrollo del capital intelectual como ventaja competitiva. En A.R. Malacara (Ed.), La cooperación y nuevos enfoques estratégicos ante la complejidad del entorno empresarial globalizado (pp. 2439-2454). México: Editorial Universidad del Valle de Atemajac.

Moya, M. y Gómez, H. (2017b). Hacia un modelo de madurez de la gestión del talento humano para el desarrollo del capital intelectual como ventaja competitiva. En A. Olivares, P. Peralta, J. Ochoa y F. Espinoza (Coords.), Estrategias básicas de competitividad (pp. 131154). Hermosillo: Qartuppi. http://dx.doi.org/10.29410/QTP.17.04

Naranjo C., Parra J. y Zuluaga, L. (2016). Capital intelectual y resultados organizativos: análisis en un conjunto de empresas del eje cafetero colombiano. (Tesis de maestría). Universidad Autónoma de Manizales. Manizales, Colombia.

Pardo, S., Coronel, J. E., Bertone, R. y Thomas, P. (2013). Gestión del Conocimiento: Un enfoque aplicado en la Administración Pública. XVIII Congreso Argentino de Ciencias de la Computación. Red de Universidades con Carreras en Informática (RedUNCI). Recuperado de http://hdl.handle.net/10915/31302

Pedraza, A.L., Obispo, S.K., Vásquez, G.L. y Gómez, G.L. (2015). Cultura organizacional desde la teoría de Edgar Schein: estudio fenomenológico, Clío América, 9(17), 17-25. Recuperado de https://dialnet.unirioja.es/descarga/articulo/5139907.pdf 
Quintanilla, J. y Barrera, M. (2018). Liderazgo y cultura. Influencia en la eficiencia organizacional. Publicando, 5(14).

Ramírez, Y. (2010). Aproximación a una taxonomía del capital intelectual. Revista Contabilidad, (227), 60-75.

Rodríguez, J.M. (2005). El capital intelectual como diferencia entre los activos y los pasivos intangibles. Revista madri+d, (28). Recuperado de http://www.madrimasd.org/revista/ revista28/sumario.asp

Rojas, G.E. y Vera, M.A. (2016). Cultura organizacional en la gestión del conocimiento. Revista Apuntes de Administración, 1(1), 50-59.

Romero, D. y Pascual, F. (2011). Análisis de madurez de la gestión del capital intelectual en la pequeña y mediana empresa latinoamericana. Revista da Micro e Pequena Empresa, 5(3), 40-60. Recuperado de http://oa.upm.es/11349/1/INVE_MEM_2011_104104.pdf

Salazar, A. (2008). Estudio de la cultura organizacional según Cameron y Quinn: Caso de una empresa del sector asegurador venezolano. (Tesis especialización). Universidad Católica Andrés Bello, Caracas, Venezuela.

Sánchez, S.M., Trillo, M.A., Mora, C. y Ayuso, M.Á. (2006). La cultura organizacional como núcleo central en la medición del capital intelectual. Revista de Psicología del Trabajo y de las Organizaciones, 22(2), 179-202. Recuperado de http://www.redalyc.org/ $\mathrm{pdf} / 2313 / 231317125003 . \mathrm{pdf}$

Sánchez, A., Melián, A. y Hormiga, E. (2007). El concepto del capital intelectual y sus dimensiones. Investigaciones Europeas de Dirección y Economía de la Empresa, 13(2), 97-111.

Stewart, T. (1991). La Nueva Riqueza de las Organizaciones: el capital intelectual. Buenos Aires, Argentina: Ediciones Granica. 


\section{Capítulo 5}

Estructura de sueldos: un ejemplo práctico para una microempresa

Angélica María Rascón Larios¹, Francisco Espinoza Morales²

y Pabla Peralta Miranda

${ }^{1}$ Universidad de Sonora, México. maqueka@navojoa.uson.mx

2 Universidad de Sonora, México. fespinoz@navojoa.uson.mx

${ }^{3}$ Universidad Simón Bolívar, Colombia. pperalta@unisimonbolivar.edu.co 


\section{Introducción}

Con la génesis de una organización, cualquiera que sea su tamaño o giro, el empresario adquiere una serie de compromisos laborales orientados a ofrecer a los empleados un trabajo digno que considere jornada máxima, días y horas de descaso, capacitación y adiestramiento, seguridad social, seguridad e higiene, así como un medio ambiente adecuado; entre otras prestaciones (Ley Federal del Trabajo [LFT), 2018) destacando para efectos de este trabajo, un salario equitativo en términos del nivel de exigencia del puesto.

Hoy en día, legalmente se aborda el término de trabajo digno o decente para todas las relaciones laborales; entendiéndose como

aquél en el que se respeta plenamente la dignidad humana del trabajador; no existe discriminación por origen étnico o nacional, género, edad, discapacidad, condición social, condiciones de salud, religión, condición migratoria, opiniones, preferencias sexuales o estado civil; se tiene acceso a la seguridad social y se percibe un salario remunerador; se recibe capacitación continua para el incremento de la productividad con beneficios compartidos, y se cuenta con condiciones óptimas de seguridad e higiene para prevenir riesgos de trabajo. (LFD, 2018, p. 1)

Considerándose como se aprecia dentro de este concepto el término salario; el que es definido por la misma LFT (2018) como "la retribución que debe pagar el patrón al trabajador por su trabajo" (p. 21); debe ser remunerador y determinado con base a la calidad y cantidad, correspondiendo a trabajo igual, salario igual. Sin embargo, la deficiente administración de la remuneración que presentan muchas de las empresas, en especial las micro y pequeñas, ha suscitado inequidad en el pago que recibe el empleado propiciando efectos desmotivadores en ellos y la consiguiente rotación de personal con consecuencias, en ocasiones, serias en la competitividad de la entidad.

Tales consideraciones, establecidas por mandato legal y por razones sociales al ser el salario el principal medio de sustento, fundamenta la necesidad de aplicar en las organizaciones, la administración de sueldos y salarios, aunado a que se considera el tema de la remuneración como el más crucial y debatido dentro del campo laboral (Uquijo y Bonilla, 2008, p. 115). 


\section{Planteamiento}

Existen también otros fundamentos para que deben contemplarse como el "salario justo" entra la consideración del salario como medio de vida del trabajador: "Es el hombre mismo, inseparable de su actividad, es su vida, representada por el único medio de ganársela, que es su trabajo, lo que entra en la prestación del obrero" (López, 1997, p. 448); también, está la igualdad del salario o principio de igualdad:

El principio de trato igual en materia remuneratoria aparece en el artículo 23-2, como principio de "igual remuneración por igual tarea", en la Declaración Universal de los Derechos del Hombre. Y como principio de "igual remuneración por trabajo de igual valor", en el Convenio número 100 de la OIT sobre igualdad de remuneración entre el personal masculino y el femenino. Lo que se trata de impedir ----y, por lo tanto, se prohíbe---- con el principio de "trato igual" es la discriminación arbitraria. en la prestación del obrero. (López, 1997, p. 449)

Para Reyes Ponce (2007):

El salario es una prestación procedente de un contrato y constituye la contraprestación de algo que se dio a cambio de él: el servicio. Por ello está regido por la justicia sin pretender entrar a hacer el análisis fisiológico o jurídico completo de este concepto adoptaremos por su tradición clásica definición de Ulpiano: "la justicia es la voluntad perpetua y constante de dar a cada quien su derecho". (Reyes, 2007, p. 20)

Se puede observar que son muchas las razones por las que es importante implementar una buena administración de salarios; lo que es bien llevado por las grandes y medianas empresas; sin embargo, en la micro y pequeña empresa no es lo mismo; en México hay más de 4.1 millones de microempresas, que aportan $41.8 \%$ del empleo; las pequeñas suman 174,800 y representan $15.3 \%$ de empleabilidad (Cruz, López, Cruz y Meneses, 2016) y uno de los tantos 
problemas que afrontan está relacionado con la desigualdad en el ingreso; en una nota recientemente publicada en La Jornada en línea se plantea:

La productividad de las pequeñas y medianas empresas (pymes) de los países afiliados a la Organización para la Cooperación y Desarrollo Económicos (OCDE) se ha reducido en las últimas dos décadas y, "ello está vinculado con la desigualdad en el ingreso", advirtió Mari Kivinienmi, secretaria adjunta de la organización [...]

Hay "una diferencia tremenda" en productividad y salarios entre las pymes y las compañías más grandes, dijo, y los efectos de la globalización "ponen en peligro los pactos de la apertura comercial porque sus dividendos no se están compartiendo entre quienes menos tienen", incluidos las pequeñas empresas y las startup's. (González, 2018, párr. 1-2)

Es necesario el apoyo al microempresario para que mejore en muchos sentidos su administración; en el caso particular, es importante destacar la administración de sueldos como una medida de control para los costos por las remuneraciones, ya que éstas tienen una doble visión; por un lado, pueden analizarse desde el punto de vista de la inversión y, por otro, como un costo.

Por lo anterior, el objetivo básico de este trabajo fue realizar un análisis de las remuneraciones en una microempresa, considerando algunos puestos tipo para determinar si los salarios actualmente establecidos mantenían relación con la importancia del cargo y equidad interna entre estos, se parte del supuesto de que, a mayor importancia relativa del puesto, mayor deberá de ser la percepción que su ocupante reciba.

Werther y Davis (2000) presentan un modelo de las consecuencias de una mala compensación, se observan los efectos devastadores tanto para el empleado y la empresa como producto de un mal sistema de remuneraciones (figura 1). Un nivel inadecuado de compensación también conduce a dificultades, sentimientos de ansiedad y desconfianza por parte del empleado y a pérdida de rentabilidad y competitividad de la organización. Los costos altos de la compensación pueden reducir la posibilidad de proporcionar empleo a los que disfrutan de una compensación inmoderada (Werther y Keith, 2000). 


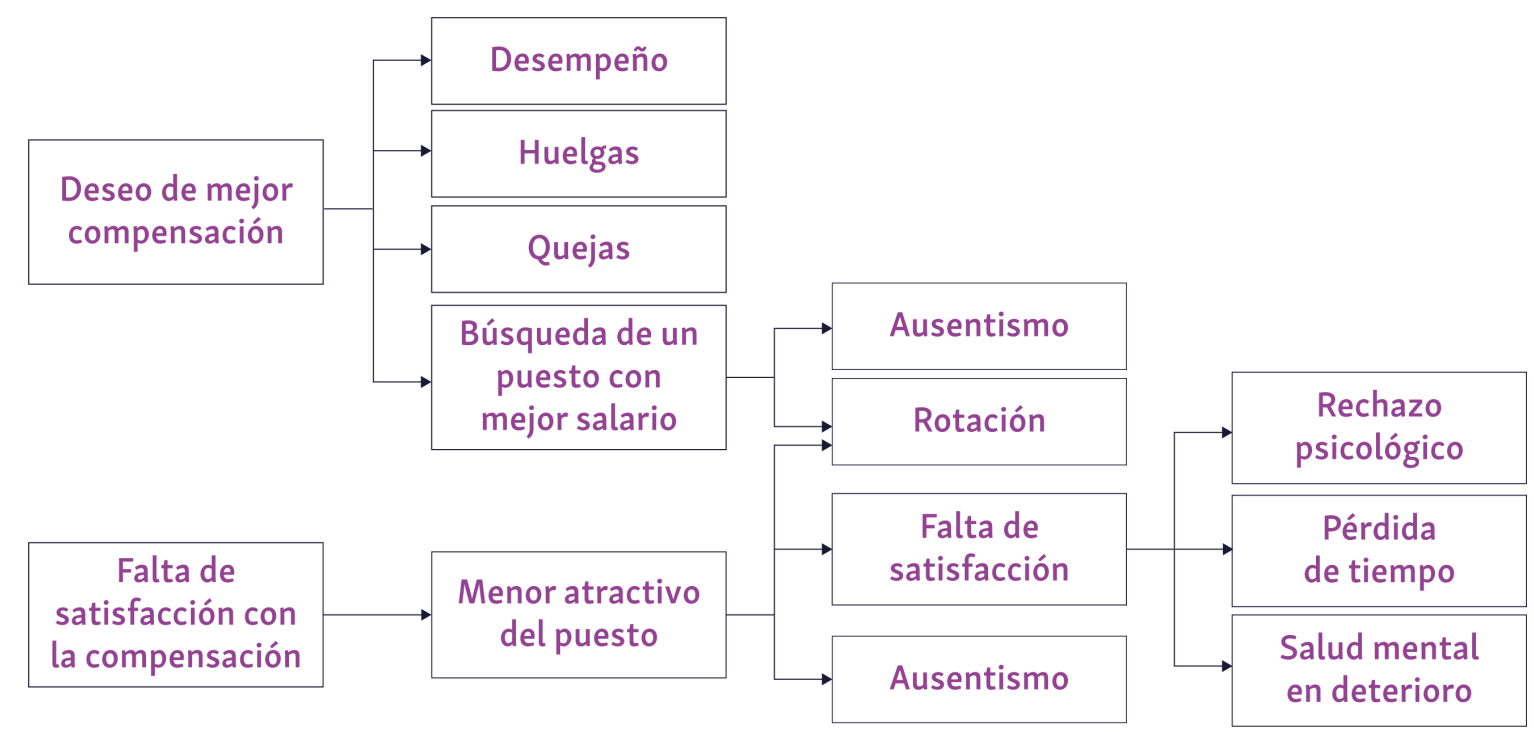

Figura 1. Modelo de las consecuencias de la falta de satisfacción por la compensación.

Fuente: Werther y Keith (2000).

Todos estos argumentos conducen a establecer la siguiente interrogante: ¿Es posible realizar un análisis de los salarios establecidos en la microempresa para determinar si estos son justos y equitativos a las exigencias de los puestos?

\section{Marco teórico}

Este planteamiento permite establecer como propósito fundamental de este trabajo el analizar la estructura actual de una microempresa para demostrar la viabilidad de aplicar herramientas de la administración del talento humano para el mejoramiento de las condiciones de trabajo; en este caso, en el rubro salarial, requiriendo aplicar modelos de análisis de puestos y de valuación de puestos.

Antes de destacar ciertos aspectos genéricos de la empresa en estudio, es relevante establecer algunas definiciones.

Primeramente, se aborda lo referente a la administración de sueldos y salarios que, para Chiavenato (2011) es: 
Un conjunto de normas y procedimientos que pretenden establecer y/o mantener estructuras de salarios justas y equitativas en la organización; esas estructuras deben serlo así de acuerdo con: 1 . Los salarios en relación con los demás puestos de la propia organización, con la intención de alcanzar un equilibrio interno y 2. Los salarios en relación con los mismos puestos de otras empresas del mercado de trabajo, para alcanzar un equilibrio externo. (p. 237)

Por otro lado, una de las herramientas de la administración de sueldos y salarios que permite desarrollar una estructura lógica de los salarios es la denominada Valoración de puestos o, también llamada, Evaluación de cargos; la Comisión Nacional de la Productividad de España la define como "un procedimiento sistemático utilizado para el estudio de los trabajos y la determinación de la importancia de cada uno de ellos, y su mérito en relación con los demás trabajos de la empresa" (Morales y Velandia, 1999, p. 65).

En referencia a la descripción del micronegocio en estudio, se localiza al sur del estado de Sonora, dedicado a la prestación de servicios de hospedaje; dispone de un recepcionista con un sueldo de $\$ 130.00$ pesos diarios, dos cocineras con un sueldo de $\$ 120.00$ cada una, dos camareras con un sueldo de $\$ 115.00$ cada una, un jardinero con un suelo de $\$ 110.00$ y un guardia de seguridad con un sueldo de $\$ 115.00$ pesos diarios. Los salarios anteriores son proporcionados en horas normales de trabajo, pero la mayoría realiza horas extras aumentando el salario.

\section{Metodología}

Refiriéndose al aspecto metodológico de este trabajo, se caracteriza como estudio de caso exploratorio debido a que este problema no es muy estudiado para este tipo de empresa; no experimental (Hernández, Fernández y Baptista, 2014).

Para iniciar la valoración de las posiciones, se necesitó partir de los análisis de puestos, los que se desarrollaron iniciando con el diseño de un cuestionario aplicado a los empleados para describir las actividades y responsabilidades relacionadas con sus puestos de trabajo (Varela, 2013, p. 73). 
Para la elaboración del cuestionario se recurrió al modelo propuesto por Reyes (2007), el cual es uno de los más completos y presenta una estructura bien organizada, contemplando seis apartados:

1. Generalidades del puesto. Esta sección contempla información del puesto que tiene que ver con su denominación, puesto inmediato superior, puestos inmediatos inferiores, horarios y días de trabajo y aquella información general de identificación de cada posición.

2. Descripción genérica u objetivo del puesto. Esta parte señala el propósito u objetivo genérico del puesto.

3. Descripción específica o analítica de las funciones del puesto. Pese a que, en este apartado se recomienda que se enumeren las tareas dando respuesta al "qué", "cómo", "cuándo", "dónde" e incluso "para qué" se hace cada función, para efectos del trabajo que aquí se desarrolla, únicamente se decidió enlistar las actividades bajo la organización de actividades diarias, actividades periódicas (tal como su nombre lo indica, las que tienen cierta periodicidad) y actividades eventuales (actividades realizadas de vez en cuando.

4. Especificaciones o requerimientos de los cargos. Esta sección se constituyó de cuatro factores generales bajo los que se agrupan los diversos requerimientos de los puestos: Habilidad, Responsabilidad, Esfuerzo y Medio Ambiente y Riesgo. A su vez, cada factor se descompone en subfactores, de los que se trató de elegir los más comunes a los puestos sujetos al análisis y atendiendo a los principios de universalidad y discriminación; quedando integrados como sigue:

a. Habilidad: escolaridad, experiencia y conocimientos especiales.

b. Responsabilidad: en dinero, en equipo o materiales.

c. Esfuerzo: físico y mental

d. Medio ambiente y Riesgo: ambiente, riesgo de accidentes, riesgo de enfermedades.

5. Perfil del puesto. Incluyó información como sexo, estado civil y edad del ocupante ideal del puesto.

6. Referencias. Relativa a los participantes en el acopio de la información y nombre de los entrevistados (que para los efectos de este trabajo serán omitidos por razones éticas); además, la fecha de elaboración d dichos análisis de puestos. 


\section{Análisis de datos}

Una vez recogida la información, se procedió a realizar las descripciones y las especificaciones de cada posición. También se diseñó el manual de valoración de los puestos, considerando los factores de habilidad, responsabilidad, esfuerzo y condiciones de trabajo. Se determinaron los subfactores y sus ponderaciones con base a lo que especifica el método de valuación por puntos (Reyes, 2007, pp. 55-69), quedando de la siguiente forma:

\section{Tabla 1. Factores de evaluación}

\begin{tabular}{cc}
\hline Factores & Pesos promedio \\
\hline Habilidad & $50 \%$ \\
\hline Responsabilidad & $25 \%$ \\
\hline Esfuerzo & $15 \%$ \\
\hline Condiciones de trabajo & $10 \%$ \\
\hline TOTAL & $100 \%$ \\
\hline
\end{tabular}

La tabla 1 presenta la ponderación otorgada a cada uno de los factores de evaluación, según la importancia relativa entre ellos y cuya sumatoria debe ser igual a 100\%.

La tabla 2 muestra los subfactores elegidos correspondientes al factor habilidad y su peso derivado del valor asignado al factor.

La tabla 3 destaca aquellos subfactores seleccionados para el factor responsabilidad, con sus consiguientes ponderaciones a partir del valor asignado al factor.

Tabla 2. Subfactores del factor habilidad

\begin{tabular}{cc}
\hline Subfactor & Valor asignado \\
\hline $\begin{array}{c}\text { Conocimientos de otras } \\
\text { operaciones }\end{array}$ & $25 \%$ \\
\hline Escolaridad & $25 \%$ \\
\hline TOTAL & $50 \%$ \\
\hline
\end{tabular}

Tabla 3. Subfactores del factor responsabilidad

\begin{tabular}{cc}
\hline Subfactor & Valor asignado \\
\hline Evitar demoras & $15 \%$ \\
\hline $\begin{array}{c}\text { Información } \\
\text { confidencial }\end{array}$ & $10 \%$ \\
\hline TOTAL & $25 \%$
\end{tabular}


La tabla 4 enumera los subfactores que correspondieron al factor esfuerzo y sus valores con base al peso otorgado al factor.

La tabla 5 plantea los subfactores escogidos para el factor condiciones de trabajo y sus ponderaciones con base al peso otorgado al factor.

Tabla 4. Subfactores del factor esfuerzo

\begin{tabular}{cc}
\hline Subfactor & Valor asignado \\
\hline Físico & $10 \%$ \\
\hline Mental & $5 \%$ \\
\hline TOTAL & $15 \%$ \\
\hline
\end{tabular}

Tabla 5. Subfactores del factor condiciones de trabajo

\begin{tabular}{cc}
\hline Subfactor & Valor asignado \\
\hline Riesgo de Enfermedades & $5 \%$ \\
\hline Riesgo de Accidentes & $5 \%$ \\
\hline TOTAL & $10 \%$ \\
\hline
\end{tabular}

Enseguida, se realizó la tabla 6 que permitió generar el manual de evaluación de puestos, así como evaluar las posiciones para poder llegar a las conclusiones y recomendaciones.

Tabla 6. Prorrateo de factores, subfactores y grados de cada subfactor por progresión geométrica

\begin{tabular}{|c|c|c|c|c|c|c|}
\hline \multirow{2}{*}{ Factores } & \multirow{2}{*}{$\begin{array}{l}\text { Valor } \\
\text { asignado }\end{array}$} & \multirow{2}{*}{ Subfactores } & \multicolumn{4}{|c|}{ Grados } \\
\hline & & & I & II & III & IV \\
\hline \multirow{2}{*}{ Habilidad } & \multirow{2}{*}{$50 \%$} & Conocimientos de otras operaciones & 25 & 50 & 75 & 100 \\
\hline & & Escolaridad & 25 & 50 & 75 & 100 \\
\hline \multirow{2}{*}{ Responsabilidad } & \multirow{2}{*}{$25 \%$} & Evitar demoras & 15 & 30 & 45 & 60 \\
\hline & & Información confidencial & 10 & 20 & 30 & 40 \\
\hline \multirow{2}{*}{ Esfuerzo } & \multirow{2}{*}{$15 \%$} & Físico & 10 & 20 & 30 & 40 \\
\hline & & Mental & 5 & 10 & 15 & 20 \\
\hline \multirow{2}{*}{$\begin{array}{c}\text { Condiciones } \\
\text { de trabajo }\end{array}$} & \multirow{2}{*}{$10 \%$} & Riesgo de enfermedades & 5 & 10 & 15 & 20 \\
\hline & & Riesgo de accidentes & 5 & 10 & 15 & 20 \\
\hline TOTAL & $100 \%$ & & 100 & 200 & 300 & 400 \\
\hline
\end{tabular}

La tabla 6 concentra los factores, subfactores y los grados establecidos para cada uno de los subfactores, los que a su vez se valorizaron iniciando con los pesos asignados previamente (grado I) (tablas 2, 3, 4 y 5) y definiendo los grados II, III y IV a través de una progresión aritmética. 


\section{Valoración de resultados}

Una vez valorados los puestos, se presentan los siguientes resultados de cada una de las posiciones (tabla 7, 8, 9, 10 y 11) representando su valor estimado de acuerdo al grado de intensidad exigido por los cargos de cada uno de los subfactores citados antes (tabla 6).

Tabla 7. Resultados de evaluación del puesto de camarera

\section{Subfactores}

Escolaridad su labor.

El puesto requiere tener la secundaria terminada para realizar

El puesto requiere tener algunos conocimientos relativos a

Conocimientos de otras operaciones ciertas operaciones como: limpieza y preparación de ciertos alimentos para realizar su labor.

\begin{tabular}{clcc}
\hline $\begin{array}{c}\text { Evitar demoras } \\
\begin{array}{c}\text { Información } \\
\text { confidencial }\end{array}\end{array}$ & $\begin{array}{l}\text { El puesto tiene una alta responsabilidad en evitar demoras. } \\
\text { cial hasta en un 80\% de sus actividades. }\end{array}$ & IV & 60 \\
\hline Físico & $\begin{array}{l}\text { El puesto exige de esfuerzo físico del 65\% para realizar su } \\
\text { labor. }\end{array}$ & IV & 40 \\
\hline Mental & $\begin{array}{l}\text { El puesto exige de un 25\% de esfuerzo mental para realizar } \\
\text { sus actividades. }\end{array}$ & II & 10 \\
\hline $\begin{array}{c}\text { Riesgo de } \\
\text { enfermedades }\end{array}$ & El puesto tiene un bajo riesgo de enfermedades de trabajo. & II & 10 \\
\hline $\begin{array}{c}\text { Riesgo de } \\
\text { accidentes }\end{array}$ & El puesto tiene un mediano riesgo de accidente de trabajo. & III & 15 \\
\hline TOTAL & 100\% & 275
\end{tabular}

Tabla 8. Resultados de evaluación del puesto de recepcionista
Grado Puntos

II $\quad 50$

II $\quad 50$

50

\section{Especificaciones del puesto}

Grado Puntos

El puesto requiere tener la preparatoria terminada o contar con carrera técnica.

El puesto requiere tener algunos conocimientos de otras ope-

Conocimientos de otras operaciones

Subfactores raciones administrativas, computación, manejo de software, 


\begin{tabular}{clcc} 
Evitar demoras & El puesto tiene una alta responsabilidad en evitar demoras. & IV & 60 \\
\hline $\begin{array}{c}\text { Información } \\
\text { confidencial }\end{array}$ & $\begin{array}{l}\text { El puesto tiene responsabilidad sobre información confiden- } \\
\text { cial hasta en un 80\% de sus actividades. }\end{array}$ & IV & 40 \\
\hline Físico & $\begin{array}{l}\text { El puesto exige de esfuerzo físico del 15\% para realizar su } \\
\text { labor. }\end{array}$ & II & 20 \\
\hline Mental & $\begin{array}{l}\text { El puesto exige de un 80\% de esfuerzo mental para realizar } \\
\text { sus actividades. }\end{array}$ & IV & 20 \\
\hline $\begin{array}{c}\text { Riesgo de } \\
\text { enfermedades }\end{array}$ & El puesto tiene un bajo riesgo de enfermedades de trabajo. & II & 10 \\
\hline $\begin{array}{c}\text { Riesgo de } \\
\text { accidentes }\end{array}$ & El puesto tiene un bajo riesgo de accidente de trabajo. & II & 10 \\
\hline TOTAL & $100 \%$ & 360 \\
\hline
\end{tabular}

Tabla 9. Resultados de evaluación del puesto de jardinero

\section{Subfactores}

Especificaciones del puesto

Grado Puntos

Escolaridad

El puesto requiere tener la primaria terminada para realizar su labor.

El puesto requiere tener algunos conocimientos relativos a

Conocimientos de
otras operaciones ciertas operaciones como: limpieza y preparación de ciertos alimentos para realizar su labor.

\begin{tabular}{clcc}
\hline Evitar demoras & El puesto tiene una baja responsabilidad en evitar demoras. & II & 30 \\
\hline $\begin{array}{c}\text { Información } \\
\text { confidencial }\end{array}$ & $\begin{array}{l}\text { El puesto tiene responsabilidad sobre información confidencial } \\
\text { hasta en un 10\% de sus actividades. }\end{array}$ & II & 20 \\
\hline Físico & $\begin{array}{l}\text { El puesto exige de esfuerzo físico del 65\% para realizar su } \\
\text { labor. }\end{array}$ & IV & 40 \\
\hline Mental & $\begin{array}{l}\text { El puesto exige de un 25\% de esfuerzo mental para realizar sus } \\
\text { actividades. }\end{array}$ & II & 10 \\
\hline $\begin{array}{c}\text { Riesgo de } \\
\text { enfermedades }\end{array}$ & El puesto tiene un mediano riesgo de enfermedades de trabajo. & III & 15 \\
\hline $\begin{array}{c}\text { Riesgo de } \\
\text { accidentes }\end{array}$ & El puesto tiene un mediano riesgo de accidente de trabajo. & III & 15 \\
\hline TOTAL & $100 \%$ & 205 \\
\hline
\end{tabular}


Tabla 10. Resultados de evaluación del puesto de cocinera

Subfactores

Escolaridad

El puesto requiere tener la preparatoria trunca para realizar su labor.

III $\quad 75$

El puesto requiere tener algunos conocimientos relativos a

Conocimientos de

otras operaciones

ciertas operaciones como: limpieza y preparación de ciertos

II $\quad 50$

alimentos para realizar su labor.

\begin{tabular}{clcc}
\hline $\begin{array}{c}\text { Evitar demoras } \\
\begin{array}{c}\text { Información } \\
\text { confidencial }\end{array}\end{array}$ & $\begin{array}{l}\text { El puesto tiene una alta responsabilidad en evitar demoras. } \\
\text { cial hasta en un 80\% de sus actividades. }\end{array}$ & IV & 60 \\
\hline Físico & $\begin{array}{l}\text { El puesto exige de esfuerzo físico del 65\% para realizar su } \\
\text { labor. }\end{array}$ & IV & 40 \\
\hline Mental & $\begin{array}{l}\text { El puesto exige de un 45\% de esfuerzo mental para realizar } \\
\text { sus actividades. }\end{array}$ & III & 15 \\
\hline $\begin{array}{c}\text { Riesgo de } \\
\text { enfermedades }\end{array}$ & El puesto tiene un bajo riesgo de enfermedades de trabajo. & II & 10 \\
\hline $\begin{array}{c}\text { Riesgo de } \\
\text { accidentes }\end{array}$ & El puesto tiene un mediano riesgo de accidente de trabajo. & III & 15 \\
\hline $\begin{array}{c}\text { TOTAL } \\
\text { 100\% }\end{array}$ & 305
\end{tabular}

Tabla 11. Resultados de evaluación del puesto de guardia de seguridad

Subfactores

\begin{tabular}{cllc} 
Escolaridad & $\begin{array}{l}\text { El puesto requiere tener la preparatoria trunca para realizar } \\
\text { su labor. }\end{array}$ & III & 75 \\
\hline $\begin{array}{c}\text { Conocimientos de } \\
\text { otras operaciones }\end{array}$ & $\begin{array}{l}\text { El puesto requiere de otras operaciones y técnicas o métodos } \\
\text { de seguridad relacionados con la supervisión para realizar su } \\
\text { labor y vigilancia. }\end{array}$ & III & 75 \\
\hline Evitar demoras & El puesto tiene una alta responsabilidad en evitar demoras. & IV & 60 \\
\hline $\begin{array}{c}\text { Información } \\
\text { confidencial }\end{array}$ & $\begin{array}{l}\text { El puesto tiene responsabilidad sobre información confiden- } \\
\text { cial hasta en un 80\% de sus actividades. }\end{array}$ & IV & 40 \\
\hline Físico & $\begin{array}{l}\text { El puesto exige de esfuerzo físico del 65\% para realizar su } \\
\text { labor. }\end{array}$ & IV & 40 \\
\hline
\end{tabular}


Subfactores

\begin{tabular}{clcc}
\hline Mental & $\begin{array}{l}\text { El puesto exige de un 45\% de esfuerzo mental para realizar } \\
\text { sus actividades. }\end{array}$ & III & 15 \\
\hline $\begin{array}{c}\text { Riesgo de } \\
\text { enfermedades }\end{array}$ & El puesto tiene un bajo riesgo de enfermedades de trabajo. & II & 10 \\
\hline $\begin{array}{c}\text { Riesgo de } \\
\text { accidentes }\end{array}$ & El puesto tiene un alto riesgo de accidente de trabajo. & IV & 20 \\
\hline TOTAL & $100 \%$ & 335 \\
\hline
\end{tabular}

Tabla 12. Comparación de los salarios y valores en puntos

\begin{tabular}{cccc} 
Tïtulo del puesto & Puntos & Salario diario & Salario mensual \\
\hline Jardinero & 205 & $\$ 110$ & $\$ 3,300$ \\
\hline Camarera & 275 & $\$ 115$ & $\$ 3,450$ \\
\hline Cocinera & 305 & $\$ 120$ & $\$ 3,600$ \\
\hline Guardia de seguridad & 335 & $\$ 115$ & $\$ 3,450$ \\
\hline Recepcionista & 360 & $\$ 130$ & $\$ 3,900$ \\
\hline TOTAL & 1,480 & $\$ 1,300$ & $\$ 17,700$ \\
\hline
\end{tabular}

En la tabla 12 se aprecian los resultados de la evaluación de los puestos, así como los salarios diarios y mensuales asignados por la empresa.

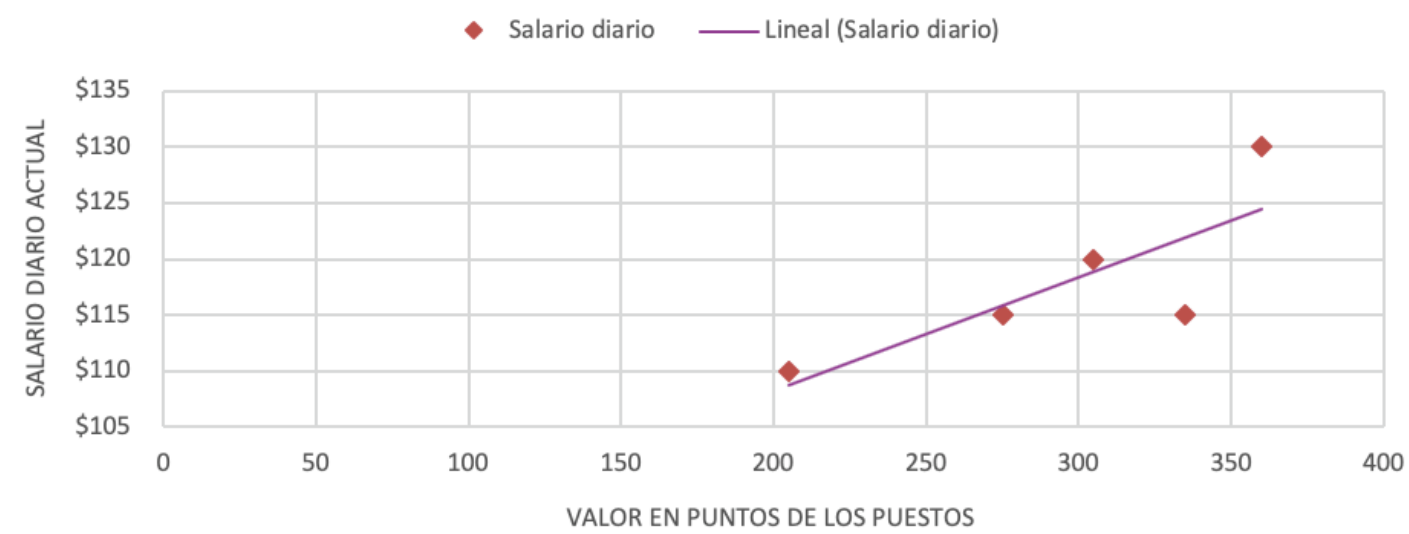

Figura 2. Correlación entre el valor en puntos de los puestos y salario. 
En la figura 2, se puede observar en los marcadores mediante un análisis de dispersión que existe una dirección similar en 3 de los 5 puestos evaluados, representada por una línea recta que indica cierta relación entre el valor en puntos de los puestos y los salarios actuales asignados; sin embargo, para los puestos de jardinero y camarera el valor en puntos tiene una diferencia más amplia que en lo que respecta al sueldo, pues solo varía con $\$ 5.00$. Algo similar se aprecia en los puestos de cocinera y guardia de seguridad con la misma variación.

\section{Tabla 13. Comparación de los salarios y valores en puntos}

\section{Título del puesto}

Puntos

Valor en puntos

Salario actual asignado

\begin{tabular}{cccc}
\multirow{2}{*}{ Valor en puntos } & \multicolumn{1}{c}{ Correlación de Pearson } & 1 & $.802^{*}$ \\
\cline { 2 - 4 } & Sig. (bilateral) & & .103 \\
\cline { 2 - 4 } & $\mathrm{N}$ & 5 & 5 \\
\hline \multirow{3}{*}{ Salario actual asignado } & Correlación de Pearson & $.802^{*}$ & 1 \\
\cline { 2 - 4 } & Sig. (bilateral) & .103 & \\
\cline { 2 - 4 } & $\mathrm{N}$ & 5 & 5 \\
\hline
\end{tabular}

*Nota: La correlación es significante al nivel 0,05 (bilateral).

El valor de $r=0,802$ es positivo y elevado, así como significativo para cualquier nivel, con lo cual se confirma la impresión proporcionada por el gráfico acerca de la existencia de asociación lineal entre las variables.

\section{Conclusiones y recomendaciones}

Definitivamente, la administración de sueldos y salarios es factible de ser aplicada para cualquier tipo y tamaño de empresa; sin embargo, por razones de debilidades en la gestión administrativa como la falta de conocimiento de las técnicas relacionadas por los microempresarios, éstas no son utilizadas.

Es importante para una buena definición salarial partir de los análisis de puestos que brindan información relativa a las tareas y exigencias de estos, ya que, en función de dichos 
requerimientos exigibles, las posiciones varían en importancia; unas con respecto a otras, y en ese mismo sentido, deberán establecerse las remuneraciones.

Para el caso de la empresa en estudio, sí hay significancia en la relación del sueldo y su valor. La recomendación sería ajustar los sueldos de la camarera, el guardia de seguridad y recepcionista, para lo que se sugiere aplicar algún método de ajuste de salarios.

Se pudo observar a través de este ejercicio práctico que los sueldos asignados en las microempresas pueden ser sujetos a evaluación. Se sugiere buscar la asesoría de expertos al momento de definirlos para disminuir o evitar subjetividades o inequidades que conduzcan a potenciales conflictos con los empleados por una administración deficiente en los salarios. 


\section{Referencias}

Chiavenato, I. (2011). Administración de Recursos Humanos, el capital Humano de las Organizaciones. México: McGraw-Hill.

Cruz, M., López, E., Cruz, R. y Meneses, G. (2016). ¿Por qué no crecen las Micro y Pequeñas empresas en México? ECORFAN. Recuperado de http://www.ecorfan.org/actas/A_1/29. pdf

González, S. (2018). Baja productividad de pymes en países de OCDE. La Jornada. Recuperado de http://www.jornada.unam.mx/ultimas/2018/02/20/baja-productividad-de-pymes-enpaises-de-ocde-7812.html

Hernández, R., Fernández, C. y Baptista, P. (2014). Metodología de la Investigación. México: McGraw-Hill.

Ley Federal del Trabajo (2018). Última reforma publicada. Diario Oficial de la Federación, DOF 2206-2018. Recuperado de http://www.diputados.gob.mx/LeyesBiblio/pdf/125_220618. pdf

López, J. (1997). El salario. En N. de Buen y E. Morgado (Coords.), Instituciones de derecho del trabajo y de la seguridad social. México: Universidad Nacional Autónoma de México. Recuperado de https://archivos.juridicas.unam.mx/www/bjv/libros/1/139/29.pdf

Morales, J. y Velandia, N. (1999). Salarios estrategia y sistema salarial o de compensación. México: McGraw-Hill.

Reyes, A. (2007). Administración de Personal Sueldos y salarios. México: Limusa.

Uquijo, J. y Bonilla, J. (2008). La remuneración del trabajo. Venezuela: Publicaciones UCAB.

Varela, R. (2013). Administración de la compensación. México: Pearson Educación.

Werther, W. y Keith, D. (2000). Administración de Personal y de Recursos Humanos. México: McGraw-Hill. 


\section{Capítulo 6}

El recurso humano en las PyMEs del sector comercial

Rosa María Rincón Ornelas ${ }^{1}$, Lidia Amalia Zallas Esquer ${ }^{2}$

y María Guadalupe Alvarado Ibarra ${ }^{3}$

\footnotetext{
${ }^{1}$ Universidad de Sonora, México.rosa.rincon@unison.mx

2 Universidad de Sonora, México. Izallas@navojoa.uson.mx

${ }^{3}$ Universidad de Sonora, México. lalvarado@navojoa.uson.mx
} 


\section{Introducción}

Toda empresa es el pilar básico del desarrollo de un país. Hoy en día, las pequeñas y medianas empresas (PyMEs) constituyen el centro del sistema económico en el ámbito nacional e internacional. El enorme crecimiento de la influencia de estas empresas se debe al interés de la sociedad por mejores alternativas para alcanzar la independencia económica; "estas empresas representan una gran oportunidad, a través de la cual los grupos en desventaja económica han podido iniciar y consolidarse por méritos propios" (Pérez, Patrón, May y Llanes, 2016, p. 6).

De acuerdo con Andersen (1999), la PyMe es "una unidad económica de producción y decisión, que mediante la organización y coordinación de una serie de factores (capital y trabajo), persigue obtener un beneficio produciendo y comercializando productos o prestando servicios en el mercado".

Las PyMEs son motores de desarrollo económico y generadores de empleo; adquieren gran relevancia, no solo en cifras si no en contribución social y fiscal; el gobierno se ve favorecido ya que el recurso humano se autoemplea, da empleo a otros -ayudando a combatir el desempleo-y contribuye al propio gasto público. Considerándose que las pequeñas y medianas empresas se deben de atender y tratar las áreas de oportunidad con el recurso humano que están presenten para encaminarlas a un buen desarrollo y lograr el éxito.

\section{Planteamiento}

Las PyMEs son muy importantes para la economía de cualquier país. En México son más de cuatro millones, que generan $72 \%$ del empleo y aportan 52\% del Producto Interno Bruto (PIB). Estos negocios son los que hacen competitivo a un país, pues atraen inversiones y fortalecen las industrias. "Sin embargo, la incertidumbre económica en el mundo ha hecho que algunas empresas en desarrollo no se consoliden apropiadamente y sean vulnerables ante los constantes cambios" (Carriedo, 2017).

Las empresas de hoy cuentan con mayor tecnología para hacer frente a sus necesidades por las operaciones normales que se le presentan. Se hace necesario realizar "un cambio en las personas que las dirigen y un cambio en todo el personal que trabaja en ellas. Hoy, las empresas están orientadas a satisfacer a los clientes" (Gómez, 2009). 
"La pyme juega un rol muy importante en la economía de los países, fundamentado esto en: la generación de empleo, contribución al PIB, crecimiento de la productividad, contribución al comercio internacional y una fuente de iniciativa empresarial” (Saavedra, 2012, p. 97).

En Sonora, las PyMEs aportan el $85 \%$ del producto interno bruto (PIB); no obstante, se encuentran en peligro de extinción por falta de liquidez y por la dificultad de financiamiento para las de nueva creación (Paredes, Macías y Quintana, 2018).

En los últimos años se han venido presentando diferentes movimientos de apoyo y ayuda a la pequeña y mediana empresa. Estos programas han estado patrocinados por universidades, secretarías y organizaciones privadas (Caraballo et al., 2015, p. 6).

Sin embargo, no se atienden de manera clara y sostenida las áreas de oportunidad que presentan estas empresas (figura 1), por lo cual se ven afectadas sus utilidades e incluso su permanencia en el mercado. Por lo cual, diversos expertos han propuesto modelos para mejorar la situación de las empresas, no obstante, algunos son ambiciosos para las pequeñas y medianas empresas (PyMEs), debido a la estructura informal y carencia de conocimientos técnicos de las mismas. Algunos hacen referencia indirecta a los flujos de información interna (Cano, Orue, Martinez, Mayett y López, 2015) y otros, a las mejoras del desempeño posible con la implantación de sistemas de remuneración justos y basados en méritos (Trujillo, 2014).

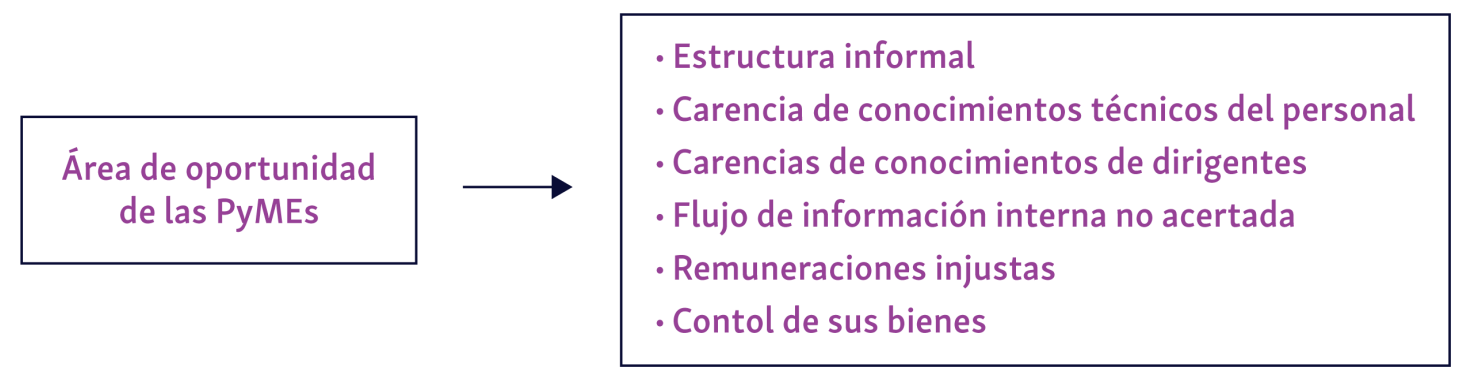

Figura 1. Áreas de oportunidad de las PyMEs. Fuente: Elaboración propia.

\section{Importancia de las PyMEs}

La importancia cuantitativa de la pyme no se limita únicamente a su magnitud con respecto a su relevante participación en el total de empresas existentes (Saavedra, 2012). Se considera que las Pymes son importantes ya que tradicionalmente contribuyen al desarrollo económico 
mediante la creación de empleo (Barquero, 2003). Asimismo, las PyMEs también juegan un papel importante de carácter social ya que promueven el autoempleo. "Así, estas empresas sirven a la mayoría de los países latinoamericanos como amortiguadores del alto desempleo que afecta a la región, constituyéndose en un instrumento de 'movilidad social'”' (Saavedra, 2008, p. 98).

\section{Giro principal de la pequeña y mediana empresa}

En las empresas existen necesidades de formación, que se deducen a la observación de problemas concretos; en estos casos nos encontramos ante necesidades de formación reactiva. Mientras que, por otro lado, también existen necesidades de formación para anticiparse al futuro y responder a sus exigencias, en cuyo caso nos encontramos ante necesidades de formación proactivas, y su satisfacción capacita al personal para hacer frente a las innovaciones (Fernández, Castresana y Fernández, 2006)

Las PyMEs son unidades económicas, operadas por una persona natural o jurídica, bajo cualquier forma de organización jurídica o gestión empresarial, y que desarrolla cualquier tipo de actividad, ya sea de producción, comercialización o prestación de servicios (Condusef, 2015, citado por Paredes et al., 2018).

La mayoría de las pequeñas y medianas empresas se dedican a la actividad comercial; aun aquellas que se dedican a la trasformación de los productos, se dedican también a la actividad comercial, pues ellas mismas se encargan de comercializar los productos que elaboran, logrando con ello un mayor acercamiento a sus consumidores (Anzola, 1996, citado por Cruz, s.f., p. 2).

La pequeña y mediana empresa enfocan sus ventas hacia el detalle, es decir, se mantiene constante contacto entre el productor y el posible consumidor; este sector es de los más competidos y el que deja menor margen de utilidades, sin embargo, resulta atractivo para muchas personas pues los riesgos en sus operaciones son bajos (Cruz, s.f.).

En este tipo de empresas, el propietario realiza las funciones de personal administrativo y director de la misma, por lo que él posee la mayoría de las acciones, es la persona que controla la empresa, colocando a los miembros de su familia como colaboradores en la dirección y administración, generalmente. 


\section{El recurso humano en las organizaciones}

El factor humano es el activo más valioso de las organizaciones y posee carcaterísticas como: posibilidad de desarrollo, creatividad, ideas, imaginación, sentimientos, experiencia, habilidades, etc., que lo diferencian de los demás recursos (Münch, 2012).

En toda organización, las personas son parte fundamental para alcanzar el éxito y mantener la continuidad, por tal razón es importante el estudio de las personas, pues constituyen la unidad básica de dichas organizaciones (Chiavenato, 2000, p. 60).

Los recursos humanos juegan una función importante en la competitividad de las empresas. En las PyMEs, en las primeras etapas del desarrollo, el director gerente o dueño tienen una amplia participación, tanto en la administración como en las operaciones de la empresa, por lo que su formación y experiencia, así como las de su equipo administrativo, influyen de manera determinante en la supervivencia, crecimiento y desempeño de este tipo de empresas (Estrada, García y Sánchez, 2009).

Los recursos humanos, en definitiva, son los responsables finales de satisfacer al cliente, son los que tienen en sus manos la posibilidad de lograr que su empresa aprenda a vivir para brindar un servicio. El empleado es el eslabón fundamental para anclar al cliente en la preferencia de la empresa, para asistirlo en sus necesidades y para ser el codificador de sus mensajes, de forma tal que se pueda satisfacer sus expectativas plenamente (Hernández, Chumaceiro y Atencio, 2009).

El recurso humano es la clave en cualquier ámbito. "La falta de personal debidamente capacitado, lo convierten en un recurso escaso, al que hay que motivar y formar, ya que continuamente presenta nuevas inquietudes y no puede ser substituidos por ninguna tecnología" (Estrada et al., 2009, p. 172).

El manejo de los recursos humanos puede ser concebido como "una estrategia empresarial que manifiesta la importancia de la relación individual frente a las relaciones colectivas entre gestores, directivos o trabajadores, propiciando una participación activa de todos los trabajadores de la empresa" (Rubio y Aragón, 2005; Martínez y Álvarez, 2006; y Estrada, 2010; citados por Saavedra, 2012, p. 106). 
El comportamiento de las personas en una organización depende de factores internos (consecuentes de sus características de personalidad, como capacidad de aprendizaje, motivación, percepción del ambiente interno y externo, actitudes, emociones, valores, entre otros) y externos (consecuentes de las características organizacionales, tales como sistemas de recompensas y castigos, de factores sociales, de políticos, de la cohesión grupal existente, etc. (Chiavenato, 2000, p. 67).

Por lo anterior, es importante plantearse la siguiente interrogante: ¿Cuáles son las áreas de oportunidad que tienen las empresas PyMEs del sector comercial en el área de recursos humanos? Para contribuir en las investigaciones referentes a esta temática, se plantea el siguiente objetivo: Determinar las áreas de oportunidad que presentan las empresas PyMEs del sector comercial.

\section{Referencias teóricas}

En nuestro país, se tiene una economía muy lastimada, con una crisis financiera que se viene arrastrando de administraciones gubernamentales anteriores; en algunos sexenios han sido demasiado graves las acciones realizadas y han repercutido hasta tiempos actuales; los ciudadanos nos vemos afectados por el desequilibrio que se tiene en los ingresos y egresos que se perciben para llevar a cabo una vida normal, en ocasiones, no se cuenta con un empleo que proporcione dicho ingreso; esto, ha motivado a muchas personas a buscar nuevas fuentes de ingreso para poder subsistir o dar un sustento digno a sus familias, y lo han encontrado a través del autoempleo, es decir, inician sus propios negocios en pequeño, apoyándose en la propia familia para poder operarlo. Otra situación que se presenta es que las personas, aun contando con un empleo, no tienen un salario suficiente para sufragar los gastos, por lo cual deciden emplearse en alguna otra actividad que, en ocasiones, es iniciar un negocio pequeño o mediano (Barcelata-Chávez, 2008).

Otro problema que se presenta es la disminución del poder adquisitivo, lo cual reduce el gasto y el ahorro de las personas $y$, por consiguiente, disminuye el consumo de productos $y$ servicios. Lo anterior, afecta a las empresas al disminuir sus ventas $y$, por lo tanto, sus utilidades. Esta situación afecta tanto a empresarios como a empleados, proveedores e inclusive a los mismos clientes (Méndez, 2011). 
En este sentido, toda empresa -independientemente de su tamaño- debe estar preparada para afrontar diversas situaciones $y$, para ello, deberá tomar decisiones constantemente.

En el ambito empresarial, la toma de decisiones es una actividad cotidiana por parte de cada uno de los responsables y de quienes participan en las distintas actividades. Su importancia está relacionada con el éxito de la actividad empresarial, y el crecimiento y desarrollo de las organizcaiones en general (Pomar, Ramírez y Rendón, 2011).

\section{Metodología}

La investigación es cuantitativa; utiliza la recolección y análisis de datos para constatar preguntas de investigación, confía en la medición numérica de conteo, estableciendo con exactitud patrones de comportamiento en una población.

El alcance del estudio es de tipo exploratorio; pretende especificar, buscar características específicas e importantes del fenómeno que se analiza, detallar cómo son y cómo se manifiestan, a partir de una visión general. La investigación se llevó a cabo con un diseño no experimental; se recolectan datos en un solo momento, un tiempo único.

\section{Magnitud de las empresas}

Según Münch (2012), las empresas son una fuente de ingresos para trabajadores, proveedores, gobierno y empresarios, promueven el desarrollo económico de la sociedad, contribuyen al sostenimiento de servicios públicos, representan un medio para la realización o satisfacción personal y fomentan la capacitación y el desarrollo de habilidades, así como la inversión y la formación de capital.

Existen varios criterios para la clasificación de las empresas, el más utilizado es el tamaño; así, las empresas se clasifican de acuerdo a su tamaño en micro, pequeño, mediano y grande. En este estudio, se consideraron únicamente dos tipos: pequeñas y medianas.

Los criterios para clasificar a las empresas por su tamaño son diversos; en este estudio, consideramos la clasificación establecida por la Secretaría de Economía (SE, 2009). La clasificación de las micro, pequeñas y medianas empresas (MiPyMEs) se basa en el número de empleos que genera y establece como determinarse el nivel de ventas anuales (tabla 1 ). 
Tabla 1. Clasificación de las pequeñas y medianas empresas

\begin{tabular}{cccc} 
Tamaño & Sector & Rango de número de trabajadores & $\begin{array}{c}\text { Rango de monto de } \\
\text { ventas anuales (mdp) }\end{array}$ \\
\cline { 2 - 3 } Pequeña & Comercio & Desde 11 hasta 30 & Desde $\$ 4.01$ hasta $\$ 100$ \\
\cline { 2 - 3 } Mediana & Industria y Servicio & Desde 11 hasta 50 & \multirow{2}{*}{ Desde $\$ 100.01$ hasta $\$ 250$} \\
\cline { 2 - 3 } & Comercio & Desde 31 hasta 100 & \\
\cline { 2 - 3 } & Servicios & Desde 51 hasta 100 & Desde 51 hasta 250
\end{tabular}

Fuente: Elaboración propia con datos de Secretaría de Economía (2009).

\section{Las pequeñas y medianas empresas en México}

En las PyMEs se observa que, por lo general, los dueños o encargados del negocio no dedican tiempo suficiente a la administración del mismo, sino que se dejan llevar por las actividades cotidianas sin hacer una planeación. Con frecuencia, carecen de sistemas de planeación, organización, administración y control eficiente de sus recursos. Lo anterior debido, en ocasiones, por la falta de conocimiento en estos aspectos y la falta de asesoría, ya que, por lo regular:

Las [PyMES] no tienen acceso a servicios de consultoría por los altos costos que ésta representa con respecto a sus ingresos. Sin embargo, las [PYMES] son las que probablemente más lo necesitan, y también las que más fácilmente logran mejorar sus procesos. (Fuentes et al., 2015, p. 4)

Otra deficiencia que se presenta en las PyMEs es que, aunque muchas veces cuenten con personal con un alto potencial, no saben cómo motivarlo, capacitarlo y no le dan la importancia ni la atención que requiere. Los dueños o encargados tratan de administrar el recurso humano de forma empírica, sin tener una guía para administrarlo. Esta deficiencia puede impactar de manera negativa a la empresa en distintas formas como, por ejemplo, baja productividad, alta rotación de personal, pérdidas por trabajo mal hecho, etc. 
Trujillo (2014) considera que la mejora del desempeño es posible con la implantación de sistemas de remuneración justos y que estén basados en los méritos.

Si bien, dirigir, confrontar y trabajar con personas es una de las actividades más difíciles en una empresa, la persona encargada del recurso humano debe tener la capacidad para poder tener control sobre este, saberlo llevar de tal manera que se aproveche al máximo y que al mismo tiempo las personas o empleados estén conformes con la atención que se les brinde. Pues, la competitividad de las empresas se debe, en gran medida, a la calidad de sus recursos humanos; de tal manera que, dedicar tiempo y recursos a adquirir, mantener y desarrollar las competencias de los empleados es un factor de ventaja competitiva y un objetivo estratégico fundamental (Gómez-Mejía, Balkin y Cardy, 2001).

La pequeña empresa valora más la actitud del candidato que los mismos conocimientos; valoran de manera significativa la responsabilidad, las buenas relaciones, la creatividad y el dinamismo, la honestidad y la transparencia, la estabilidad en otros cargos, la disposición para trabajar, el compromiso, la calidad humana y el interés por aprender (Fernández et al., 2006).

\section{Conclusiones y recomendaciones}

La forma de hacer negocio hoy en día ha cambiado y seguirá evolucionando debido a los cambios en los mercados, avances tecnológicos, cambios en los hábitos de consumo, cambios culturales, entre otros, por lo que toda empresa, incluidas las PyMEs, deben adaptarse; para ello, será determinante la actitud de los dirigentes, así como el conocimiento y control que se tenga sobre la empresa.

Por lo anterior, es importante implementar reglas y normas, realizar manuales de procedimientos, que permita homogeneizar las actividades y tener un control en toda la estructura organizacional, inclusive si opera un solo departamento o es solo una persona quien realiza todas las actividades.

Además, la administración debe poner especial interés en el recurso humano, pues es el factor primordial en la marcha de una empresa. De la habilidad de aquel, de su fuerza física, de su inteligencia, conocimiento y experiencias, depende el logro de los objetivos de la empresa y el adecuado manejo de los demás elementos (Münch y García, 2015). 
El empresario de las PyMEs debe mantener una actitud positiva e inclusive transmitirla a su equipo de trabajo, debe tener una gran visión para poder desarrollarse de la mejor manera, debe querer progresar, ponerse metas y trabajar para conseguirlas.

"El nivel de vida de una nación depende a largo plazo de su capacidad de alcanzar un elevado y ascendente nivel de productividad en los sectores que compiten sus empresas" (Porter, 2001, p. 23). Para poder lograr lo anterior, las empresas no solo requieren tener dentro de su fuerza laboral trabajadores o empresarios capaces de enfrentar las diversas situaciones turbulentas que se presentan en los mercados cambiantes y competitivos, sino que además exigen figuras que alcancen niveles de liderazgo, basado en valores éticos (Barbuzón, Varela, Gómez y Balkin, 2011).

Si las PyMEs desean subsistir, quienes las dirigen deben ocuparse de su negocio, interesarse, mantenerse informado de lo que sucede en lo interno y en el entorno, prepararse y adaptarse a los cambios necesarios.

En general, se observó que las PyMEs tienen muchas necesidades y carencias. Sin embargo, su sobrevivencia y continuidad dependerán, en gran parte, de la capacidad de gestión y atención de sus dirigentes; pues, para obtener resultados satisfactorios, el recurso humano debe ser motivado y capacitado constantemente; por lo cual es importante la existencia de programas que apoyen al buen funcionamiento de las PyMEs de manera sostenida. 


\section{Referencias}

Andersen, A. (1999). Diccionario de Economía y negocios. España: Editorial Espasa.

Barbuzón, M.O., Varela, R., Gómez, L. y Balkin, D. (2011). Formación empresarial. México: Universidad de Sonora/Pearson.

Barcelata-Chávez, H. (2008). La economía mexicana, Crisis y Reforma. Universidad. México: Hilario Barcelata. Recuperado de http://www.eumed.net/libros-gratis/2008b/383/index.htm

Barquero, I. (2003). El Estado y la competitividad de la micro, pequeña y mediana empresa. Tegucigalpa, Honduras: PNUD.

Cano, P., Orue, F., Martínez, J., Mayett, J. y López, G. (2015). Modelo de gestión logística para pequeñas y medianas empresas en México. Contaduría y Administración, 60(1).

Caraballo, W., Marcano, Y., Mendoza, L., Rivas, R., Sarramera, L. y Sbero, T. (2015). PYMES en Venezuela. Pymes una gran alternativa empresarial. Recuperado de https://issuu.com/ zumarin/docs/revista_pymes

Carriedo, C. (2017). Pymes mexicanas y su estrategia para 2017. Forbes. Recuperado de https:// www.forbes.com.mx/pymes-mexicanas-y-su-estrategia-para-2017/

Chiavenato, l. (2000). Administración de Recursos humanos. México: McGraw-Hill.

Cruz, L. (s.f.). Importancia de la Mercadotecnia en la Pequeña y Mediana Empresa en México. Retos de las ciencias administrativas desde las economías emergentes: Evolución de sociedades. Recuperado de http://acacia.org.mx/busqueda/pdf/15_PF497_Importancia_ de_la_Mercadotecnia.pdf

Estrada, R., García, D. y Sánchez, V. (2009). Factores determinantes del éxito competitivo en la pyme: estudio empírico en México. Revista Venezolana de Gerencia, 14(46), 169-182.

Gómez, C.O. (2009). El liderazgo y la gerencia de las organizaciones y empresas del futuro. Zona económica. Recuperado de http://www.zonaeconomica.com/node/2639

Gómez-Mejía, l., Balkin, D. y Cardy, R. (2001). Dirección y gestión de recursos humanos. Madrid: Prentice Hall.

Fernández, R., Castresana, J. y Fernández, N. (2006). Los recursos humanos en las Pymes: Análisis empírico de la formación, rotación y estructura de propiedad. Cuadernos de Gestión, 6(1), 63-80. 
Fuentes, A., Mass, M., Suárez, M., Sánchez, M., Vespa, A. y Vespa, Y. (2015). Pequeñas y Medianas industrias. Sistemas PYME. Recuperado de https://issuu.com/revistasobrelaspymes/ docs/revista_pymes

Hernández, H., Chumaceiro, A. y Atencio, E. (2009). Calidad de Servicio y recurso humano: caso estudio tienda por departamentos. Revista Venezolana de Gerencia, 14(47).

Trujillo, M. (2014). La evaluación del desempeño. Job performance. Grado en Relaciones Laborales, Facultad de Derecho, Universidad de La Laguna.

Mendez, J.S. (2011). La Economía en la empresa. En la sociedad del conocimiento. México: McGrawHill.

Münch, L. (2012). Fundamentos de administración. Casos y prácticas de gestión. México: Trillas.

Münch, L. y García, J. (2015). Fundamentos de Administración. México: Trillas.

Paredes, D., Macías, V. y Quintana, R. (2018). Factores de satisfacción laboral que inciden en el clima organizacional de los empleados de las PyMEs de comercio ubicadas en Villa Juárez, Sonora, México. Revista de Investigación Académica sin Fronteras, 10(25).

Pérez, C.A., Patrón, R.M., May, N.C. y Llanes, C.M. (2016). Aproximación teórica al concepto de evasión a la incertidumbre y orientación a largo plazo en las Mipymes. Revista electrónica del Desarrollo Humano para la Innovación Social, 3(6).

Pomar, S., Ramírez, H.T. y Rendón, A. (2011). La toma de decisiones con orientación estratégica en una pyme del sector metalmecánico. XV Congreso Internacional de Investigación en Ciencias Administrativas, Boca del Río, Veracruz, 2011. Recuperado de http://acacia.org. mx/busqueda/pdf/03_22_Toma_de_Decisiones.pdf

Porter, M. (2001). La ventaja competitiva de las naciones. Buenos Aires: Javier Vergara Editores.

Saavedra, M. (2008). Caracterización e importancia de las PYMES en Latinoamérica: Un estudio comparativo. Actualidad Contable. Faces, 17, 122-134.

Saavedra, M. (2012). Una propuesta para la determinación de la competitividad en la pyme Latinoamericana. Pensamiento y gestión, (33), 93-124. Recuperado de http://www.scielo. org.co/pdf/pege/n33/n33a05.pdf

Secretaría de Economía (SE). (2009). ACUERDO por el que se establece la estratificación de las micro, pequeñas y medianas empresas. Diario Oficial de la Federación, DOF 30-06-2009. 


\section{Capítulo 7}

Estrategias promocionales para la reactivación del turismo en El Triunfo, Baja California Sur, México

Elda Patricia Castro Cota ${ }^{1}$, Melany Araduvi Gómez Vizcarra ${ }^{2}$ y Amado Olivares Leal ${ }^{3}$

\footnotetext{
${ }^{1}$ Instituto Tecnológico de la Paz, México. epatrichia1371@hotmail.com

${ }^{2}$ Instituto Tecnológico de la Paz, México. melanny_magv@hotmail.com

${ }^{3}$ Universidad de Sonora, México. amado.olivares@unison.mx
} 


\section{Introducción}

En México, el turismo representa una de las principales actividades del país con crecimiento sostenido. Sin embargo, para entrar a los nuevos mercados internacionales se requiere ser competitivo, innovador y tener calidad, por lo que México necesita redoblar esfuerzos en la modernización de los servicios turísticos. Y, como es un destino turístico muy tradicional requiere una modernización no sólo en lo referente a su infraestructura sino también al desarrollo de una cultura turística (Zamorano, 2007).

Algunas modalidades del turismo se conciben no sólo como una posibilidad de la activación económica de zonas rezagadas, sino también como estrategias prioritarias para la conservación de los recursos naturales, el mantenimiento de ecosistemas y la preservación del patrimonio histórico y cultural (Zamorano, 2007, p. 10).

En Baja California Sur, el turismo es una de las principales fuentes de empleo e ingresos, razón por la cual es relevante la promoción a nivel local, nacional e internacional. Por lo anterior, una sensible demanda a los prestadores de servicios en este sector es tener una buena actitud hacia los visitantes y una mejor preparación para entender la dinámica del turismo, ya que ellos son el primer contacto con los visitantes.

Por su parte, El Triunfo, pueblo antiguamente minero de Baja California Sur, es un poblado dedicado principalmente al turismo extranjero. Sin embargo, los prestadores de servicios carecen de una buena actitud, tienen limitaciones del idioma inglés para comunicarse con turistas extranjeros y manifiestan una falta de preparación para contar la historia del pueblo; además, se tiene una escasa oferta de hospedaje, se cuenta con limitadas actividades de entretenimiento para el visitante y se desaprovecha la oportunidad de promover al pueblo como atractivo turístico minero.

Asimismo, en los últimos años, la falta de promoción turística a esta comunidad, la ubicación geográfica, el olvido de las autoridades y la falta de apoyo por parte de inversionistas, ha ocasionado una importante reducción en el número de turistas que visitan el pueblo, lo que implica una afectación económica para sus habitantes. En resumen, se pueden enlistar los principales problemas que requieren de una pronta atención: 
- Falta de difusión de los servicios turísticos que ofrece "El Triunfo" a sus visitantes.

- Falta de empleo para los pobladores.

- Migración a otras ciudades por parte de los habitantes de esta comunidad al buscar una mejor calidad de vida.

- Falta de actividades de entretenimiento para los visitantes.

Con el fin de ayudar a resolver la problemática de la falta de promoción turística de El Triunfo, en este trabajo se presenta un conjunto de estrategias de promoción que apoye a las autoridades del gobierno y permita atraer un mayor número de turistas locales e internacionales.

\section{Metodología}

La metodología fue de tipo transversal y descriptiva (Malhotra, 2008). Se realizaron entrevistas tanto al personal de la Secretaría de Turismo de La Paz, B.C.S. como a la Delegada de El Triunfo, quien mostró interés por promocionar el pueblo; asimismo, se realizaron encuestas a los locatarios de negocios en El Triunfo, durante los meses de octubre y noviembre de 2017. Se realizaron varias visitas, en las cuales se hizo un recorrido por el pueblo y se elaboraron reportes de observación de los aspectos que eran necesarios atender para poder promocionar al pueblo. Se encuestaron a pobladores con un rango de edad de entre 15 y 65 años, quienes desearon colaborar con la encuesta.

Se revisaron varios modelos de planes de marketing turístico para elaborar un conjunto de estrategias de promoción para El Triunfo, eligiendo el propuesto por Acerenza (2007), el cual consta de las siguientes siete etapas: 1) Información sobre la situación del destino, 2) Definición de objetivos, 3) Selección de la estrategia promocional, 4) Determinación de las acciones que se van a desarrollar (publicidad, promoción de ventas, relaciones públicas), 5) Elaboración del presupuesto, y 6) Calendarización del presupuesto.

\section{Resultados}

Con el fin de ofrecer una alternativa de solución a cada uno de los problemas mencionados con anterioridad, se elaboró un conjunto de estrategias de promoción turística, las cuales se basan en el siguiente diagnóstico. 


\section{Diagnóstico}

Como oferta turística, El Triunfo brinda a sus visitantes tres opciones de hospedaje, con un total de 12 habitaciones. Respecto a la gastronomía, existen escasas opciones de establecimientos de alimentos: a) Café “El Triunfo”, b) Restaurante Bar “El Minero”, y c) Lonchería "La Pasadita”.

Algunas operadoras de tours en Los Cabos tienen paseos a El Triunfo, entre ellos, My cabo tours (Explore La Paz), Rancho Tours (Paseo a La Paz) y Baja Challenge Tours (Paseo a El Triunfo). La Secretaría de Turismo de B.C.S. no lleva registro de los visitantes que llegan a la comunidad, por lo que no existen indicadores de demanda, por lo general, los visitantes no permanecen más de dos días en el pueblo. De acuerdo a los datos recopilados en el diagnóstico, los principales visitantes son personas residentes de La Paz, los cuales se definen como turistas locales, quienes acostumbran hacer viajes por carretera los fines de semana o acuden al pueblo a eventos diversos en fechas establecidas con antelación. Los turistas estadounidenses de la tercera edad son quienes representan el segundo lugar en visitas, según las encuestas aplicadas a los pobladores. Estos, generalmente, viajan en grupos o contratan servicios en operadoras de tours quienes programan las visitas a la comunidad. El turista extranjero busca conocer la historia y consumir los productos regionales.

Respecto a la infraestructura y servicios se cuenta con una planta purificadora de agua eliminadora de arsénico (herencia de la época del auge de la minería), servicio de red telefónica, suministro de red eléctrica, y servicio de alcantarillado y agua potable.

Después de recopilar la información y analizarla, se encontró que El Triunfo es una comunidad con un gran valor histórico para el estado de Baja California Sur, debido a sus antecedentes mineros y los vestigios que se conservan de la época. Sin embargo, a pesar de contar con lugares históricos tan valiosos y tangibles, el potencial del lugar se ve mermado por las malas condiciones en las que se encuentran, debido al deterioro por el paso del tiempo y la falta de apoyo en infraestructura, que incluye los accesos a los lugares emblemáticos. Esto significa que el pueblo no tiene capacidad para recibir grandes grupos turísticos, por la falta de actividades permanentes en la comunidad y los problemas que presenta en algunos servicios que ofrece como: internet inalámbrico, cajeros y teléfonos públicos; además de la escasa oferta en restaurantes, hoteles, venta de artesanías y recorridos turísticos guiados con dominio de otros 
idiomas, siendo este último una limitación importante ya que prácticamente ninguno de los pobladores domina un segundo idioma. Todas estas situaciones repercuten directamente en la economía de sus habitantes y comerciantes.

También se identificó que uno de los obstáculos más importantes para detonar el turismo en esta comunidad es el bajo presupuesto para promoción turística por parte del gobierno estatal y municipal. Por tanto, se deben buscar estrategias viables y de bajo costo que permitan alcanzar los objetivos de cualquier plan turístico. Finalmente, se identificó que las escasas estrategias de promoción únicamente se dan a conocer al público a través de una página de Facebook poco conocida y con falta de actualización en el contenido.

La delegación de "El Triunfo" no cuenta con equipo de cómputo e impresora, tampoco tienen material publicitario como carteles, trípticos o folletos que puedan ser entregados a los turistas con la información de los servicios prestados en el lugar.

\section{Plan de marketing}

El enfoque de marketing que se utilizó para el diseño de estrategias fue indiferenciado, ya que se cuenta con dos públicos fuertes y no es viable para la dependencia desarrollar campañas para cada uno de ellos por falta de recursos (Kotler y Armstrong, 2012).

A continuación, se presenta un plan de marketing turístico para incentivar la visita de turistas nacionales e internacionales al pueblo El Triunfo, Baja California Sur.

\section{Publicidad}

En la tabla 1, se concentran las estrategias de publicidad para promover a El Triunfo como destino turístico. Estas estrategias serán administradas por la Delegación de El Triunfo. 
Tabla 1. Resumen de estrategias de publicidad

\begin{tabular}{|c|c|c|}
\hline Estrategia & Objetivo & Acciones \\
\hline $\begin{array}{l}\text { Utilización de } \\
\text { medios masivos }\end{array}$ & $\begin{array}{l}\text { Dar a conocer la comunidad al mayor } \\
\text { número de personas posibles. }\end{array}$ & $\begin{array}{l}\text { - Colocar espectaculares } \\
\text { en puntos estratégicos. }\end{array}$ \\
\hline Internet & $\begin{array}{l}\text { A través de redes sociales, dar a } \\
\text { conocer las actividades y atractivos. }\end{array}$ & $\begin{array}{l}\text { - Pagar publicidad de Facebook } \\
\text { cuando haya un evento. } \\
\text { - Crear un correo electrónico. } \\
\text { - Crear una cuenta de Instagram. }\end{array}$ \\
\hline $\begin{array}{l}\text { Utilización de medios } \\
\text { alternativos }\end{array}$ & Llamar la atención a turistas potenciales. & - Utilizar Mupis. \\
\hline
\end{tabular}

Nota: Mupis = mobiliario urbano para información .

Respecto a las diferentes estrategias, se utilizarán las siguientes acciones:

\section{Colocar espectaculares en puntos estratégicos}

En las figuras 1 y 2 , se muestran ejemplos de diseño de espectaculares, con el fin de instalarse en lugares estratégicos en todo el Estado de Baja California Sur.

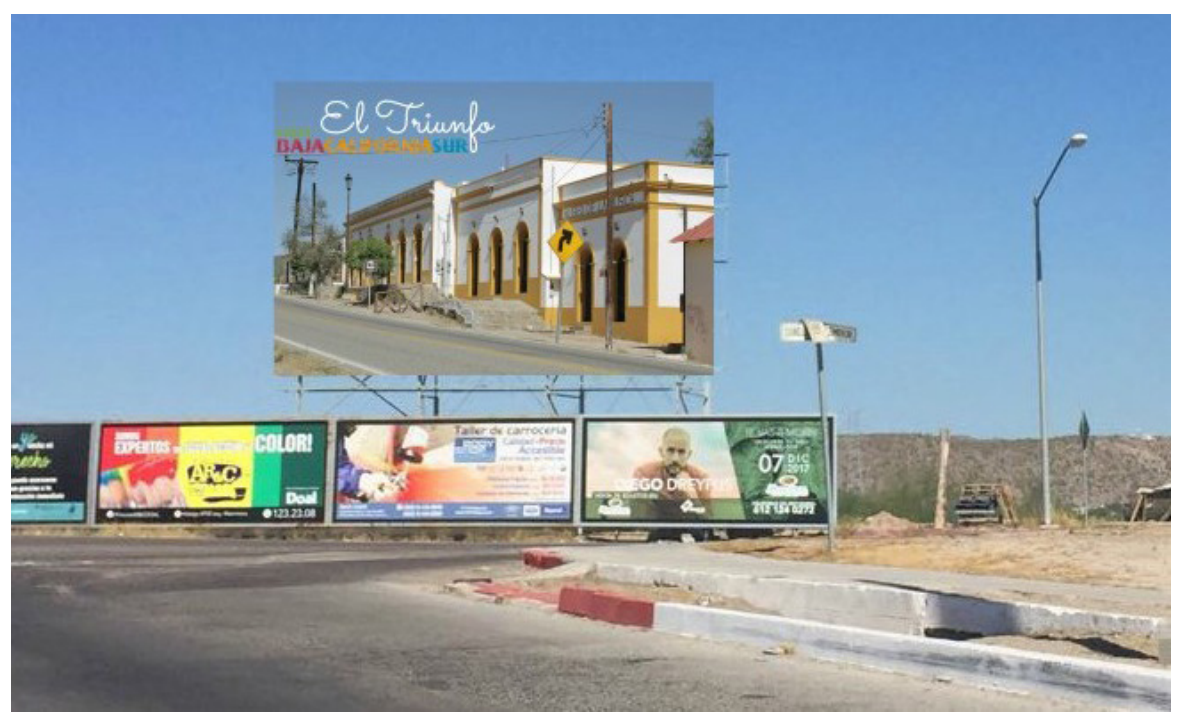

Figura 1. Ejemplo de un diseño de espectacular. 


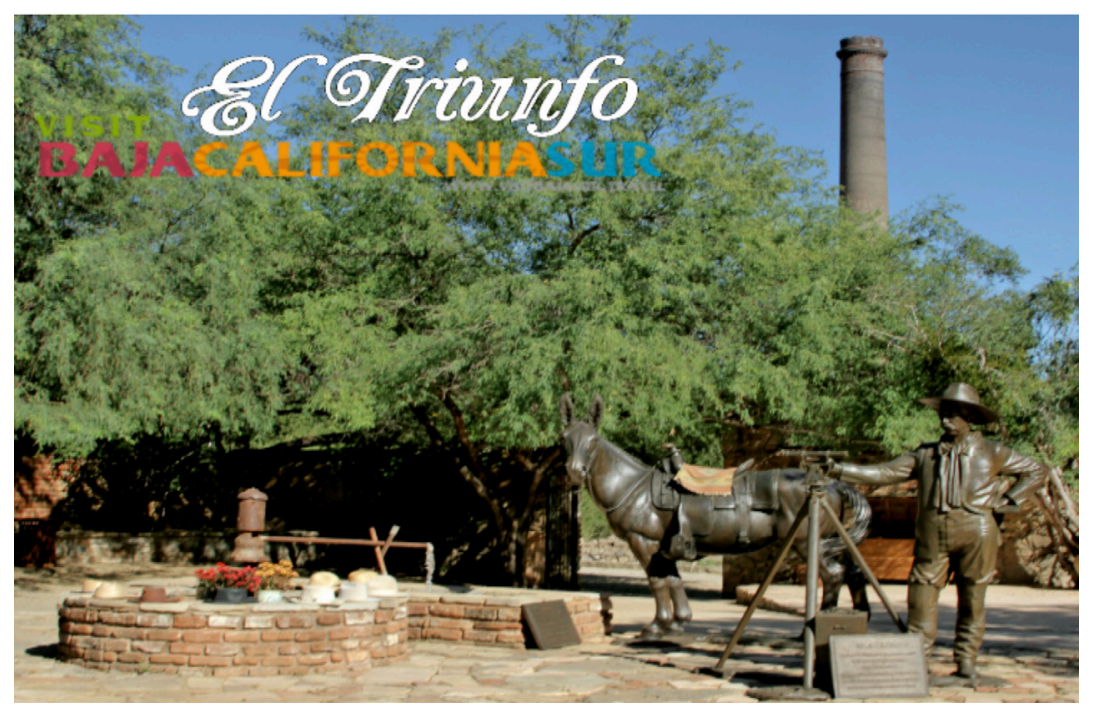

Figura 2. Ejemplo de un segundo diseño de espectacular.

Pagar publicidad de Facebook cuando haya un evento

Para emplear esta estrategia se sugiere empezar el pago de publicidad por 15 días antes de cualquier evento para obtener una mayor concurrencia. El alcance de este tipo de publicidad es de 7,500 personas, lo que también es benéfico para la página por ser "Likes" potenciales. En la figura 3, se muestra un ejemplo de una página de Facebook.

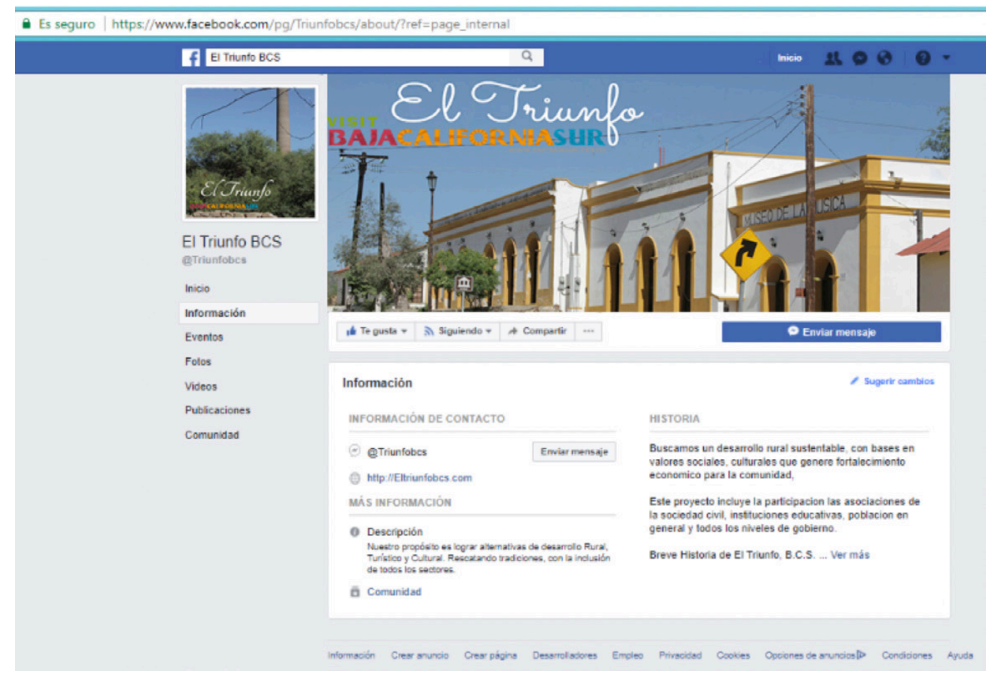

Figura 3. Ejemplo de página de Facebook. 


\section{Crear un correo electrónico}

Para llega a un mayor número de personas es conveniente crear un correo electrónico para facilitar la información y contacto con empresas turísticas, proveedores de servicios o la Secretaría de Turismo, entre otros. Es muy importante mantener este instrumento en constante actualización y agregar la dirección del e-mail en toda información que brinde la Delegación de El Triunfo.

\section{Crear una cuenta de Instagram}

El uso de esta aplicación puede ayudar a acceder a una enorme y activa audiencia, a través de imágenes visualmente atractivas. Además, puede crearse anuncios publicitarios enfocados a una audiencia específica.

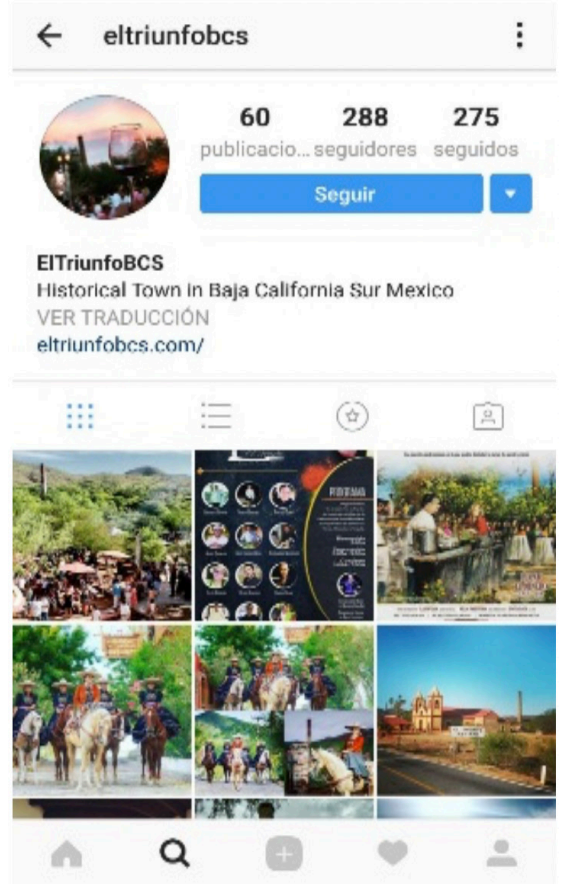

Figura 4. Ejemplo de la interfaz de Instagram

\section{Utilizar mupis}

Una opción adicional a los espectaculares es el mupi. En la figura 5, se muestra un ejemplo del diseño, el cual puede ser instalado en lugares estratégicos en todo el Estado de Baja California Sur. 


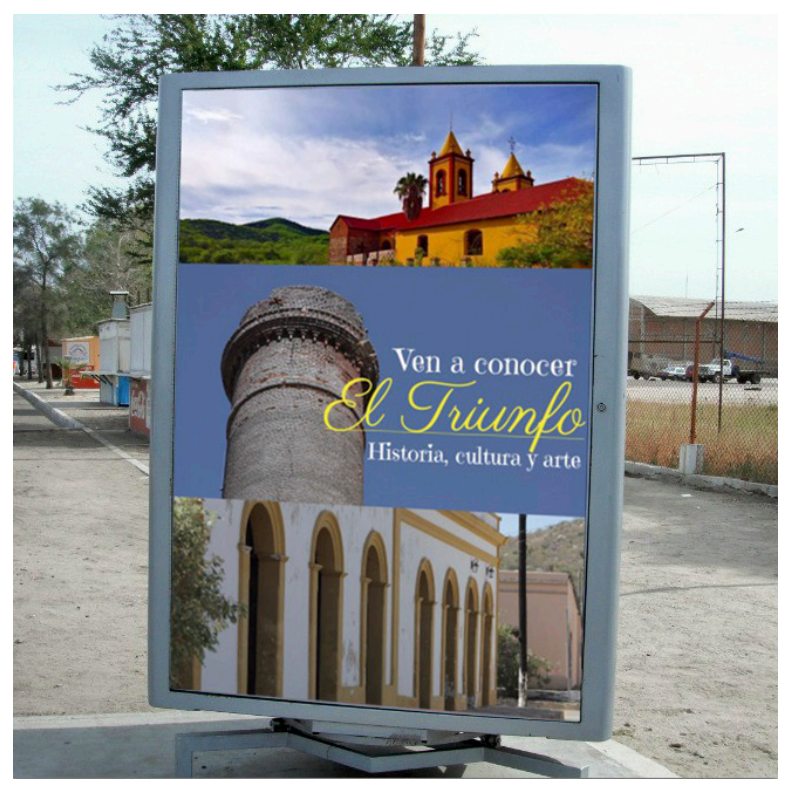

Figura 5. Ejemplo de un Mupi (versión en español).

\section{Promoción}

En la tabla 2, se presenta un resumen de las principales estrategias de promoción que se pueden llevar a cabo para promover El Triunfo como destino turístico.

Tabla 2. Resumen de las estrategias de promoción

\begin{tabular}{lll}
\multicolumn{1}{c}{ Estrategia } & \multicolumn{1}{c}{ Objetivo } & \multicolumn{1}{c}{ Acciones } \\
$\begin{array}{l}\text { Ubicar un kiosko } \\
\text { informativo }\end{array}$ & $\begin{array}{l}\text { Brindar un lugar donde los turistas sean } \\
\text { informados de las actividades y servicios } \\
\text { que hay en la comunidad }\end{array}$ & $\begin{array}{l}\text { - Diseñoar el kiosko. } \\
\text { - Ubicarlo estratégicamente. }\end{array}$ \\
\hline $\begin{array}{l}\text { Participación en } \\
\text { ferias de turismo }\end{array}$ & $\begin{array}{l}\text { Promover el atractivo histórico de la } \\
\text { comunidad }\end{array}$ & $\begin{array}{l}\text { Distribuir material informativo y } \\
\text { publicitario. }\end{array}$ \\
& & $\begin{array}{l}\text { Presentar video. } \\
\text { Elaborar calendario de activida- } \\
\end{array}$ \\
\end{tabular}




\section{Ubicar un kiosko informativo}

La creación de un módulo informativo ayudará a los visitantes a conocer más sobre los vestigios y antecedentes de la comunidad. Se considera que el lugar más adecuado para la instalación de este kiosko es junto al mupi de información sobre el estado. En la figura 6 , se muestra un modelo de kiosko, el cual se sugiere sea adaptado al espacio físico.

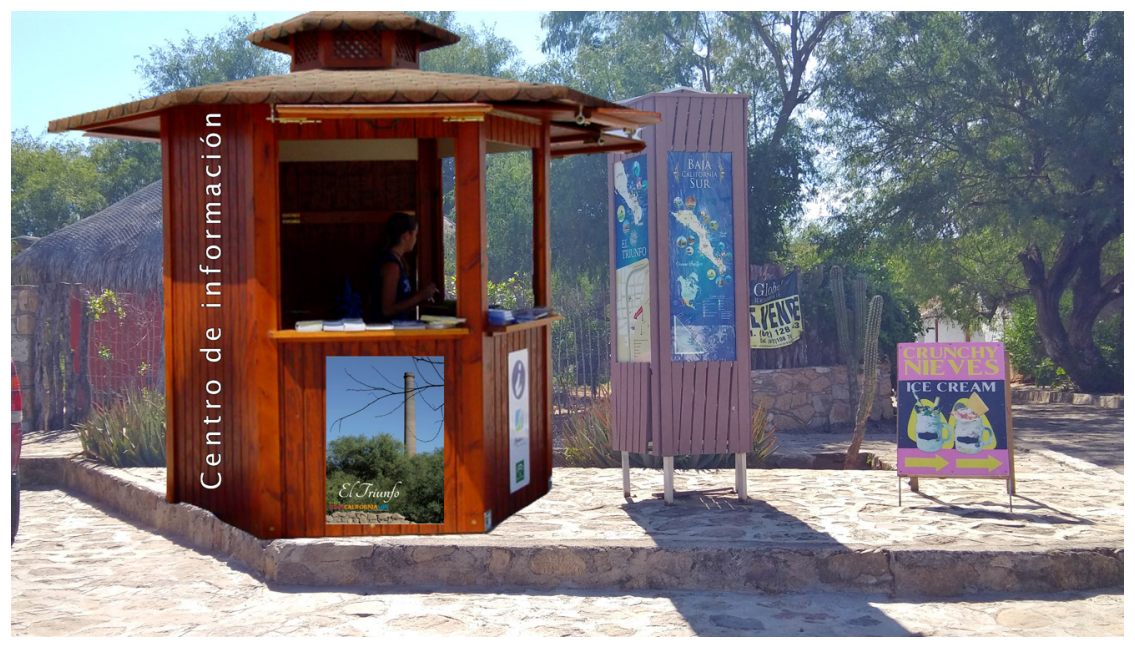

Figura 6. Propuesta de un kiosko informativo.

Participación en ferias de turismo

La segunda estrategia contempla la participación de la Secretaría de Turismo, a la cual se le hará entrega del material publicitario presentado anteriormente, para la presentación en diferentes eventos, tales como el Tianguis Turístico que se celebra cada año en el mes de abril. Además, podrán hacer uso de esta información al recibir turistas en cruceros o cuando se les solicite información en las oficinas. Su propósito es dar a conocer a El Triunfo como uno de los destinos turísticos del Estado de Baja California Sur.

\section{Relaciones públicas}

En la tabla 3, se muestra un resumen de las estrategias que pueden establecerse para mejorar las relaciones públicas del pueblo con los visitantes. 
Tabla 3. Resumen de las estrategias de relaciones públicas

\begin{tabular}{lll}
\multicolumn{1}{c}{ Estrategia } & \multicolumn{1}{c}{ Objetivo } & \multicolumn{1}{c}{ Acciones } \\
$\begin{array}{l}\text { Incorporar } \\
\text { policía turística }\end{array}$ & $\begin{array}{l}\text { Brindar seguridad } \\
\text { a los visitantes }\end{array}$ & $\begin{array}{l}\text { - Solicitar la presencia de elementos policiacos } \\
\text { cuando haya grupos y eventos. }\end{array}$ \\
\hline $\begin{array}{l}\text { Distribución de material } \\
\text { informativo en Secretaría }\end{array}$ & Tener un mayor alcance & - Entregar material publicitario. \\
de Turismo & & \\
\hline
\end{tabular}

Incorporar a la de policía turística

Debido al impacto que ha tenido el aumento de la violencia en Baja California Sur para el sector turístico, una buena opción es solicitar la presencia de elementos de Policía Turística en la comunidad, lo que daría una nueva imagen al lugar.

Distribución de material informativo en Secretaría de Turismo Como parte del alcance que se desea, la Secretaría de Turismo tendrá acceso a la información publicitaria para hacer uso de ella, debido a la participación que tienen en grandes eventos y su importancia para potencializar los destinos turísticos.

Distribución de material a representantes de Tour Operadoras Se encontró que pocas Tour Operadoras en el Estado ofrecen paseos a El Triunfo en sus páginas de internet y su publicidad, por tanto, la entrega de material publicitario ayudará a la difusión de la comunidad.

\section{Presupuesto}

En la tabla 4, se muestra el presupuesto para el desarrollo de las estrategias planteadas. 
Tabla 4. Presupuesto del programa

\begin{tabular}{cccccccccccc} 
Concepto & ENE & FEB & MAR & ABR & MAY & JUN & AGO & SEP & OCT & NOV & DIC \\
\hline Facebook & $\$ 1175$ & $\$ 1175$ & $\$ 1175$ & $\$ 1175$ & $\$ 1175$ & $\$ 1175$ & $\$ 1175$ & $\$ 1175$ & $\$ 1175$ & $\$ 1175$ & $\$ 1175$ \\
\hline $\begin{array}{c}\text { Instagram } \\
\text { Mupis/Paradas } \\
\text { de autobus }\end{array}$ & $\$ 150$ & $\$ 750$ & $\$ 750$ & $\$ 750$ & $\$ 750$ & $\$ 750$ & $\$ 750$ & $\$ 750$ & $\$ 750$ & $\$ 750$ & $\$ 750$ \\
\hline $\begin{array}{c}\text { Espectaculares } \\
\text { y Vallas }\end{array}$ & $\$ 1420$ & $\$ 1420$ & $\$ 1420$ & $\$ 1420$ & $\$ 1420$ & $\$ 1420$ & $\$ 1420$ & $\$ 1420$ & $\$ 1420$ & $\$ 1420$ & $\$ 1420$ \\
\hline Revistas & $\$ 2041$ & $\$ 2041$ & $\$ 2041$ & $\$ 2041$ & $\$ 2041$ & $\$ 2041$ & $\$ 2041$ & $\$ 2041$ & $\$ 2041$ & $\$ 2041$ & $\$ 2041$ \\
\hline $\begin{array}{c}\text { Carteles (100, } \\
\text { Tamaño tabloide) }\end{array}$ & $\$ 750$ & $\$ 750$ & $\$ 750$ & $\$ 750$ & $\$ 750$ & $\$ 750$ & $\$ 750$ & $\$ 750$ & $\$ 750$ & $\$ 750$ & $\$ 750$ \\
\hline $\begin{array}{c}\text { Trípticos (500, } \\
\text { Tamaño Carta) }\end{array}$ & $\$ 988$ & & & & $\$ 988$ & & & & & & \\
\hline $\begin{array}{c}\text { Subtotales } \\
\text { M }\end{array}$ & $\$ 8549$ & $\$ 7561$ & $\$ 7561$ & $\$ 7561$ & $\$ 7561$ & $\$ 8549$ & $\$ 7561$ & $\$ 7561$ & $\$ 7561$ & $\$ 7561$ & $\$ 7561$ \\
\hline
\end{tabular}

Nota: Precios en moneda nacional (MXN), no incluyen IVA.

\section{Calendarización}

Se propone un periodo de un año para desarrollar las actividades (tabla 5).

Tabla 5. Calendario de actividades

\begin{tabular}{|c|c|c|c|c|c|c|c|c|c|c|c|c|}
\hline Actividades & ENE & FEB & MAR & ABR & MAY & JUN & JUL & AGO & SEP & OCT & NOV & DIC \\
\hline $\begin{array}{c}\text { Pago de } \\
\text { publicidad }\end{array}$ & $x$ & $x$ & $x$ & & & $x$ & $x$ & & & & $x$ & $x$ \\
\hline Instagram & $x$ & & & & & & & & & & & \\
\hline Televisión & $x$ & $x$ & $x$ & & & & & & & & & \\
\hline Revista & & & $x$ & & & & $X$ & & & & $X$ & $x$ \\
\hline Espectaculares & $x$ & $x$ & $x$ & $x$ & $x$ & $x$ & $x$ & $x$ & $x$ & $x$ & $x$ & $x$ \\
\hline Mupi & & & & & & & & & & $x$ & $x$ & $x$ \\
\hline $\begin{array}{l}\text { Paradas de } \\
\text { autobuses }\end{array}$ & & & & & & & & & & $x$ & $x$ & $x$ \\
\hline Kiosko & $X$ & $X$ & $x$ & $x$ & $x$ & $X$ & $x$ & $X$ & $X$ & $x$ & $x$ & $x$ \\
\hline $\begin{array}{c}\text { Honorarios } \\
\text { policía turística }\end{array}$ & & $x$ & $x$ & & & & $x$ & & & & $x$ & $x$ \\
\hline
\end{tabular}




\section{Conclusiones}

Se ha presentado un conjunto de estrategias para la promoción turística del pueblo El Triunfo, B.C.S. basado en un diagnóstico completo que incluye información valiosa de sus habitantes. Durante las visitas realizadas a la comunidad y la información recabada se realizó un plan de marketing turístico para incentivar la visita de turistas nacionales e internacionales al pueblo El Triunfo, Baja California Sur, entre las actividades dentro de las diferentes estrategias se propuso, a través de la instalación de un kiosko, dar información turística verbal para orientar al visitante, así como entregar folletos con información relevante del lugar; participar en las ferias gastronómicas y festivales; y organizar recorridos turísticos peatonales guiados. Las actividades anteriores, ayudarían a enfrentar la problemática del pueblo respecto al desempleo, ya que los lugareños podrían emplearse en dichas actividades y obtener un ingreso que les permita permanecer en el pueblo en lugar de migrar en busca de trabajo. También se lograría abatir la falta de actividad para los visitantes con los recorridos turísticos por el pueblo y degustación de platillos típicos de la región.

El plan de promoción propuesto permite generar estrategias que mejoren la difusión del pueblo como un lugar turístico, y aprovechar la cercanía con las ciudades de los Cabos y La Paz para atraer visitantes. 


\section{Referencias}

Acerenza, M.Ā. (2005). Promoción turística. México: Trillas.

Kotler, P. y Armstrong, G. (2012). Marketing. México: Prentice Hall.

Malhotra, K. (2008). Investigación de Mercados. México: Pearson Educación.

Zamorano, F.M. (2007). Turismo alternativos. Servicios turísticos diferenciados. México: Trillas. 


\section{PARTE III INNOVACIÓN, COMPETITIVIDAD Y ESTRATEGIAS EDUCATIVAS}




\section{Capítulo 8}

Autoevaluación: una experiencia para comparar y contrastar dos modelos de evaluación de calidad de programas educativos de posgrado

Blanca Isela Ramírez ${ }^{1}$ Mirna Sulema Oleta Luna²

y Concepción Suástegui Barrera ${ }^{3}$

\footnotetext{
${ }^{1}$ Universidad Autónoma de Sinaloa, México. resistencia20112011@hotmail.com

2 Universidad Autónoma de Sinaloa, México. mirna_oleta@live.com

${ }^{3}$ Universidad Autónoma de Sinaloa, México. conchissua@hotmail.com
} 


\section{Introducción}

Las Instituciones de Educación Superior (IES) son agentes de generación de capital humano del más alto nivel para una sociedad sustentada en la innovación y desarrollo tecnológico. La Universidad Autónoma de Sinaloa, parte de la premisa de que su papel comprende desde la generación del conocimiento hasta la forma en que este se emplea en las organizaciones, por ello, en el Plan de Desarrollo Institucional Consolidación Global 2021, en su Eje 2: Generación de conocimiento y formación de alto nivel, establece la estrategia de elevar la competitividad de su posgrado para asegurar su calidad en atención a los criterios institucionales del Consejo Nacional de Ciencia y Tecnología, así como de organismos internacionales (Guerra, 2017).

Por lo anterior, esta institución educativa convocó a realizar una autoevaluación de los programas educativos acreditados por el Programa Nacional de Posgrados de Calidad, a partir del Modelo de la Asociación Universitaria Iberoamericana de Postgrado. Estas autoevaluaciones fueron expuestas en el Seminario-Taller "Gestión de la Calidad del Posgrado" impartido por expertos de esta asociación.

Lo anteriormente expuesto, se justifica dado que el posgrado es considerado parte del potencial de innovación social en una sociedad sometida a cambios vertiginosos y en la que se da un uso intensivo de los conocimientos (Abreu y De la Cruz, 2015) por lo que los programas educativos de doctorado que ofrecen las IES en México no pueden ser de nivel inferior a los de países más desarrollados (Cruz, 2005); en este marco, las universidades dan prioridad a la formación de capital humano capaz de incursionar exitosamente en el mercado laboral global.

Es en este contexto, en el que la Facultad de Ciencias Económico Administrativas de la Universidad Autónoma de Sinaloa realizó un ejercicio de autoevaluación del Doctorado en Gestión de las Organizaciones, aplicando los criterios del modelo de la Asociación Universitaria Iberoamericana de Postgrado (AUIP). En esta experiencia de autoevaluación, se hizo evidente que los participantes han colaborado en diferentes niveles de concreción del doctorado ${ }^{1}$, algunos desde su gestación, otros durante su puesta en marcha y, recientemente, se ha incorporado a este programa un integrante clave, la coordinadora del programa en la UAS. Para lograr un len-

1 El diseño curricular queda subsumido en el desarrollo curricular, dado que se concreta en diferentes actividades en las que intervienen diferentes actores (Gimeno, 1989). 
guaje y enfoque común entre los participantes se analizaron las características principales del Doctorado en Gestión de las Organizaciones, mismas que se presentan en el primer apartado de este capítulo.

En un segundo apartado, se muestran la forma como se realizó la comparación y contrastación del Modelo de la Asociación Universitaria Iberoamericana de Posgrado (variables, elementos, aspectos, indicadores, medios de verificación, criterios) (AUIP, 2014), con el Modelo del Programa Nacional de Posgrados de Calidad, dado que el Doctorado en Gestión en las Organizaciones fue diseñado a partir de los elementos de este último (compromiso institucional, categorías y plan de mejoras) (SEP/CONACYT/PNPC, 2015a). Este ejercicio, que tenía como propósito llenar el instrumento de evaluación proporcionado por el organismo internacional, se enriqueció con el Seminario-Taller "Gestión de la Calidad del Posgrado", del cual se retoman los siguientes aspectos, que implicaron la realización de una investigación documental: tasa de graduación, publicaciones y organización curricular.

Finalmente, se presentan las conclusiones derivadas del desarrollo del presente trabajo.

\section{Características del Doctorado en Gestión de las Organizaciones}

Para comprender las perspectivas, los supuestos y actividades que sustentaron los procesos curriculares del Programa Educativo del Doctorado en Gestión de las Organizaciones (DGO), se recurrió a presentaciones que se han utilizado ante autoridades de la UAS e integrantes del Núcleo Académico Básico (NAB) de la misma institución, el plan de estudios y los lineamientos para la operación del DGO. Además, los participantes enriquecieron la información con diversos eventos, sentidos, historias y narraciones que no estaban documentadas. A continuación, se presentan las principales características del doctorado.

\section{a) Interinstitucional}

El proyecto del Doctorado en Gestión de las Organizaciones (DGO) inició en febrero de 2014 con la integración del Comité Curricular y fue aprobado por el Programa Nacional de Posgrados de Calidad (PNPC), el 18 de marzo de 2016. Este éxito fue posible por la integración de esfuerzos de tres Instituciones de Educación Superior: la Universidad Juárez del Estado de Durango (UJED), 
la Universidad Autónoma de Nayarit (UAN) y la Universidad Autónoma de Sinaloa (UAS); por lo anterior, este programa se ubica como un programa interinstitucional.

Los programas interinstitucionales son el resultado de la integración de esfuerzos y fortalezas entre dos o más instituciones que comparten el mismo plan de estudios, en el área del conocimiento y Líneas Generales de Aplicación y Generación del Conocimiento (LGAC). (SEP/CONACYT/PNPC, 2015b, p. 3)

Se parte del supuesto de que estos posgrados contribuyen a la integración de núcleos académicos básicos más sólidos en cuanto a capacidades académicas para el desarrollo de proyectos de investigación y desarrollo, lo que favorece el trabajo colegiado; además, permite compartir la infraestructura académica a fin de ofrecer servicios educativos de calidad, con la finalidad de estimular la vinculación con los sectores de la sociedad.

Para vigilar la operación del plan de estudios, el apego a los lineamientos específicos del DGO y la legislación universitaria correspondiente, se constituyeron dos órganos colegiados:

- El Comité de Posgrado Interinstitucional (CPI), integrado por los responsables de posgrado e investigación de las instituciones participantes, con la función principal de establecer los mecanismos operativos de organización y desarrollo. De los integrantes de este comité se designa una presidencia que coordina las actividades interinstitucionales.

- El Consejo Académico del Doctorado (CAD) que coordina los trabajos académicos del programa educativo, el cual es administrado por un secretario técnico.

Para la operatividad del programa, cada institución designa un coordinador del programa, el cual es miembro del Núcleo Académico Básico (NAB), (UAN/UAS/UJED, 2015b).

La organización administrativa del DGO se muestra en la figura 1. 


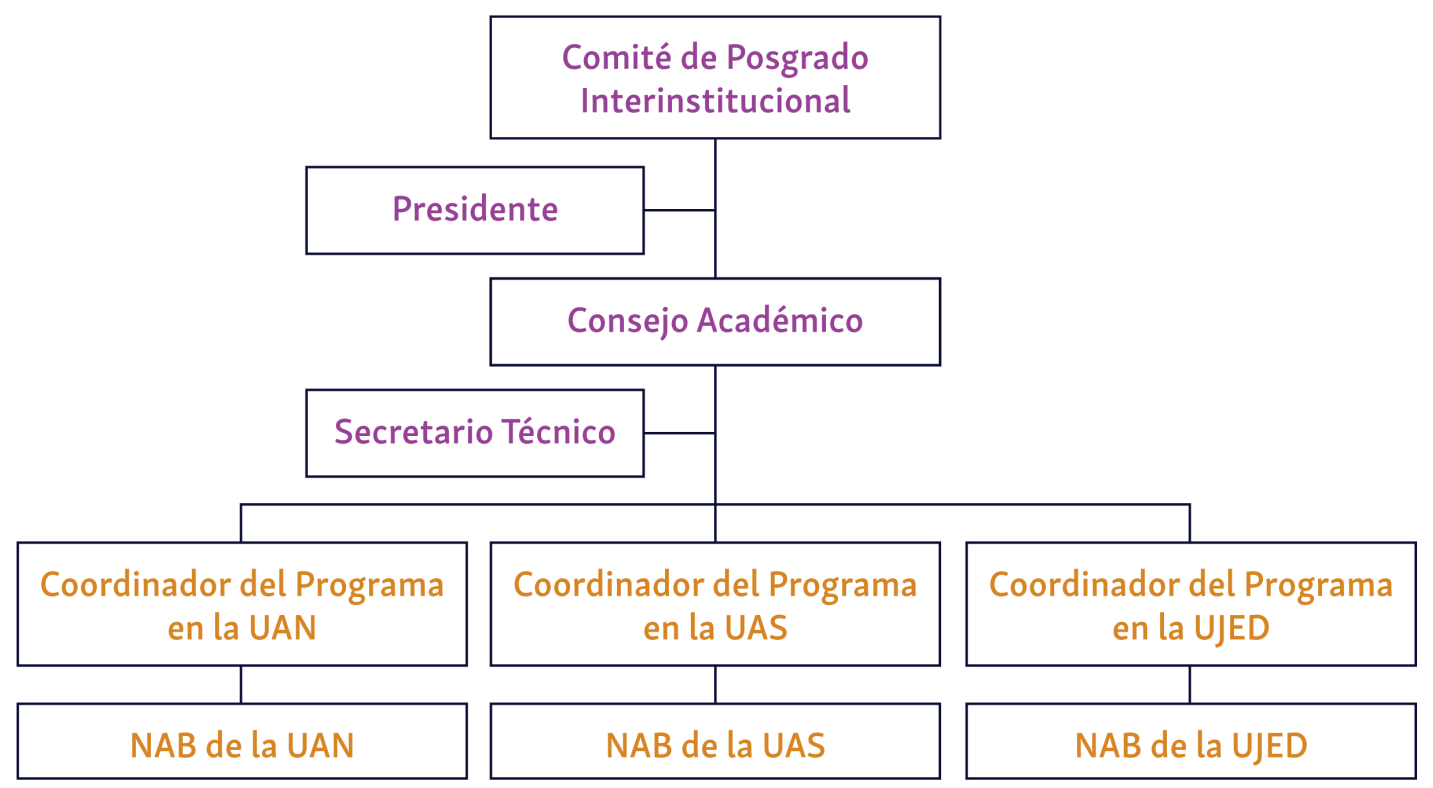

Figura 1. Organigrama del Doctorado en Gestión de las Organizaciones.

Fuente: UAN/UAS/UJED $\left(2015^{\mathrm{a}}\right)$.

\section{b) Programa con orientación profesional}

Este tipo de programas, son posgrados de especialidad, de maestría o de doctorado que responden a necesidades de los sectores de la sociedad (empresarial, social, gubernamental, entre otros), por lo que cuenta con una fuerte vinculación con estos sectores. Además, proporciona al estudiante una formación amplia y sólida en un campo de conocimiento con alta capacidad para el ejercicio profesional y los alumnos deben realizar estancias en los sectores de la sociedad (SEP/CONACYT/PNPC, 2018). El DGO es el primer programa educativo profesionalizante acreditado por el PNPC dado que, hasta 2015, este organismo solo contemplaba para los doctorados la orientación hacia la investigación.

\section{c) Interdisciplinario}

Las soluciones de los problemas actuales no son sólo del interés de una disciplina, sino que, por el contrario, necesitan discusión y análisis de diferentes áreas de conocimiento. La creación del DGO obedece a la necesidad de integrar diferentes saberes para solucionar los problemas que 
aquejan a las organizaciones, a partir del diálogo y una visión interdisciplinaria desde la economía, la administración y la sustentabilidad; su objeto de estudio son las organizaciones.

\section{d) Diseño curricular basado en competencias}

Se eligió el diseño curricular basado en competencias (Argudín, 2005) dado que en el estudio de pertinencia se estableció que el propósito de un posgrado profesionalizante es el desarrollo de competencias profesionales y sus destinatarios son principalmente profesionistas con experiencia acumulada, en busca de especialización o profundización de conocimientos y competencias aplicadas. A continuación, se describen brevemente las cuatro fases metodológicas:

Fase I. Fundamentación

Para afrontar los retos derivados de los problemas y necesidades detectadas en el estudio de pertinencia, se estableció como objetivo general del DGO:

Formar recursos humanos de alto nivel en las disciplinas del área económico administrativa, que tengan como objeto de estudio las organizaciones, que generen alternativas de innovación y desarrollo sustentable, por medio de procesos de investigación, diagnóstico, planeación e intervención aplicados a los problemas comunes del entorno. (UAN/UAS/UJED, 2015a, p. 26)

Y se determinaron cuatro competencias genéricas que requieren del conjunto de disciplinas que sustentan el DGO: Diagnóstico, Diseño, Intervención y Evaluación.

\section{Fase II. Perfil de Egreso}

En este apartado se muestran los saberes teóricos, prácticos y actitudinales que adquirirá el alumno en su trayectoria de seis semestres por el DGO, dado que en el periodo de su creación los modelos educativos de las tres instituciones participantes establecían la formación integral de los estudiantes en la generación de nuevos programas educativos. Estos saberes se determinaron generando para cada una de las competencias genéricas, competencias específicas. Las 
competencias específicas, se caracterizan por tener un alto grado de especialización y hacer la diferenciación de un programa educativo.

\section{Fase III. Organización y Estructuración}

Esta fase se concretó en el mapa curricular del DGO, este se ubica como un currículo semiflexible (tabla 1), el cual se organizó y estructuró a partir de las siguientes directrices: Orientación profesionalizante; Diseño Curricular basado en competencias; Investigación aplicada; Formación Integral; Educación centrada en el aprendizaje; Flexibilidad curricular: créditos, cursos optativos (selección de trayectoria por el estudiante), movilidad académica; Estructura curricular se constituye por los siguientes espacios curriculares: módulos (interdisciplinariedad) y unidades de aprendizaje; Estancia profesional (convenios, vinculación); y Actividades complementarias.

\section{Tabla 1. Mapa Curricular del Doctorado en Gestión de las Organizaciones}

\begin{tabular}{|c|c|c|c|c|c|c|c|}
\hline \multicolumn{2}{|c|}{ NIVEL DE FORMACIÓN } & \multicolumn{2}{|c|}{ BÁSICO } & \multicolumn{2}{|c|}{ PROFESIONALIZANTE } & \multicolumn{2}{|c|}{ ACENTUACIŌN } \\
\hline & SEMESTRE & PRIMERO & SEGUNDO & PRIMERO & SEGUNDO & PRIMERO & SEGUNDO \\
\hline \multirow{8}{*}{ 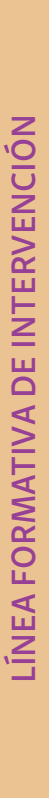 } & $\begin{array}{l}\text { MARCO ECONÓMICO } \\
\text { Y FINANCIERO DE LAS } \\
\text { ORGANIZACIONES }\end{array}$ & \multirow{5}{*}{$\begin{array}{l}\text { Fundamenta- } \\
\text { ción técnica y } \\
\text { Metodología } \\
\text { de las organi- } \\
\text { zaciones } \\
\text { C: } 24\end{array}$} & \multirow{5}{*}{$\begin{array}{c}\text { Estudio y } \\
\text { análisis de las } \\
\text { organizacio- } \\
\text { nes } \\
\text { C: } 24\end{array}$} & $\begin{array}{l}\text { Optativa I } \\
\text { C: } 6\end{array}$ & $\begin{array}{c}\text { Optativa IV } \\
\text { C: } 6\end{array}$ & \multirow{5}{*}{$\begin{array}{c}\text { Estancia } \\
\text { profesional } \\
\text { C: } 6\end{array}$} & \multirow{5}{*}{$\begin{array}{l}\text { Seminario de } \\
\text { formulación } \\
\text { de proyectos } \\
\text { C: } 12\end{array}$} \\
\hline & $\begin{array}{c}\text { MARCO } \\
\text { ADMINISTRATIVOY } \\
\text { ORGANIZACIONAL }\end{array}$ & & & $\begin{array}{l}\text { Optativa II } \\
\text { C: } 6\end{array}$ & $\begin{array}{l}\text { Optativa V } \\
\text { C: } 6\end{array}$ & & \\
\hline & MARCO DEL & & & & & & \\
\hline & DESARROLLO & & & Optativa III & Optativa VI & & \\
\hline & $\begin{array}{c}\text { SUSTENTABLE EN LAS } \\
\text { ORGANIZACIONES }\end{array}$ & & & $C: 6$ & C: 6 & & \\
\hline & \multirow[t]{3}{*}{$\begin{array}{l}\text { METODOLÓGICO- } \\
\text { INTEGRADOR }\end{array}$} & $\begin{array}{c}\text { Métodos } \\
\text { cuantitativos } \\
\text { C: } 6\end{array}$ & $\begin{array}{c}\text { Métodos } \\
\text { cualitativos } \\
\text { C: } 6\end{array}$ & $\begin{array}{c}\text { Seminario de } \\
\text { investigación } \\
\text { aplicada I } \\
\text { C: } 6\end{array}$ & $\begin{array}{l}\text { Seminario de } \\
\text { investigación } \\
\text { aplicada II } \\
\text { C: } 6\end{array}$ & $\begin{array}{l}\text { Seminario de } \\
\text { investigación } \\
\text { aplicada III } \\
\text { C: } 6\end{array}$ & $\begin{array}{c}\text { Seminario de } \\
\text { investigación } \\
\text { aplicada IV } \\
\text { C: } 6\end{array}$ \\
\hline & & \multicolumn{6}{|c|}{ Actividades complementarias } \\
\hline & & & & & $C=$ & réditos & le Créditos: 148 \\
\hline
\end{tabular}

Fuente: UAN/UAS/UJED (2015a, p. 58). 
Fase IV. Sistema de Evaluación

- Evaluación Interna. El DGO considera tres elementos centrales como referencia para esta evaluación: a) evaluación del aprendizaje, b) evaluación de la tutoría y dirección de trabajo terminal o tesis y c) evaluación del programa académico.

- Evaluación Externa. Los criterios que se siguieron para la creación del DGO fueron los del PNPC del CONACYT, logrando su aprobación por este organismo el 18 de marzo de 2016. A partir de su aprobación, se han realizado autoevaluaciones del programa a partir del plan de mejora, la integración y seguimiento de indicadores, la recuperación y creación de evidencias con la finalidad mantener la permanencia del DGO en el PNPC, además, de cumplir con las exigencias y políticas institucionales de fortalecimiento del posgrado.

\section{Ejercicio de autoevaluación}

El seguimiento y autoevaluación de los programas educativos de posgrado interinstitucionales como lo es el DGO, se realiza de manera conjunta entre las instituciones educativas participantes; sin embargo, este ejercicio se realizó de manera colaborativa con miembros del NAB de la UAS, maestros colaboradores internos de la UAS², la Coordinadora del Programa en la UAS y la Secretaria Técnica del DGO.

Se acordó compartir y analizar en próximas reuniones con las otras instituciones participantes (UAN y UJED) las acciones de mejora para el DGO surgidas del ejercicio de autoevaluación, a partir de los parámetros de calidad del modelo de la AUIP y socializar la necesidad de fortalecer el Programa Educativo del DGO, asegurando su calidad a través de una autoevaluación en atención a los criterios institucionales, los que define el PNPC y de un organismo internacional como lo es la AUIP.

Como se señaló anteriormente, para el diseño y autoevaluación del DGO se han observado los criterios del PNPC, en atención a los criterios institucionales, los cuales ahora se orientan a incorporar a este proceso los parámetros de un organismo internacional como lo es la AUIP.

2 Son docentes de las universidades participantes en el programa, pero que no son integrantes del NAB y pueden participar en la impartición de cursos y actividades académicas específicas a las que sean invitados, bajo la autorización del CAD (UAN/UAS/UJED, 2015b). 
Esta orientación responde a la Política Institucional de la UAS de incrementar la consolidación del posgrado de acuerdo a los parámetros Institucionales, del CONACYT e internacionales, contenida en el Eje 2: Generación de conocimiento y formación de alto nivel, del Plan de Desarrollo Institucional Consolidación Global 2021 (Guerra, 2017).

Para completar el instrumento de autoevaluación se fueron comparando y contrastando los elementos de los modelos de evaluación de programas educativos de posgrado (tabla 2).

\section{Tabla 2. Comparación entre variables de AUIP y Categorías de PNPC}

\section{Variables del Modelo AUIP}

1. Estudiantes

2. Profesores

3. Plan de Formación

4. Investigación científica, desarrollo tecnológico, innovación y desempeño profesional de alta calidad

5. Gestión

6. Entorno y pertinencia

7. Egresados e impacto

8. Evaluación y mejora continua

Fuente: Elaboración propia a partir de AUIP (2014) y SEP/CONACYT/PNPC (2015a).

En la tabla 3, se ejemplifica la manera como se ubicaron cuatro de las ocho variables de AUIP en las categorías y criterios del PNPC. Lo anteriormente expuesto, facilitó comparar los indicadores de AUIP con los subcriterios del PNPC, así como los medios de verificación propuestos por cada modelo.

El Programa del DGO con base en los elementos del PNPC (Compromiso institucional, Categorías y el Plan de mejoras) tiene carpetas con medios de verificación digitalizados (0. Compromiso Institucional, 1. Estructura y personal académico del programa, 2. Estudiantes, 3. Infraestructura del programa, 4. Resultados y Vinculación, 5. Autoevaluación-Plan de mejora). 
Tabla 3. Ubicación de las variables de AUIP en categorías y criterios de PNPC

Variables del Modelo AUIP

1. Estudiantes

2. Profesores

3. Plan de Formación

4. Investigación científica, desarrollo tecnológico, innovación y desempeño profesional de alta calidad

\section{Categorías del Modelo PNPC}

1. Estudiantes

2. Estructura y personal académico del programa/Criterios

3. Núcleo académico básico

4. Estructura y personal académico del programa/Criterio 5. Plan de estudios

7. Líneas de generación y aplicación del conocimiento

A partir de estos documentos se fueron eligiendo las evidencias que se presentarían a los pares académicos externos de la AUIP; para ello, se analizaron los medios de verificación, a partir de los criterios de existencia, claridad, pertinencia, eficacia etc. También se revisaron las propuestas del plan de mejora del DGO y las recomendaciones hechas por CONACYT en el documento "Evaluación Plenaria", todo ello, permitió identificar fortalezas y debilidades del programa educativo y, a partir de ellas, determinar las acciones de mejora.

\section{Aspectos retomados del Seminario Taller "Gestión de la Calidad del Postgrado"}

El ejercicio que tenía como propósito llenar el instrumento de evaluación, llevó a los participantes a juicios precipitados de considerar la no existencia del medio de verificación solicitado por el organismo internacional como debilidad del programa educativo del DGO. Sin embargo, esta experiencia se enriqueció con el Seminario-Taller "Gestión de la Calidad del Posgrado", en el cual, a partir de relatorías, se analizaron los programas de posgrados acreditado por CONACYTy autoevaluados a partir del modelo de evaluación de la AUIP; los expositores plantearon aspectos centrales del enfoque curricular del modelo, el cual implica una concepción de currículo, con el cual se pretende formar un individuo con ciertas características, para lo cual proporciona información sobre cuatro componentes que se relacionan entre sí: qué enseñar; cuándo enseñar; cómo enseñar; y qué evaluar, cómo evaluar y cuándo evaluar (Ramírez, 2008). 
Lo anterior, permitió considerar que todo currículo -como lo es el programa educativo del DGO- se concreta en diferentes actividades en las que intervienen diferentes actores, y las decisiones que toman las instituciones educativas respecto a un programa educativo están tamizadas por decisiones tomadas en el contexto externo (política educativa; organismos internacionales, evaluadores, acreditadores) (Ramírez, 2008), de tal manera que, el DGO se deriva de estudios de pertinencia y factibilidad, los cuales determinaron las características que anteriormente fueron señaladas y que están tamizadas por los criterios establecidos por el modelo de PNPC, por lo que agregar enfoques o elementos sin analizar estas características deformaría al DGO. Los cambios deben de ser ampliamente justificados para que puedan reorientar el programa y que éste se adapte a los cambios presentes en el entorno, es decir, para innovar el programa educativo del DGO.

En este apartado, se retoman tres aspectos que sin duda implican un cambio de la visión de los docentes del DGO, derivada del modelo del PNPC: tasas de graduación de alumnos, las publicaciones y la organización curricular de los programas educativos de doctorado.

\section{a) Tasa de titulación}

El DGO con base a la clasificación del PNPC, es un programa de nueva creación el cual al término de la segunda generación (primera cohorte 2016-2019, segunda cohorte 2017-2020, tercera cohorte 2018-2021), deberá evaluarse y renovar su registro en alguno de los siguientes niveles y cumplir con el parámetro de eficiencia terminal correspondiente: en desarrollo $40 \%$, consolidado $50 \%$, competencia internacional $70 \%$. Para cumplir con este parámetro, los alumnos del DGO deben obtener el grado de doctor, según el plan de estudios (tres años) más 6 meses; de exceder este plazo la obtención de grado no cumple con el criterio (SEP/CONACYT/PNPC, 2015c).

De acuerdo a Abreu y De la Cruz (2015), el cumplimiento de la tasa de eficiencia terminal por cohorte en el tiempo establecido se ha impulsado desde los organismos financieros dado que, para ellos, la obtención de grado es la culminación del proceso formativo, y con éste se lograr el beneficio derivado de la inversión económica realizada. Sin embargo, al presionar para elevar este indicador, la titulación se convierte en un fin en sí mismo, en desmerito de la formación y calidad de la investigación. 


\section{b) Publicaciones}

Las publicaciones son un indicador de relevancia y han permitido el acceso a los investigadores universitarios como autores a revistas internacionales indexadas y al Sistema Nacional de Investigadores (SNI), lo cual es un avance considerable dado que, son un medio para preservar el conocimiento. Sin embargo, convertirlo en un fin "en el factor central de la evaluación puede deformar a la investigación, favoreciendo el montaje de fábricas de publicaciones en temas puntuales e irrelevantes" (Abreu y De la Cruz, 2015, p. 165). El parámetro de profesores de tiempo completo pertenecientes al SNI señalado por el PNPC para programas de doctorado es el siguiente: de nueva creación $30 \%$; en desarrollo $40 \%$; consolidado $60 \%$ y al menos $40 \%$ en los niveles I, II y III; de competencia internacional $60 \%$ y al menos el $40 \%$ en los niveles II y III.

Los dos aspectos anteriores, son estándares de corte estructural incluidos en la primera generación de sistemas de calidad y evaluación del posgrado, si bien, por un lado se reconoce las virtudes de este tipo de evaluación y su papel para limitar la apertura de programas educativos que incumplen con los estándares mínimos; por otro, se hace evidente que no imprime un rumbo al posgrado ni impulsa su inserción en la sociedad del conocimiento, por ello, Abreu y De la Cruz (2015) proponen elementos para construir un modelo de calidad y una segunda generación de instrumentos de evaluación.

\section{c) Organización curricular en los programas educativos de doctorado}

El DGO fue diseñado siguiendo los criterios señalados por el PNPC, este organismo evalúa que el plan de estudios incluya obligatoriamente, entre otros elementos, el mapa curricular con la organización de los contenidos en sus dimensiones de verticalidad y horizontalidad, el número de cursos y su distribución por periodo lectivo, los cursos obligatorios y optativos, trabajos de campo con relación a las necesidades formativas del programa del doctorado, los créditos o asignaturas, la seriación (SEP/CONACYT/ PNPC, 2015a; SEP/CONACYT/PNPC, 2015b). Este programa educativo en relación con la organización de su contenido es un currículo semiflexible (figura 2), entre las principales características de este tipo de currículo, de acuerdo a Sánchez (1995), están: 
- Los conocimientos requeridos en el programa académico se organizan en etapas constituidas por grupos de asignaturas que no necesariamente tienen secuencia temporal obligatoria previamente definida.

- Generalmente, este tipo de currículo se organiza en tres niveles: el nivel de cursos básicos de nivel general, que son comunes a todos los programas del área del conocimiento; el segundo, que corresponde a los requerimientos específicos del programa académico seleccionado; y un tercero que permite profundizar en un área del programa de estudios o de un programa distinto.

- En este modelo, en algunas de las etapas las asignaturas están organizadas por áreas.

- Para determinadas asignaturas se señala una seriación obligatoria y cuáles asignaturas deberán ser cursadas como requisito previo.

- Esta forma de organización está centrada más en asignaturas que en currículos completos.

- Está basado en el sistema de créditos.

Las ventajas del currículo semiflexible son, de acuerdo con Sánchez (1995):

- Favorece la constante revisión de planes de estudio. Con este tipo de organización curricular se acorta el tiempo que las instituciones educativas requieren para el diseño e implementación de una reforma curricular, dado que este modelo se integra en tres niveles, lo que permite actualizar el currículo a través del tercer nivel, sin necesidad de modificar por completo su estructura básica. Bajo esta organización de contenidos, se brinda la posibilidad de elaborar programas académicos con la capacidad de adaptarse a los nuevos retos profesionales, con el propósito de ofrecer una respuesta adecuada y oportuna a los acelerados cambios de la sociedad y el mercado de trabajo.

- Al estar basado en el sistema de créditos, puede ser flexible en el tiempo en que se realizan los estudios. Los alumnos identifican los valores en créditos asignados a cada uno de sus cursos, así la culminación de sus estudios no está ya determinada por el número de materias cursadas o semestres que integran el plan de estudios, sino por el número de créditos que se requiere aprobar y podrán acumular el total de créditos exigidos por su plan de estudios en rangos de tiempo (mínimo y máximo). 
- Los estudiantes podrán, dentro de ciertos límites y siguiendo criterios preestablecidos, seleccionar cursos optativos que constituirán parte del currículo, con lo que se permite una mejor adecuación de sus aptitudes e intereses.

- Posibilita la movilidad de los estudiantes, dado que la utilización del sistema de créditos garantiza la transferencia de los mismos entre programas, ya que facilita el reconocimiento y acreditación de los cursos y créditos ya obtenidos, cuando el estudiante decide hacer cambio de carrera, abandona temporalmente los estudios o decide cambiar de institución, siempre que se encuentre acompañado de una normatividad institucional apropiada.

Las desventajas del currículo semiflexible son que, para el funcionamiento óptimo de este modelo, se requiere una importante infraestructura de apoyo e importantes transformaciones administrativas; así, como de personal docente capacitado dentro del modelo para que ofrezcan tutorías a los alumnos. Esta actividad es relevante para el funcionamiento del modelo, ya que se puede presentar confusión en los estudiantes si no se cuenta con el asesoramiento adecuado en las ilimitadas posibilidades de selección de cursos y se pueden dispersar los esfuerzos de los académicos y estudiantes (Sánchez, 1995).

El aspecto desarrollado en este apartado es relevante, dado que el PNPC orienta al diseño del currículo semiflexibles basado en créditos; sin embargo, una estrategia de formación que recomienda la AUIP a la UAS, es que debe desarrollar un modelo curricular flexible y dinámico, apto para mantenerse en la frontera del conocimiento en un área, favorecer la formación multi y trasdisciplinaria y enseñar a transferir el conocimiento; asimismo, recomienda eliminar los créditos en el doctorado (toda vez que han obtenido la formación en maestría).

De acuerdo con Sánchez (1995), en México se encuentran programas educativos desarrollados con base en el modelo flexible únicamente a nivel de doctorado. A continuación, se presentan las características de este modelo:

- Este tipo de currículo (programas en los que se incorporan los estudiantes más destacados de la institución en grupos especiales y que requieren una mayor dedicación de estudiantes y académicos) permite que las actividades de aprendizaje se seleccionen considerando tanto los requerimientos del programa como las características del estudiante. 
- En este modelo no hay un listado predeterminado de materias a cursar y/o actividades escolarizadas definidas y secuenciadas.

- Se definen con precisión los objetivos del programa, el perfil de ingreso, las características de los académicos participantes y el perfil de egreso.

- La determinación de los cursos, seminarios y actividades a desarrollar por los estudiantes es hecha generalmente por un tutor asignado a cada estudiante y/o una instancia colegiada en la que participa el cuerpo docente asignado al programa.

- El trabajo de investigación juega un papel fundamental en la definición de las actividades a desarrollar por el estudiante.

- El modelo de currículo flexible es utilizado con frecuencia en programas de tipo tutorial, donde el currículo no se centra en asignaturas, sino que es definido por cada uno de los participantes en el programa, de acuerdo con el proyecto de investigación.

- Las ventajas del currículo flexible se centran en que la flexibilidad en el diseño facilita la colaboración entre instituciones y una utilización más eficiente de los recursos.

La incorporación de diversas modalidades en la organización curricular se han realizado para dar flexibilidad al currículo, sin embargo, para las instituciones educativas que pretenden cambiar su organización curricular y el tipo de estructura académico-administrativa que influyen en la problemática relacionada con el reconocimiento de los estudios entre programas de la misma institución, es fundamental revisar la normatividad relativa al reconocimiento, y equivalencia de estudios, ya que puede imponer trabas innecesarias a la movilidad entre programas e instituciones; modificaciones a esta reglamentación son necesarias para permitir una mayor flexibilidad (Sánchez, 1995).

Por lo que, si en la fase metodológica de diseño curricular de organización, las universidades autónomas como la UAS determinan que uno de los elementos a cambiar es la organización curricular, esta decisión conlleva la necesidad de modificar su estructura académico-administrativa, reformar su Ley Orgánica y su Estatuto General, ya que en estos documentos se señala la organización académica-administrativa con la que opera la institución. Este cambio, también repercutirá en el organigrama y el manual general de organización de la institución; en 
este último documento administrativo se expone en detalle la estructura orgánica y funcional de la universidad en su conjunto y en cada una de sus entidades académicas y administrativas que la conforman, así como sus respectivas relaciones, de allí lo complejo de concretar cambios en el tipo de currículo (Ramírez, 2008).

\section{Conclusiones}

En una autoevaluación, la ausencia de evidencias, más que llevar a juicios precipitados de considerar la no existencia del medio de verificación como debilidad de un programa educativo, debe llevar a reflexionar acerca de la pertinencia de agregar indicadores señalados por un modelo de evaluación distinto con base al cual fue diseñado dicho programa; es conveniente conocer no solo los elementos que constituyen los modelos de evaluación, sino también el enfoque y teorías que los fundamentan para que los cambios en las características de los programas educativos sean ampliamente justificados.

En este camino de tránsito de un modelo a otro se tendría que analizar hasta qué punto la universidad desea hacer el cambio: una modificación sin alterar la estructura de lo establecido o una ruptura del paradigma establecido por un modelo de evaluación alternativo. Asimismo, será conveniente clarificar cómo asimila el cambio cada programa educativo. 


\section{Referencias}

Abreu, L.F. y De la Cruz, G. (2015). Crisis en la calidad del posgrado. Evaluación de la obviedad, o evaluación de procesos para impulsar la innovación en la sociedad del conocimiento. Perfiles Educativos, XXXVII(147), 162-182. Recuperado de http://www.iisue.unam.mx/ perfiles/perfiles_articulo.php?clave=2015-147-162-182

Argudín, Y. (2005). Educación Basada en Competencias. Nociones y Antecedentes. México: Trillas. Asociación Universitaria Iberoamericana de Postgrado (AUIP). (2014). Evaluación de Programas de Postgrado. Cuadernillo de Trabajo. España: AUIP. Recuperado de https://www.auip.org/ images/stories/DATOS/PDF/2014/Premios_AUIP/cuadernillo_de_trabajo_6_edicion. pdf

Cruz, C.V. (2005). Tendencias de la Formación Superior Avanzada en América Latina. I Congreso Bolivianoen Educación Postgraduada, Sucre, Bolivia. Recuperado dehttp://www.auip.org/ index.php/es/premios-auip-a-la-calidad/155-publicaciones/293-publicacionesonline

Guerra, J.E. (2017). Plan Institucional de Desarrollo. Consolidación Global 2021. Sinaloa: Universidad Autónoma de Sinaloa. Recuperado de http://sau.uas.edu.mx/pdf/Plan_de_Desarrollo_ Institucional_Consolidacion_Global_2021.pdf

Gimeno, J. (1989). El currículum: una reflexión sobre la práctica. Madrid: Morata.

Ramírez, B. (2008). Análisis del diseño curricular 1982-1986 y 1995-2003 de la Licenciatura en Contaduría Pública de la Escuela de Contabilidad y Administración de Mazatlán UAS. Tesis doctoral. Universidad de Durango. Campus Mazatlán, Sinaloa, México.

Sánchez, M. (1995). Temas de hoy en la Educación Superior. Modelos Académicos. México: ANUIES. Recuperado de https://docenciaiep.files.wordpress.com/2016/06/modelos-academicos. pdf

Secretaría de Educación Pública, Consejo Nacional de Ciencia y Tecnología, Programa Nacional de Posgrados de Calidad (SEP/Conacyt/PNPC). (2018). Convocatoria 2018. Programas de Renovación. Recuperado de https://www.conacyt.gob.mx/index.php/becas-yposgrados/programa-nacional-de-posgrados-de-calidad/convocatorias-avisos-yresultados/convocatorias-abiertas-pnpc/17213-conv-18-pnpc-renov/file 
Secretaría de Educación Pública, Consejo Nacional de Ciencia y Tecnología, Programa Nacional de Posgrados de Calidad (SEP/CONACYT/PNPC). (2015a). Marco de referencia para la evaluación y seguimiento de Programas Presenciales. Recuperado de https://www.uv.mx/ posgrado/files/2012/11/MARCO-DE-REFERENCIA-PNPC-V6.pdf

Secretaría de Educación Pública, Consejo Nacional de Ciencia y Tecnología, Programa Nacional de Posgrados de Calidad (SEP/CONACYT/PNPC). (2015b). Anexo B. Programas Interinstitucionales, multi-sedey multi-dependencia. Versión 2. Recuperado de https://www. conacyt.gob.mx/index.php/becas-y-posgrados/programa-nacional-de-posgrados-decalidad/convocatorias-avisos-y-resultados/anexos-pnpc/6767-anexo-b/file

Secretaría de Educación Pública, Consejo Nacional de Ciencia y Tecnología, Programa Nacional de Posgrados de Calidad. (SEP/CONACYT/PNPC). (2015c). Anexo A. Programas de Orientación Profesional. Versión 4.1. Recuperado de https://www.conacyt.gob.mx/index. $\mathrm{php/becas-y-posgrados/programa-nacional-de-posgrados-de-calidad/convocatorias-}$ avisos-y-resultados/anexos-pnpc/6757-anexo-a-op/file

Universidad Autónoma de Nayarit, Universidad Autónoma de Sinaloa, Universidad Juárez del Estado de Durango (UAN/UAS/UJED). (2015a). Programa Interinstitucional Doctorado en Gestión de las Organizaciones. Plan de Estudios.

Universidad Autónoma de Nayarit, Universidad Autónoma de Sinaloa, Universidad Juárez del Estado de Durango (UAN/UAS/UJED). (2015b). Lineamientos para la Operación del Doctorado en Gestión de la Organizaciones. 


\section{Capítulo 9}

Experiencias de aprendizaje por proyectos, para la adquisición de competencias profesionales en estudiantes universitarios

Elsa Armida Ortega Verdugo ${ }^{1}$, Nubia J. Félix Orduño y Yessica Lara Soto ${ }^{3}$

\footnotetext{
${ }^{1}$ Universidad de Sonora, México. armida.ortega@unison.mx

2 Universidad de Sonora, México. nubia.felix@unison.mx

3 Universidad de Sonora, México. yessica.lara@unison.mx
} 


\section{Introducción}

El Aprendizaje Basado en Proyectos (ABP) es una metodología que permite a los alumnos adquirir los conocimientos y competencias clave en el siglo XXI, mediante la elaboración de proyectos que den respuesta a problemas de la vida real; como actividad de enseñanza-aprendizaje es una técnica innovadora para entrenar a universitarios en una actividad profesional específica y que, al mismo tiempo, promueve experiencias que propicien el desarrollo de sus habilidades competitivas, como es el caso del presente estudio de formación de Licenciados en Sistemas Administrativos, los cuales requieren conocimientos teóricos y prácticos para fomentar una cultura más crítica y reflexiva en su educación universitaria, la cual les permita potencializar su capacidad creativa al enfrentarlos a la solución de problemas actuales.

En la Universidad de Sonora, Campus Santa Ana, se imparten en el octavo semestre el Taller de Proyectos de Inversión y en el noveno el Taller de Proyectos Integradores, los cuales se evalúan mediante un proyecto final que permite no sólo la vinculación de los alumnos con el sector social y empresarial, sino además obtener experiencias de aprendizaje que les favorezca la adquisición de competencias profesionales, y al mismo tiempo se promueven actividades de docencia e investigación que propicien el desarrollo de capacidades con responsabilidad, compromiso y valores humanos que los egresados de esa institución universitaria deben adquirir. Los productos de esos talleres se exponen en la Feria de Creatividad y Vinculación Universitaria o Certamen Búho Innova-T, que durante quince años ha promovido la Universidad de Sonora, Unidad Centro y donde convergen proyectos de distintas categorías y de otras licenciaturas, siendo el Campus Santa Ana uno de los privilegiados en obtener merecidos reconocimientos por impulsar el Programa de Emprendedores Universitarios (PEU-Unison) desde sus inicios en el año 2003.

\section{Planteamiento del problema}

La sociedad y el conocimiento se configuran en un permanente cambio y, por ello, demandan estudiantes y profesionales con mayores niveles de comprensión y desarrollo de competencias; con capacidad para plantear y resolver problemas; con iniciativa y actitudes emprendedoras; con capacidades para crear y operar procesos o tecnologías que contribuyan al crecimiento y desarrollo económico del estado y el país. 
Desarrollar aptitudes creativas, críticas e innovadoras, implica que el enfoque de enseñanza tradicional basada en la instrucción directa de conocimientos y hechos evaluados con exámenes ya no es adecuado, por lo cual es sustituido por un modelo centrado en el alumno y basado en su participación activa, mediante un proceso de reflexión, crítica e interpretación. El propósito es promover la formación de universitarios imaginativos que, viendo las cosas desde diferentes ángulos, puedan desenvolverse en un mundo en constante cambio y enfrentarse a un futuro incierto (UNESCO, 2012).

Los modelos educativo y curricular de la Universidad de Sonora, actualmente se encuentran en proceso de integración y revisión y se han llevado a cabo análisis de los procesos institucionales que se realizan para el desarrollo curricular, aunado a que se ha trabajado en las competencias genéricas, las cuales fueron seleccionadas a través de un proceso inclusivo con estudiantes, docentes, egresados, empleadores y con la sociedad en su conjunto. "Asimismo, se están elaborando propuestas de actualización normativa para los reglamentos: Lineamientos generales para un modelo curricular y Criterios para la formulación y aprobación de planes y programas de estudio" (Universidad de Sonora, 2017, p. 34).

El aprendizaje basado en proyectos consiste en enfocar actividades individuales y en equipo, relacionadas con "aprender a aprender juntos", resolver problemas educativos reales, poner en práctica los conocimientos adquiridos y buscar soluciones en forma integrada (Ramírez, 2012). Al respecto, ¿si los docentes utilizan metodologías por proyectos, pueden impulsar a la adquisición de competencias profesionales en sus alumnos universitarios? La presente investigación se hizo con la finalidad de obtener información sobre experiencias de aprendizaje y de las competencias adquiridas, utilizando metodología por proyectos en talleres impartidos a 131 estudiantes de la Universidad de Sonora, Campus Santa Ana.

\section{Marco teórico}

\section{Modelo educativo basado en competencias}

El Plan de Desarrollo Institucional (PDI 2017-2021) de la Universidad de Sonora, menciona: 
Las universidades que forman egresados de mayor calidad académica son aquellas basadas en la investigación, las que a su vez se desarrollan vinculadas con su entorno. Así, una educación universitaria de buena calidad se alcanza sólo con una efectiva articulación entre la docencia y la investigación, para crear un ambiente de innovación y creatividad. (Universidad de Sonora, 2017, p. 66)

La innovación sería el vehículo para generar esos cambios en el sistema educativo universitario actual, siendo necesario que los profesores superen la sobrevaloración de su experiencia subjetiva e implementen un proceso metodológico en que se enseñe enseñando (Imbernón, 2001).

Como proceso innovativo, en los últimos años se ha incorporado en el contexto curricular nacional e internacional la lógica de las competencias, modelo en que la educación superior se estructura bajo una mirada integral del conocimiento, por niveles, acentuando la formación transversal de los estudiantes e incorporando formatos y estrategias de enseñanza distintos a los utilizados tradicionalmente. El modelo de competencias no es nuevo en su sentido más básico, y puede ser rastreado en la filosofía Platónica y Socrática. (Tobón, 2006, p.57)

Mientras que la Organización para la Cooperación y el Desarrollo Económico (OCDE, 2017), describe que la elección del método de proyectos tuvo lugar teniendo en cuenta, principalmente, los nuevos planteamientos de la reforma educativa basada, como principal eje, las competencias básicas. Como se puede observar en las tres grandes categorías que estableció de las competencias básicas: 1) utilizar instrumentos de forma interactiva, 2) interactuar en grupo heterogéneos y, 3) actuar de forma autónoma.

\section{Vinculación de competencias profesionales con el medio externo}

En opinión de Peluffo (2010): 
En la actualidad una de las transformaciones más evidentes en el ámbito de la gestión universitaria es la vinculación con el medio externo, a tal punto que se ha transformado en una dimensión a evaluar por los sistemas de acreditación institucional nacionales [...] En ese sentido, hay que innovar en el modo de hacer las cosas, y quienes mejor conocen esa realidad son los expertos o aquellos con mayor experiencia en las [Instituciones de Educación Superior] IES. (p. 44)

Schwartzman (2009) menciona que los actuales desafíos de las universidades en América Latina son: 1) bajar la tasa de deserción y reprobación, 2) mejorar la vinculación con el sector público y sector privado, 3) mejorar la empleabilidad de los egresados, 4) mejorar la vinculación de la educación universitaria con la educación (técnica) media, 5) aumentar la eficiencia y eficacidad de la formación universitaria, 6) internacionalizar la oferta académica, 7) aumentar la flexibilidad, actualización y cambio de los diseños curriculares de las carreras y 8) aumentar la calidad, equidad y relevancia de la oferta académica.

\section{Metodología}

En el presente estudio se consideró a dos de los programas de talleres que se ofrecen en la Licenciatura en Sistemas Administrativos de la Universidad de Sonora, Campus Santa Ana, con tendencia hacia el desarrollo de proyectos, mismos que coadyuven a la integración de la docencia, investigación y vinculación mediante experiencias de aprendizajes y competencias adquiridas para los estudiantes, así mismo, el objetivo de la investigación descriptiva fue obtener información sobre experiencias de aprendizaje y competencias adquiridas, utilizando metodología de proyectos mediante talleres impartidos anualmente. Los períodos analizados fueron del 2015-1 al 2018-2.

\section{Determinación de la muestra}

El universo del estudio constó de 131 estudiantes que han cursado los talleres de proyectos de Inversión y de proyectos Integradores durante los períodos 2015-1 al 2018-2, de los cuales solo 73 estudiantes participaron en ferias anuales de Creatividad y/o Certamen Búho Innova-T, en los 
períodos: 2015-2 (36), 2016-2 (25), 2018-1 (12). Del universo total, se excluyeron a 40 estudiantes que no pudieron participar por no haberse convocado a certamen en el período 2017-2 (31), más 9 estudiantes del período 2018-1 que por razones laborales no lograron concursar, pero que sí cursaron ambos talleres y elaboraron proyectos. Cabe destacar que en el semestre actual 2018-2 participan en proyectos 18 estudiantes en el Taller de Proyectos Integradores, por lo que están en proceso de presentarse nuevos resultados.

\section{Fases que incluye el Proceso de E-A por proyectos}

El presente estudio sobre experiencias de aprendizaje aborda las actividades para desarrollar el método de proyectos, el cual incluye las siguientes fases:

- Fase I. Naturaleza y categorías de proyectos. En el Taller de Proyectos de Inversión, la estrategia que se utiliza es inicialmente aplicar una dinámica de generación de ideas de proyectos mediante técnica delphi y consenso por equipos de trabajo, se explica la investigación documental para el desarrollo de metodología (análisis administrativo, de mercado, técnico y financiero, etc.) que se basa en el manual para desarrollo de proyectos elaborado para apoyar a los participantes; se sigue con la elaboración de anteproyecto concentrado en ficha técnica; se consultan en sitios electrónicos otros modelos apegados a la naturaleza del proyecto a realizar con el objeto de comparar evidencias innovadoras en el tema; se elabora cuestionario para aplicar encuesta con el objeto de analizar viabilidad administrativa, técnica, de mercado y financiera (en su caso) o de implementar proyecto productivo, de consultoría u otra categoría; se elabora prototipo del proyecto para exponer las experiencias desarrolladas durante la primer fase del taller. En cada una de las actividades anteriores se van evaluando los proyectos por rúbricas, observación, avances en línea, investigación documental y de campo, y el desarrollo de competencias en el aula, mediadas por la instructora con observaciones y apoyo en cada fase, a fin de motivar a que los estudiantes puedan posteriormente concursar el proyecto y no solo consideren una materia para pasar la clase.

- Fase II. Seguimiento de elaboración de proyectos. Se imparte el Taller de Proyectos Integradores, en el cual se da seguimiento a los avances según metodología aplicada, además 
de adecuar cambios a los que se exige por los términos de referencia de la convocatoria para concursar en la Feria de Creatividad y/o Certamen Búho Innova-T; se imparte adicionalmente un taller de metodología canvas (lienzo de negocios) y se elaboran videos de la producción de proyectos, se ensayan a los participantes mediante exposición de proyectos finalistas, se procede a inscribirse en la convocatoria de la feria, evento que se celebra anualmente en la Universidad de Sonora. Cuando son seleccionados los proyectos se organizan las gestiones para apoyar su presentación, se organiza el viaje, se presentan los proyectos y, en caso de ser ganadores, queda a decisión de los participantes dar seguimiento de implementación al plan de negocios, productivos, consultoría, etc.

En la Tabla 1, se muestra un cronograma Gantt de la secuencia de actividades y fases de los talleres impartidos anualmente. En ambas fases del proceso se culmina con la evaluación de los participantes y la instructora procede a registrar nuevos proyectos con nuevos alumnos que deben llevar ambos talleres.

\section{Tabla 1. Cronograma Gantt de Talleres de proyectos}

\section{Actividades}

FASE I. Naturaleza y Categorías de Proyectos:

Taller de Proyectos de Inversión (Metodología)

Dinámica Generación de Ideas (Técnica Delphi)

Investigación documental (Manual de Proyectos)

Elaboración de Anteproyecto (Ficha Técnica)

Consulta electrónica de modelos de innovación

Elaborar Cuestionarios y aplicación de Encuestas

Analizar resultados de viabilidad: Administrativa, Técnica, Mercado y Financiera del proyecto

Elaborar Prototipo y Exposición del Proyecto 
FASE II. Naturaleza y Categorías de Proyectos:

Taller de Proyectos Integradores (Metodología)

Convocatoria Feria Creatividad (Términos Referencia)

Taller de Metodología Canvas (Lienzo de Negocios)

Elaboración de Videos sobre producción de proyectos

Ensayo de participantes por proyectos en el aula

Inscripción en Convocatoria de la Feria de Creatividad

Gestión de apoyos a participantes en Feria Creatividad

Organizar viaje a la Feria de Creatividad y Vinculación

Presentar proyectos seleccionados en Feria Creatividad

Seguimiento a proyectos: plan negocios, productivos, consultoría, científicos-tecnológicos, culturales, etc.

Registros de nuevos proyectos (VIII y IX Semestre)

Fuente: Elaboración propia, adaptado de Ortega (2015).

Instrumento de medición y aplicación de encuesta

Se utilizó como instrumento un cuestionario diseñado por Ortega (2015), que incluye ocho interrogantes, de los cuales dos apartados contuvieron escalas de Likert con 26 ítems, cinco preguntas fueron de opción múltiple para evaluar las opiniones $y$, finalmente, hubo una pregunta abierta con el objeto de valorar las experiencias de los encuestados. La encuesta tuvo como objetivo obtener información sobre experiencias de aprendizaje y competencias adquiridas por los estudiantes participantes en talleres de proyectos anuales. Se aplicó por la vía personal y otra parte en línea mediante redes sociales; cualquier duda fue atendida inmediatamente y de esa forma se obtuvo la información necesaria.

Los resultados permitieron evaluar actitudes y grado de conformidad de los encuestados, cuestionándoseles respecto al trabajo realizado en ambos talleres y los productos realizados mediante proyectos finales, además de emitir su propia valoración del proceso de enseñanzaaprendizaje que se haya tenido en cada una de las fases de su desarrollo, el valor que asignaron los estudiantes a su formación integral universitaria, percepción acerca de sus experiencias de 
aprendizaje por proyectos, desarrollo de competencias y habilidades, el uso de tecnologías y de su propia experiencia en la participación de Ferias de Creatividad y Vinculación Universitaria y/o Certamen Búho Innova-T.

\section{Resultados}

Según los resultados obtenidos de las encuestas aplicadas a 131 estudiantes, los cuales participaron en talleres de proyectos en el aula impartidos en la Universidad de Sonora, Campus Santa Ana, se tomó en cuenta que en los períodos 2015-1 al 2018-2, el 17\% lo representan los estudiantes que han cursado el Taller de Proyectos Integradores, el $28 \%$ los que cursaron solo Talleres de proyectos de inversión y, los estudiantes que cursaron ambos talleres se representa con el $54 \%$ (figura 1 ).

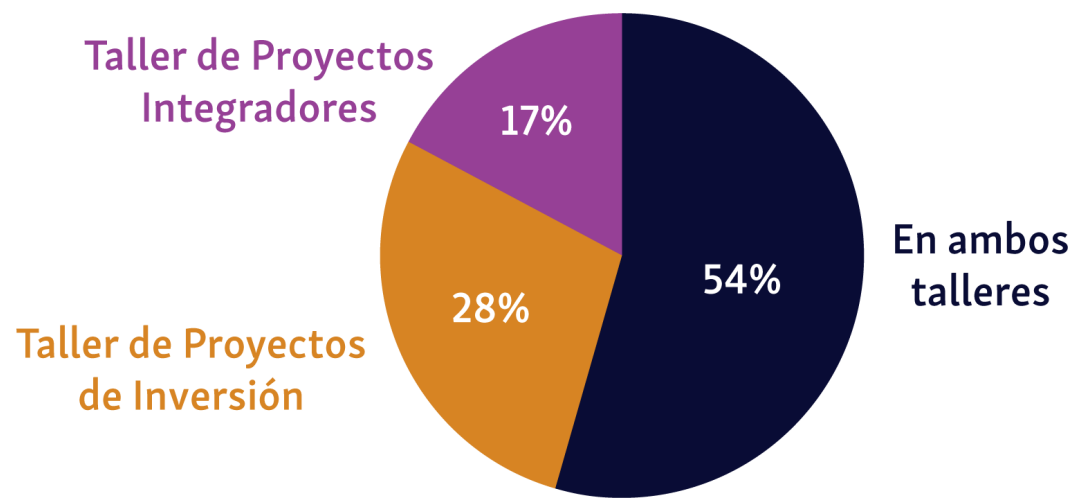

Figura 1. Talleres en los que han participado los estudiantes que conforman la muestra.

Respecto a la valoración de los encuestados sobre los aspectos que son estimulados mediante el trabajo por proyectos, cabe mencionar que en su mayoría los estudiantes que ya participaron han tenido experiencias gratas de haber sido seleccionados y ganadores en diferentes convocatorias de la Feria de Creatividad y Vinculación Universitaria y/o Certamen Búho Innova-T, así mismo, el $64 \%$ consideran que aprender a realizar proyectos, motivan su actividad profesional debido a que algunos ya han adquirido una visión global y madura del mercado de trabajo, porque han logrado comprender la metodología y bases para realizar un plan de nego- 
cios o proyecto mediante la enseñanza adquirida en esos talleres; el $21 \%$ consideró que le motiva en lo personal realizar proyectos, el $6 \%$ opinó que en lo cultural, el $9 \%$ en lo social y en otros aspectos ninguno opinó sentirse desmotivado (figura 2).

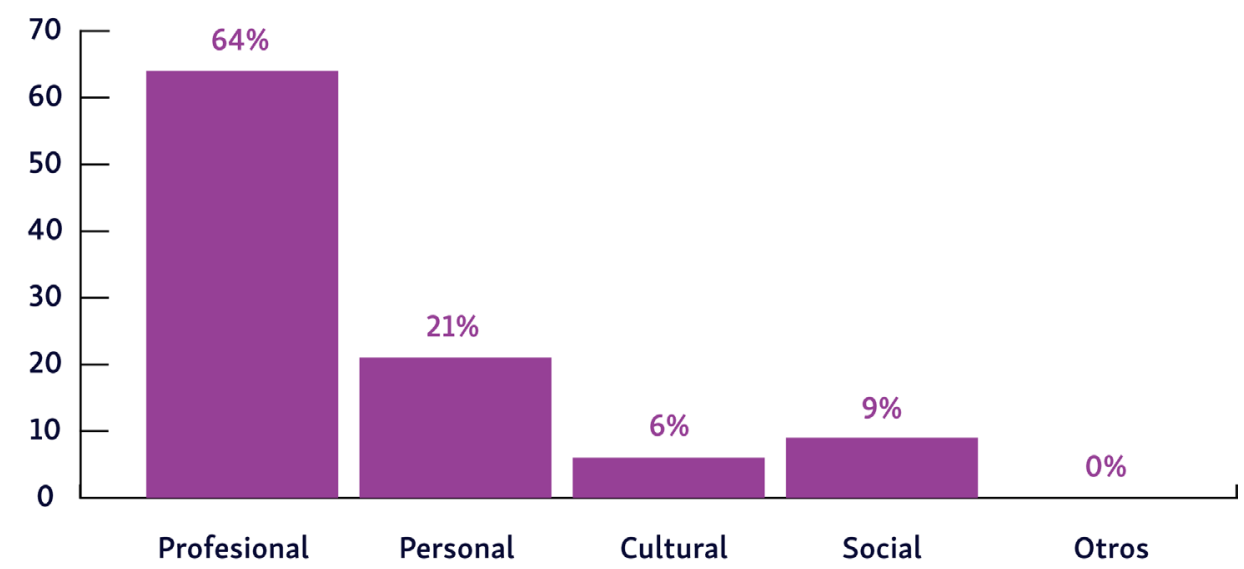

Figura 2. Aspectos que son estimulados mediante el trabajo por proyectos.

En el marco de la teoría constructivista, los proyectos se consideran una propuesta metodológica a desarrollar en el aula que permite incorporar los aprendizajes a la solución de un problema y a partir de un plan, que permitan a los estudiantes no solamente adquirir conocimientos, sino también habilidades y actitudes. El presente estudio revela que, en una escala de 5 a 10 puntos, las calificaciones que los encuestados consideraron respecto a sus experiencias de aprendizaje, por medio de actividades desarrolladas en el aula universitaria fueron: aplicar Técnica Delphi (9.65), Elaborar prototipo y exponer sus ideas de proyecto (incluyendo videos) (9.45), así como su presentación final en la Feria de Creatividad y Vinculación Universitaria (9.1); Comparar distintos tipos de proyectos (9.3); saber utilizar metodología o lienzo de negocios Canvas (9.35), elaborar ficha técnica del proyecto (9.1), saber realizar un resumen ejecutivo (9.3), utilizar manual de proyectos (9.1); aprender a diseñar cuestionarios y aplicar encuestas (9.0), consultar modelos de innovación (9.2) y determinar el análisis de viabilidad del proyecto en sus diferentes fases: Administrativo, Técnico, de Mercado, Legal y Financiero (8.85) (figura 3). 


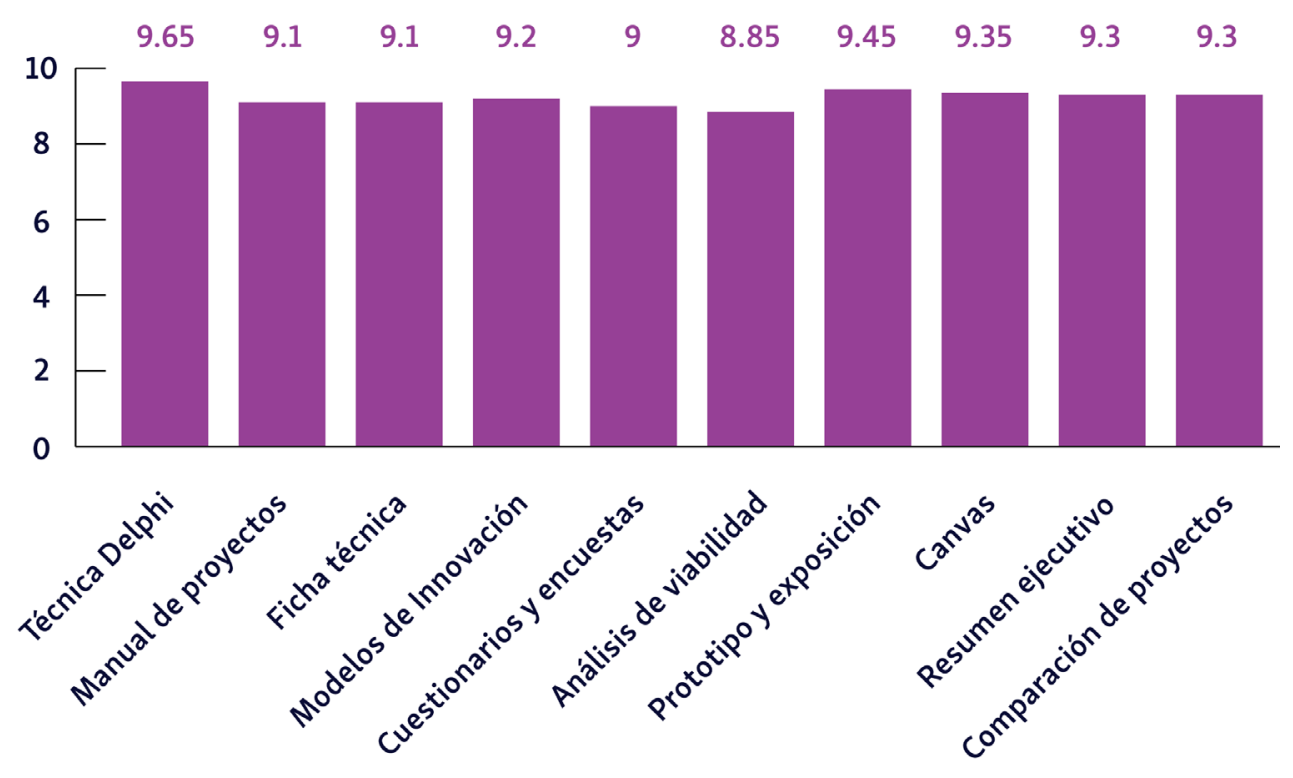

Figura 3. Calificación de experiencias de aprendizaje proporcionada por las actividades desarrolladas en el aula.

A partir de las estrategias utilizadas por el docente en proyectos-aula, los alumnos pueden desarrollar competencias (conocimientos, habilidades y actitudes), que les permiten desenvolverse de mejor manera, no sólo en el ámbito académico, sino también en el social. Se les pidió que indicaran qué calificación otorgarían respecto al desarrollo de sus competencias y habilidades. En una escala de valor de 5 a 10 puntos, los estudiantes otorgaron el máximo valor a la actividad de Aprendizaje por proyectos (9.7); descubrir Nuevos conocimientos (9.6), practicar Ética profesional (9.5), Mejorar su autoestima (9.4), desarrollar la Comunicación oral y escrita (9.3), ser Creativos (9.3), aprender a Investigar (9.4), fomentar la Responsabilidad (9.3), habilidad para Autoaprendizaje y practicar la Tolerancia (9.2), practicar habilidades de Liderazgo (9.1), el Trabajo a desarrollar por Equipo (9.1), tener Espíritu de servicio (9.0) y, finalmente, la Solución a problemas de aprendizaje (8.8). Aunque la calificación respecto al desarrollo de competencias $y$ habilidades adquiridas por los estudiantes no es baja, es necesario indicar que el docente deberá trabajar continuamente en esas actividades y en algunas otras metodologías y técnicas educativas (figura 4). 


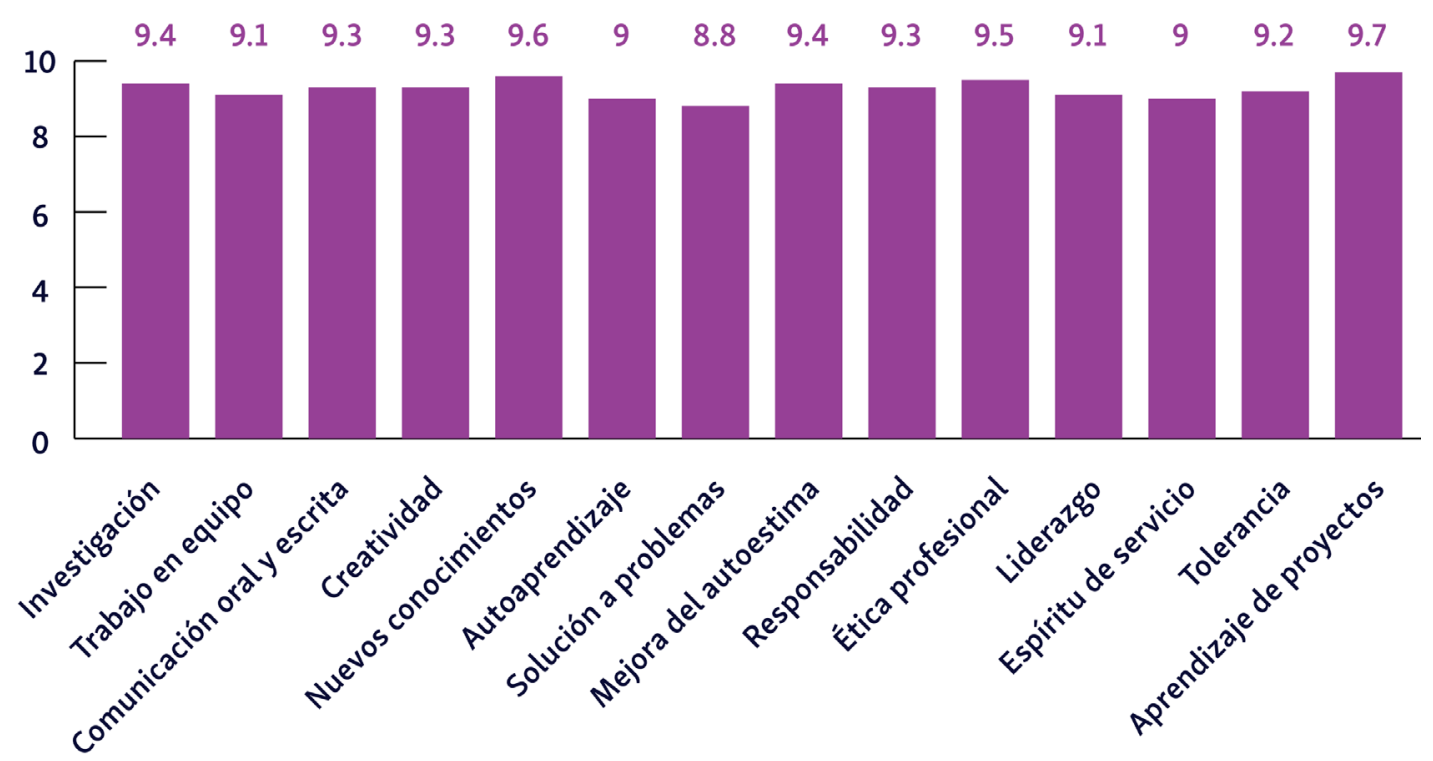

Figura 4. Calificación respecto al desarrollo de competencias y habilidades.

Respecto a la percepción sobre, si lo aprendido tendría aplicación en el desempeño laboral de los estudiantes, el $87 \%$ contestó estar totalmente de acuerdo, el $9 \%$ estuvo solo de acuerdo, el 4\% opinó que tal vez (figura 5); según estudios de Tippelt y Lindemann (2001), el desarrollo de competencias humano-sociales, metodológicas y profesionales, así como la vinculación con el campo profesional se manifiesta a través del aprendizaje por proyectos, por lo que es necesario que mediante actividades de docencia-investigación y vinculación, el estudiante

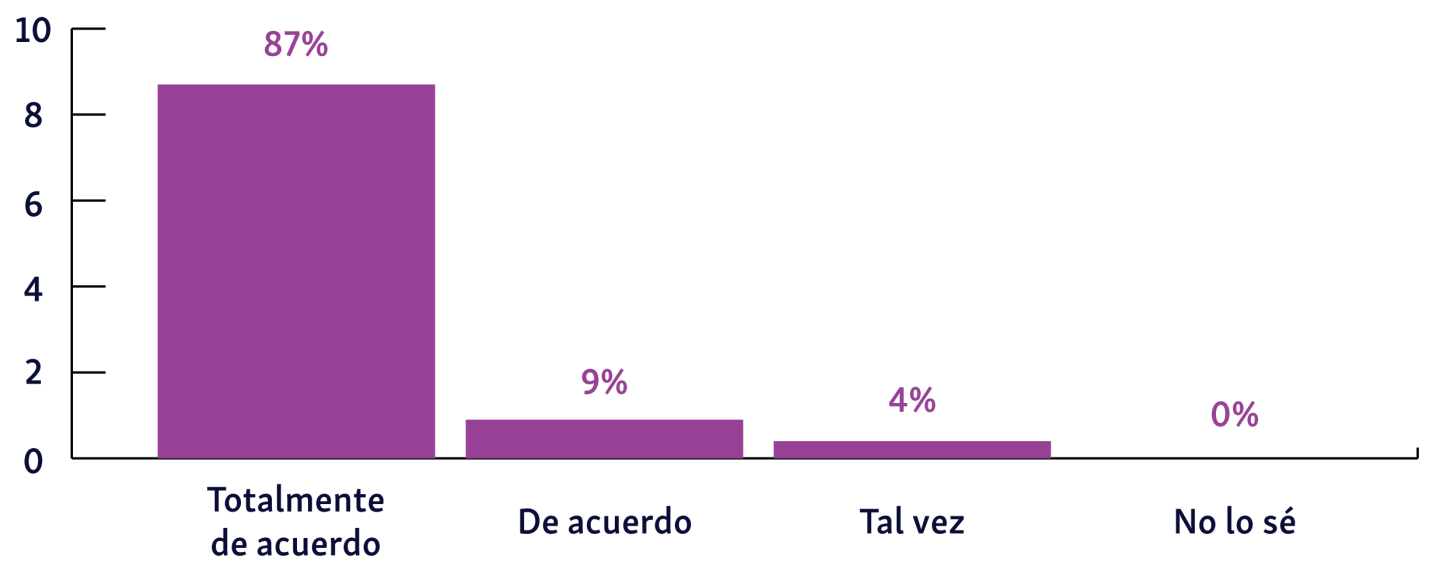

Figura 5. Calificación respecto al desarrollo de competencias y habilidades. 
pueda ser preparado con mejores estrategias educativas que les permita aprender a aprender, y esto puede ser posible con el aprendizaje por proyectos en el aula.

La universidad se ve directamente afectada por cambios en el mundo del trabajo, en la tecnología y en el mundo del conocimiento debido al producto del desarrollo científico, en la cual es necesario asumir el rol de docencia, con metodologías y estrategias que ayuden a desarrollar la investigación y vinculación con la sociedad que demanda los servicios de educación superior (Gómez y Célis, 2004). Al respecto, se interrogó sobre cómo valoraban los estudiantes la integración de la docencia-investigación-vinculación por el manejo de proyectos de aula: el $86 \%$ siempre veían ejemplos de los tres elementos cuando realizaron su proyecto, el $10 \%$ opinó que regularmente, el $1 \%$ que a veces y nadie mencionó que nunca lograba comprender la integración de los elementos; lo cual supone que si el alumno se motiva a aprender e interesarse por elaborar proyectos, ese $1 \%$ restante puede ser menor, siempre y cuando se automotive 0 , bien, se le ayude a cambiar su percepción negativa y se le estimule a trabajar más en equipo, o en actividades que le favorezcan más en su estilo de aprendizaje (figura 6).

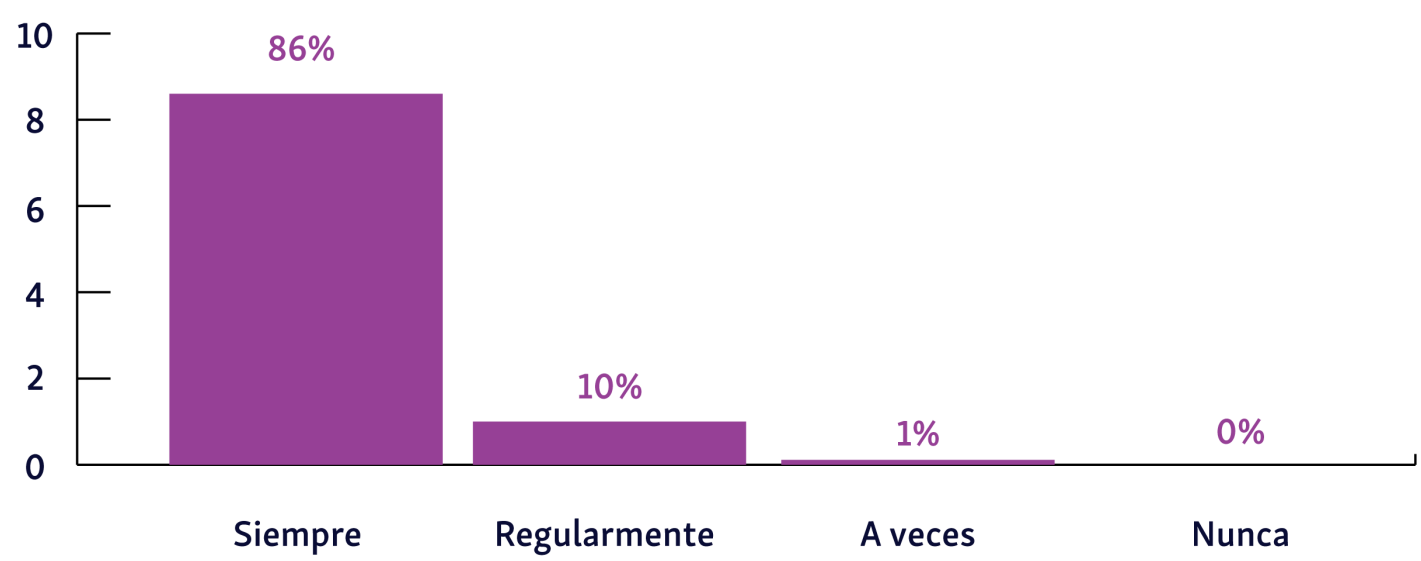

Figura 6. Calificación respecto al desarrollo de competencias y habilidades.

De las ocho preguntas del cuestionario, dos fueron sobre el uso de tecnologías en el aula y experiencias de los estudiantes. En relación al tipo de tecnología para la elaboración de los proyectos en el aula, se les pidió a los estudiantes que indicaran del 1 al 3 la frecuencia en que utilizaban la tecnología, los resultados fueron: uso del correo electrónico (2.5), modalidad 
virtual (1.6), manejo de Word y Excel (2.8), plataforma virtual (1.6), uso de videos (2.5). Estos resultados permiten identificar que en el diseño y aplicación del proyecto-aula en ambos talleres impartidos, estuvieron presentes los recursos tecnológicos.

En la interrogante final de la encuesta se les preguntó: ¿Qué experiencias (positivas o negativas) valoraste el haber participado en un Concurso de la Feria de Creatividad y Vinculación Universitaria y/o o Certamen Búho Innova-T? De los 73 estudiantes que participaron, los aspectos que más destacaron fueron:

- Me ha permitido lograr un mejor desenvolvimiento al interactuar con empresarios, conferencistas, docentes, poder conocer otros proyectos de participantes en diferentes categorías de trabajos y de otras licenciaturas.

- He logrado una mayor integración como equipo de trabajo, compromiso con mis compañeros al realizar actividades para la elaboración del proyecto, y poder presentarlo al público con más seguridad.

- La retroalimentación en sesiones presenciales fueron experiencias buenas para aclarar dudas y conocer la situación de los demás participantes y nuestras competencias.

- La feria de creatividad o certamen es un programa que nos motiva como estudiantes a desarrollar habilidades o iniciativa emprendedora, porque apoya con recursos para poder asistir, por lo que el rol del docente es muy importante para motivarnos a participar.

- La maestra ha sido muy paciente con los estudiantes que casi no sabemos elaborar proyectos, pero su apoyo y metodología nos impulsa a motivarnos a que aprendamos, lo realicemos, y además lo presentemos, como parte de la calificación final; nos instruye durante todo el proceso y también nos acompaña a la presentación en la feria de creatividad. Eso nos ayuda a traer premios importantes y destacar en nuestra institución universitaria.

- Haber sido ganadores en Certamen Búho Innova-T en el período 2018-1 nos ha motivado a querer aprender más en lo profesional, no solo obtener el premio de poder asistir a la Semana Nacional del Emprendedor en Ciudad de México. Son experiencias que valoramos y agradecemos a nuestra académica, por habernos inspirado a realizar proyecto para un concurso universitario, en el cual sus enseñanzas fueron la clave del éxito. 


\section{Conclusiones}

El aprendizaje por proyectos es una de las estrategias metodológicas líderes para fomentar el cambio y la mejora educativa en las últimas décadas, ya que permite al alumno enfrentarse a desafíos, trabajar con sus compañeros y docente en un entorno autónomo, pero requiere ser un proceso organizado y con un docente facilitador que sea comprometido, tenga experiencia pedagógica, asesore y evalúe durante todo el proceso educativo en la metodología para elaborar proyectos desde el aula. Los resultados más relevantes del presente estudio reflejaron que:

- Los encuestados validaron muy favorable sus experiencias de aprendizaje por medio de las diversas actividades desarrolladas en el aula universitaria, lo cual les motiva en el ámbito educativo, profesional, cultural, personal y social.

- Consideran que aprender a realizar proyectos, motiva su actividad profesional debido a que pueden adquirir una visión madura del mercado de trabajo, mediante la comprensión de la metodología y bases para realizar un plan de negocios o proyecto personal, por la enseñanza adquirida en esos talleres.

- En el desarrollo de sus competencias y habilidades (de 14 mencionadas), han logrado ubicar la mayoría planteadas en el estudio mediante el aprendizaje por proyectos y de aprendizaje colaborativo, y que pueden ser de aplicación en su desempeño laboral.

- Se logró que los estudiantes comprendieran la importancia de adquirir experiencias de aprendizaje y competencias de formación profesional mediante la elaboración de proyectos, lográndose el objetivo de la presente investigación.

- Los alumnos que trabajaron con proyectos presentaron mayor motivación, mejor relación con su maestra y abordaron temas transversales hacia otras asignaturas; ya que la mayoría de los estudiantes expresaron el haber obtenido experiencias gratas de haber sido seleccionados y ganadores en diferentes convocatorias de la Feria de Creatividad y Vinculación Universitaria, previo haber llevado los Talleres de Proyectos de Inversión y de Proyectos Integradores.

- Con los resultados obtenidos, se podrá fortalecer el perfil de egreso de los estudiantes del programa de Licenciatura en Sistemas Administrativos de la Universidad de Sonora, Campus Santa Ana, sobre todo en el área de emprendimiento. 


\section{Recomendaciones}

De la investigación se desprenden las siguientes recomendaciones:

- Que, en ambos talleres impartidos en la Unison, Campus Santa Ana, se sigan centrando en el proceso de aprendizaje crítico y colaborativo, que incida en el desarrollo de las competencias, habilidades, valores y actitudes, para que los estudiantes logren obtener una formación académica integral, de acuerdo a las necesidades de responsabilidad que la sociedad demanda.

- Extender dicha investigación a nivel institucional con el Programa de Emprendedores Universitarios (PEU-Unison), con el objeto de que se motive o apoye más a la difusión, colaboración, recursos para los estudiantes y de los docentes que facilitan la labor de enseñanza-aprendizaje a base de proyectos en el aula.

- Es necesario valorar el seguimiento al programa de emprendedores universitarios en todos los campus, con el objeto de posibilitar la motivación y participación activa de sus estudiantes en Ferias de Creatividad Universitaria o Certámenes Búho Innova-T, como se hizo en catorce convocatorias continuas hasta el período 2016-2 (cancelada en el período 2017-2) y convocada en 2018-1, en el cual se realizaron miles de proyectos universitarios.

- No debe decaer el entusiasmo docente-alumnos para seguir construyendo ambientes de aprendizaje, que conduzcan al análisis crítico-constructivo y al reforzamiento de las competencias profesionales de los universitarios que la sociedad demanda. 


\section{Referencias}

Gómez, V. y Célis, J. (2004). Factores de Innovación Curricular y Académica en la Educación Superior. Revista Ibero Americana de Educación, (33), 1-13. Recuperado de https://rieoei. org/historico/deloslectores/773Gomez.PDF

Imbernón, F. (2001). El Currículum como Campo de Intervención y Desarrollo Profesional del Profesorado. Un debate sobre la Teoría y la Práctica. Revista de Teoría, Investigación y Práctica Educativa, (10).

Organización de las Naciones Unidas para la Educación, la Ciencia y la Cultura (UNESCO). (2012). Tendencias Universidad. En pos de la educación activa. Cátedra UNESCO de gestión y política universitaria. Universidad Politécnica de Madrid, España.

Organización para la Cooperación y el Desarrollo Económicos (OCDE). (2017). Definition and Selection of Competencies. Theorical and conceptual Foudations (DeSeCo). Recuperado de http:/ /www.deseco.admin.ch

Ortega, E.A. (2015). Manual de Proyectos de Inversión. México: Universidad de Sonora.

Peluffo, M. (2010). Gestión del conocimiento tácito: buenas prácticas y lecciones aprendidas en la internacionalización universitaria. Innovación Educativa, 10(51), 43-55.

Ramírez, M. (2012). Modelos y estrategias de enseñanza para ambientes innovadores (presenciales y a distancia). México: ITESM.

Schwartzman, S. (2009). Los desafíos de la educación superior en América Latina. Asuntos del Sur. Discutiendo escenarios para América Latina. Recuperado de http://www.schwartzman. org.br/sitesimon/?p=986\&lang=pt-br

Tippelt, R. y Lindemann, H. (2001). El método de proyectos. El Salvador/Berlín: Ministerio de Educación de El Salvador. Recuperado de http://www.halinco.de/html/doces/Met-proyAPREMAT092001.pdf

Tobón, S. (2006). Formación basada en competencias. Pensamiento complejo, diseño curricular y didáctica. Bogotá: ECOE.

Universidad de Sonora (2017). Programa de Desarrollo Institucional (2017-2021). Recuperado de http://www.uson.mx/institucional/pdi2017-2021.pdf 


\section{Capítulo 10}

Diagnóstico de los factores que impactan el índice de reprobación en alumnos de educación secundaria.

Caso: Escuela Secundaria Federal en Tijuana, Baja California, México

Arabela $\operatorname{Arcos}^{1} y$ Luis Alfonso Valencia Ponce ${ }^{2}$

${ }^{1}$ Universidad Xochicalco, Campus Tijuana, México. arcoslaura@yahoo.com.mx

${ }^{2}$ Instituto Tecnológico de Tijuana, México. valencia.ponce.luis@gmail.com 


\section{Introducción}

Los jóvenes que cursan la educación básica padecen diversos problemas, uno de los más importantes es el índice de reprobación. En esta investigación, se pretendió conocer los factores que más impactan en dicho índice, a través de la aplicación de una encuesta, estructurada en cuatro segmentos, diseñada y dirigida a los alumnos de los tres grados escolares de una Escuela Secundaria Federal en la ciudad de Tijuana, Baja California, en el turno matutino. El objetivo general fue elaborar un diagnóstico de los factores con mayor impacto e identificar las causas más relevantes. Los resultados finales, vinculados a las variables, fueron obtenidos por medio del análisis e interpretación de las encuestas y con base en los resultados se propuso un modelo, dando cumplimiento a los objetivos.

\section{La calidad educativa}

La calidad educativa es la resultante sobre la conjugación de una serie de aspectos que involucra al menos "las dimensiones de pertinencia, relevancia, eficacia interna, eficacia externa, impacto, suficiencia, eficiencia y equidad" (Instituto Nacional para la Evaluación de la Educación [INEE], 2006). En ese sentido, la calidad educativa en la educación básica implica que todos aquellos que reciban los servicios educativos, brindados en cualquier nivel o modalidad, alcancen los aprendizajes que deban lograr en los periodos y con los recursos programados para ello y que lo hagan íntegramente para su desarrollo personal, familiar y social.

\section{Antecedentes del índice de reprobación en México}

Para la prueba estandarizada ENLACE 2012 , se evaluaron a 6,785 alumnos de 2,149 escuelas secundarias. Español fue el área con menor avance en el lapso del 2006 al 2012, pues apenas crecieron siete puntos porcentuales en los resultados de todo el sexenio. En matemáticas, el $77.6 \%$ de los adolescentes que cursan de primer a tercer año de secundaria se ubicaron con niveles insuficientes y elementales, y sólo el $22.4 \%$ aprobaron la materia. Los resultados apenas

1 "La Evaluación Nacional de Logro Académico en Centros Escolares (ENLACE) es una prueba del Sistema Educativo Nacional que se aplica a planteles públicos y privados del País (Secretaría de Educación Pública [SEP], 2014). 
son mejores cinco puntos porcentuales respecto al año previo, cuando presentaron deficiencias el $82.9 \%$ de los evaluados. En Puebla, sólo el $20.1 \%$ de los alumnos de secundaria obtienen resultados positivos en español, mientras que el restante $79.9 \%$ (es decir, 8 de cada 10) se ubican en niveles insuficientes y elementales en la materia, según se desprende de los datos de la Evaluación Nacional de Logro Académico en Centros Escolares (Alfaro, 2012).

\section{Estudio de caso}

La Escuela Secundaria Federal (ESF), localizada en la ciudad de Tijuana, Baja California, se encuentra dentro del Programa de Escuelas de Calidad (PEC) ${ }^{2}$ de la Secretaría de Educación Pública (SEP), cuyo objetivo es contribuir a la mejora educativa con los alumnos de escuelas públicas de educación básica, en donde la cifra máxima de índices de reprobación para esta Institución es del 6.2\%, de acuerdo con los datos proporcionados por el Titular de la ESF. Así, también informó que los números de esta escuela secundaria en el año 2010 fue del 14.3\%, en el 2011 del 16.1\% y en 2012 del 19.3\%; se observa un índice de reprobación al alza, manteniéndose muy por encima del promedio de las escuelas de la región (6.2\%), lo cual representa un foco de atención y, por lo tanto, se plantea la importancia de identificar los factores que causan esta situación.

\section{Objetivos}

Ante el panorama anterior, el objetivo general del estudio fue "Elaborar un diagnóstico de los factores que impactan el índice de reprobación de los alumnos de la Escuela Secundaria Federal en la ciudad de Tijuana, Baja California, del turno matutino, ciclo escolar 2012-2013 con el propósito de identificar las causas y prever una futura deserción escolar".

Se definieron los siguientes objetivos específicos:

1. Identificar en qué grados escolares se presenta el mayoríndice de reprobación de alumnos.

2. Identificar cuáles son las materias donde se ubica el mayor índice de reprobación de los alumnos.

2 Este programa surge en el ciclo escolar 2001-2002 como una iniciativa de reforma para superar los diversos obstáculos para mejorar el logro educativo en los alumnos de las escuelas públicas de educación básica, mediante la transformación de la gestión educativa (SEP, 2015). 


\section{Diseño de la investigación}

La presente investigación cuenta con un enfoque de tipo cualitativo, ya que se espera identificar los factores a los que se les atribuye el incremento del índice de reprobación de los alumnos de la Escuela Secundaria Federal. El estudio cuenta con un alcance explicativo, donde se analizarán y explicarán las causas del porqué reprueban los alumnos, tomando en cuenta factores tales como: familia, educación, salud y diversión. A continuación, se presenta el diseño del estudio, basado en la metodología del ciclo de mejora continua "Planificar-Hacer-Verificar-Actuar" conocido como "Ciclo de Deming" ${ }^{3}$ mostrando el desarrollo del estudio en las siguientes etapas:

- Etapa 1. Planear. Se estableció una entrevista con la directora de la escuela para obtener información y datos de las generaciones 2010-2012, para identificar qué porcentaje de los alumnos han reprobado. Con el propósito de determinar cuáles son las materias que cuentan con mayor índice de reprobación y en qué grado.

- Etapa 2. Hacer. Se diseñó como instrumento un cuestionario dirigido a los alumnos de los tres grados escolares que se encuentran actualmente (2012) estudiando, con el propósito de saber cuáles son los motivos que han influenciado en la reprobación de materias.

- Etapa 3. Control estadístico de procesos. Se tabularon los resultados de la aplicación de la encuesta a los alumnos mediante gráficas, con el propósito de obtener información de los factores que impactan los índices de reprobación.

- Etapa 4. Actuar. Se llevó a cabo una reunión con los directivos y profesores con el propósito de informar resultados obtenidos mediante la determinación de un diagnóstico de los factores que impactan el índice de reprobación.

\section{Sujeto de estudio}

Se seleccionó a los alumnos de primero, segundo y tercer año, del turno matutino de las generaciones 2010 al 2012 de la Escuela Secundaria Federal "Belisario Domínguez", en Tijuana, B.C.

3 Basado en un concepto ideado por Walter A. Shewhart, e impulsado por Edwards Deming (García, Quispe y Páez, 2003). 


\section{Instrumento}

El instrumento utilizado fue un cuestionario, conformado por un total de 30 preguntas, dividido en cuatro segmentos: salud, familia, educación y diversiones.

La validez del instrumento se realizó con una prueba piloto con la aplicación de seis cuestionarios a los alumnos de los tres grados escolares: dos a primero, dos a segundo y dos a tercero, con el fin de detectar posibles errores en la redacción y en la forma de responder a cada reactivo, obteniendo como resultado de esta prueba piloto dos preguntas del segmento educación que ocasionaron confusión en sus respuestas. Tales preguntas fueron replanteadas para una mejor comprensión y facilidad del lector. Y después, el instrumento se aplicó al total de la muestra (289 alumnos, representando el $43 \%$ del universo).

\section{Análisis e interpretación de los resultados}

De acuerdo a los resultados, el 32\% de los alumnos de primer grado ha reprobado alguna materia; de los alumnos de segundo, el 35\% y de los alumnos de tercer grado, el 32\%. Es decir, el índice de reprobación es mayor en el segundo año.

En relación con lo anterior, como se observa en la figura 1, Matemáticas es la materia con mayor índice de alumnos reprobados en los tres grados.

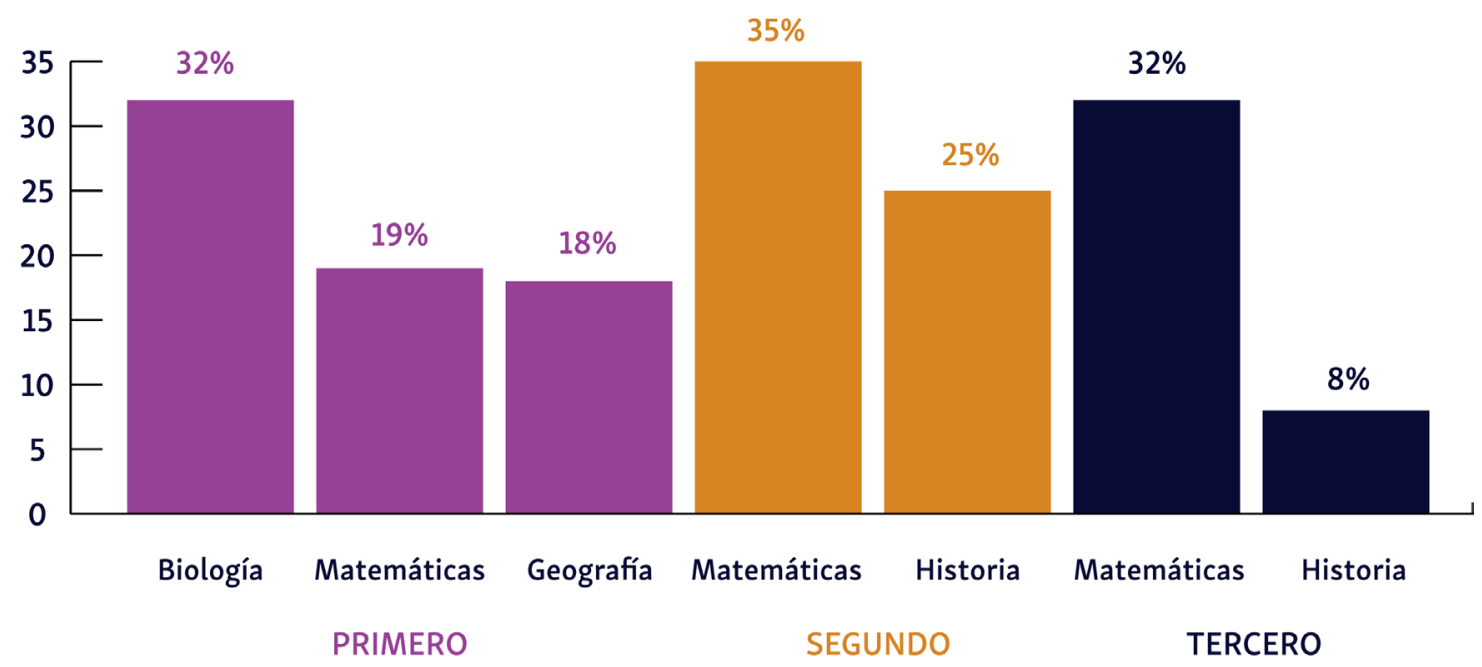

Figura 1. Materias más recurrentes en reprobación. 
El índice de reprobación se ve afectado principalmente, de acuerdo a la variable Educación, por no poner atención en clase y el estado de ánimo. Se puede observar que, al acercarse el final de su educación secundaria, los alumnos estudian, pero no saben por qué lo hacen. Asimismo, se puede observar que, de acuerdo a la variable Diversiones, el tiempo que destinan los alumnos a la comunicación afecta significativamente este índice, dejando poco tiempo a estudiar. También, la utilización de equipos de comunicación en clase es recurrente en los tres grupos de alumnos de secundaria.
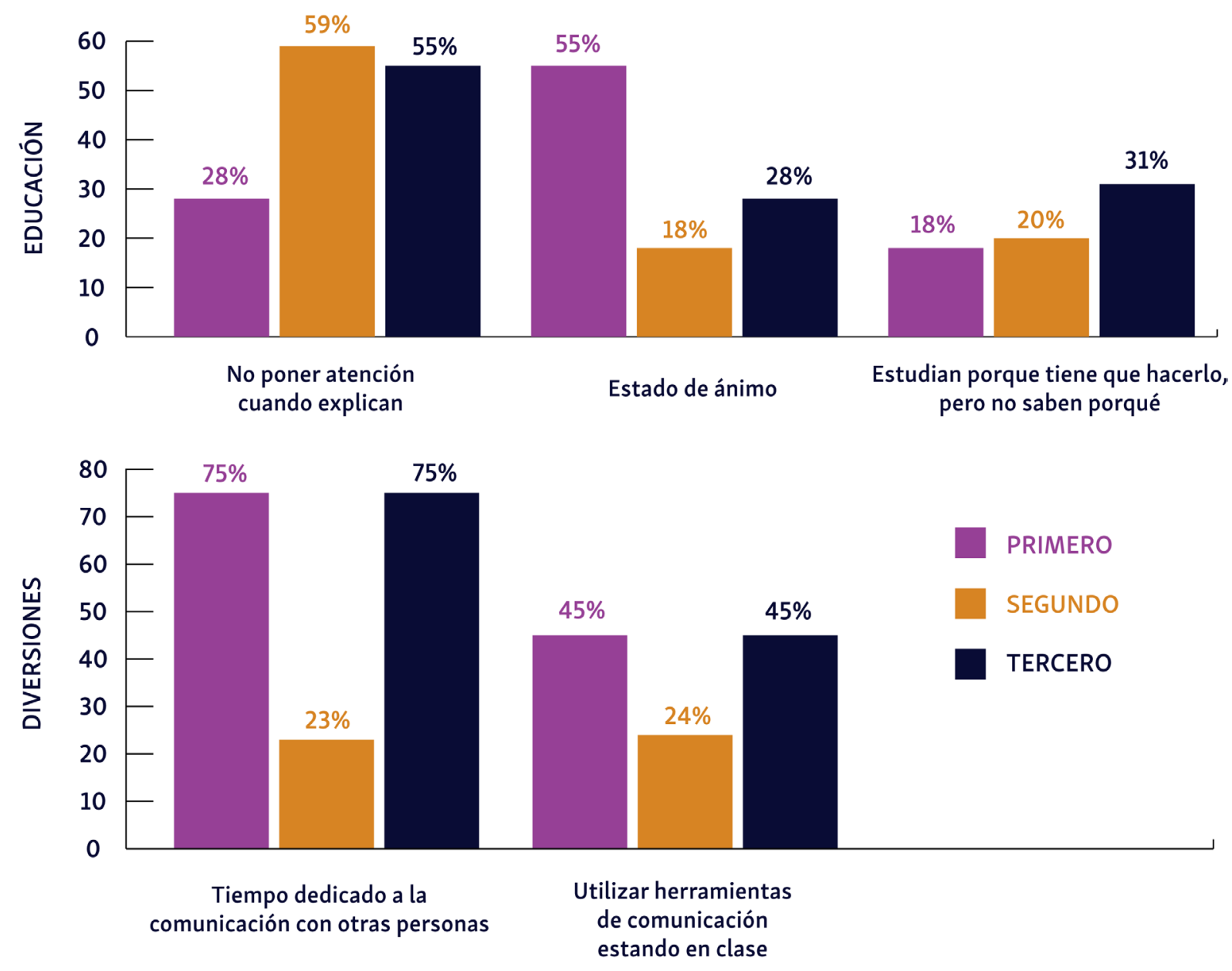

Figura 2. Resultados vinculados a Educación y Diversiones. 
De acuerdo con los resultados del análisis e interpretación de la información se estructuró un diagnóstico preliminar de las causas que involucran la situación problemática del incremento del índice de reprobación de los alumnos de la Escuela Secundaria Federal, mediante el desarrollo de un Esquema de Ishikawa ${ }^{4}$ como se muestra en la figura 3.

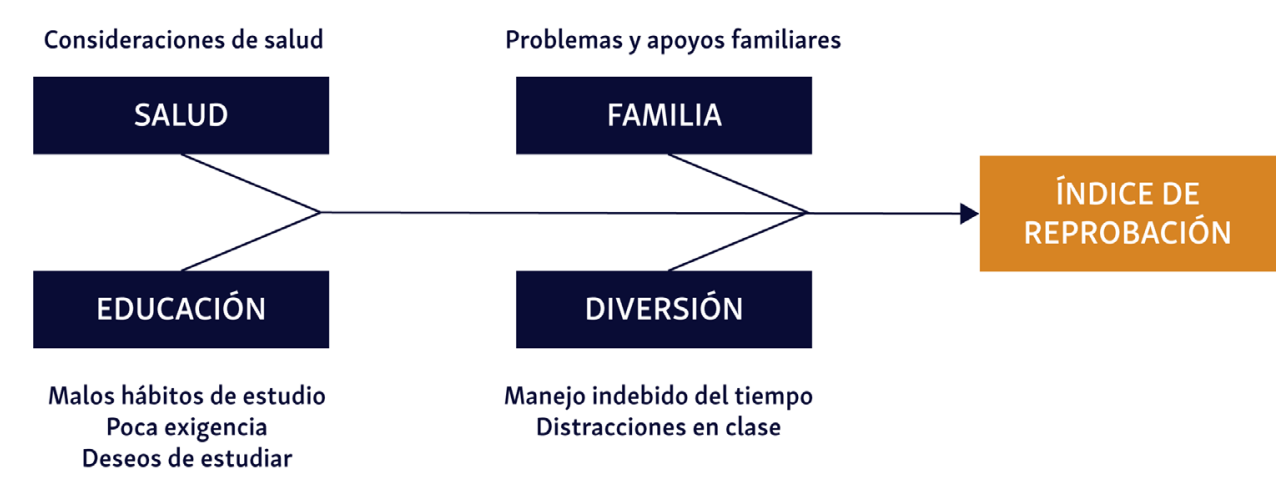

Figura 3. Factores que intervienen en los índices de reprobación. Fuente: Elaboración propia.

\section{Conclusiones y recomendaciones}

A continuación, se presentan las conclusiones que se determinaron derivadas del análisis e interpretación de los datos, en donde los factores que impactan el índice de reprobación en los alumnos de educación secundaria caso particular Escuela Secundaria Federal "Belisario Domínguez" son los siguientes:

Los mayores porcentajes se encontraron en los segmentos Educación y Diversiones. En el primero, se detectó que los alumnos refieren no poner la debida atención en clase, asimismo, mencionan que el estado de ánimo influye en el aprovechamiento y aprendizaje de las materias. En el segundo, se detectó que los alumnos dedican el mayor tiempo a la diversión y esparcimiento, dentro y fuera de las aulas de clase, debido a los medios de comunicación y tecnológicos que hoy en día los jóvenes tienen acceso.

$4 \quad$ Kaoru Ishikawa (Japón, 1915-1989), teórico japonés de la administración de empresas, experto en el control de calidad. Se le considera el padre del análisis científico de las causas de problemas en procesos industriales, dando nombre al diagrama Ishikawa, cuyos gráficos agrupan por categorías todas las causas de los problemas (Hernández, 2009, p. 4). 
En cuanto a la determinación de los hallazgos es importante considerarlos ya que son preocupaciones que exteriorizan los alumnos en esta etapa de su vida. Con el propósito de mejorar la atención de los alumnos en clase y mejorar el nivel de aprobación en las materias, se recomienda el siguiente modelo:

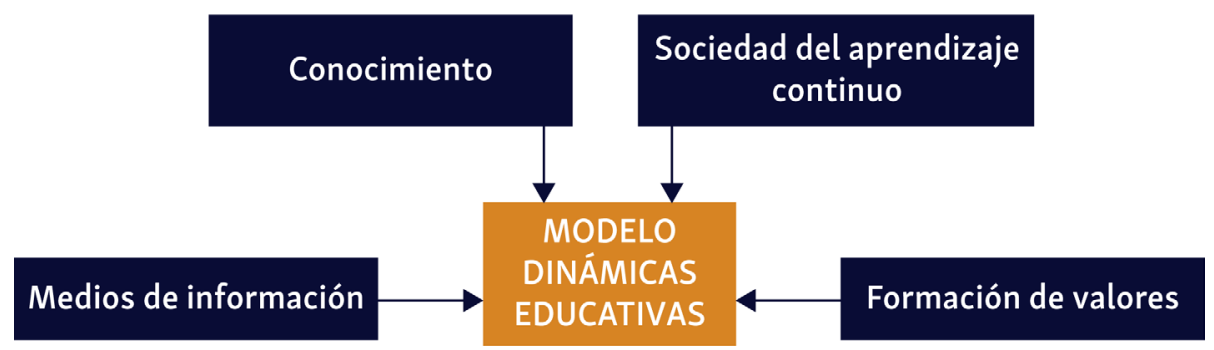

Figura 4. Factores que intervienen en los índices de reprobación. Fuente: Elaboración propia.

Se puede apreciar un modelo de dinámicas basado en los resultados del diagnóstico de la investigación, donde el centro de la estructura está rodeado por los siguientes elementos: Medios de información. De acuerdo con los avances tecnológicos el docente puede hacer uso de estas herramientas para un mejor aprovechamiento de los alumnos y encaminarlos al buen uso de éstas en el aula, desarrollando creatividad en los adolescentes.

- Conocimiento. En los jóvenes de nivel secundaria se debe promover la creatividad y el conocimiento de manera significativa, fomentando actividades de superación y retos mediante concursos de comprensión con un nivel epistemológico, estableciendo para cada una de ello altas expectativas y alentando al alumno a realizar siempre el máximo esfuerzo.

- Sociedad del aprendizaje continuo. Proponer reuniones o redes de estudio adicionales en las materias básicas que más inciden en los índices de reprobación como son: Matemáticas, Biología, Español y Geografía.

- Formación de valores. La adopción de valores en el nivel de educación secundaria dentro del aula por parte del docente, es de vital importancia en la formación y desarrollo de futuros ciudadanos íntegros, beneficiando a la sociedad y sectores productivos con valores como la honestidad, integridad, responsabilidad, lealtad y respeto, reflejando personas con una calidad humana, con un alto sentido de compromiso hacia los demás. 


\section{Referencias}

Alfaro, A. (2012). ENLACE: en Puebla, 70\% de alumnos de básica con resultados "insuficientes". La Jornada de Oriente. Recuperado de http://www.lajornadadeoriente.com.mx/noticia/ puebla/enlace-en-puebla-70-de-alumnos-de-basica-con-resultados-insuficientes_ id_12801.html

García, M., Quispe, C. y Paéz, L. (2003). Mejora continua de la calidad en los procesos. Notas científicas, 6(1), 89-94.

Hernández, G. (2009). Calidad de la educación media superior en México. Cuadernos de Educación y Desarrollo, 1(5). Recuperado de http://www.eumed.net/rev/ced/05/ghs.pdf

Instituto Nacional para la Evaluación de la Educación (INEE). Plan Maestro de Desarrollo 20072014. Ciudad de México: INEE.

Secretaría de Educación Pública (SEP). (2014). ¿Qué es ENLACE? Recuperado de http://www. enlace.sep.gob.mx/que_es_enlace/

Secretaría de Educación Pública (SEP). (2015). Programas Escuelas de Calidad. Recuperado de https://www.gob.mx/sep/acciones-y-programas/programas-escuelas-de-calidad. 


\section{PARTE IV POLÍTICA SOCIAL Y AMBIENTAL DE LA EMPRESA}




\section{Capítulo 11}

Paradigmas sobre la problemática de los Residuos Ambientales Eléctricos y Electrónicos (RAEE)

Berenice Citlalli Cárdenas Aragón ${ }^{1}$ y Rosalinda Gámez Gastélum²

${ }^{1}$ Universidad Autónoma de Sinaloa, México. berenice.cca81@gmail.com

2 Universidad Autónoma de Sinaloa, México.rosalinda.gamez@uas.edu.mx 


\section{Introducción}

En este capítulo se abordan tres de los paradigmas que sustentan las propuestas de estrategias para enfrentar la problemática Residuos Ambientales Eléctricos y Electrónico (RAEE): el desarrollo sustentable, la responsabilidad extendida del productor y la educación ambiental. También se presenta el consumismo y la obsolescencia programada como posibles causas del incremento de dichos residuos. Además, se presenta el análisis descriptivo de la encuesta RAEE-CLN 2016, en cuanto a la conducta del uso y desuso de los electrónicos.

\section{Desarrollo sustentable en el manejo de los RAEE}

A partir del informe Nuestro Futuro Común, el desarrollo sustentable comienza a constituirse como un concepto central de la política y es definido como aquel desarrollo que permite satisfacer las necesidades del presente, sin comprometer la capacidad de las futuras generaciones para satisfacer las propias (González, 1995).

La generación de RAEE se puede ver como una medida de la no sustentabilidad. Los residuos representan una carga económica importante para la sociedad, pues es necesario asegurar que tengan un fin de vida adecuado. El desarrollo de mejoras ambientales en la gestión y manejo de residuos - particularmente, los considerados de riesgo para la salud y el ambiente- ha tomado relevancia en el mundo en años recientes (Mejía, Román y Beltrán, 2007). Esto, en virtud de que la producción de residuos electrónicos es generada por los procesos industriales, por la provisión de servicios, así como por la sociedad en general.

Los debates en torno a la sustentabilidad se refieren comúnmente a tres dimensiones: la económica (formas de producción y de consumo que no ponen en peligro las condiciones de vida de futuras generaciones), la social (estructuras y formas de interacción sociales que no perjudican el entorno ecológico; por tanto, es preciso erradicar la pobreza, la guerra y la violencia) y la ecológica (conservación de las condiciones ecológicas y de la biodiversidad). Los tres componentes interrelacionan la economía, la estructura y las relaciones sociales con el ámbito natural (Sieglin, 2001). Por lo tanto, los estudios referentes a residuos electrónicos deben considerar estas dimensiones para tener una visión más amplia de la complejidad del problema. 
En este sentido, los retos para el gobierno y la sociedad deben encaminarse a construir modalidades de crecimiento y desarrollo. Estos retos deben generar procesos amplios de descentralización y multiplicación de nuevos agentes activos, que influyan en la concepción de las políticas económicas y sociales y delimiten las nuevas relaciones entre los ámbitos de lo público y lo privado, en el proceso de conformación e instrumentación de proyectos de manejo de residuos electrónicos (Borrayo, 2002).

En México, la Ley General para la Prevención y Gestión Integral de Residuos (LGPGIR) clasifica los residuos en tres estratos: peligrosos, de manejo especial y sólidos urbanos; los residuos electrónicos se encuentran dentro de la clasificación de manejo especial. La LGPGIR establece que deberán sujetarse a planes de manejo (PM) los residuos peligrosos y aquello de manejo especial. Se plantea, entre otros conceptos básicos, la sustentabilidad del manejo de residuos, de tal manera que la gestión de residuos electrónicos debe ser ambientalmente efectiva, económicamente viable y socialmente aceptable (Mejía et al., 2007).

La efectividad ambiental comprende la reducción de las cargas ambientales generales de la gestión de los residuos, ambas en términos del consumo de recursos y la generación de emisiones. La viabilidad económica incluye que los costos de los sistemas de gestión de residuos sean aceptables para los distintos sectores (sector privado, sector social y las órdenes de gobierno). La aceptación social requiere que el sistema de gestión de residuos refleje los valores y prioridades de la sociedad.

De una revisión clásica sobre el concepto de sustentabilidad en la literatura, hecha por Pezzey (1992), derivan las siguientes implicaciones: 1) el concepto de sustentabilidad involucra el contexto geográfico temporal; 2) aunque el concepto de crecimiento ignora los efectos directos que tiene el medio ambiente sobre el bienestar social, el concepto de desarrollo los involucra; 3) la más común, aunque subjetiva, definición de sustentabilidad es que el bienestar de las generaciones futuras no debería ser menor que el de las presentes; 4) uso sustentable de los recursos subraya el mantenimiento de un stock de recursos renovables, observando que objetivamente puede ser más importante la base de recursos que las nociones de bienestar intergeneracional, sobre todo cuando se estudian las economías de los países pobres; 5) muchas definiciones del desarrollo sustentable demandan la atención a las necesidades de los pobres de la generación actual, tanto como las necesidades de las generaciones futuras; y 6) otro grupo de 
propuestas pueden interpretarse en términos del mantenimiento del stock de capital (natural y físico) dela economía, aunque las definiciones sobre el stock del capital sean diferentes.

El desarrollo sustentable supone una integración de esfuerzos y compromiso por parte del Estado, comunidad científica, iniciativa privada, organizaciones no gubernamentales y sociedad civil en general, universidades incluidas.

Hay por lo menos dos vertientes que alimentaron el enfoque del desarrollo sustentable. La primera tiene relación con las corrientes que desde la economía sometieron a revisión el concepto de desarrollo económico y las políticas correspondientes, en particular a partir de principios de los años setenta. La segunda, tiene que ver con la emergencia de la crítica ambientalista al modo de vida contemporáneo, que también se expresó en corrientes diversas pero con ejes comunes y ha transitado por diversas etapas [...] a partir de la Conferencia de las Naciones Unidas sobre Medio Ambiente Humano [...]

Es necesario recuperar estas dos vertientes porque el enfoque del desarrollo sustentable no pretende ser ni ambientalista ni economicista, sino integrar estas y otras dimensiones. (Carabias y Provencio, 2001, pp. 1-2)

En el caso de las ciencias sociales, el enfoque del desarrollo sustentable debe ser hacia la sociedad, como generadora de daños ambientales y a la salud; a la vez ser la fuerza para cambiar esos daños por acciones positivas.

Con el uso de viejas o nuevas tecnologías, existe el riesgo de rebasar umbrales y caer en procesos que pudieran llevar indefectiblemente al deterioro ambiental, con distintos grados de repercusión en la sociedad en general y en el tiempo. Ejemplo de ello, es el caso de los RAEE, cuya situación se encuentra en el umbral, las decisiones que se tomen en la actualidad tanto en legislación, manejo, prácticas de consumo y desuso de electrónicos por parte de la sociedad pueden modificar el entorno y aprovechar los recursos utilizados para desarrollar nuevos AEE. El consumo y la obsolescencia (programada y percibida) son algunas de las causas del incremento de las cantidades de RAEE, sin embargo, éstas se pueden mitigar a través de asumir responsabilidades y de la educación ambiental. 


\section{El consumo actual como causa de la generación de RAEE}

Los aparatos eléctricos y electrónicos son un símbolo visible del consumismo sostenido actual, donde todo se orienta a promover la frecuente sustitución por equipos más nuevos. Obedeciendo a los avances en la tecnología, Nadine Gordmier, que ha actuado como embajadora de buena voluntad del Programa de las Naciones Unidas para el Desarrollo (PNUD) puntualizó que "El consumo es necesario para el desarrollo humano cuando amplia la capacidad de la gente y mejora su vida, sin menoscabo de la vida de los demás" (EUREKA, 2007, p. 191). Mientras que, para "los consumidores descontrolados, es necesario consumir menos, para las personas más pobres del mundo aumentar su consumo es cuestión de vida o muerte y un derecho básico" (Gordmier, 1999 citado por EUREKA, 2007, p. 191).

Pero, en la actualidad, el consumo de aparatos eléctricos y electrónicos es algo más que un momento en la cadena de la actividad económica. Es una manera de relacionarse con los demás y de construir identidad. En las sociedades denominadas como avanzadas, desde la irrupción de la producción en masa, el consumo y, especialmente, el consumo de mercancías no necesarias para la supervivencia se ha convertido en regla. El consumo es un hecho social total, "pues es una realidad objetiva y material pero es, a la vez, e indisolublemente, una producción simbólica que depende de los sentidos y valores que los grupos sociales le dan a los objetos y a las actividades de consumo" (Alonso, 2007 citado por Rodríguez, 2012, p. 5).

Los estilos de vida de la gente están relacionados en forma estrecha con el medio ambiente y los inventarios de los recursos naturales. Los estilos de vida se entienden como la forma de vida de las personas. Estos estilos están determinados por un conjunto de factores (físicos, sociales, laborales, ambientales) que dependerán tanto del individuo como del complejo entorno que le rodea, dando lugar a estilos de vida medianamente saludables. La relación del consumo con los estilos de vida se define, por un lado, por el modelo de crecimiento y, por el otro, por el sistema de producción que se distingue por ser unidireccional, el cual consiste en extraer, producir, consumir y desechar recursos.

El consumo, definido por la publicidad, induce al consumidor a adquirir tan rápido como le sea posible el nuevo modelo. Esta forma de consumo crea, por un lado, la prosperidad y, por el otro, socava o corta los recursos naturales y luego, en breve tiempo, se les entierra o se 
les quema (McDonough y Braungart, 2002). El aumento de los problemas ambientales resulta ser un reflejo de las tendencias en los patrones de comportamiento del consumo (Tellegen y Wolsink, 1998).

Los aparatos eléctricos y electrónicos, al ser algo de tipo material, algo concreto, tienen un peso entrópico. De modo tal que grava al sistema mayor que es el sistema de la vida, de la biósfera y ésta es una cuestión que no es trivial, es bastante significativa. Por otra parte, en cuanto tienen peso entrópico, están acotados dentro de límites que no se puede transgredir. Por ejemplo, en algún momento la cantidad de bienes se traducen en chatarra y por más que creamos que los procesos económicos terminan exclusivamente en los bienes, eso es falso. Terminan en lo que es fundamentalmente producción de basura y eso implica problemas como el de dónde depositar los desechos. Un indicador del desarrollo es la producción de residuos; en la medida que aumenta el ingreso per cápita y, por lo tanto, el consumo, aumentan los residuos.

En los años recientes, se ha producido una sociedad consumidora que ha aprendido a malgastar, a usar y tirar las cosas, a sentirse insatisfecho incluso con el último modelo de teléfono celular y a anhelar el nuevo modelo (Elizalde, 2003).

\section{La obsolescencia programada como causa generadora de RAEE}

Uno de los aspectos más interesantes y, paradójicamente, menos estudiados de la evolución de la actividad económica en las sociedades avanzadas, es el considerable desarrollo de la obsolescencia programada. La moda, las marcas, la publicidad y la continua innovación en los productos constituyen el cortejo que explica cómo bienes que sirven perfectamente para cumplir su función primigenia se quedan fuera del mercado. En el ámbito de la obsolescencia planeada podemos distinguir tres vertientes fundamentales (Elizalde, 2003):

- Funcional. Se origina en la continua aparición de nuevos productos o en las variaciones tecnológicas de los ya existentes. Las computadoras, teléfonos celulares, televisores, algunos electrodomésticos, etc. experimentan continuos cambios en sus contenidos operativos (con los teléfonos se pueden tomar fotos, las computadoras tienen más potencia, se puede acceder a internet desde las pantallas planas), induciendo la esterilización funcional de bienes que permiten perfectamente desarrollar sus cometidos básicos (el teléfono celular obsoleto permite hablar, el televisor ver la programación, etc.). 
- Cualitativa. Se vincula con el desgaste de los bienes. Se fabrican productos que duran poco. Los AEE como los electrodomésticos, equipos móviles, se producen en serie con costes y precios reducidos, pero generan un inmenso dispositivo de mantenimiento y reparaciones. Los productos se abaratan, pero tienen un desgaste prematuro que favorece el desarrollo de múltiples actividades industriales y de servicios.

- Psicológica o percibida. Se relaciona con el desenvolvimiento de la moda, la publicidad. Un teléfono celular que sirve para cubrir la necesidad de comunicarse queda fuera del mercado por los imperativos de la moda.

Ejemplos clarísimos son los aparatos eléctricos y electrónicos, con los que se produce una disminución notable del valor de uso de los bienes. El propio concepto de bien de consumo duradero entra en crisis. Los mercados no se saturan y se desarrollan establecimientos especializados en bienes de escasa duración. En definitiva, la producción en serie suele desarrollar un déficit técnico que predestina al objeto producido a la mediocridad funcional y a la aceleración de la postergación, y un déficit de estilo que condena al producto seriado a los abismos de la falta de estilo y originalidad. Estos "déficit" son el sustrato nutritivo del proceso de obsolescencia planeada. Si la elegancia formal y las prestaciones técnicas de calidad de los materiales son elevadas, hay que recurrir inexorablemente a los componentes psicológicos vinculados con la moda y el cambio en el diseño (Elizalde, 2003).

La tendencia hacia la saturación de los mercados [...] obliga a disminuir la durabilidad de los productos y genera una obsolescencia programada que puede tener componentes funcionales (aparición de nuevos productos con alguna prestación adicional), cualitativos (rápido desgaste del producto), psicológicos (la moda, la presentación estética) y tecnológica (nuevos avances en el diseño tecnológico). (Casares, 2003, p. 8)

Algunos ejemplos relevantes, de acuerdo a Casares (2003) son: "la continuación innovación tecnológica y funcional de los teléfonos celulares, computadores, etc., para conseguir que el consumidor compre continuamente nuevos modelos" (p. 8); las frecuentes averías que 
presentan los AEE y el imperio de la moda que elimina del mercado productos que sirven perfectamente para cumplir su función primigenia.

A esa actitud se le llama obsolescencia percibida y se produce no porque el antiguo modelo haya presentado una variabilidad funcional y por ello deje de desempeñar su función, sino porque el consumidor, por efecto de la publicidad, quiere ir al rito de la "última moda". Esta actitud derrochadora es, precisamente lo que viene llevando a la biosfera a un estado de peligro irreversible (Díaz, 2010).

\section{Concepto de Responsabilidad Extendida del Productor}

El término Responsabilidad Extendida del Productor (REP) fue oficialmente presentado en el informe para el Ministerio de Medio Ambiente de Suiza. Posteriormente, el concepto fue revisado y definido como principio ambiental, dándole un matiz legal en el sentido que hace legalmente vinculantes las acciones de los organismos internacionales, la práctica estatal y los compromisos con las leyes (Lindhqvist et al., 2008).

"La extensión de las responsabilidades de los fabricantes varía según el programa REP, tanto en cuanto a los tipos de responsabilidades como a las actividades de las que se deben encargar" (Lindhqvist et al., 2008, p. 20). Existen diferentes tipos de responsabilidad:

"La legal implica la responsabilidad por daños probados al medio ambiente causados por el producto en cuestión. El alcance de la responsabilidad legal lo determina la legislación y puede incluir las diferentes etapas del ciclo de vida útil del producto, incluido su uso y disposición final" (Lindhqvist, 2000 citado por Lindhqvist et al., 2008, p. 21). La responsabilidad física, se refiere a la responsabilidad directa o indirecta del manejo físico de los productos al final de su vida útil. La responsabilidad financiera, se refiere a la responsabilidad del productor en cuanto a pagar todo o parte del costo del manejo del residuo al final de la vida útil del producto que lo origina; incluye su recolección, separación y tratamiento. La responsabilidad informativa, implica el deber del productor de informar sobre el producto y sus efectos durante las distintas fases de su ciclo de vida (por ejemplo, eco-etiquetado, información sobre energía o ruido involucrados en su producción, etc.). La responsabilidad ante el daño se refiere a una responsabilidad específica ante un daño probado al ambiente o a la salud causado por el producto, cuya procedencia se analiza judicialmente. 
Cabe destacar que, en última instancia:

es responsabilidad de los gobiernos controlar y hacer cumplir la ley y que cualquier gobierno debe destinar la capacidad necesaria para cumplir esta función, aun cuando un diseño inteligente de características autorreguladas y de sistemas de control comunes a toda la industria puede aliviarle el peso administrativo al gobierno. La función de los centros de gestión de información [...] permite contar con varias $\mathrm{ORP}^{1} \mathrm{y}$ con sistemas organizados individualmente. (Lindhqvist et al., 2008, p. 21)

Uno de los desafíos actuales más importantes es la implementación del concepto de REP, considerando el alto porcentaje de computadoras clonadas existente en el mercado, donde es difícil identificar un productor responsable. El valor material de los equipos eléctricos y electrónicos descartados es el motor de un sistema de gestión de residuos electrónicos y, al mismo tiempo, representa la clave de su base financiera. Las ORP pueden beneficiarse de este valor agregado.

Los sistemas de gestión de residuos electrónicos para equipos informáticos obsoletos:

deben considerar la posibilidad de combinar el reacondicionamiento y el reciclaje. El [reutilizar los] equipos que no han cumplido su ciclo de vida útil es un mandato, dado el limitado acceso a tecnologías de la información en los países en desarrollo. De ahí que los sistemas futuros deban integrar las actividades de reacondicionamiento y desarrollar sinergias con los respectivos actores. (Boeni, Silva y Ott, 2009, p. 11)

La logística inversa, que va desde el consumidor final hacia la cadena productiva, incluye las etapas del consumo, recolección, recuperación y disposición, además participan todos los actores involucrados en la generación y manejo de los residuos: los consumidores, instituciones 1 Organización para la responsabilidad del productor. 
de la sociedad civil, los productores o importadores, los vendedores, autoridades municipales y gubernamentales, empresas de acopio, operadores de residuos, empresas de refinado y recuperación de metales (Garcés y Silva, 2009, p. 5). Por tanto, el modelo REP sigue una lógica no solo desde la etapa de generación de los residuos, sino también, y principalmente, desde el momento de la producción de los aparatos. Las responsabilidades que a cada uno de los actores involucrados le corresponda dependerán de diversos factores. En el modelo REP el empresario productor de aparatos eléctricos y electrónicos desempeña un papel fundamental.

\section{La educación ambiental como marco para mitigar la generación de RAEE}

La idea central que sustenta la educación ambiental radica en que, si los problemas ambientales son problemas humanos, la educación es una herramienta clave para el cambio y esto se puede aplicar a cualquier problemática, incluyendo los RAEE. Por tanto:

el reto de la educación ambiental es mucho mayor que hacer actividades ambientales o manejar conceptos ambientales. Su gran reto es generar participación, compromiso de los diferentes actores, públicos y privados en la gestión ambiental. Entonces, se convierte en una herramienta de apoyo para que la gestión ambiental, en cualquier tema, sea efectiva y eficiente. (Solano, 2009, p. 77)

El tema de los residuos electrónicos debe apoyarse "en la educación ambiental para que su público objetivo se comprometa y haga suyos los procesos que promueve" (Solano, 2009, p. 77).

El informe de la Comisión Brundtland y posteriores documentos sobre política ambiental destacan la importancia de contar con datos confiables y buena información científica como componentes básicos para el desarrollo sostenible. Los esfuerzos del desarrollo, incluyendo la lucha contra la pobreza y la asistencia humanitaria, deben tener en cuenta todos los conocimientos posibles sobre la contribución del medio ambiente y los servicios del ecosistema a la mejora del bienestar humano. Por lo tanto, invertir en infraestructura y capacidad para conseguir información sobre residuos electrónicos equivale a invertir en desarrollo sostenible. El acceso a la información y a la educación es un derecho humano fundamental y un aspecto 
importante para el bienestar humano, para la creación de conocimientos que relacionen los análisis ecológicos con los desafíos sociales, y esencial para el proceso de toma de decisiones.

Ante procesos de deterioro que requieren una atención urgente y diferenciada, la educación puede reforzar el cumplimiento de normas jurídicas o la aceptación de ciertas medidas de política. No cabe duda que la educación tiene una gran responsabilidad en la gestación y desenvolvimiento de lo que se denomina conciencia ecológica de la sociedad, promoviendo desde la simple preocupación y denuncia, hasta la investigación y la información que contribuyen a formar las condiciones propicias para producir, interpretar y aplicar el conocimiento sobre temas ambientales. De allí el papel central que juegan como instrumentos de política ambiental (Valderrabano, Castro, Trujillo y Hernández, 2011).

Cabe señalar que las políticas de educación ambiental no necesariamente inciden tan sólo en lo que concierne al público en general en los niveles educativos básicos y medio, pues también se las puede relacionar y enlazar con las políticas de atención científica y tecnológica de los problemas de medio ambiente y de las planificaciones en los centros de educación superior. Las políticas de educación ambiental se pueden ubicar en tres niveles preferentemente: a) Nivel general, enfocado al público en general; b) Nivel escolar, enfocados a programas de escolaridad básico y medio; y c) Nivel profesional, enfocado a los profesionales, centros de educación superior, tomadores de decisiones y planificadores.

\section{Metodología}

La generación de Residuos de Aparatos Eléctricos y Electrónicos (RAEE) como consecuencias del desuso de los Aparatos Eléctricos y Electrónicos (AEE), ya sea porque el aparato cumplió con su ciclo de vida y dejó de funcionar, o porque el usuario lo sustituyó por un equipo más nuevo obedeciendo a las prácticas de mercadeo y a la aceleración en la innovación tecnológica, se ha convertido en una problemática de dimensiones globales; la cual requiere ser analizada desde diferentes enfoques y con base en los paradigmas de la sustentabilidad, la responsabilidad extendida del productor, la obsolescencia programada y la educación ambiental.

Con la finalidad de realizar el análisis con base en los enfoques planteados, se diseñó una encuesta titulada RAEE-CLN 2016, que en el tercer apartado del instrumento aplicado se rea- 
lizaron una serie de preguntas que atienden a la percepción que las personas tienen acerca del uso y desuso que se debe tener de los RAEE. Para ello, la metodología se planteó de la siguiente manera: la unidad de selección son las viviendas de Culiacán y las unidades de observación son los hogares equipados con Aparatos Eléctricos y Electrónicos. La población bajo estudio son los hogares y sus residentes habituales que posean alguno o todos de los siguientes aparatos: teléfono móvil, computadora portátil y tableta electrónica para su uso personal.

El tamaño de la muestra se estimó con base en los datos de INEGI para los hogares con equipamiento de aparatos eléctricos y electrónicos, seleccionando los que cuentan con Televisión, ya que el $97 \%$ de los hogares en Culiacán cuentan con este equipo electrónico. La muestra calculada es de 384 para un nivel de confiabilidad de $95 \%$ y un margen de error de $5 \%$.

La fórmula utilizada fue la siguiente:

$$
\mathrm{n}=\left[\frac{Z_{\alpha}}{\varepsilon}\right]^{2} \mathrm{pq} \quad \begin{aligned}
& \mathrm{Z}^{2}=1.962 \\
& \mathrm{q}=\text { proporción }(0.5) \\
& \begin{array}{l}
\mathrm{q}=1-\mathrm{p}(1-0.5=0.5) \\
\mathrm{d}=(5 \%)
\end{array}
\end{aligned}
$$

El método utilizado fue muestreo por estratos, se aplicaron 407 instrumentos con la finalidad de garantizar que se cumpliera con el tamaño requerido por algún inconveniente en el trabajo de campo. La selección de las colonias a encuestar se realizó de manera aleatoria. El levantamiento de los datos fue realizado en los meses de junio-julio del año 2016, con apoyo de la Facultad de Ciencias de la Tierra y el Espacio de la Universidad Autónoma de Sinaloa.

\section{Análisis de los datos}

Una vez aplicado el instrumento, se procedió a realizar el manejo de los datos con el programa estadístico SPSS, las siguientes tablas representan un análisis descriptivo de las prácticas de uso y desuso de los electrónicos en Culiacán, Sinaloa. 
Tabla 1. Práctica de desuso de televisores a partir del apagón analógico

\begin{tabular}{lcccc} 
& Frecuencia & Porcentaje & $\begin{array}{c}\text { Porcentaje } \\
\text { válido }\end{array}$ & $\begin{array}{c}\text { Porcentaje } \\
\text { acumulado }\end{array}$ \\
\hline Intercambie al gobierno por uno nuevo & 48 & 11.8 & 11.8 & 11.8 \\
\hline Compré un adaptador & 153 & 37.6 & 37.6 & 49.4 \\
\hline Lo tengo almacenado & 96 & 23.6 & 23.6 & 73.0 \\
\hline Lo llevé a un centro de acopio & 20 & 4.9 & 4.9 & 77.9 \\
\hline Lo tiré & 50 & 12.3 & 12.3 & 90.2 \\
\hline Otro & 40 & 9.8 & 9.8 & 100.0 \\
\hline TOTAL & 407 & 100.0 & 100.0 & \\
\hline
\end{tabular}

En la tabla 1, se muestra que el $37.6 \%$ de los encuestados continuó usando el televisor con el que contaba, el $\mathbf{1 1 . 8 \%}$ lo intercambió por uno nuevo en el programa que implementó el gobierno, el $12.3 \%$ lo tiró y solamente un 4.9\% lo llevó a un centro de acopio. Esto se puede interpretar como una falta de cultura de la sustentabilidad, ya que un 35.9\% de la población desechó de manera inadecuada los televisores obsoletos, al tirarlos o mantenerlos almacenados.

Tabla 2. Responsabilidad de los RAEE

\begin{tabular}{lcccc} 
& Frecuencia & Porcentaje & $\begin{array}{c}\text { Porcentaje } \\
\text { válido }\end{array}$ & $\begin{array}{c}\text { Porcentaje } \\
\text { acumulado }\end{array}$ \\
\hline Gobierno Federal & 108 & 26.5 & 26.5 & 26.5 \\
\hline Gobierno Local & 108 & 26.5 & 26.5 & 53.1 \\
\hline Empresas productoras de electrónicos & 57 & 14.0 & 14.0 & 67.1 \\
\hline El usuario & 41 & 10.1 & 10.1 & 77.1 \\
\hline Responsabilidad compartida & 82 & 20.1 & 20.1 & 97.3 \\
\hline Otro & 11 & 2.7 & 2.7 & 100.0 \\
\hline TOTAL & 407 & 100.0 & 100.0 & \\
\hline
\end{tabular}


En la tabla 2, se muestran los resultados acerca de quién debería hacerse responsable de los RAEE. De acuerdo con la población de Culiacán encuestada, el 53.1\% considera que debe ser el gobierno, tanto a nivel federal como local, quien se haga responsable de los residuos electrónicos, en contraste con un $10.1 \%$ que considera que debería ser el usuario y un $20.1 \%$ indicó que la responsabilidad debe ser compartida.

\section{Tabla 3. Prioridad al comprar un aparato electrónico}

\begin{tabular}{lcccc} 
& Frecuencia & Porcentaje & $\begin{array}{c}\text { Porcentaje } \\
\text { válido }\end{array}$ & $\begin{array}{c}\text { Porcentaje } \\
\text { acumulado }\end{array}$ \\
$\begin{array}{l}\text { Que tenga etiqueta de amigable } \\
\text { con el medio ambiente }\end{array}$ & 54 & 13.3 & 13.3 & 13.3 \\
\hline Menor precio & 143 & 35.1 & 35.1 & 48.4 \\
\hline Marca famosa & 82 & 20.1 & 20.1 & 68.6 \\
\hline Recomendación de amigos o familiares & 78 & 19.2 & 19.2 & 87.7 \\
\hline Con promoción por parte de la tienda & 26 & 6.4 & 6.4 & 94.1 \\
\hline Otro & 24 & 5.9 & 5.9 & 100.0 \\
\hline TOTAL & 407 & 100.0 & 100.0 & \\
\hline
\end{tabular}

En la tabla 3, en cuanto a la prioridad que los usuarios consideran al momento de comprar un aparato electrónico, los resultados nos muestran que son: el precio con un 35.1\% y la marca con un $20.1 \%$ lo que mayormente determina la decisión de compra; esto es indicador de un estilo de vida de consumo en la cual el mercadeo es un factor importante en la toma de decisiones al momento de adquirir un equipo electrónico.

En la tabla 4, se refleja que el aspecto ambiental más importante considerado para adquirir un aparato electrónico por parte de la población de Culiacán es el ahorro de energía con un $44.7 \%$. En términos generales representa un impacto en la economía, por lo que el cuidado al medio ambiente tiene ese peso económico. 
Tabla 4. Aspectos medioambientales considerados al comprar un aparato electrónico

\begin{tabular}{lcccc} 
& Frecuencia & Porcentaje & $\begin{array}{c}\text { Porcentaje } \\
\text { válido }\end{array}$ & $\begin{array}{c}\text { Porcentaje } \\
\text { acumulado }\end{array}$ \\
\hline Que sea ahorrador de energía & 182 & 44.7 & 44.7 & 44.7 \\
\hline Que no afecte la calidad del aire & 73 & 17.9 & 17.9 & 62.7 \\
\hline $\begin{array}{l}\text { Que contenga la menor cantidad } \\
\text { de sustancias peligrosas }\end{array}$ & 56 & 13.8 & 13.8 & 76.4 \\
\hline Que no haga ruido & 82 & 20.1 & 20.1 & 96.6 \\
\hline Otro & 14 & 3.4 & 3.4 & 100.0 \\
\hline TOTAL & 407 & 100.0 & 100.0 & \\
\hline
\end{tabular}

Tabla 5. Razones por las que renueva los aparatos electrónicos en el hogar

\begin{tabular}{lcccc} 
& Frecuencia & Porcentaje & $\begin{array}{c}\text { Porcentaje } \\
\text { válido }\end{array}$ & $\begin{array}{c}\text { Porcentaje } \\
\text { acumulado }\end{array}$ \\
$\begin{array}{l}\text { Porque tengo capacidad económica } \\
\text { para comprarlos }\end{array}$ & 42 & 10.3 & 10.3 & 10.3 \\
\hline $\begin{array}{l}\text { Porque ya no tienen capacidad } \\
\text { suficiente }\end{array}$ & 96 & 23.6 & 23.6 & 33.9 \\
\hline Porque ya no enciende & 231 & 56.8 & 56.8 & 90.7 \\
\hline Otro & 38 & 9.3 & 9.3 & 100.0 \\
\hline TOTAL & 407 & 100.0 & 100.0 & \\
\hline
\end{tabular}

En la tabla 5, se muestran que el $56.8 \%$ de las personas de Culiacán encuestadas renuevan sus equipos del hogar una vez que no encienden, esto es, una vez que ya cumplieron con su ciclo de vida; cabe resaltar que los equipos considerados en esta categoría son los grandes electrodomésticos, por ejemplo: refrigeradores, lavadoras y secadoras, que son equipos de alto costo. 
Tabla 6. Desuso de los electrónicos

\begin{tabular}{lcccc} 
& Frecuencia & Porcentaje & $\begin{array}{c}\text { Porcentaje } \\
\text { válido }\end{array}$ & $\begin{array}{c}\text { Porcentaje } \\
\text { acumulado }\end{array}$ \\
\hline Lo almaceno & 103 & 25.3 & 25.3 & 25.3 \\
\hline Lo regreso a la empresa productora & 44 & 10.8 & 10.8 & 36.1 \\
\hline Lo vendo a los recolectores informales & 112 & 27.5 & 27.5 & 63.6 \\
\hline Lo regalo & 106 & 26.0 & 26.0 & 89.7 \\
\hline Lo llevo a un centro de acopio & 20 & 4.9 & 4.9 & 94.6 \\
\hline Otro & 22 & 5.4 & 5.4 & 100.0 \\
\hline TOTAL & 407 & 100.0 & 100.0 & \\
\hline
\end{tabular}

En la tabla 6, se muestran las formas en que la población de Culiacán encuestada desecha sus residuos electrónicos: el $25.3 \%$ los mantiene almacenados, el $10.8 \%$ los regresa a la empresa productora (esto es responsabilidad extendida del productor), el $27.5 \%$ los vende a recolectores informales, el $26 \%$ los regaló y solamente un $4.9 \%$ los llevó a un centro de acopio.

Se puede asumir, que hace falta implementar mejores políticas ambientales en cuanto al manejo adecuado de los residuos electrónicos, apoyándose en la educación ambiental para una mayor cultura de la sustentabilidad en la concientización en el uso y desuso de los electrónicos.

\section{Conclusiones}

El estudio de los Residuos Ambientales Eléctricos y Electrónicos (RAEE) es complejo, ya que se puede analizar desde diferentes enfoques.

Los paradigmas del desarrollo sustentable, la responsabilidad extendida del productor y la educación ambiental permiten plantear un análisis de la generación de los residuos electrónicos desde las prácticas empresariales hasta las individuales.

Es necesario ampliar el estudio en cuanto a la caracterización de los RAEE, para contabilizar e identificar los grandes generadores en las regiones y poder plantar propuestas de política ambiental que permitan mitigar el impacto nocivo de los RAEE y convertirlos en una oportunidad en la valorización económica de los recursos. 
Es importante una educación ambiental: informar a los ciudadanos sobre la naturaleza de los productos que consumen, las consecuencias del consumo para el medio ambiente, el desarrollo sostenible y la calidad de vida; y así, conozcan la responsabilidad en la toma de decisiones sobre el consumo.

Asimismo, es importante que esta educación llegue al sector empresarial, ya que las organizaciones son fuertes productoras de RAEE. Las empresas a través del paradigma de Empresa Socialmente Responsable (ESR) deben pugnar por una cultura de sustentabilidad; por lo que, la educación ambiental se convierte en un elemento central en las organizaciones. 


\section{Referencias}

Boeni, H., Silva, U. y Ott, D. (2009). Reciclaje de residuos electrónicos en América Latina. Panorama general, desafíos y potencial. En U. Silva (Edit.), Gestión de residuos electrónicos en América Latina. Chile: Ediciones SUR.

Borrayo, R. (2002). Sustentabilidad y desarrollo económico. México: UNAM.

Carabias, J.y Provencio, E. (2001). El Enfoque del Desarrollo Sustentable. Una nota introductoria. En A. Azuela, J. Carabias, E. Provencio y G. Quadri, Desarrollo Sustentable. Hacia una política ambiental. México: UNAM. Recuperado de https://www.enpro.mx/publica/enfoque.pdf

Carosio, A. (2008). El género del consumo en la sociedad de consumo. Revista de Estudios de Género. La ventana, (27), 130-169.

Casares, J. (2003). El nuevo paisaje del consumo. Distribución y Consumo, 13(70), 5-9.

Castillejo, J.L., Colom, A.J., Alonso, P.M., Rodríguez, T., Sarramona, J., Touriñán, J.M. y Vázquez, G. (2011). Educación para el consumo. Educación XX1, 14(1), 35-58. Recuperado de http:// www.redalyc.org/pdf/706/70618224002.pdf

Díaz, J., Montaner, J. y Prieto, M. (2007). Formación ética para un desarrollo sustentable. Revista de Ciencias Sociales (Ve), XIII(1), 159-171.

Elizalde, A. (2003). Desde el desarrollo sustentable hacia sociedades sustentables Polis. Revista de la Universidad Bolivariana, 1(4).

EUREKA. (2007). Consumo responsable. Revista Eureka sobre Enseñanza y Divulgación de las Ciencias, 4(1), 189-192. Recuperado de http://www.redalyc.org/pdf/920/92040112.pdf

Garcés, D. y Silva, U. (2009). Responsabilidad Extendida del Productor en la Gestión de Residuos Electrónicos, un modelo replicable en Chile. Jornada Derecho REP Chile, Chile. Recuperado de http://www.residuoselectronicos.net/archivos/documentos/Jornada_derecho_REP_ chile.pdf

González, M.C. (1995). Principales tendencias de educación ambiental en el Sistema escolar. Revista Iberoamericana de Educación, (11), 13-74. 
Heras, F. (2009). La Educación Ambiental frente al desafío ambiental global. Algunas tendencias positivas en la práctica educativa. En R. Arrué (Ed.), Balance y perspectivas de la Evaluación Ambiental en Chile e Iberoamérica. Chile: Gobierno de Chile/Comisión Nacional de Medio Ambiente. Recuperado de http://educacionysustentabilidad.tecsuma.cl/wp-content/ uploads/2011/11/EA-CHILE-01-Balance-Ed-Amb-Chile-Latin-America-2010.pdf

Lindhqvist, T., Manomaivibool, P. y Tojo, N. (2008). La responsabilidad extendida del productor en el contexto latinoamericano. La gestión de residuos de aparatos eléctricos y electrónicos en Argentina. Suiza: Lund University, International Institute for Industrial Environmental Economics. Recuperado de https://www.greenpeace.org/argentina/PageFiles/38438/ la-responsabilidad-extendida-d.pdf

Mejía, A., Román, G.J. y Beltrán, L. (2007). El manejo de residuos peligrosos en México. En J.L. Calva (Coord.), Agenda para el desarrollo, vol 14. Sustentabilidad y desarrollo ambiental. México: Miguel Ángel Porrúa.

Montaño, H. (2012). Sustentabilidad, responsabilidad social y organizaciones. México: Ed. Hess. McDonough, W., \& Braungart, M. (2002). Design for the triple top line: new tools for sustainable commerce. Corporate Environmental Strategy, 9(3), 251-258.

Nadal, A. (2007). El desarrollo sustentable: un concepto multidsciplinario en un mundo complejo y cambiante. En Desarrollo Sustentable y Cambio Global. México: El Colegio de México.

Pezzey, J. (1992). Sustainable Development Concepts: An economic Analysis. World Bank Environment, Paper Number 2. Recuperado de http://www-wds.worldbank.org/servlet/ WDSContentServer/WDSP/IB/1999/10/21/000178830_98101911160728/Rendered/ PDF/multi_page.pdf

Rodríguez, S. (2012). Consumismo y sociedad: una visión crítica del homo consumens. Nómadas, 34(2). Recuperado de http://www.redalyc.org/articulo.oa?id=18126057019

Sieglin, V. (2001). Algunos apuntes introductorios. En V. Sieglin (Comp.), Desarrollo sustentable, cultura e identidad. México: Fondo estatal para la cultura y las artes de Nuevo León. 
Solano, D. (2009). Las cinco etapas de la Educación Ambiental. En R. Arrué (editor), Balance y perspectivas de la Evaluación Ambiental en Chile e Iberoamérica. Chile: Gobierno de Chile/ Comisión Nacional de Medio Ambiente. Recuperado de http://educacionysustentabilidad. tecsuma.cl/wp-content/uploads/2011/11/EA-CHILE-01-Balance-Ed-Amb-Chile-LatinAmerica-2010.pdf

Tellegen, E., \& Wolsink, M. (1998). Society and Its Environment. An Introduction. Amsterdam: Gordon and Breach Publishers.

Valderrabano, M.L., Castro, J., Trujillo, M.M. y Hernández, H. (2011). Cuaderno de Política Ambiental. México: IPN/CIIEMAD. 


\section{Capítulo 12}

La universidad y su responsabilidad con la sustentabilidad:

el caso de la Universidad de Sonora

Ramona Flores-Varela ${ }^{1}$, Juana Alvarado-Ibarra ${ }^{2}$ yngélica Ochoa-Flores ${ }^{3}$

${ }^{1}$ Universidad de Sonora, México. monyf@pitic.uson.mx

2 Universidad de Sonora, México. juana.alvarado@unison.mx

${ }^{3}$ Centro de Investigación en Alimentación y Desarrollo, México. liloreal14@gmail.com 


\section{Introducción}

Actualmente, la humanidad enfrenta una tremenda disyuntiva: reconciliarse con la tierra o culminar el grave proceso de deterioro del ambiente. Por otro lado, la Agenda 21 de la ONU, en su capítulo 36 deja claro que la educación, hoy por hoy, debe orientarse hacia la sustentabilidad, fomentando actitudes, aptitudes y habilidades para construir un mundo mucho más habitable. Esto implica que las nuevas generaciones deberían ser partícipes directos de la educación ambiental.

Ante tal panorama, en este capítulo se busca dar respuesta a la siguiente interrogante: ¿Qué parte de responsabilidad asume la Universidad ante esta temática? Es imperativo observar qué hace la comunidad universitaria al respecto. Cómo se genera conciencia y cómo se ofrece educación ambiental a sus estudiantes. Lo anterior, se hace desde el análisis de la situación que guarda la Universidad de Sonora, con base en información institucional, además de dar cuenta de los trabajos y esfuerzos de la comunidad universitaria para apoyar lo que desde hace décadas se ha venido sugiriendo a nivel mundial.

\section{Antecedentes}

Desde la publicación del documento llamado Nuestro futuro común resultado del Informe Brundtland $^{1}$ se advertía que la humanidad debía cambiar su estilo de vida si no quería escalar a una era de sufrimiento y degradación ecológica inaceptable (Comisión Mundial del Medio Ambiente y del Desarrollo, 1988). El ser humano tendría que aceptar vivir bajo un nuevo precepto, aquel que armonice el crecimiento económico con la conservación y defensa de los recursos naturales, poniendo un alto al deterioro ambiental, buscando especialmente el equilibrio y la equidad social.

A partir de este documento, surge el concepto de desarrollo sostenible, reconocido y avalado, sin duda alguna, por todos los estudiosos del tema, como "aquel desarrollo que satisface las necesidades presentes sin comprometer las habilidades de las generaciones futuras para cubrir sus necesidades" (Comisión Mundial del Medio Ambiente y del Desarrollo, 1988). Aparece la sustentabilidad señalando hacia el futuro, hacia la solidaridad y el compromiso con esas generaciones futuras: "La sustentabilidad del desarrollo anuncia el límite de la racionalidad

1 Documento básico en todos los estudios y espacios referentes a la sustentabilidad, donde se expresa la opinión de 21 políticos, científicos y ecologistas reconocidos en esa época a nivel internacional. 
económica, proclamando los valores de la vida, la justicia social y el compromiso con las generaciones venideras" (Leff, 2000, p. 1).

Se habla de la búsqueda de un desarrollo equilibrado, sin perjuicio de la naturaleza y sus recursos; generando, en la medida de lo posible, el menor daño ambiental. Según Enkerlin (1997), el desarrollo económico y social debe descansar en la sustentabilidad, como concepto clave de las políticas de desarrollo sostenible, buscando guiar las interacciones entre la naturaleza y la sociedad; permeando los cambios locales y globales en aras de la equidad social, del mantenimiento de la biodiversidad y del cuidado y protección de la población y sus recursos.

Es evidente que estamos todos retados a revisar "nuestra posición frente a la naturaleza”, así como también, los sectores ricos (o los países ricos) están obligados, además, a revisar su actitud "frente al resto de la humanidad", si lo que realmente se pretende es alcanzar el progreso económico sin menoscabo de la calidad de vida y el cuidado del ambiente (Novo, 1998).

A partir de lo anterior, se hace un llamado al cambio de paradigma en todos los niveles, incluida la educación (Novo, 1998; Disterheft, Caeiro, Miranda y Leal, 2013). En la sociedad actual, las expectativas ecológicas y las preocupaciones por lo social cobran cada vez más relevancia. El desarrollo sustentable ha tomado impulso para mantener su vigencia, porque lo que, en este momento de evolución en una sociedad globalizada, lo que se requiere para hacer frente a la cuestión ambiental es otro pensamiento, constituido bajo una nueva óptica cultural, ética, científica, económica y social.

Lo anterior implica re-aprender e incluso desaprender actitudes, acciones y patrones de comportamiento que como "currículum oculto" se van transmitiendo de generación en generación. Sólo incursionando en un nuevo proceso de aprendizaje se encontrará una alternativa a los problemas de hoy, cristalizados en la siguiente pregunta: ¿La humanidad será capaz de sobrevivir a sí misma?

\section{La educación en el siglo XXI y su apego a la sustentabilidad}

Cuando se buscan referentes para el análisis, se puede observar que los problemas del medio ambiente no son locales, se exteriorizan y cruzan en lo global. Fenómenos económicos, sociales y políticos ponen en evidencia la crisis gravísima de deterioro ambiental: abandono y pobreza 
de espacios rurales; migraciones intermitentes e inacabables; deforestación y tala de árboles; sobrepoblación urbana, entre muchos más que impactan en problemas de contaminación del aire, del agua, de luz, por ruido, por uso de automóvil. En suma, una contaminación sin fronteras (Gil, Vilches, Toscano y Macías, 2006):

- Contaminación del aire

- De los suelos

- De las aguas superficiales y subterráneas

- Contaminación acústica

- Contaminación lumínica

- La contaminación del espacio próximo a la tierra

- Entre otras

Estas situaciones no son producto de la casualidad. La búsqueda del progreso económico tiene consecuencias ${ }^{2}$. Es momento de recuperar el papel que a la Universidad y a la comunidad científica le corresponde. Es fundamental. Y aceptar que tanto las ciencias que trabajan con objetos de estudio físicos como las que estudian al ser humano, tienen algo (o mucho) que decir. En el caso de la ciencia económica, por ejemplo, por mucho tiempo ha guardado silencio en torno a esta problemática. Siguiendo el paradigma dominante de la "educación en economía" se ha dejado pasar el análisis reflexivo y el posicionamiento ante tremendo problema respecto al cuidado del ambiente. Lo que ha implicado también, desligarse de la dimensión humana y social que conlleva como compromiso la formación del economista.

Acercarse a esta problemática desde el ámbito educativo, es el gran reto de hoy. Porque justo ahí, es donde se manifiesta la conducta humana en su actuación cotidiana. Se predica con el ejemplo a partir de lo que se comparte con los educandos. Se puede contribuir a construir

2 Es menester anotar, por ejemplo, el crecimiento de la población mundial, que en los últimos 50 años se vio duplicada, gracias a las buenas políticas de cuidado de la salud y en detrimento de las políticas de control de natalidad, para algunos países. Como nunca, estas últimas cuatro décadas dejan de manifiesto la capacidad del ser humano para agigantar la "sociedad del desperdicio", gracias al avance de la ciencia y la tecnología. 
una mejor sociedad, más habitable o, por el contrario, seguir manteniendo en el imaginario de la juventud esa idea de dominación hombre-recurso natural. La moneda está en el aire ante la oportunidad de potenciar nuevos valores y actitudes, creando una conciencia ambiental a través de la conformación de una cultura de cuidado del espacio en que vivimos y buscando formas alternativas para la gestión económica y social de los bienes, bajo un lente sustentable del crecimiento y desarrollo de la sociedad.

\section{La Agenda 21}

En este nuevo siglo, con el debate acerca del desarrollo sustentable se hace necesaria una revalorización en materia educativa a partir de la nueva cultura en el contexto universitario. La Agenda $21^{3}$ impacta las políticas educativas desde el momento en que sugiere una educación dirigida a resguardar los principios de sustentabilidad, a partir de nuevos objetivos y enfoques educativos de empoderamiento y pensamiento crítico (UNESCO, 2007), trayendo consigo cambios a nivel mundial en la manera de transmitir conocimiento y promover procesos de enseñanza-aprendizaje en todos los ámbitos del quehacer educativo. A nivel de instituciones de educación superior (IES), remueve el debate sobre las competencias a generar en el estudiante; sobre la importancia de la interdisciplinariedad, intenta provocar un cambio sustancial tanto en el docente como en el estudiante al introducirlos en un mundo de aprendizaje y acción sobre sustentabilidad.

Se puede definir a la Agenda 21 como una estrategia global que se lleva a la práctica de manera local, involucrando a todos los sectores de una comunidad y es, como lo dice Borrás (2018), un compromiso hacia la mejora del medio ambiente y, por ende, de la calidad de vida de los habitantes de una comunidad, municipio o región.

3 El Programa 21, aprobado el 14 de junio de 1992. Gestado en la Conferencia Mundial sobre el Medio Ambiente y Desarrollo Sostenible de la Naciones Unidas, celebrada en Río de Janeiro, Brasil, conocida también como Cumbre de la Tierra. Suscrita por 172 países, miembros de la ONU, cuyo compromiso fue aplicar políticas ambientales, económicas y sociales con miras a lograr un desarrollo sustentable. Se acordó que cada región elaboraría su propia agenda local 21, para generar programas acordes a sus condiciones regionales y locales. 
Son muchos los temas que incluye la Agenda ${ }^{4}$ pero, retomando el punto que nos interesa, su capítulo 36 deja claro que la educación debe orientarse hacia la sustentabilidad, fomentando actitudes, aptitudes y habilidades para construir un mundo mucho más habitable. Esto implica que las nuevas generaciones sean partícipes directos de la educación ambiental. Entre sus principales recomendaciones figura la reorientación de la educación hacia el desarrollo sostenible:

\section{Bases para la acción}

[...] Debe reconocerse que la educación -incluida la enseñanza académica-, la toma de conciencia del público y la capacitación, configuran un proceso que permite que los seres humanos y las sociedades desarrollen plenamente su capacidad latente. La educación es de importancia crítica para promover el desarrollo sostenible y aumentar la capacidad de las poblaciones para abordar cuestiones ambientales y de desarrollo [...] La educación es igualmente fundamental para adquirir conciencia, valores y actitudes, técnicas y comportamiento ecológicos y éticos en consonancia con el desarrollo sostenible [...] Para ser eficaz, la educación en materia de medio ambiente y desarrollo debe ocuparse de la dinámica del medio físico/biológico y del medio socioeconómico y el desarrollo humano. Integrarse en todas las disciplinas y utilizar métodos académicos y no académicos y medios efectivos de comunicación. (Apartado 36.3)

4 Los temas y objetivos medioambientales son, entre otros: La protección de la atmósfera; La planificación y la ordenación de los recursos de tierras; La lucha contra la deforestación; La lucha contra la desertificación y la sequía; El desarrollo sostenible de las zonas de montaña; El fomento de la agricultura y del desarrollo rural; La conservación de la diversidad biológica; La protección de los océanos y de los mares, así como de las zonas costeras; La calidad y el suministro de los recursos de agua dulce; La gestión racional de los productos químicos tóxicos; gestión de los desechos peligrosos, sean o no radioactivos y gestión de los residuos sólidos. 
Objetivos

a) Apoyar las recomendaciones de la Conferencia Mundial sobre Educación para Todos 5 : Satisfacción de las necesidades básicas de aprendizaje [...]

b) Crear conciencia del medio ambiente y el desarrollo en todos los sectores de la sociedad a escala mundial y a la mayor brevedad posible;

c) Procurar facilitar el acceso a la educación sobre el medio ambiente y el desarrollo, vinculada con la educación social, desde la edad escolar hasta la edad adulta en todos los grupos de población;

d) Promover la integración de conceptos ecológicos y de desarrollo, incluida la demografía, en todos los programas de enseñanza, en particular el análisis de las causas de los principales problemas ambientales y de desarrollo en un contexto local [...] (Apartado 36.4)

Se propone, para lograr lo anterior, un gran cúmulo de actividades, donde destacan para efecto de nuestro interés, el fomento de la capacitación:

La capacitación es uno de los instrumentos más importantes para desarrollar los recursos humanos y facilitar la transición hacia un mundo más sostenible. La capacitación debería apuntar a impartir conocimientos que ayuden a conseguir empleo y a participar en actividades relativas al medio ambiente y el desarrollo. Al mismo tiempo, los programas de capacitación deberían fomentar una mayor conciencia de los asuntos relativos al medio ambiente y el desarrollo como proceso de aprendizaje dual. (Apartado 36.12)

5 La Declaración Mundial sobre Educación para Todos y el Marco de Acción para Satisfacer las Necesidades Básicas de Aprendizaje, aprobados por la Conferencia Mundial sobre Educación para Todos (Jomtien, Tailandia, marzo de 1990), con participación del Fondo de las Naciones Unidas para la Infancia (UNICEF), el Programa de las Naciones Unidas para el Desarrollo (PNUD), la Organización de las Naciones Unidas para la Educación, la Ciencia y la Cultura (UNESCO) y el Banco Mundial. La Conferencia fue patrocinada por 18 gobiernos. 
Donde destacan estos objetivos:

- Establecer o reforzar programas de formación profesional que atiendan a las necesidades del medio ambiente y el desarrollo [...]

- Aumentar la capacidad nacional, particularmente en materia de enseñanza y capacitación científicas, para permitir a los gobiernos, empleadores y trabajadores alcanzar sus objetivos en materia de medio ambiente y desarrollo [...] (Apartado 36.13)

Como se puede leer, los objetivos y metas planteadas, a la vuelta de más de dos décadas, aún tienen tareas inconclusas. Los programas han sido elaborados, los discursos han sido pronunciados, pero en su ejecución todavía se le debe mucho a la sociedad, cristalizada en esos millones de infantes y jóvenes que asisten a los espacios educativos.

En la Primera Cumbre de la Tierra (Río de Janeiro, 1992) se hizo un llamado a los educadores de todos los campos y niveles a contribuir a formar ciudadanos conscientes de la grave situación de emergencia planetaria y que estuvieran preparados para participar en la toma de decisiones. Diez años después, en la Segunda Cumbre de la Tierra (Johannesburgo, 2002), surgió la idea de una Década de la Educación para el Desarrollo Sostenible ${ }^{6}$, para insistir en los mismos objetivos de la Primera Cumbre, teniendo en consideración que esta situación de emergencia es resultado de comportamientos orientados a la búsqueda de beneficios individuales y de corto plazo, sin atender a sus consecuencias futuras (Gil, Vilches, Toscano y Macías, 2006).

Queda claro que la educación debe proporcionar esa percepción correcta de los problemas, al mismo tiempo que fomenta actitudes y comportamientos favorables para el logro de un desarrollo sustentable. Por esta razón, en ese documento se propone la campaña "Compromiso por una Educación para la Sostenibilidad".

En la actualidad, y bajo este escenario cabe preguntarse ¿Qué se está haciendo desde la Universidad, como institución de educación superior?

6 Reunión del Consejo del PNUMA (Programa Nacional de las Naciones Unidas para el Medio Ambiente, creado en 1972), celebrada en febrero de 2005 en Nairobi, se crea este Documento buscando reivindicar el objetivo básico de la educación: enseñar para la sustentabilidad en todos sus ámbitos y mostrando las soluciones más pertinentes desde lo económico, social, ambiental y de derechos humanos. 


\section{La Universidad como compendio del conocimiento}

En el campo de la educación superior de manera imprescindible se cita La Carta de Bogotá sobre Universidad y Medio Ambiente en América Latina (1985) o La Declaración de Talloires (1990), espacios de encuentro donde quedó clara la manifestación y compromiso de las universidades con la sustentabilidad y el medio ambiente (Martínez-Fernández y González, 2015). Las declaraciones emanadas de ahí se manifiestan en la formulación de políticas universitarias para la sustentabilidad.

Sus compromisos, aunque expresados en lo general, relacionan las funciones sustantivas de la Universidad (Martínez-Fernández y González, 2015) como actores clave en la promoción del desarrollo sustentable (Cortese, 2003; Sterling y Villanueva, 2011) y esto se observa cuando uno recorre los campus universitarios: lo verde salta a la vista, los jardines bien cuidados, las plantas nativas; recipientes indicativos de donde poner qué tipo de basura; avisos de cuidado del ambiente. Y ni qué decir de las nuevas líneas de investigación, muchas de ellas se han inclinado hacia esa perspectiva teórico-metodológica, donde lo ambiental se entremezcla con cualquier objeto de estudio.

De la misma manera, se observa cómo el currículo de las distintas carreras universitarias, poco a poco van introduciendo esta vertiente, a partir de la inclusión explícita de materias de sustentabilidad, economía ambiental, ecología, educación ambiental, etc. y se habla más de la transversalidad de esta temática en los distintos programas académicos de licenciatura y posgrado, así como en los espacios administrativos de cualquier universidad7.

Al mismo tiempo, dentro del debate en torno al desarrollo, siguiendo a los expertos, se hace énfasis con mayor regularidad a la evaluación y al desarrollo de indicadores de desarrollo sustentable con la finalidad de estudiar el avance en el tema; sus puntos clave y su problemática, en busca de mejorar y ser más eficientes en la aplicación de políticas y programas ambientales diseñadas expresamente para cada institución.

$7 \quad$ Entre las experiencias pioneras se encuentran el Programa Ambiental Universitario de la Universidad Autónoma de Baja California (UABC), la Agenda Ambiental de la Universidad Autónoma de San Luis Potosí (UASLP), el Programa de Medio Ambiente de la Universidad Nacional Autónoma de México (UNAM) y el de la Universidad de Guadalajara (U de G); a éstas se fueron sumando un creciente número de IES tan distintas como distantes en el territorio mexicano, que alimentaron con abundante experiencia la implementación de políticas para la sustentabilidad. 
En ese sentido, las universidades aplican diferentes tipos de herramientas de evaluación indagando su situación en cuanto al problema de la sustentabilidad (Roorda, 2001; Beringer, 2007; Lozano, 2006), por ejemplo, sistemas de gestión ambiental y productos ISO, auditorías internas e informes generados por instancias académicas y administrativas, entre otros, buscando dar cuenta del andamiaje en conocimiento y la masa crítica que en más de 15 años se ha venido generando para el caso de la Universidad de Sonora.

Sin embargo, cabe destacar que los docentes y estudiantes aún muestran poca participación en este tipo de instrumento e indicadores. Se está en la primera etapa de manifestación institucional e implementación de programas. De buenas intenciones. Aún no se evalúa realmente la acción cotidiana en materia de sustentabilidad en nuestros recintos universitarios, esto es, no se tiene certeza de cuánto se ha aprendido como docente, estudiante o trabajador manual y administrativo, desde el transitar diario por el campus hasta el contacto directo con el entorno, sea este familiar, laboral o social.

No se debe olvidar que las universidades tienen el reto de reflexionar $y$, si es necesario, replantear sus objetivos educativos con miras a la implementación del concepto de sustentabilidad en su dimensión más práctica de investigación-acción, especialmente, si se aspira a educar con espíritu de total acercamiento a la sociedad ${ }^{8}$.

En nuestro país, ideando esa perspectiva de futuro, a través de la Asociación Nacional de Universidades e Instituciones de Educación Superior y la Secretaría de Medio Ambiente y Recursos Naturales (ANUIES/Semarnat, 2001) se creó el Plan de Acción para el Desarrollo Sustentable en las Instituciones de Educación Superior, tomando como referencia la visión al año 2020 del

8 Por ejemplo, FritjofCapra (2004) propone una pedagogía especial que denomina "Modelos Sustentables de Vida", en donde sugiere enseñar mediante el "ecoalfabetismo" basado en un enfoque vivencial, participativo y multidisciplinario, que permita comprender mejor la ecología y la sustentabilidad. Propone una educación que integre armónicamente lo humano, lo ecológico y lo sostenible y que propicie el logro de aprendizajes significativos en los alumnos, lo cual supone implementar, desde una pedagogía constructivista, el conocimiento de expectativas, motivaciones, valores y experiencias de los participantes en un determinado contexto sociocultural que incluye la familia, la comunidad, el sistema educativo y los organismos vinculados con la escuela y la sociedad. Una propuesta muy razonable en esta era. 
sistema de educación superior? . Esta visión incluye "tanto la generación, transmisión y difusión del conocimiento y su articulación, como la colaboración con los diversos organismos sociales y gubernamentales" (p. 12), y manifiesta que "Las IES han incorporado la dimensión ambiental en los planes de desarrollo institucional, incluyendo acciones de transmisión, generación, aplicación y difusión del conocimiento, así como sistemas de manejo ambiental para el uso eficiente y ahorro de los recursos institucionales" (p. 12).

A partir de lo anterior, se sugiere a todas las IES:

1. Que las actividades críticas de una institución de educación superior sean ecológicamente sanas, socialmente justas y económicamente viables y que siga siendo así para las generaciones futuras (The Talloires Declaration, 1990).

2. Se reconozca que los problemas del desarrollo sustentable son altamente complejos y, por lo tanto, requieren del concurso de las diferentes profesiones y disciplinas, en una labor académica del más alto nivel de calidad, pertinencia y equidad.

3. Los programas y proyectos sean el resultado, en primer lugar, de la colaboración intrainstitucional, con énfasis en el trabajo horizontal, llevado a cabo por diferentes dependencias académicas, y en segundo lugar, de la cooperación con otras instituciones educativas del nivel superior y de otros niveles educativos, así como con los organismos gubernamentales, privados y de la sociedad civil.

4. Se dé una mayor difusión a los resultados de investigaciones y programas educativos y de extensión en educación ambiental y desarrollo sustentable a fin de compartir los conocimientos y facilitar su utilización en las diferentes regiones del país. (ANUIES/Semarnat, 2001, p. 16)

Así, se puede observar en el plano institucional, un cúmulo de planes y programas en materia de educación ambiental y desarrollo sustentable, incluyendo acciones educativas, de investigación y de extensión. Se inicia un proceso de reformulación de planes y programas de estudios incorporando transversalmente enfoques y contenidos de sustentabilidad, ya que:

9 La visión del sistema de educación superior se retoma del documento: La educación superior en el siglo XXI. Líneas estratégicas de desarrollo. ANUIES, octubre de 1999. 
En cada programa de licenciatura los egresados deberán conocer las implicaciones que su profesión o disciplina tiene con el medio ambiente y el desarrollo sustentable. Especialmente lo relacionado con el uso, conservación, sustitución y aprovechamiento sustentable de los recursos naturales. (ANUIES/Semarnat, 2001, p. 18)

Se promueve, además, el manejo ambiental en el uso y ahorro eficiente de recursos que utilizan las instituciones educativas del nivel superior. En materia de investigación se pretende "contar con un programa de investigación científico- social sobre el medio ambiente y desarrollo sustentable en cada una de las instituciones de educación superior" (ANUIES/Semarnat, 2001, p. 20). En síntesis, se pretende conducir la oferta educativa de las IES a la altura de los retos que el nuevo milenio nos pone enfrente, construyendo una currícula de corte sustentable relevante.

\section{Universidad de Sonora}

Con la intención de abonar un poco en la evaluación de lo que la Universidad de Sonora hace en el tema de la sustentabilidad, se presentan una serie de estrategias a partir de la práctica educativa denominada Educación No Formal $(E N F)^{10}$, en un ejercicio metodológico de enfoque mixto, donde se retoma una visión cualitativa del problema bajo la técnica de observación directa y la aplicación de una encuesta piloto con el objetivo de indagar, de manera incipiente, el recorrido de la institución en este rubro. El ejercicio se realizó en 3 etapas:

- Primera etapa. Obtención y análisis de información. Se revisaron los informes anuales del Plan de Desarrollo Institucional de los últimos 5 años y el Plan de Desarrollo Sustentable de la Universidad de Sonora, para la elaboración de un diagnóstico de las diferentes

10 La ENF generalmente se ha constituido como una práctica educativa asumida como una actividad compensatoria de deficiencias del sistema educativo formal, y complementaria de programasy políticas encaminadas al desarrollo del medio rural (Marúm-Espinosa y Reynoso-Cantú, 2014). También, como aquélla que se desarrolla paralela o independiente a la educación formal, debida a que ésta no queda inscrita en los programas del ciclo del sistema escolar (Rogers, 2004), ya que según Hernández (2012), la educación ha sido limitada a escolaridad y se le ha restado importancia a otras prácticas, espacios y escenarios sociales que son igual de importantes para la formación de las personas. 
actividades de educación no formal realizadas; al mismo tiempo, mediante la técnica de observación se identificaron algunas posibles áreas de oportunidad para la Universidad.

- Segundaetapa.Diseñoyaplicacióndelaencuestapilotoa473estudiantesbajolaherramienta estadística, muestra aleatoria simple "MAS" sin reemplazo, con la siguiente formula:

Donde:

$$
n=\frac{N Z^{2} p q}{\left(Z^{2} p q\right)+\left[d^{2}(N-1)\right]} \quad \begin{aligned}
& \mathrm{N}=\text { total del universo } \\
& \mathrm{Z}=1.645 \text { que equivale al } 90 \% \text { de confianza } \\
& \mathrm{pq}=0.5 \\
& \mathrm{~d}=0.10
\end{aligned}
$$

- Tercera etapa. Análisis e interpretación de los datos recabados; elaboración de conclusiones y comunicación de resultados.

\section{Presentación de resultados}

En la tabla 1, se muestra un concentrado de las actividades que desarrolló la Universidad de Sonora en sus diferentes áreas, desde la creación del Plan de Desarrollo Sustentable en el 2012 hasta la fecha.

\section{Tabla 1. Actividades de educación no formal que realiza la Universidad de Sonora}

\section{Área universitaria}

Departamento

de Psicología

Departamento de Cien-
cias Químico Biológicas

Cuerpo Académico de Desarrollo Sustentable

\section{Actividades}

Estatus

Publicación de reportes de investigación en área ambiental

Concluido

Proyecto de tratamiento de residuos de laboratorio

Concluido

Diagnóstico de residuos peligrosos

Concluido

Creación del Programa Institucional de Salud y Seguridad Ambiental

En curso Jornada de motivación para la cultura del medio ambiente y la promoción de la vida sustentable
Concluido 


\begin{tabular}{|c|c|c|}
\hline \multirow{4}{*}{$\begin{array}{l}\text { Cuerpo Académico de } \\
\text { Desarrollo Sustentable }\end{array}$} & Taller Internacional "Sustentabilidad en la Maquiladora" & Concluido \\
\hline & Curso "Contabilidad ambiental y sustentabilidad" & Concluido \\
\hline & Programa de Radio & Concluido \\
\hline & $\begin{array}{l}\text { Platicas a escuelas primarias "Valores del cuidado del } \\
\text { medio ambiente" }\end{array}$ & Concluido \\
\hline \multirow{3}{*}{ Educación Continua } & Curso Ambiental ISO 14001:2004 & En curso \\
\hline & $\begin{array}{l}\text { Curso/Taller de formación de instructores en materia de } \\
\text { Protección Civil }\end{array}$ & En curso \\
\hline & Taller de Materiales y Residuos Peligrosos & En curso \\
\hline \multirow{4}{*}{$\begin{array}{l}\text { Departamento } \\
\text { de Agricultura y } \\
\text { Ganadería (DAG) }\end{array}$} & Reducción de consumos de agua en riego & $\begin{array}{l}\text { Por realizar- } \\
\text { se }\end{array}$ \\
\hline & $\begin{array}{l}\text { Uso de Biofertilizantes en sustitución parcial de } \\
\text { fertilizantes }\end{array}$ & $\begin{array}{l}\text { Por realizar- } \\
\text { se }\end{array}$ \\
\hline & Limpieza de relleno sanitario & Concluido \\
\hline & Programa separación de residuos sólidos no peligrosos & Permanente \\
\hline $\begin{array}{l}\text { Departamento } \\
\text { de Economía }\end{array}$ & Encuentro Turismo Rural Sustentable & Permanente \\
\hline $\begin{array}{l}\text { Departamento de } \\
\text { Ciencias del Deporte y la } \\
\text { Actividad Física }\end{array}$ & IV Carrera de la Sustentabilidad & Concluido \\
\hline $\begin{array}{l}\text { Departamento de } \\
\text { Investigaciones } \\
\text { Científicas y Tecnológicas } \\
\text { (DICTUS) }\end{array}$ & $\begin{array}{l}\text { Investigaciones en el reconocimiento de zonas áridas y } \\
\text { su aplicación biotecnológica en los recursos marinos y la } \\
\text { acuacultura, Combustibles Verdes entre otros. }\end{array}$ & En curso \\
\hline \multirow{2}{*}{$\begin{array}{l}\text { Departamento de } \\
\text { Investigación en } \\
\text { Polímeros y Materiales }\end{array}$} & Seminario reciclaje y separación PET & Concluido \\
\hline & Programa permanente Reciclaje PET & Permanente \\
\hline $\begin{array}{l}\text { Departamento de } \\
\text { Medicina y Ciencias } \\
\text { de la Salud }\end{array}$ & Colecta Anual de Reciclaje & Permanente \\
\hline
\end{tabular}




\begin{tabular}{|c|c|c|}
\hline \multirow{3}{*}{ División de Ingeniería } & $\begin{array}{l}\text { Entrega de Juguetes Sustentables a la Organización } \\
\text { "Pintando Sonrisas" }\end{array}$ & Concluido \\
\hline & $\begin{array}{l}\text { Entrega de materiales recuperados a los miembros de la } \\
\text { Organización "Mensajeros de Ayuda" }\end{array}$ & Concluido \\
\hline & $\begin{array}{l}\text { Curso "Introducción a la Ingeniería Ambiental y Análisis } \\
\text { de Riesgos Industriales" }\end{array}$ & Concluido \\
\hline \multirow{6}{*}{ Unidad Regional Centro } & $\begin{array}{l}\text { I Seminario "Cambio Climático, Municipio y Ciudadanía/ } \\
\text { Hacia la construcción de una política municipal" }\end{array}$ & Concluido \\
\hline & II Seminario de la Red de Arquitectura Bioclimática & Concluido \\
\hline & $\begin{array}{l}\text { Programa de Liderazgo Aplicado en Energías Renovables } \\
\text { y Eficiencia Energética }\end{array}$ & Concluido \\
\hline & Jornada del día de educación ambiental & Concluido \\
\hline & $\begin{array}{l}\text { Creación de espacios de convivencia y jardines con } \\
\text { plantas nativas }\end{array}$ & Concluido \\
\hline & $\begin{array}{l}\text { Colocación de contenedores para basura, con tapa azul } \\
\text { marcados con la leyenda de reciclables y con tapa negra } \\
\text { con la leyenda no reciclable }\end{array}$ & Concluido \\
\hline \multirow{4}{*}{$\begin{array}{l}\text { Unidad Regional Centro } \\
\text { Áreas administrativas }\end{array}$} & Separación de papel y plástico & En curso \\
\hline & Sustitución de copias impresas por electrónicas & En curso \\
\hline & Sustitución de lámparas fluorescentes por focos LED & En curso \\
\hline & Eliminación de vasos y platos de poliestireno & En curso \\
\hline
\end{tabular}

Fuente: Universidad de Sonora, Plan de Desarrollo Sustentable.

Dentro las actividades de educación no formal desarrolladas en la Universidad de Sonora, se puede observar que se realizaron cursos, talleres, seminarios y otras actividades diversas.

También se observa que del total de actividades un 70\% fueron concluidas, $15 \%$ son de estatus permanente, $10 \%$ se encuentran en curso y un $5 \%$ están por realizarse. Se puede observar que, en su mayoría, las diferentes actividades de educación no formal llegan a tener los tres puntos clave de la sustentabilidad: ambiental, económico y social, ya que las actividades recurren a la recolección de diversos materiales reciclables y lo recaudado económicamente se destinó a diferentes instituciones u organizaciones de apoyo social de Hermosillo, Sonora. 
Respecto a la encuesta, los resultados se muestran a continuación:

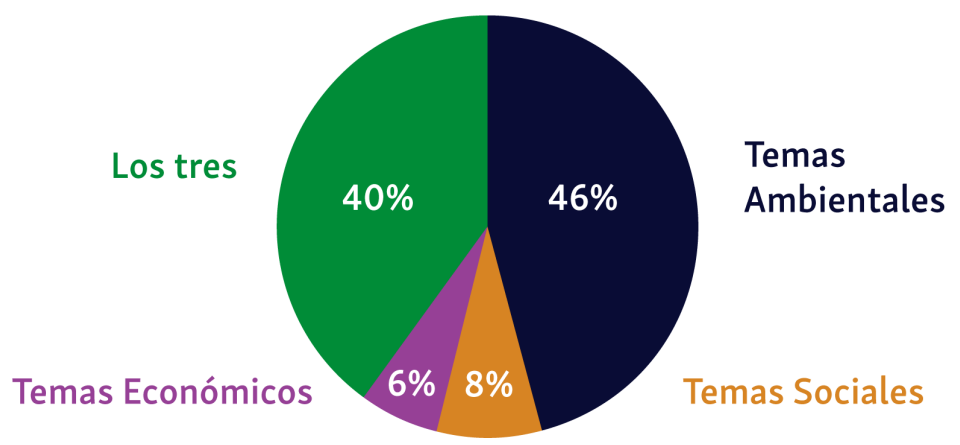

Figura 1. Para ti, ¿qué comprende el desarrollo sustentable?

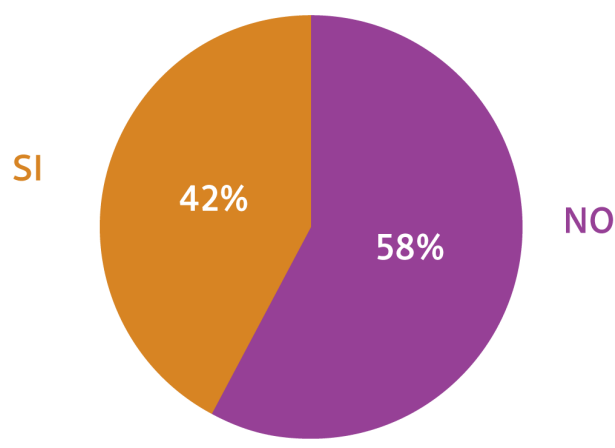

Figura 2. ¿La universidad te ofrece alguna actividad de educación no formal para el desarrollo sustentable?

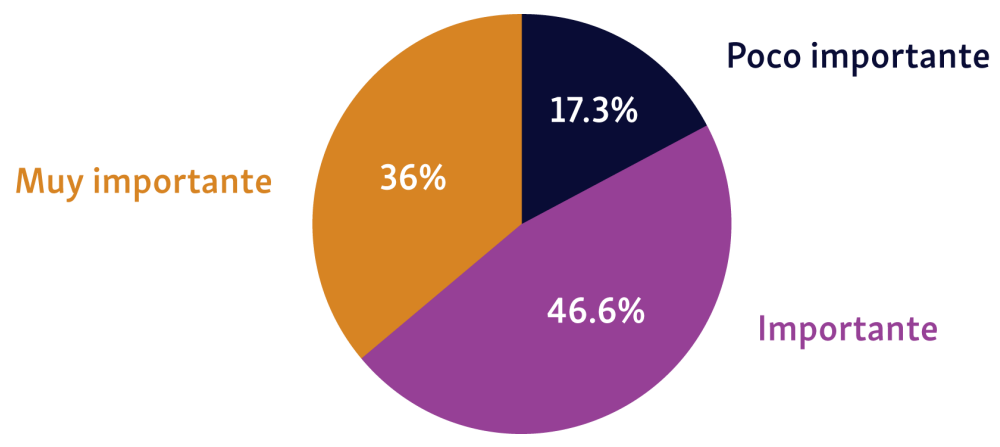

Figura 3. ¿Qué tan importante crees que sería la impartición de actividades de educación no formal para el crecimiento profesional? 


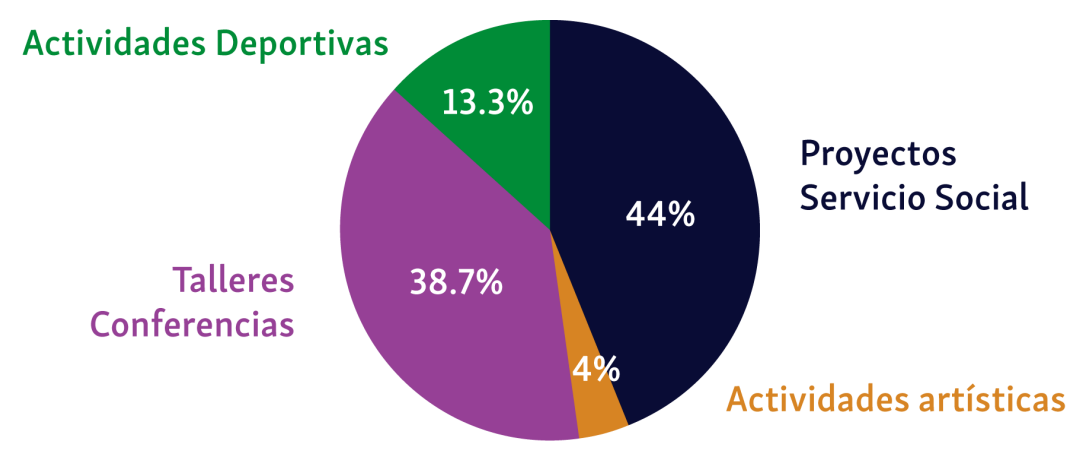

Figura 4. ¿En qué actividades te gustaría participar para aprender de desarrollo sustentable?

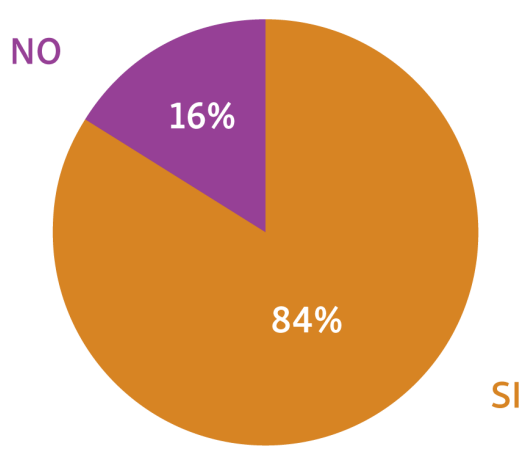

Figura 5. ¿Te gustaría que se ofrecieran talleres y/o conferencias con temas de desarrollo sustentable?

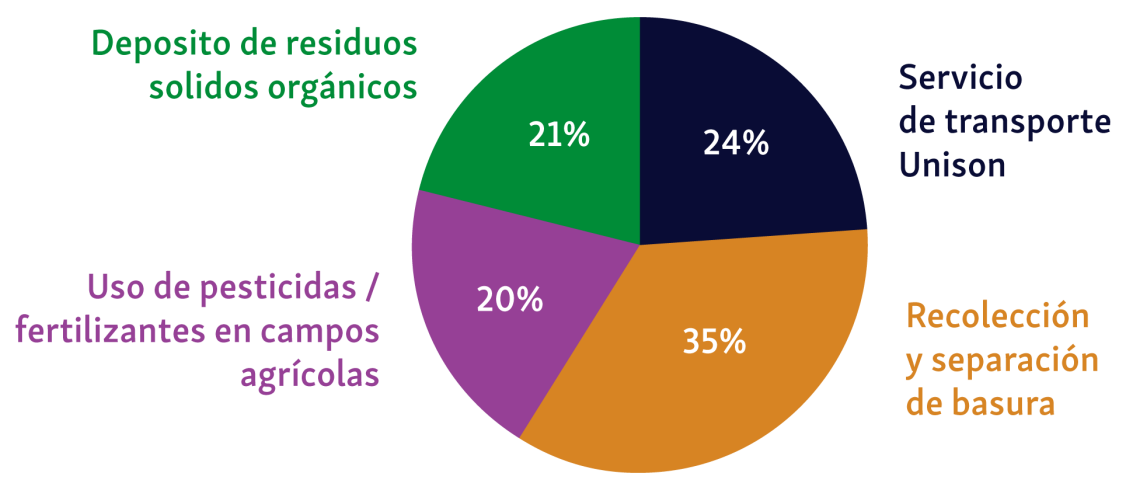

Figura 6. ¿Qué acciones o actividades en la universidad consideras no sustentables? 
Gracias a los resultados de la encuesta se encontraron las siguientes áreas de oportunidad:

1. Educación sobre el desarrollo sustentable. Un objetivo para llegar al desarrollo sustentable es la educación de calidad, la cual pretende garantizar una educación inclusiva, equitativa y de calidad y promover oportunidades de aprendizaje durante toda la vida. En este ejercicio de investigación se encontró que un $46 \%$ de los entrevistados piensa que el desarrollo sustentable sólo incluye temas ambientales.

2. Los estudiantes estarían interesados en participar en distintos tipos de actividades que los forme y sensibilice en desarrollo sustentable.

3. Es interesante observar la plena conciencia del encuestado acerca de lo "no sustentable" en la universidad. Admiten que no existe sustentabilidad en la recolección y separación de basura; manejo y destino de materiales que pueden ser reciclados o reutilizados; en el ahorro y buen aprovechamiento de nuestros recursos naturales; en la importancia de hacer una buena separación y recolección de nuestros desechos, etc. Es común observar depósitos de basura en lugares donde pueden llegar a ser una molestia pública, restar estética al panorama y/o emitir gran nivel de contaminación.

Es menester apuntar que recién se inicia un proyecto de servicio social en el cual los estudiantes participan en la difusión y concientización de la importancia del tema. Se observan estrategias fundamentales de participación configuradas con base en la integración de la comunidad universitaria (profesores, investigadores, estudiantes, trabajadores y autoridades universitarias):

1. Transversalidad de la cultura de la sustentabilidad en planes y programas académicos.

2. Talleres, congresos y otros eventos cuyo eje es la sustentabilidad.

3. Proyectos de reducción de residuos orgánicos e inorgánicos, de cuidado y manejo de la basura, de reciclaje, etc.

4. Semanas culturales y deportivas de la sustentabilidad

La idea es concientizar, sensibilizar y empezar a crear ese perfil sustentable tan deseable en el egresado. Proceso que ya está en marcha en la Universidad de Sonora, ayudada con acciones como las siguientes: 
- Difusión por medio de material visual (lonas).

- Colocación de contenedores en lugares estratégicos con diferentes colores.

- Educar/informar a la comunidad universitaria para que conozca los diferentes contenedores que existen y los tipos de residuos que se colocan en cada uno.

Para finalizar, vale decir que la educación es esencial para el desarrollo sustentable. Nuestra base de conocimientos actual no contiene las soluciones a todos los problemas ambientales, sociales y económicos. Por ello, es crucial desarrollar en los jóvenes las habilidades para descubrir iniciativas y crear nuevos senderos hacia un futuro mejor, especialmente si se considera que en la Universidad de Sonora no existe un punto neurálgico donde se concentre y dé seguimiento a las actividades de educación no formal que se realizan en las diferentes áreas de la institución, como sus Departamentos Académicos y las Divisiones académicoadministrativas.

A casi 15 años del Decenio de las Naciones Unidas de la Educación para el Desarrollo Sostenible (2005-2014) (UNESCO, 2018), es impensable que las IES se mantengan al margen. Al contrario, cada vez más se observa el compromiso formal con el cuidado del ambiente y los recursos naturales a través de la aparición de diversos programas y, esencialmente, en la inclusión de la transversalidad del aspecto ambiental en cada uno de los ámbitos de trabajo en la Universidad, al mismo tiempo que se ha ido creando una masa crítica con capacidades individuales y colectivas que los lleve a participar más activamente en tareas concretas con la sociedad. La incorporación de la sustentabilidad en las Universidades no son sólo buenas intenciones o análisis de cubículo. Va mucho más allá. Resulta muy pertinente, entonces, repensar la investigación en sustentabilidad como la primera puerta para generar esa extensión y vinculación hacia la sociedad, área que hasta hoy, todavía es insuficiente. 


\section{Referencias}

Asociación Nacional de Universidades e Instituciones de Educación Superior / Secretaría de Medio Ambiente y Recursos Naturales (ANUIES/SEMARNAT). (2001). Plan de acción para el desarrollo sustentable en las instituciones de educación superior. México: ANUIES. Recuperado de http://www.complexus.org.mx/Documentos/ANUIESPlandeAccionSemarnat.pdf

Beringer, A. (2007). The Lüneburg Sustainable, University Project in international comparison. An assessment against North American peers. International Journal of Sustainability in Higher Education, 8(4), 446-461.

Borrás, C. (2018). Qué es la Agenda 21: resumen y objetivos. Recuperado de https://www. ecologiaverde.com/que-es-la-agenda-21-resumen-y-objetivos-137.html

Comisión Mundial del Medio ambiente y del Desarrollo (1988). Nuestro futuro común (Informe Brundtland). Madrid: Alianza.

Cortese, A. (2003). The critical role of higher education in dreating a sustainable future. ERIC. Planning for higher education, 31(3), 15-22.

Disterheft, A., Caeiro, S., Miranda, U. y Leal, W. (2013). Sustainability Science and Education for Sustainable Development in Universities: A Way for Transition. En S. Caeiro, U. Miranda, W. Leal y C.J. Chiappetta, Sustainability assessment tools in higher education institutions: Mapping trends and good practices around the world (pp. 3-27). Berlin: Springer.

Enkerlin, H.E. (1997). Ciencia ambiental y desarrollo sostenible. Herramientas de aprendizaje. México: International Thomson.

Gil, D., Vilches, A., Toscano, J.C. y Macías, O. (2006). Década de la educación para un futuro sostenible (2005-2014): un punto de inflexión necesario en la atención a la situación del planeta. Revista iberoamericana de educación, (40), 125-178. Recuperado de https://rieoei. org/historico/documentos/rie40a06.pdf

Hernández, C. (2012). El proceso de planeación, génesis de una buena administración de la educación en México. Visión Educativa IUNAES, 6(13), 15-24.

Leff, E. (2000). Tiempo de sustentabilidad. Revista Ambiente \& Sociedad, III (6-7). 
Lozano, R. (2006). Incorporation and institutionalization of SD into universities: breaking through barriers of change. Journal of cleaner production, 14(9), 787-796.

Martínez-Fernández, C.N. y González, E. (2015). Las políticas para la sustentabilidad de las IES en México: entre el debate y la acción. Revista de educación superior, ANUIES, XLIV (2), 6174.

Marúm-Espinosa, E., Reynoso-Cantú, E.L. (2014). La importancia de la educación no formal para el desarrollo humano sustentable en México. Revista Iberoamericana de Educación Superior, $V(12)$, 137-155.

Novo, M. (1998). La educación ambiental en el marco del paradigma ambientalista. Madrid: Fundación Universidad- Empresa.

Organización de las Naciones Unidas para la Educación, la Ciencia y la Cultura (UNESCO). (2007). Educación para Todos. Satisfacción de necesidades básicas de aprendizaje. París: UNESCO.

Organización de las Naciones Unidas para la Educación, la Ciencia y la Cultura (UNESCO). (2018). Decenio de las Naciones Unidas de la Educación para el Desarrollo Sostenible (20052014). Recuperado de https://es.unesco.org/themes/educacion-desarrollo-sostenible/ comprender-EDS/decenio-onu\#

Rogers, A. (2004). Looking again at non-formal and informal education - towards a new paradigm. Recuperado de www.infed.org/biblio/non_formal_paradigm.htm

Roorda, N. (2001). Auditing Instrument for Sustainability in Higher Education. Amsterdam: Dutch Committee for Sustainable Higher Education. Recuperado de http://www. sustainabilityexchange.ac.uk/files/aishe-book1_5.pdf

Sterling, B. y Villanueva, E. (2011). Geografía y medio ambiente. México: Esfinge.

Universidad de Sonora (2012). Plan de Desarrollo Sustentable, ¿Para qué? Recuperado de http:// www.sustentabilidad.uson.mx/plandedesarrollo.html 
Qartuppi, S. de R.L. de C.V. está inscrita de forma definitiva en el Registro Nacional de Instituciones y Empresas Científicas y Tecnológicas (RENIECYT) con el número 1600052.

Qartuppi, S. de R.L. de C.V. es miembro activo de la Cámara Nacional de la Industria Editorial Mexicana (CANIEM) con número de registro 3751.

ISBN 978-607-98270-5-2

DOI 10.29410/QTP.19.01

Esta obra se terminó de producir en enero de 2019.

Su edición y diseño estuvieron a cargo de:

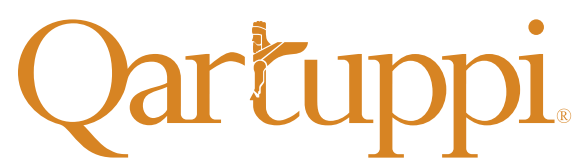

Qartuppi, S. de R.L. de C.V.

http://www.qartuppi.com 
ISBN 978-607-98270-5-2

\section{Qartuppi.}

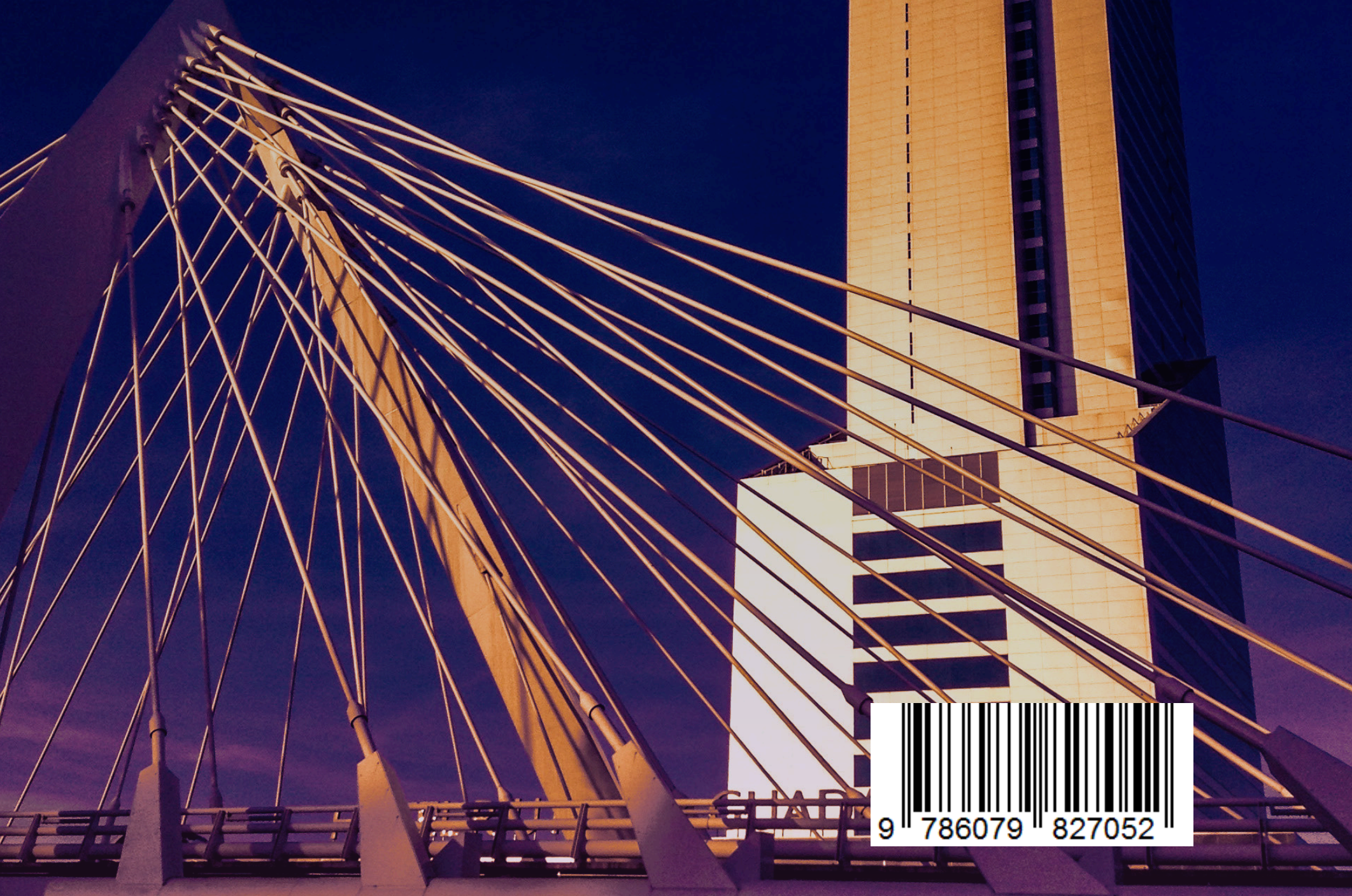

